\title{
7 Die albanische Division „Skanderbeg“
}

\section{1 Übersicht}

Frühjahr 1944. Ein Jahr war vergangen, seit die Aufstellung der „Handschar“ begonnen hatte, und zwei Jahre, seit die Rekrutierungen für die „Prinz Eugen“ einsetzten. In einigen Gebieten Europas war der Krieg bereits zu Ende oder das Kriegsende war zumindest absehbar, in anderen sollten die Konflikte noch ein weiteres Jahr andauern. Die meisten Albaner, insbesondere diejenigen aus den Dörfern in der Peripherie „Neualbaniens“, waren über die internationale Entwicklung des Zweiten Weltkriegs nur vage informiert - im Gegensatz zu den albanischen Eliten, die oft im Ausland studiert hatten und über ein internationales Netzwerk verfügten. Was aber trieb Albaner dazu, in die neu aufgestellte Division „Skanderbeg“ einzutreten oder diese Rekrutierungen zu unterstützen?

Um das Verhalten der albanischen Bevölkerung in dieser Region zu verstehen, sind mehrere geographische und soziodemographische Eingrenzungen notwendig: Ob man auf „neualbanischer“ Seite lebte, also im Kosovo und angrenzenden montenegrinischen, mazedonischen oder griechischen Gebieten beheimatet war, oder in „Altalbanien“, ob man einer der führenden Schichten - Großgrundbesitzer im Süden und Clanchefs im Norden - angehörte, ob man in einer konservativ ländlichen Umgebung nahe der Grenze oder aber in einer der Küstenstädte sein Leben verbrachte, ob man aus dem muslimisch-katholisch dominierten Norden, oder aus dem griechisch-orthodox geprägten Süden stammte, beeinflusste die Entscheidung für oder gegen einen Beitritt in die Waffen-SS wesentlich. ${ }^{1}$

Die 21. Waffen-Gebirgs-Division der SS „Skanderbeg“ sollte die deutschen Truppen im Partisanenkampf an den Grenzen „Großalbaniens“ unterstützen und den reibungslosen Abbau kriegswirtschaftlich relevanter Rohstoffe gewährleisten. Sie baute vor allem auf zwei Vorgängereinheiten auf, einerseits der Division „Handschar“, andererseits der sogenannten „Albanisch-Muselmanischen SS-Freiwilligenlegion“. Diese „Freiwilligenlegion“, deren Existenz spätestens ab Herbst 1943 - erste Rekrutierungsabsichten tauchen aber bereits 1941 auf $^{2}$ - und bis ins Frühjahr 1944 im Sandžak nachzuweisen ist, operierte manchmal bis tief in serbisches Gebiet hinein, oft aber dicht an der serbischmontenegrinischen Grenze in der Sandžak-Region. ${ }^{3}$

1 Vgl. Zaugg, Albanische Muslime, S. 138-140.

2 Vgl. ebd., S. 180, 183.

3 Vgl. Alban. Muselman. SS-Freiwilligenlegion an SS-Hascha., Peter Nippgen, 30.4.1944, VA, HEM. OK.BOJCKA, 9/6-176/42. Daneben existierte bereits im Februar auch ein kosovarisches (Gendarme- 
Wie im vorangehenden Kapitel gezeigt, wurde von März 1943 bis September 1943 in diesem Gebiet intensiv für die Division „Handschar“ geworben. Die Rekrutierungen für die Division „Skanderbeg“ setzten schließlich im März 1944 ein. Im Mai 1944 fanden sie mit der Zuführung albanischer Kriegsgefangener, die im Balkankonflikt 1941 als jugoslawische Soldaten in deutsche Kriegsgefangenschaft geraten waren, ihren Höhepunkt. Aus den Akten des Arhiv Jugoslavije lassen sich Anzahl und Verteilung der Rekrutierten aus diesem Gebiet zumindest zum Teil zurückverfolgen. ${ }^{4}$

Für die geplante albanische Division galten folgende Bestimmungen, die jedoch nur teilweise umgesetzt werden konnten: Das deutsche bzw. „volksdeutsche“ Rahmenpersonal sollte aus der „Prinz Eugen“ und der Division „Handschar“ stammen, die Größe der Division etwa 19.000 Mann betragen. ${ }^{5}$ Taktisch sollte die „Skanderbeg“ dem XXI. Gebirgskorps unterstellt werden. ${ }^{6}$ Die vorgesehenen Rekrutierungsanstrengungen sollten sich auf den Kosovo beschränken und in etwa das Dreieck Pejë/Peć-Prishtina/Priština-Prizren abdecken. ${ }^{7}$ Schließlich wurde aber auf der Suche nach Personal auch noch in anderen Orten, die weit außerhalb dieses Dreiecks lagen, rekrutiert, wie Personalunterlagen der albanisch-stämmigen Soldaten in den Archiven in Belgrad und Prishtina/Priština zeigen. ${ }^{8}$ Trotz dieser Anstrengungen konnte die angestrebte Divisionsgröße nie erreicht werden; die für einen späteren Zeitpunkt geplante zweite albanische Division blieb Utopie.

Obwohl diese Division nur wenige Monate, von März bis November 1944 (bzw. als Regiment bis Januar 1945) bestand, einen beschränkten Einsatzradius aufwies und mit einer Stärke von rund 8.500 Mann Ende August 1944 nicht ein-

rie-) Regiment. Es hinterließ allerdings selbst bei den Deutschen den Eindruck einer „unkultivierten, räuberischen“ Einheit, da die Gendarmen Nahrung und Habseligkeiten aus den Häusern beschlagnahmten. Vgl. Neuwirth, Widerstand und Kollaboration, S. 176, 178.

4 Zahlreiche Rekrutierungen sind in den Gebieten um Plevlje/Plevlja und Besianë/Podujevo einige aber auch Mitrovica/Kosovska Mitrovica zu finden. Bei vielen fehlt jedoch die Ortsangabe. Vgl. bspw. AJ, Fond 110, Arhiv Komizija (DK), F695, F697, F699, F704, F723, F727, F729, F730.

5 Vgl. Stärkemeldung „Skanderbeg“, 5.9.1944, BArchB, NS19/1475, Bl. 13.

6 Vgl. Schmidhuber, „Zusammenfassender Bericht“, 2.10.1944, BArchF, RS 3-21/1, S. 3 f.

7 Vgl. ebd.

8 Vgl. Ortsangaben, die sich in der Sandžak-Region befinden, wie Plevlje. Bei zahlreichen Rekrutierten fehlen diese aber. Vgl. bspw. AJ, Fond 110, Arhiv Komizija (DK), F695, F697, F699, F704, F723, F727, F729, F730. Im Staatsarchiv Prishtina sind außerdem zahlreiche Rekrutierungsorte (insbesondere in Polizei-Bataillone) zu finden, die weit in das heutige Mazedonien, damals Teil Bulgariens, sowie bis nach Nordgriechenland hineinreichen. Vgl. Arkivi Kosoves, F: Dosjete robërve të luftës në Gjermani, V: 1940-1945, K: 1. 
mal annähernd die Hälfte der regulären Divisionsstärke erreicht hatte, ${ }^{9}$ überschattet die - oft politisch aufgeladene - Erinnerung an sie bis heute sowohl die öffentliche wie auch private Diskussion auf kosovarischer und serbischer Seite. ${ }^{10}$

\subsection{Bürgerkriegsähnliche Zustände: Die Kapitulation Italiens und das Gegeneinander von Partisanengruppen}

Bereits Monate vor dem „Fall Alarich“, wie die Kapitulation Italiens von deutscher Seite genannt wurde, waren die deutsche Wehrmacht und Verwaltungsstellen über den Verbindungsstab bei der 2. Italienischen Armee über die Situation in Albanien informiert. ${ }^{11}$ Im Spätsommer 1943 unterrichteten deutsche Verbindungsoffiziere die vorgesetzten Stellen über die rasche Zunahme nationaler und kommunistischer Partisanen im Raum Albanien-Montenegro und die sprunghaft ansteigenden Sabotageakte gegen italienische Infrastruktur sowie temporäre Besetzungen albanischer und angrenzender Gebiete durch Partisanen. Parallel dazu nahmen auch Desertionen von Albanern aus dem italienischen Dienst merklich $\mathrm{zu}^{12}$

Als im Sommer 1943 das Ende der italienischen Herrschaft in „Großalbanien“ näher rückte und schließlich offensichtlich wurde, sah sich Hitler zum Handeln gezwungen. 1.000 Mann der 100. Jäger-Division wurden bereits in den Sommermonaten 1943 in Albanien stationiert. Weitere Truppenteile der Wehrmacht besetzten kurz vor der italienischen Kapitulation die Flughäfen und den Hafen von Durrës. ${ }^{13}$ So berichtet Neubacher, dass zum Zeitpunkt der Kapitulation kurz vor seiner Heinkel 111 drei Junkers 52 mit sechzig Männern der Division Brandenburg (Abwehr II) als „vorläufige deutsche Kriegsmacht“ auf dem

9 Vgl. Stärkemeldung „Skanderbeg“, 5.9.1944, BArchB, NS19/1475, Bl. 13.

10 Siehe bspw. die mehrteilige Serie zu Kollaboration und Rekrutierung für die „Skanderbeg“ in der serbischen Zeitung „Novosti“ http://www.novosti.rs/dodatni_sadrzaj/feljtoni.120.html? item_id=795 (Stand: 8.1.2019).

11 Vgl. zur Lage in Albanien in den Monaten Juli, August und September 1943 bis zur Kapitulation Italiens ausführlich: Deutscher Verbindungsstab bei Ital. AOK 2, BArchF, RH 31/XI-7. Vgl. hierzu auch OB Südost, Bericht „Entwicklung der militärischen Lage in Albanien im Herbst 1944“, undatiert, BArchF, RW 40/116a, Bl. 10. Vgl. zu den deutschen Vorbereitungen auch Stamm, Besetzung Albaniens, S. $100 \mathrm{f}$.

12 Vgl. beispielsweise Deutscher Verbindungsstab bei Ital. AOK 2, Schreiben vom 2., 3., 9., 12., 24. und 26.7.1943, BArchF, RH 31-XI/7.

13 Vgl. Aga Rossi, Giusti, Guerra a parte, S. 309f. Vgl. auch Kasmi, Deutsche Besatzung in Albanien, S. 9. 
Flughafen Tirana landeten. ${ }^{14}$ Mit nur zweieinhalb Divisionen der 2. Panzerarmee besetzten die Deutschen nach dem 9. September 1943 Albanien. Neben Teilen der 100. Jäger-Division wurden zuerst die 118. Jäger-Division, die bald darauf durch die 181. Infanterie-Division abgelöst wurde, und die 297. Infanterie-Division eingesetzt. ${ }^{15}$

Die Verhältnisse vor Ort gestalteten sich chaotisch. Die Oberbefehlshaber der 6. und 9. Italienischen Armee, General Ezio Rosi und General Lorenzo Dalmazzo, waren über die bevorstehende Kapitulation nicht informiert worden. Die Soldaten wurden ohne weitere Befehle ihrem eigenen Schicksal überlassen. ${ }^{16}$ Über 100.000 italienische Soldaten, die in Albanien stationiert waren, irrten nun umher, sammelten sich auf Straßen und Plätzen oder warteten in den Häfen meist vergeblich auf eine Rückfahrgelegenheit in die Heimat, ${ }^{17}$ wobei es zu blutigen Übergriffen kam. Die aufgestaute Abneigung der albanischen Bevölkerung eskalierte während und nach der Kapitulation in gewalttätigen Akten gegen italienische Militärs und Zivilpersonen. Der Beauftragte für Albanien der Republikanisch Faschistischen Partei schrieb an den deutschen Verbindungsstab im Juli 1944 rückblickend:

Die in Albanien nach dem 8. September entstandene Lage war für die Italiener äußerst unglücklich. Nachdem alle diplomatischen Vertreter abgereist waren und seitens des deutschen [sic] Reiches die Unabhängigkeit Albaniens anerkannt worden war, begann eine hasserfüllte Presse-Kampagne gegen die Italiener und die in Albanien ansässigen Italiener, die derart heftig war, dass es zu jeder Art von Italienerverfolgungen kam. ${ }^{18}$

Doch die Italiener hatten noch andere, neue Feinde: Deutsche Einheiten der Wehrmacht und Waffen-SS verfolgten und massakrierten ihre früheren Verbündeten zum Teil gnadenlos, ${ }^{19}$ zumal der Umgang mit italienischen Soldaten von

14 Neubacher, Sonderauftrag Südost, S. 106.

15 Vgl. Fischer, Kollaborationsregimes, S. 372. Im Vergleich zu den bis zu acht italienischen Divisionen, welche in Albanien stationiert waren, war das eine geringe Truppenstärke. Vgl. Kühmel, Deutschland und Albanien 1943-44: die Auswirkungen der Besetzung auf die innenpolitische Entwicklung des Landes, Dissertation Universität bochum 1981, S. 207. Vgl. auch Neuwirth, Widerstand und Kollaboration, S. 121. Daneben existierten zwei albanische Regimenter, eines davon war im Kosovo stationiert.

16 Vgl. Aga Rossi, Giusti, Guerra a parte, S. 310.

17 Vgl. ebd., S. 309.

18 Republikanisch Faschistische Partei, der Beauftragte für Albanien, gez. unleserlich, Aktennotiz für den deutschen Verbindungsstab, 14.7.1944, BArchF, RH 31-XVI/7, Bl. 125. Vgl. Aga Rossi, Giusti, Guerra a parte, S. 309. Vgl. Neubacher, Sonderauftrag Südost, S. 106 f.

19 Durch HSSPF Josef Fitzthum wurden die Italienerverfolgungen vordergründig gestoppt. Dieser hatte bei Innenminister Deva interveniert und damit die Einstellung der Verfolgungen, die Deva selbst unterstützt hatte, erreicht. Ein „Fürsorge-Komitee für Italiener“ wurde mit dem 
deutscher Seite nicht klar geregelt war. Wenn sie nicht kurzerhand erschossen wurden, wurden sie in drei Kategorien eingeteilt, nämlich in reguläre Kriegsgefangene, Militärinternierte oder ehemalige vereidigte Hilfswillige, und wurden zur Zwangsarbeit nach Deutschland deportiert. ${ }^{20}$ Der italienische Unteroffizier Emilio Moncalvo erinnerte sich an das plötzlich veränderte Verhalten: „Da alleati ad aperti nemici. Ora i tedeschi [hanno] gettato la maschera.“ - „Von Verbündeten zu offenen Feinden. Jetzt haben die Deutschen ihre Maske fallen gelassen. “21 Bei Vlorë wurden zahlreiche italienische Offiziere und Unteroffiziere, aber auch einfache Soldaten, gesammelt und erschossen. ${ }^{22}$ Zahlreiche Soldaten mussten in langen Fußmärschen Sammellager, beispielsweise bei Prilep in Bulgarien, erreichen, bevor sie zur Zwangsarbeit ins Reich deportiert wurden. ${ }^{23}$ Auf diesen Gefangenenmärschen wandten die Deutschen auch willkürlich Gewalt gegen albanische Zivilisten an: Camillo Magnaghi und Roberto Rubolotta berichteten bei ihrer Rückkehr nach Italien, dass ihre deutschen Bewacher auf dem Weg ganze Dörfer niedergebrannt hätten. ${ }^{24}$

Nach Schätzungen wurden von den sechs italienischen Divisionen ungefähr 90.000 Soldaten durch die Deutschen entwaffnet. Wenige hatten das Glück, von der Britischen Militärmission (Special Operations Executive, SOE) heimlich außer

Auftrag eingerichtet, durch Spenden von Firmen und Privatleuten das Leid der im Land verbliebenen Italiener zu lindern, „die vollkommen ausgeplündert und ohne Beschäftigung waren“. Republikanisch Faschistische Partei, der Beauftragte für Albanien, gez. unleserlich, Aktennotiz für den deutschen Verbindungsstab, 14.7.1944, BArchF, RH 31-XVI/7, Bl. 125. Italienische Soldaten berichteten aber ebenso von zahlreichen Übergriffen, Deportationen und Erschießungen durch deutsche Truppen. Vgl. bspw. Bericht Marco de Ferrari, AUSSME, I3/b14/ f2; Bericht D'Ulivo, Fabbri, Sacchelli, Santi, De Vita, undated, AUSSME, I3/b13/f1, S. 2.

20 Vgl. OB Südost, Bericht „Entwicklung der militärischen Lage in Albanien im Herbst 1944“, undatiert, BArchF, RW 40/116a, Bl. 43. Vgl. auch Tönnes, Sonderfall, S. 455, 457 und Fischer, Kollaborationsregimes, S. 372.

21 Bericht von sottotenente Emilio Moncalvo, 9/21/1943, AUSSME, I3/b13/f1, S. 2. Vgl. auch Bericht von Lamberto Francesconi und Roberto Ponsard, 10/31/1943, AUSSME, I3/b13/f1, S. 1f. Vgl. Nevila Nika, Storie di italiani dopo l'8 settembre in Albania, in: Lia Tosi, Caro nemico: Soldati pistoiesi e toscani nella resistenza in Albania e Montenegro, 1943-1945, Pisa: Edizioni ETS 2018, S. 148.

22 Vgl. Bericht Marco de Ferrari, AUSSME, I3/b14/f2. Bericht D’Ulivo, Fabbri, Sacchelli, Santi, De Vita, undated, AUSSME, I3/b13/f1, S. 2. Vgl. zu solchen Erschießungen in derselben Region auch Meyer, Blutiges Edelweiß, Die 1. Gebirgs-Division im Zweiten Weltkrieg, Ch. Links Verlag, Berlin 2008, S. 405, 434, 449.

23 Vgl. OB Südost, Bericht „Entwicklung der militärischen Lage in Albanien im Herbst 1944“, undatiert, BArchF, RW 40/116a, Bl. 43.

24 Vgl. Bericht Camillo Magnaghi, AUSSME, I3/b13/f3, p.3. Bericht Marsilio Marsili, 6/19/1944, AUSSME, I3/b13/f3. Report by Roberto Rubolotta, undated, AUSSME, I3/b13/f3, S. 2. 
Landes gebracht zu werden. ${ }^{25}$ Teile verschiedener Divisionen, wie etwa der 41. Infanterie-Division „Firenze“ und der 151. Infanterie-Division „Perugia“, auch Einheiten der 11. Infanterie-Division „Brennero“ und der 49. Infanterie-Division „Parma“, schlossen sich den Partisanen an, um nicht von den Deutschen erschossen oder zur Zwangsarbeit deportiert zu werden. ${ }^{26}$

Darin lag ein weiterer Druckfaktor, der die Bildung lokaler Verbände für den Partisanenkrieg förderte bzw. notwendig machte: Durch die große Zahl italienischer Überläufer vergrößerten sich die nationalistischen und kommunistischen Partisaneneinheiten mit einem Schlag angeblich um rund 15-20.000 Mann. ${ }^{27}$ Diese verfügten nicht nur über eine militärische Ausbildung und teilweise jahrelange Kriegserfahrung, sondern hatten oft auch Kenntnis über deutsche Einrichtungen und Einheiten in der Region. Es gab aber auch Italiener, darunter Einheiten der „Milizia Volontaria per la Sicurezza Nazionale“, die den Deutschen ihre Dienste anboten und dabei festgenommen und zur Zwangsarbeit deportiert wurden. ${ }^{28}$ Einigen „Camicie Nere“ gelang es allerdings, auch nach der Kapitulation in deutschen Reihen weiterzukämpfen. ${ }^{29}$

25 Vgl. Bericht Lamberto Francesconi und Roberto Ponsard, 10/31/1943, AUSSME, I3/b13/f1, p. 7.

26 Vgl. Bericht „Situazione in Albania fino al 10 Ottobre“, capitanio Predone e tenente Cortese, AUSSME, I3/b14/f1, S. 1f. Vgl. auch http://www.regioesercito.it/reparti/fanteria/rediv49. htm (Stand: 11.6.2019).

27 Diese Zahl scheint etwas hoch gegriffen, wenn wir davon ausgehen, dass etwas über 100.000 Soldaten zum Zeitpunkt der Kapitulation in Albanien stationiert waren und davon rund 90.000 in deutsche Gefangenschaft gerieten. Vgl. Nika, Storie di italiani, S. 149. Vgl. Aga Rossi, Giusti, Guerra a parte, S. 309 und Bericht Domenico Perari, 30.6.1944, Uff.Stor. I3/b13/f3, S. 2. Lia Tosi geht von 120-130.000 italienischen Soldaten in Albanien zum Zeitpunkt der Kapitulation aus. Vgl. Lia Tosi, Caro nemico, S. 127. Die italienischen Angaben widersprechen sich auch für die Folgemonate: Nach Angaben des italienischen Außenministeriumns waren Mitte Dezember 1944 noch 7.000 Italiener in Albanien, davon ca. 2.000 bei den Partisanen. Nach Piccini hingegen befanden sich noch 12-15.000 Italiener in Albanien, davon 3-3.500 bei den Partisanen. Vgl. Ministero per gli Affari Esteri, Appunto per la commissione alleata,14.12.1944, AUSSME, I3/b14/f2 und Piccini an das italienische Hochkommisariat für Kriegsgefangene und zur Kenntnis an das italienische Kriegsministerium, 10.2.1945, AUSSME, I3/b14/f2.

28 Dem Kriegstagebuch der 181. Infanterie-Division ist zu entnehmen: „Etwa 60 ältere Mannschaften des Schwarzhemden-Btl. 144 sollen aus diesem in das Gef.-Lager Kotor überführt werden.“ RH26-181/30, Kriegstagebuch Nr. 3 181. Inf.Div. Abt. 1a, 1.11.1943-31.12.1943, Eintrag vom 23.12.2943, S. 11 .

29 Vgl. OB Südost, Bericht „Entwicklung der militärischen Lage in Albanien im Herbst 1944“, undatiert, BArchF, RW 40/116a, Bl. 43. 


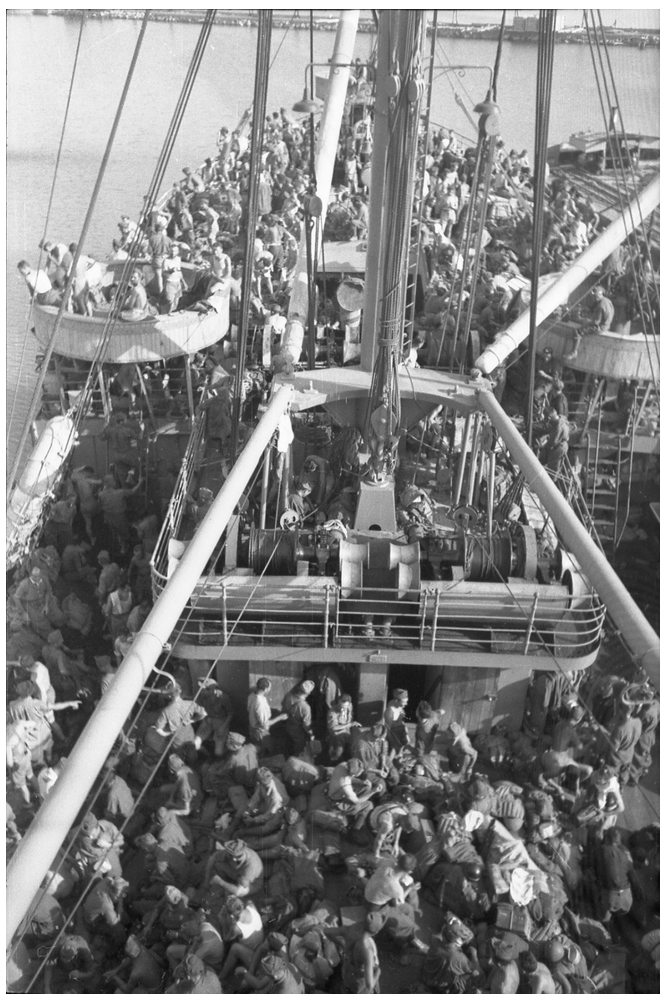

Abb. 27: Italienische Soldaten versuchen von Albanien nach Italien zu gelangen. ${ }^{30}$

Die bürgerkriegsähnliche Situation wird im Wehrmachtbericht zur „Entwicklung der militärischen Lage in Albanien im Herbst 1944“ nach der italienischen Kapitulation Italiens mit folgenden Worten beschrieben: „Dieses kaum entwirrbare Durcheinander, wo Angehörige desselben Volkes einmal als mit der Waffe kämpfende Feinde, ein anderes Mal als Bundesgenossen auf engstem Raume zudem noch in einem dritten neutralen Staate in Erscheinung traten, war nicht dazu angetan, die Behandlung der italienischen Frage zu vereinfachen. ${ }^{\text {"31 }} \mathrm{Zu}$ den chaotischen Zuständen, die sich nicht zuletzt aus den neuen Rollen der ehemaligen Achsenpartner entwickelten, kam die schwierige Situation, in welcher sich der inneralbanische Widerstand befand, der sich grob in Kommunisten (Nationale

30 Bildberichter Henisch, BArch, Bild 101I-203-166529.

31 OB Südost, Bericht „Entwicklung der militärischen Lage in Albanien im Herbst 1944“, undatiert, BArchF, RW 40/116a, Bl. 43. 
Befreiungsfront), Zogisten (Legaliteti) und Nationalisten wie auch Demokraten (Balli Kombëtar) unterteilen lässt. Noch bis in den Sommer 1943 hatte sich ein mögliches Zusammengehen der verschiedenen albanischen Widerstandsgruppierungen abgezeichnet. ${ }^{32}$ Der Britische Verbindungsoffizier Julian Amery berichtete, dass die SOE in Albanien seit 1940 Versuche unternommen hatte, eine albanische Dachorganisation zu bilden und darin alle Widerstandsgruppierungen zu vereinen. ${ }^{33}$ Im September 1942 fand ein gemeinsames Treffen in Peza statt. ${ }^{34}$ Noch am 26. Juli 1943 schien ein gemeinsames Vorgehen auf guten Wegen, als im Dorf Tapizë nördlich von Tirana ein Treffen zwischen nationalen und kommunistischen Widerstandskräften stattfand. An der Konferenz von Mukje vom 1. bis 2. August 1943 versuchten die Vetreter verschiedener Widerstandsgruppen, gemeinsame Ziele, Grundlagen und Vorgehensweisen festzulegen. ${ }^{35}$ Doch bereits an der Konferenz von Labinot, nur einen Monat später, am 4. September 1943, sollte das Bündnis aufgrund der „groß-“ bzw. „kleinalbanischen“ Frage für immer scheitern. Die Kommunisten betrachteten nun den „Balli Kombëtar“

32 OB Südost, Bericht „Entwicklung der militärischen Lage in Albanien im Herbst 1944“, undatiert, BArchF, RW 40/116a, Bl. 5.

33 Amery beschreibt erste Versuche, eine inneralbanische Widerstandsvereinigung zu bilden, bereits 1940: "Nevertheless the work made progress. Our couriers passed from Kossovo [sic] into Albania, preaching the aims of the United Front among the tribal chiefs, and gathering political and military information. Soon we were in communication with Muharrem Bairaktar, the lord of the Liuma, who promised his support.” Amery, Sons of the Eagle: A Study in Guerilla War, London: Palgrave Macmillan 1948, S. 37. Muharrem Bairaktar ist ein gutes Beispiel wechselnder Fraktionen: Er unterstützte zuerst den Widerstand, arbeitete aber, nachdem sich die Kommunisten gegen die Nationalen gewandt hatten, mit den Deutschen zusammen. Neuwirth, Widerstand und Kollaboration, S. 182-183, 210. Weiterführende Informationen zu den Aufgaben der SOE finden sich in Roderick Bailey, The Wildest Province. SOE in the Land of the Eagle, London: Vintage 2009.

34 Vgl. Romeo Gurakuqi, Shqipëria dhe tokat e lirueme 1939-1945, Tirana: Botimet Jozef 2018, S. 408-416 und vgl. Tönnes, Sonderfall Albanien, S. 447.

35 Es wurden folgende Grundsätze festgelegt und vom „Balli Kombëtar“ und der „Nationalen Befreiungsfront“ unterzeichnet:

1. Kampf gegen die feindliche Besatzung und andere mögliche Besatzer.

2. Kampf für ein unabhängiges Albanien, nach Grundsätzen der Atlantik Charta. Für ein ethnisches Albanien.

3. Für ein freies, unabhängiges und volksdemokratisches Albanien.

4. Ein Komitee wird mit der Aufstellung einer provisorischen Regierung beauftragt.

5. Regierungsform wird durch das Volk entschieden, eine konstituierende Versammlung wird allgemeine direkte Wahlen ausschreiben.

Auffallend ist bei den genannten Punkten das Festhalten an einem „Großalbanien“, was schließlich ein Zusammengehen der verschiedenen Koalitionen verhinderte. Vgl. Tönnes, Sonderfall Albanien, S. 455. Vgl. Neuwirth, Widerstand und Kollaboration, S. 93 f. 
als Feind und verhinderten damit ein weiteres gemeinsames Vorgehen gegen die deutschen Besatzer. ${ }^{36}$ Im Gegensatz zu den übrigen Gruppierungen aber ,verfügte die kommunistische Bewegung zu Beginn des Herbstes [1943], als der offene Kampf mit der deutschen Wehrmacht unausbleiblich war, über eine straff geführte und [in] ihrer Zusammensetzung gefährliche Gefolgschaft, die auf jeden Fall zum allgemeinen Kampf und Aufstand entschlossen war““. ${ }^{37}$ Dem militärischen Anführer der albanischen Kommunisten, Mehmet Shehu, der schon im spanischen Bürgerkrieg gekämpft hatte, wurde selbst von deutscher Seite als „ein befähigter militärischer Führer von anerkannten Qualitäten“ " gelobt. ${ }^{38}$

Diese Entschlossenheit zum Kampf gegen die Deutschen war es auch, welche die Kommunisten als Bündnispartner für die SOE attraktiv machte. Somit stellte der Herbst 1943 nicht nur hinsichtlich der Verstärkung durch ehemaliges italienisches Personal und die Abkehr von der nationalen Widerstandsbewegung, dem „Balli Kombëtar“ und den Zogisten eine Zäsur dar. Die zunehmende Unterstützung durch die SOE wie auch die veränderte Kriegslage förderten den massenhaften Zulauf zu kommunistischen Verbänden in „Großalbanien“, in Mittel- und Südalbanien, und in den nördlichen Grenzgebieten auch zu den jugoslawischen Einheiten Titos. ${ }^{39}$

Von Beginn an waren die beiden kommunistischen Widerstandsgruppen eng miteinander verbunden: Bereits im Sommer 1941 schickte die Kommunistische Partei Jugoslawiens zwei Funktionäre, Dušan Mugoša and Miladin Popović, nach Albanien, um dort beim Aufbau der Kommunistischen Partei Albaniens unterstützend mitzuwirken. Entsprechend schwierig gestalteten sich die Einsätze der

36 Vgl. Zaugg, Albanische Muslime, S. $72 \mathrm{f}$.

37 OB Südost, Bericht „Entwicklung der militärischen Lage in Albanien im Herbst 1944“, undatiert, BArchF, RW 40/116a, Bl. 16.

38 Ebd.

39 Bereits Ende 1943 forderte Davies, dass die Briten nur noch den kommunistischen Widerstand unterstützen sollten. Diese Politik wurde im Laufe des Jahres 1944 dann auch umgesetzt. Vgl. Fischer, Albania at War, S. 204f. Zu den intensiven Verhandlungen der SOE mit den verschiedenen Gruppen des albanischen Widerstands vgl. Amery, Sons of the Eagle, S. 36 f. sowie Secret Report “Albanian Minority in Yugoslavia”, 1/7/1953, CIA-RDP82-00457R0145001400028, S. 4. Noch am 12. Februar 1944 fand in Nordalbanien ein letztes Treffen zwischen den Kommunisten und anderen Widerstandsgruppen, darunter die Banden von Bajraktari und Kryeziu, statt, die als letzter Hoffnungsschimmer eines vereinten Widerstands aufflackerten. Vgl. Fischer, Albania at War, S. 204. Durch die nun einseitige Unterstützung des kommunistischen Widerstands, fühlte sich Captain A.C. Simcox rückblickend verantwortlich für das Scheitern der nationalen bzw. auch demokratisch ausgerichteten Seite: „We have let the Nationalists of Albania down. [...] Especially Gani Kryeziu who has fought well and is sacrificing more than any communist.“ zitiert nach Bailey, The Wildest Province, S. 297. 
Deutschen in den Grenzgebieten „Neualbaniens“, wo sich Partisaneneinheiten verschiedenster Couleur, von Kommunisten (albanische und jugoslawische) hin zu Nationalisten („Balli Kombëtar“ und einige Četnik-Gruppen), trafen und zudem Flüchtlinge (vor allem jüdische) von Jugoslawien nach Albanien oder (vor allem serbische) von Kosovo nach Jugoslawien ausreisen wollten. ${ }^{40}$ Dieses destabilisierte Gebiet konnte, so die Meinung auf deutscher Seite, nur mithilfe ortskundiger Soldaten hinreichend gesichert werden. ${ }^{41}$

Der endgültige Bruch mit den Kommunisten veränderte aber auch die Ausgangslage für den nationalen Widerstand um den „Balli Kombëtar“. Durch eine teilweise intensive Zusammenarbeit mit den deutschen Besatzern hofften die nationalistischen Kräfte, die für ein ethnisch homogenes „Großalbanien“ eintraten, an ihr Ziel zu gelangen. In diesen Zeitraum fällt auch die Gründung der „Zweiten Liga von Prizren“ Mitte September 1943, welche den Aufbau der Division „Skanderbeg“ unterstützte und somit ein wichtiger Faktor im blutigen Gegeneinander verschiedener albanischer und jugoslawischer Gruppierungen wurde. ${ }^{42}$ Der wichtigste Exponent in dieser Phase war der bereits im Teil zur Division „Handschar“ genannte Xhafer Deva aus Mitrovica. Dass er genaugenommen serbischer Staatsbürger war, ${ }^{43}$ hinderte die Deutschen nicht daran, ihn nun als albanischen Innenminister einzusetzen. Neubacher stellte Deva gleich nach der italienischen Kapitulation einen Fieseler Storch zur Verfügung, um möglichst rasch von Mitrovica nach Tirana zu gelangen, denn „,seine Stunde war gekommen“. 44

\subsection{Ausgangslage und Absichten auf deutscher Seite}

Ähnlich wie im Falle des Balkanfeldzugs 1941 drängten auch in Albanien äußere Umstände die Deutschen zum Handeln: Nachdem die Regierung Badoglio am 8. September 1943 kapituliert hatte, sah sich Hitler gezwungen, Albanien zu besetzen, um seine Flanke zu schützen. ${ }^{45}$ Neubacher behauptete nachträglich, dass

die Albaner [...] sehr gut [wussten], dass wir nur aus zwingenden militärischen Gründen einmarschiert waren, um uns vor einem Flankenangriff zu schützen, der von Seiten der

40 Vgl. Zaugg, Albanische Muslime, S. $254 \mathrm{f}$.

41 Vgl. Schmidhuber an die Präfekten von Prizren, Priština und Peja, „Betr.: Personenerfassung und Waffenscheine im Kosovo-Gebiet“, 25.5.1944, (Abschrift, Anlage 10 zu DGA Nr. 3046/ 44/geh.v.23.6.1944), BArchF, RH 19-XI/9, Bl. 26. Vgl. Zaugg, Albanische Muslime, S. $254 \mathrm{f}$.

42 Vgl. Elsie, Historical Dictionary of Kosovo, S. $251 \mathrm{f}$.

43 Neubacher, Sonderauftrag Südost, S. 119.

44 Ebd., S. 106.

45 Vgl. Zaugg, Albanische Muslime, S. 88. 
Alliierten über die Straße von Otranto drohte. Ich erinnere mich keines unfreundlichen Akts der Bevölkerung gegen die deutsche Wehrmacht. ${ }^{46}$

Der Historiker Marenglen Kasmi weist jedoch darauf hin, dass die Deutschen zumindest in Tirana auf Widerstand stießen, durch den sie auch Verluste erlitten. ${ }^{47}$ Das geringe Ausmaß des Widerstands zu diesem Zeitpunkt hing aber, wie bereits gezeigt, nicht etwa mit der Sympathie der Albaner für die deutsche Besatzungsmacht zusammen, sondern damit, dass sich die verschiedenen Widerstandsgruppen im September 1943 selbst in einer tiefen Krise befanden, die zu ihrer Spaltung und gegenseitigen Bekämpfung führte. ${ }^{48}$ Aus dieser Situation gingen die kommunistischen Partisanen letztlich als Sieger hervor. ${ }^{49}$ Der Divisionskommandeur der „Skanderbeg“ August Schmidhuber meldete im Sommer 1944 nach dem Unternehmen „Draufgänger“ schließlich, dass es sich bei den kommunistischen Partisanen in dieser letzten Phase nicht mehr um Banden, sondern um eine sehr gut ausgerüstete und ausgebildete Armee gehandelt habe. ${ }^{50}$

Das deutsche Vorgehen in Albanien von Herbst 1943 bis Herbst 1944 weist zwar einige Ähnlichkeiten mit demjenigen im NDH 1941 bis 1944 auf. So blieb etwa eines der wichtigsten Argumente, um „Fremdvölkische“ für die Waffen-SS zu rekrutieren, der akute Personalmangel. Allerdings existierten auch zahlreiche Abweichungen, denn „Großalbanien“ unterschied sich in vielen Belangen grundsätzlich vom „Unabhängigen Staat Kroatien“ und die deutschen Vertreter vor Ort sahen sich mit spezifischen kulturellen und politischen Problemen konfrontiert, die sie aus ihren Erfahrungen in Bosnien nicht kannten. ${ }^{51}$

Im Hinblick auf die Rekrutierungen für die „Skanderbeg“ lassen sich Bedingungen und Vorgehen der Deutschen in vier Themenkomplexe gliedern: Für die Sicherung der neuen Territorien galt es den Personalmangel in deutschen Einheiten mit lokalen Kräften auszugleichen. Dabei standen vor allem die Sicherung der Rückzugsrouten und wehrwirtschaftlich relevanten Objekte, die nach der Kapitulation Italiens unter deutsche Kontrolle gekommen waren, im Vorder-

46 Neubacher, Sonderauftrag Südost, S. 107.

47 Vgl. Kasmi, Deutsche Besatzung in Albanien, S. 11.

48 Vgl. Zaugg, Albanische Muslime, S. $72 \mathrm{f}$.

49 Vgl. OB Südost, Bericht „Entwicklung der militärischen Lage in Albanien im Herbst 1944“, undatiert, BArchF, RW 40/116a, Bl. 16.

50 Vgl. Gefechtsbericht für das Unternehmen „Draufgänger“ vom 18.7.-28.7.1944, Schmidhuber, Lagebeurteilung, 22.7.44, NARA, T314/664, F. 283.

51 Vgl. Neubacher, Sonderauftrag Südost, S. 107. Obwohl Neubacher im gleichen Absatz betont, dass die Lage in Albanien nicht sehr verworren war, zählt er dann über mehrere Seiten die sehr unterschiedlichen Kollaborateure und Opponenten auf. Vgl. Neubacher, Sonderauftrag Südost, S. 107-114. 
grund. $^{52}$ Zweitens sollten die „fremdvölkischen“ Waffen-SS-Einheiten in Albanien die stärker werdenden Partisanen in den Grenzregionen zu Montenegro, Serbien und Mazedonien bekämpfen. Drittens stand die Befriedigung der albanischen Elite im Vordergrund, die in der Regierung und regierungsähnlichen Gremien wie der „Zweiten Liga von Prizren“ vertreten war und einen großen Einfluss auf das Verhalten der Mitglieder des „Balli Kombëtar“ hatten. Viertens sollte mit der „Skanderbeg“ eine zweite muslimische Propagandadivision gebildet werden, um der arabischen Welt die Nähe zwischen Islam und Nationalsozialismus aufzuzeigen und diese zur Unterstützung zu bewegen. ${ }^{53}$

\subsubsection{Akuter Personalmangel in deutschen Einheiten}

Ausdruck der prekären Personalsituation, die nach der Kapitulation Italiens offensichtlich wurde, war die Besetzung „Großalbaniens“ mit nur rund zweieinhalb Wehrmachtsdivisionen, der 297. Infanterie-Division und der 118. Jäger-Division, welche schon bald von der 181. Infanterie-Division abgelöst wurde, und für kurze Zeit der 100. Jäger-Division. ${ }^{54}$ Der Oberbefehlshaber der Heeresgruppe F von Weichs beklagte nicht nur die geringe Stärke seiner Truppen, sondern auch, dass es sich dabei mit wenigen Ausnahmen nicht um erstklassige Verbände gehandelt habe. ${ }^{55}$ Aus diesen Gründen sollte zur Sicherung von Straßen, wehrwirtschaftlich relevanten Objekten und im Krieg gegen Partisanengruppen möglichst rasch lokales Personal eingesetzt werden. Im September 1943 wurde auf Druck Neubachers ein Rekrutierungsverbot erlassen, um die albanische Souveränität nicht zu verletzten. Dieses wurde allerdings bereits im Oktober sowohl für Rekrutierungen der Waffen-SS als auch der Wehrmacht wieder gelockert. ${ }^{56}$ Der Vorschlag der albanischen Regierung bzw. der „Zweiten Liga von Prizren“ im Frühjahr 1944, für eine albanische Waffen-SS-Division eine allgemeine Wehrpflicht einzuführen, wurde von den deutschen Vertretern positiv aufgenommen. ${ }^{57}$ HSSPF Fitz-

52 Vgl. Zaugg, Albanische Muslime, S. 113-123.

53 Reichsführer SS, SS-Hauptamt A I/M, Vermerk betr. „Mobilisierung des Islam“, 28.2.1944, BArchB, NS 31/42, Bl. 6.

54 Vgl. Zaugg, Albanische Muslime, S. 210.

55 Vgl. OB Heeresgruppe F, Generalfeldmarschall Maximilian von Weichs 25.1.1944, Anlage zu DGA Nr. 3046/44 g.v.23.6.1944, BArchF, RH 19-XI/9, Bl. 2.

56 Vgl. von Thadden über Treffen mit Neubacher vom 11.10.1943, PAAA, Inland IIg, R100984, H298703.

57 Vgl. Bedri Pejani an Ministerpräsident Rexhep Mitrovica, 23.5.1944, A.Q.SH. F.147, 1944, D I-165, Bl. 16. 
thum war aber der Meinung, dass diese nur eingehalten werden könnte, wenn Deva Innenminister blieb. ${ }^{58}$

Trotz des auch bei den anderen südosteuropäischen Divisionen herrschenden Personalmangels sollten neben Albanern vor allem Deutsche und „Volksdeutsche“ aus der „Prinz Eugen“ und der „Handschar“ als Rahmenpersonal in der „Skanderbeg“ dienen. Um diese Vakanzen bei den anderen Divisionen auszugleichen, sollten nach Unterstaatssekretär Martin Luther weitere 10.000 „Volksdeutsche“ für Waffen-SS-Verbände im Südosten geworben werden. ${ }^{59}$ Der Personalmangel konnte jedoch bei der „Skanderbeg“ nie überwunden werden. Er äußerte sich nicht nur darin, dass die Division nicht einmal die Hälfte ihrer Sollstärke erreichte, sondern auch darin, dass der Divisionsstab die meiste Zeit ohne Ia und Ic und ohne Gericht (III) blieb. ${ }^{60}$ Aus der Abteilung IVa, welche über den gesamten Zeitraum voll besetzt war, rekrutierten sich schließlich im Herbst 1944 Truppenführer für die zur Kampfgruppe umfunktionierte „Skanderbeg“ - eine Aufgabe, die ihnen indes nicht neu war: Aufgrund der prekären Personalsituation waren sie bereits seit Beginn der Aufstellung nicht nur als Verwaltungsführer, sondern auch als Truppenführer bei der Ausbildung von Rekruten eingesetzt worden. ${ }^{61}$

\subsubsection{Zwischen Sicherung der Grenzgebiete und fehlender Nähe zur Bevölkerung}

Kosovo als Teil „Großalbaniens“ und die Sandžak-Region, aufgeteilt zwischen Serbien und Montenegro, hatten als so genannte Grenzregion stets eine wichtige Bedeutung. Es erstaunt daher nicht, dass bereits im Frühjahr 1944 die „Zweite Liga von Prizren“ gegenüber der albanischen Regierung verlauten ließ, sie würde eine albanische Waffen-SS-Division „zur Verteidigung der Grenzen der befreiten

58 Fitzthum an Himmler, undatiert, BArchB, NS 19/1488, Bl. 1.

59 Vgl. Vortragsnotiz Luther, 4.6.1944, PAAA, Inland IIg R100696.

60 Bei der Abt. III ist SS-Hauptsturmführer Ziack aufgeführt, seine Funktion sei aber keine richterliche gewesen, so Schmidhuber. Der Ia sei nur acht Tage geblieben, schreibt Schmidhuber weiter. Gottlob Berger habe jedoch zur Unterstützung der Division immerhin „fachkundiges Personal des SS-Hauptamtes“ von anderen Standorten versetzen lassen. Vgl. Schmidhuber, „Zusammenfassender Bericht“, 2.10.1944, BArchF, RS 3-21/1, S. 4.

61 Dieses speziell in der Waffen-SS eingeführte System, dass Verwaltungsführer über die Führerschulen auch als Truppenführer ausgebildet wurden, hatte sich für die „Skanderbeg“ bewährt. Vgl. von Pistor an Vopersal, undatiert, BArchF, N 756/182b. 
Gebiete“ unterstützen. $^{62}$ Bereits nach dem Frieden von San Stefano und wieder nach den Balkankriegen 1912/1913 galt diese Region als Pufferzone. ${ }^{63}$ Es handelte sich um ein stark frequentiertes Gebiet, welches Flüchtlinge aus anderen Regionen (Ost-)Europas durchqueren mussten, um nach „Altalbanien“ zu gelangen. Doch auch Partisanengruppen verschiedenster Couleur agierten in diesem Gebiet und an seinen Grenzen. Bereits am 25. Mai 1944 plante Schmidhuber „zur Feststellung raumfremder Personen, welche sich derzeit als Fein[d]agenten herumtreiben“, alle ortsansässigen Einwohner in den Bezirken Prizren, Prishtina/ Priština und Pejë/Peć „kartei- oder listenmäßig“ bis zum 1. Juni 1944 zu erfassen, und an jedem Haus ein Verzeichnis mit den darin wohnenden Familien und einzelnen Familienangehörigen anzubringen. Personen ohne Personalausweise und ohne Waffenscheine sollten sofort festgenommen werden. Wer sich nicht ausweisen oder Ziel und Grund seiner Reise nicht ausreichend rechtfertigen konnte, wurde in das Anhaltelager nach Prishtina/Priština gebracht. Am 15. Juni 1944 machte Schmidhuber nochmals darauf aufmerksam, dass diese Regelung sofort zur Anwendung kommen sollte. ${ }^{64}$

Der Sicherung jenes Gebiets kam noch aus anderen Gründen Bedeutung zu: Kosovo und das angrenzende Sandžak-Gebiet waren potentielles Durchmarschgebiet für die noch in Griechenland stationierten deutschen Truppen. Bereits im September 1943 war klar, dass es im Falle eines Rückzug ein Nadelöhr darstellen würde. Da ein solcher im Frühjahr 1944 in absehbare Nähe gerückt war, galt es, die wenigen Straßen zu sichern. Oder wie von Weichs die Situation schilderte: „An einigen Eisenbahnsträngen und Straßen hängen die deutschen Machtzentren wie an dünnen Fäden aufgereiht. “65 Denn bei einem Rückzug kam nur der Weg entlang der albanisch-montenegrinischen Küste oder aber durch Kosovo infrage, und „die Beherrschung und Freihaltung der großen Straßen [wurden] schließlich zum Kernproblem der ganzen Besatzung“, wie der Bericht zur „Ent-

62 Sitzung des „Zentralkomitee zur Verteidigung Kosovos“, Nr. 14, 30.3.1944.

A.Q.SH. , F. 147, V. 1944 D I-165, S. 15.

63 Vgl. bspw. Scheer, Minimale Kosten, absolut kein Blut, S. 16f. Vgl. zu Albanien und angrenzenden Gebieten als Pufferzone auch Zaugg, Albanische Muslime, S. 37. Vgl. auch Sundhaussen, Holm, Kosovo: „Himmlisches Reich“ und irdischer Kriegsschauplatz, Kontroversen über Recht, Unrecht und Gerechtigkeit, in: Südosteuropa, 5/6 (1999), S. 241, 245.

64 Vgl. Abschrift „Kontrolle des Ein- und Durchreiseverkehrs im Kosovogebiet“, Div. Kdr. Schmidhuber, 15.6.1944 (Anlage 10 zu DGA Nr. 3046/44 g.v. 23.6.1944), BArchF, RH 19-XI/9, Bl. 24. Schreiben „Betr.: Personenerfassung und Waffenscheine im Kosovo-Gebiet“ Schmidhuber an die Präfekten von Prizren, Priština und Peć, 25.5.1944, (Abschrift, Anlage 10 zu DGA Nr. 3046/44/geh.v.23.6.1944), BArchF, RH 19-XI/9, Bl. 26.

65 OB Südost (Heeresgr. F) Generalfeldmarschall Maximilian von Weichs, H.Q., „Die große Absetzbewegung im Südosten“, Januar 1945, BArchF, RH 19-XI/86, S. 2. 
wicklung der militärischen Lage“ festhält. ${ }^{66}$ Bei der Sicherung Albaniens spielte die Eisenbahn im Innern Albaniens fast gar keine Rolle; einzig eine Schmalspurbahn führte von Struga über Tetovo nach Skopje. Eine zweite Strecke, Tirana-Durrës-Elbasan-Struga, war zwar im Rohbau von den Italienern fertiggestellt worden, konnte aber aufgrund von Zeitdruck und Personalmangel von den Deutschen nicht mehr weiter ausgebaut werden. Dagegen kam der Strecke Skopje-Mitrovica-Belgrad im Kosovo eine außerordentlich wichtige Bedeutung für Truppennachschub und den „etwaigen Rückmarsch der Truppen“ zu. ${ }^{67}$

Auf deutscher Seite war ein wichtiges Motiv zur Aufstellung einer albanischen Waffen-SS-Division, dass die Sicherung von Straßen, Pässen und wehrwirtschaftlich relevanten Objekte der Region, insbesondere in Nord- und „Neualbanien“, mehrheitlich von lokalen Soldaten übernommen werden konnte. ${ }^{68}$ Die deutschen Besatzer merkten aber bald, dass zur Bewerkstelligung dieser Aufgaben vor allem der direkte Kontakt zur Bevölkerung von Bedeutung war. Entsprechend hoch wurde rückblickend der Stellenwert von Präfekturen sowie Orts- und Platzkommandanturen eingeschätzt, da nur diese die Möglichkeit hatten, mit der Bevölkerung in direkten Kontakt zu treten und sie zu beeinflussen. Entsprechend sei der Zentralregierung eine übertriebene Bedeutung beigemessen worden, so der Autor des Berichts zur „Entwicklung der militärischen Lage“, während die traditionellen Strukturen vor allem im Norden und Nordosten „Großalbaniens“, nämlich die Macht der lokalen, teils gewählten, teils erblichen Dorfältesten und der Bairaktare nicht berücksichtigt wurden. ${ }^{69}$ Denn der Einfluss der albanischen Regierung reichte kaum über die Städte hinaus: „Dies hatte seinen weiteren Grund darin, dass die westlich aufgezogene Behördenorganisation noch keine festen Wurzeln im Volk geschlagen hatte, und zudem der Großteil der Beamten bestenfalls unfähig, häufig aber auch politisch unzuverlässig war.“70 Auch Schmidhuber war der

66 OB Südost, Bericht zur „Entwicklung der militärischen Lage in Albanien im Herbst 1944“, undatiert, BArchF, RW 40/116a, Bl. 31. Vgl. auch Tönnes, Sonderfall, S. 455, 457. Die Küstenstraße führte von Himarë im Süden Albaniens über Vlorë und Durrës nach Shkodër an der montenegrinischen Grenze, eine der wichtigsten Straßen durch das Landesinnere führte im Osten über Florina, Korçë, Struga in das Kosovogebiet hinein. Vgl. OB Südost, Bericht zur „Entwicklung der militärischen Lage in Albanien im Herbst 1944“, undatiert, BArchF, RW 40/116a, Bl. 30. 67 Vgl. OB Südost, Bericht „Entwicklung der militärischen Lage in Albanien im Herbst 1944“, undatiert, BArchF, RW 40/116a, Bl. $29 \mathrm{f}$.

68 Vgl. Zaugg, Albanische Muslime, S. 250.

69 Vgl. OB Südost, Bericht zur „Entwicklung der militärischen Lage in Albanien im Herbst 1944“, undatiert, BArchF, RW 40/116a, Bl. 27. Vgl. auch Doka, Yzeiri, Grundzüge, S. 22.

70 Vgl. OB Südost, Bericht zur „Entwicklung der militärischen Lage in Albanien im Herbst 1944“, undatiert, BArchF, RW 40/116a, Bl. 27. 
Meinung, dass sich die Präfekten und Bürgermeister bei der Bevölkerung zu wenig für die Aufstellung der Division einsetzten. ${ }^{71}$ Nach ihm wurde die Beeinflussung der lokalen Bevölkerung aber auch durch den Umstand erschwert, dass diese ihren Herrn bzw. Clanchefs in politischen Fragen oft treu ergeben waren und ihr individuelles Handeln den Entscheidungen der lokalen Eliten unterordneten. ${ }^{72}$

Als die kommunistischen Partisanen unter Führung Mehmet Shehus nach gescheiterten deutschen Operationen in Südalbanien nach Mittel- und Nordalbanien auswichen, zeigte sich ein weiteres Mal, dass den Straßen eine „lebenswichtige Bedeutung“ zukam. Durch die Beherrschung der wenigen Straßen durch Partisanen war eine „Abschnürung der Schlagadern des Verkehrs“ eingetreten, was faktisch bereits einer Beherrschung des Landes durch die kommunistischen Verbände gleichkam. Den Angehörigen der Waffen-SS und irregulären Hilfstruppen war dies nicht entgangen. Sie desertierten und liefen in großer Zahl zu den Kommunisten über, wie dem „Bericht zur Entwicklung der militärischen Lage“ zu entnehmen ist. $^{73}$

\subsubsection{Eine Waffen-SS-Division zur Befriedigung der albanischen Regierung und Eliten?}

Obwohl der deutsche Einmarsch im September 1943 keine größeren Zerstörungen verursacht hatte, verschärfte er dennoch die wirtschaftliche Krise in Albanien. ${ }^{74}$ Denn die Stationierung deutscher Truppen und deren Versorgung mit Nahrungsmitteln, der Ausbau der Küstenverteidigung und die Verbesserung der Infrastruktur zur Sicherung des Nachschubtransportes belasteten die krisengeschüttelte albanische Wirtschaft zusätzlich und strapazierten dadurch das Verhältnis zwischen dem Dritten Reich und der albanischen Regierung. ${ }^{75}$

Die Einsetzung eines vierköpfigen Regentschaftsrates und die darauf folgende Wahl einer neuen Regierung brachten nicht die gewünschte Entspannung. Nachdem Mehdi Frashëri zwischen Oktober und Anfang November 1943 ad interim als Ministerpräsident eingesetzt worden war, konstituierte sich die erste Regierung unter deutscher Besatzung erst am 5. November 1943. Zum Mi-

71 Vgl. Schmidhuber, „Zusammenfassender Bericht“, 2.10.1944, BArchF, RS 3/21-1, Bl. 2.

72 Vgl. ebd., Bl. 1.

73 Vgl. OB Südost, Bericht „Entwicklung der militärischen Lage in Albanien im Herbst 1944“, undatiert, BArchF, RW 40/116a, Bl. $19 \mathrm{f}$.

74 Vgl. Kühmel, Deutschland und Albanien, S. 325.

75 Vgl. ebd., S. 322. Vgl. hierzu auch Neubacher, Sonderauftrag Südost, S. 114. Vgl. Tönnes, Sonderfall, S. 455, 457. 
nisterpräsidenten wurde nun Rexhep Mitrovica gewählt, und Xhafer Deva als Innenminister eingesetzt. Beide waren zu diesem Zeitpunkt genau genommen gar keine albanischen Staatsbürger, da sie aus dem zu Serbien gehörenden Teil Kosovos stammten und auch dort beheimatet waren. ${ }^{76}$ Durch die Einsetzung einer den Deutschen treu ergebenen Regierung und dem Aufbau einer eigenen Gendarmerie und Polizei sollte die innenpolitische Situation stabilisiert, deutsche Ressourcen gespart und kriegswirtschaftliche Bedürfnisse der deutschen Besatzer befriedigt werden. ${ }^{77}$ Dies sollte auf einer Grundlage geschehen, die vordergründig die „relative[,] Souveränität des albanischen Staates“ wahrte, wie der Deutsche Bevollmächtigte General in Albanien, Generalleutnant Otto Gullmann, betonte. Dabei sollten die Albaner innenpolitische Aufgaben selbst übernehmen. $^{78}$

Zwei Faktoren behinderten aber die Beruhigung der innenpolitische Lage: In Mittelalbanien drohte bereits kurz nach der Besetzung des Landes durch deutsche Kräfte ein offener Bürgerkrieg zwischen den kommunistischen Partisanen und den zogistischen Kräften, während deutsche Beobachter auf der anderen Seite das „innenpolitische Intrigenspiel einzelner einflussreicher Persönlichkeiten“ beanstandeten, welches durch Zweckbündnisse die Neubildung der Regierung behinderte. ${ }^{79}$ Den Deutschen missfielen die oft wechselnden Allianzen und das opportunistische Verhalten albanischer Politiker. So arbeiteten Mehdi Frashëri und sein Sohn Vehbi Frashëri zwar mit ihnen zusammen, unterhielten aber gleichzeitig Kontakte nach Ankara und zu den Westalliierten. ${ }^{80}$

Da Deutschland dieser instabilen innenpolitischen Situation im letzten Kriegsjahr nicht mehr viel entgegenzusetzen hatte, konzentrierten sich die deutschen Vertreter einerseits auf den Abbau von Bodenschätzen, andererseits widmete sich HSSPF Fitzthum dem Aufbau einer albanischen Miliz und Gendarmerie. Zusätzlich zu diesen Verbänden sollte mit dem Aufbau der Division „Skanderbeg“ den Wünschen der Regierung und albanischen Elite entsprochen werden, einen Kern für eine zukünftige albanische Armee aufzubauen. Dass diese Formation im „neualba-

76 Vgl. Neubacher, Sonderauftrag Südost, S. 119. Vgl. zur Einsetzung des Regenschaftsrats und der verschiedenen Regierungen auch Zaugg, Albanische Muslime, S. 97-100.

77 Vgl. Umbreit, Die deutsche Herrschaft in den besetzten Gebieten, S. 92.

78 Schreiben Gullmann an Chef des Generalstabes der Heeresgruppe F, Generalmajor August Winter, 23.6.1944, BArchF, RH 19 XI/9, S. 6.

79 Vgl. Gen.kdo. XXI. Geb.A.K., 13.7.1944, NARA, T314/664, Bl. 200.

80 Vgl. Bericht „Entwicklung der militärischen Lage in Albanien im Herbst 1944“, OB Südost, undatiert, BArchF, RW 40/116a, Bl. 13. 
nischen“ Kosovogebiet formiert und stationiert werden sollte, zeigte deutlich die Stoßrichtung: „Großalbanien“ sollte auch nach Kriegsende weiter bestehen. ${ }^{81}$

Im Sommer 1944 galt aber zumindest der Aufbau der albanischen Milizverbände („Nationales Schutzkorps“ und „Landwehr“) bereits als gescheitert, wie der Chef des Generalstabes der Heeresgruppe F, Generalmajor August Winter, dem $\mathrm{OKH}$ mitteilte. ${ }^{82}$ Auch die wirtschaftliche Situation verschlechterte sich rasch - sowohl aufgrund der Ausbeutung durch die Deutschen, beispielsweise durch die Organisation Todt, als auch der instabilen innenpolitischen Situation. ${ }^{83}$ Im Süden des Landes drohte eine Hungersnot. „Erosionserscheinungen in den Reihen der Ballisten“84, wie Neuwirth die Abkehr verschiedener Vertreter des „Balli Kombëtar“ von den Deutschen nennt, stürzten den albanischen Staat in eine politische Krise. In dieser Situation sahen sich die deutschen Vertreter gezwungen, sich auch antiitalienischen Gruppierungen, die ihnen nicht in jedem Fall wohlgesinnt waren, anzunähern, beispielsweise denen um Abaz Kupi oder Fiqri Dine. Aber auch zu ehemaligen Unterstützern Italiens, wie Gjon Marka Gjoni, Mustafa Kruja oder Shefqet bei Vërlaci, einem der wohlhabendsten Großgrundbesitzer des Landes, suchten die Deutschen Kontakt. Ziel war eine möglichst rasche Regierungsneubildung. Obwohl die Deutschen nun auch die Integration von Zogisten in die Regierung in Betracht zogen, fürchteten sie eine Annäherung nationalistischer Kräfte aneinander, da die Gefahr drohte, dass diese bei einer Einigung geschlossen in Verhandlungen mit den Alliierten treten würden. $^{85}$

Die Instabilität der Lage in Albanien zeigte sich in den Sommermonaten 1944 durch die sich in rascher Folge abwechselnden Regierungen immer deutlicher:

81 Vgl. ebd., Bl. 17. Vgl. bspw. Neubacher, Sonderauftrag Südost, S. 116, 118.

82 „Auf Grund völligen Versagens der aufgestellten albanischen Miliz-Verbände (Nat. Schutzkorps und Landwehr) wurden diese vollständig aufgelöst.“ Fernschreiben Chef des Generalstabes, Winter an OKH, GenStdH, Abt. Fremde Heere West (IV), 5.7.1944, BArchF, RH 19-XI/9, Bl. 30.

83 Vgl. ausführlich Zaugg, Albanische Muslime, S. 106f. Hierbei zu nennen ist auch die geplante und teilweise umgesetzte Ausbeutung verschiedener im Land vorhandener Rohstoffe. Für diese Arbeiten unter der Organisation Todt sollten einerseits Kriegsgefangene, aber auch Landeseinwohner, Zivilfirmen und der Reichsarbeitsdienst herangezogen werden. Die lokale Bevölkerung wurde zudem etwa zur Aushebung eines 19 Kilometer langen Panzergrabens an der Ostgrenze der albanischen Tiefebene gezwungen. Vgl. Seidler, Organisation Todt, S. 83. Vgl. zur wirtschaftlichen Ausbeutung Albaniens durch die OT und dem von ihr angehäuften Schuldenberg ausführlich den Bericht des OB Südost, „Entwicklung der militärischen Lage in Albanien im Herbst 1944“, undatiert, BArchF, RW40/116a, Bl. 32.

84 Neuwirth, Widerstand und Kollaboration, S. 148.

85 Vgl. ebd., S. 148 f. 
Auf Rexhep Mitrovica, der von November 1943 bis Juli 1944 Ministerpräsident gewesen war, folgte am 18. Juli 1944 Fiqri Dine. Ziel dieses Regierungswechsels, der ohne vorherige Absprache mit den deutschen Besatzern stattgefunden hatte, war es, Innenminister Deva auszuschalten. ${ }^{86}$

Die Division „Skanderbeg“, die bisher auf Wunsch der Regierung einerseits die Aufgabe hatte, einen Grundstock für eine zukünftige nationale albanische Armee zu bilden, andererseits aber auch die von deutscher Seite kriegswirtschaftlich relevante Infrastruktur zu sichern, verlor damit ihren wichtigsten Befürworter und Unterstützer - oder, wie in einem Bericht der Wehrmacht formuliert, durch die Absetzung Devas „verschwand dann die wertvollste Schachfigur im deutschen Spiel im Hochsommer vom Brett. “87

Die versuchte Wiedereinsetzung Devas auf Druck Fitzthums fand bei den Albanern wenig Anklang: Der erst im Juli 1944 eingesetzte Fiqri Dine demissionierte bereits am 28. August 1944. Als Nachfolger wurde am 6. September Ibrahim Bey Biçaku eingesetzt: „persönlich ein einwandfreier Deutschfreund, aber politisch vollkommen unfähig und instinktlos““. ${ }^{88}$ Seine Regierung existierte zwar noch bis Ende November 1944, konnte aber innenpolitisch keine Macht mehr entfalten. ${ }^{89}$ Aufgrund der zunehmend instabilen Situation und Machtlosigkeit der Regierung wurde von der deutschen Verwaltungsgruppe der Wehrmacht ein Plan ausgearbeitet, ,auch ohne Verhängung des Ausnahmezustandes eine getarnte deutsche Verwaltung aufzuziehen“. Dieser wurde aber vom Beauftragten für Wirtschaft und Finanzen in Albanien, SA-Oberführer Karl Gstöttenbauer abgelehnt, der selbst zu diesem Zeitpunkt noch die „Neutralität“ Albaniens zu wahren versuchte. ${ }^{90}$ Deva hingegen sollte zwar nicht mehr als Innenminister, aber als Nachfolger Pejanis als Präsident der „Zweiten Liga von Prizren“ bis zuletzt an der Zusammenarbeit mit den Deutschen und dem Aufbau lokaler militärischer Ver-

86 Vgl. ebd., S. 149.

87 OB Südost, Bericht „Entwicklung der militärischen Lage in Albanien im Herbst 1944“, OB Südost, undatiert, BArchF, RW40/116a, Bl. 14. Vgl. Zaugg, Albanische Muslime, S. 250.

88 Vgl. Neuwirth, Widerstand und Kollaboration, S. 149f. Vgl. OB Südost, Bericht „Entwicklung der militärischen Lage in Albanien im Herbst 1944“, OB Südost, undatiert, BArchF, RW 40/116a, Bl. $14 \mathrm{f}$.

89 Vgl. Umbreit, Die deutsche Herrschaft in den besetzten Gebieten, S. 94. Neuwirth nennt den 21. Juli 1944 als Tag der Regierungsbildung Fiqri Dines. Vgl. Neuwirth, Widerstand und Kollaboration, S. 149f. Biçaku blieb trotz aller Warnungen in Albanien und wurde später von Kommunisten erschossen. Vgl. OB Südost, Bericht „Entwicklung der militärischen Lage in Albanien im Herbst 1944“, undatiert, BArchF, RW 40/116a, Bl. 15.

90 Vgl. ebd., Bl. $27 \mathrm{f}$. 
bände festhalten. ${ }^{91}$ Er wollte im Kosovo sogar eine neue Regierung ins Leben rufen, deren Einfluss allerdings, so waren sich die deutschen Kreise sicher, auf die Kosovoregion beschränkt bleiben würde. ${ }^{92}$

\subsubsection{Eine zweite Propaganda-Division? Schwierige Verbindung von Nationalsozialismus und Islam in „Neualbanien“}

Im Mai 1944 dokumentierte Kriegsberichter Georg Westermann die inszenierte Ankunft albanischer Kriegsgefangener aus Deutschland, die sich zum Dienst in der Division „Skanderbeg“ verpflichtet hatten. ${ }^{93}$ In einem anderen Bild-Bericht hielt er die Musterungen angehender „Skanderbeg“-Soldaten im Rekrutierungsbüro Prizren fest. ${ }^{94}$ Schließlich sollte auch die „Skanderbeg“, wie die „Handschar“ und die „ost-muselmanische Division“, „als wesentliches Propagandamittel“ für den Aufbau bzw. die Rekrutierung weiterer muslimischer Verbände dienen. ${ }^{95}$ Zudem, so schien es den Vertretern des Dritten Reiches, verlangte Albanien „als einziger, überwiegend muselmanischer Staat in Europa [...] im Rahmen der gesamten deutschen Islampolitik und insbesondere mit Rücksicht auf die Türkei unbedingt eine politische Sonderbehandlung und musste deshalb eine über seine sonstige Bedeutung wohl hinausgehende pflegliche Betreuung in der hohen Politik erfahren.“96

Als der Divisionskommandeur der „Handschar“, Karl-Gustav Sauberzweig, die Albaner seiner Division zu der sich in Aufstellung befindenden Division „Skanderbeg“ mit den Worten entließ: „Ich möchte nicht schließen, ohne besonders die Tapferkeit der Albaner anzuerkennen, die [...] ein Soldatentum ohnegleichen zeigten. Sie sind die Vorboten einer Heimat, zu der wir die Verbindung auch suchen und finden werden“",77 deutete er damit an, dass Albanien für die

91 Vgl. Schmidhuber, „Zusammenfassender Bericht“, 2.10.1944, BArchF, RS 3/21-1, S. 3. Vgl. Graf, Kriegsgefangenenbericht, 9.11.1948, VA, HEM.OK.BOJCKA, 72/2-1/32. Vgl. Malcolm, Kosovo, S. 312. Vgl. auch Zaugg, Albanische Muslime, S. 284.

92 Vgl. OB Südost, „Lagebild Südost vom 9.10.1944“, 10.10.1944, BArchF, RH 19/XI-22, Bl. 224.

93 Vgl. bspw. NARA, Kriegsberichter Westermann, Bild 32A.

94 Vgl. bspw. Ebd., Bild 29A.

95 Reichsführer SS, SS-Hauptamt A I/M, Vermerk betr. „Mobilisierung des Islam“, 28.2.1944, BArchB, NS 31/42, Bl. 6.

96 Bericht „Entwicklung der militärischen Lage in Albanien im Herbst 1944“, OB Südost, undatiert, BArchF, RW40/116a, Bl. 5.

97 Brief Nr. 9 Divisionskommandeur Sauberzweig an Mannschaft der 13. SS-Division, 27.3.1944, BAB, NS 19/2601, Bl. 216. Er spricht hier auch von den „vielen Heldentaten“ seiner Division. Ähnliches berichtet Kaesdorf, die Albaner seien besonders geübt im „Nahkampf“ 
Deutschen bisher eine terra incognita war. Im Gegensatz $\mathrm{zu}$ Bosnien, welches durch die österreichisch-ungarische Herrschaft durchaus westeuropäische Züge aufwies, stand Albanien in seiner Ausgestaltung immer noch stark unter dem Einfluss der erst kürzlich zu Ende gegangenen osmanischen Herrschaft. Schmidhuber beschrieb diesen Zustand mit folgenden Worten: „Albanien als 400-jährige türkische Provinz ist in jeder Hinsicht, türkischer‘ geblieben als die Türkei selbst. Angefangen vom Frauenschleier bis hinauf zum Volksbegriff. “98

Diese Welt war den Vertretern des Dritten Reiches, so etwa Neubacher, Schmidhuber oder Fitzthum, fremd, wie ihre Aussagen offenlegen. Ihre fast kindlich anmutenden Erklärungsversuche mithilfe von Karl May-Abenteuerromanen und „völkischen“ Forschungsergebnissen widerspiegeln ihre Unkenntnis und weisen stark orientalistische Züge auf. ${ }^{99}$ Neubacher, der seit September 1943 auch in Albanien als Sonderbeauftragter Südost eingesetzt war, schrieb rückblickend: „Ich hatte mir vor drei Wochen im Hauptquartier sehr oberflächliche Kenntnisse von der politischen Lage in Albanien verschafft [...] “100, indem ihn der ehemalige Handelsattaché der deutschen Gesandtschaft in Tirana und politische Berater für albanische Angelegenheiten beim Auswärtigen Amt, Franz von Scheiger, in aller Eile über Geschichte, Kultur und die „Feinheiten der albanischen Stammes-, Sippen- und Familienfragen“ informierte. ${ }^{101}$

Trotz der eklatanten Ignoranz von deutscher Seite sollte auch diese zweite muslimische Waffen-SS-Division eine Brücke zwischen dem Nationalsozialismus und dem Islam schlagen, wobei auf die bereits gesammelten Erfahrungen mit Albanern in der „Handschar“ zurückgegriffen werden sollte. Zu diesem Zweck fertigte SS-Untersturmführer Julius Kaesdorf, der zu der von SS-Hauptsturmführer Ekkehard Wangemann geführten Abteilung VI gehörte und somit auch für die „weltanschauliche Erziehung“ innerhalb der Division mitverantwortlich war, einen Erfahrungsbericht an, in dem er ihm wesentlich erscheinende Besonderheiten albanisch-muslimischer Soldaten wiedergab. ${ }^{102}$

Allerdings fußte das Unternehmen, eine albanische muslimische WaffenSS-Division aufzustellen, nicht nur zeitlich, sondern auch geographisch und

und in der Anwendung von Kriegslisten, "Erfahrungen mit albanischen Soldaten”, Kaesdorf, undatiert, BArchB, NS 31/444, S. $26 \mathrm{f}$.

98 Schmidhuber, „Zusammenfassender Bericht“, 2.10.1944, BArchF, RS 3/21-1, S. 1.

99 Vgl. hierzu detailliert Zaugg, Albanische Muslime, S. 300-303.

100 Neubacher, Sonderauftrag Südost, S. 105.

101 Vgl. ebd., S. 107. Vgl. auch Kasmi, Deutsche Besatzung in Albanien, S. 13.

102 Vgl. Kaesdorf, „Erfahrungen mit albanischen Soldaten“, undatiert, BArchB, NS 31/444. 
kulturell auf einer anderen Ausgangslage als in Bosnien und wies somit beim Vorgehen neben einigen Ähnlichkeiten bald zahlreiche Unterschiede auf. Zu diesen albanischen Hintergründen, vor welchen die Rekrutierung für die „Skanderbeg“ stattfand“ schrieb Franz Schmidt-Dumont bereits im Juni 1944:

Der Forderung des Großmuftis, die mohammedanischen Albaner anzusprechen, stehen zwei Bedenken entgegen: 1.) Albanien zerfällt in zwei geographisch getrennte Teile, den christlichen und den mohammedanischen, die sich Jahrhunderte lang befehdet haben. Auch den Türken ist es nicht gelungen, beide Teile auszusöhnen. Das haben erst die Österreicher während der Besatzung im Ersten Weltkrieg gekonnt und im Anschluss daran die nachfolgenden Regierungen. Würden wir jetzt die Mohammedaner durch den Großmufti von Jerusalem ansprechen lassen, so würden wir damit an kaum vernarbten Wunden rühren. 2.) Es kommt hinzu, dass die sehr rassebewussten Albaner sich von einem Araber, und wäre es auch der Großmufti von Jerusalem, nichts sagen lassen wollen. Sie haben ihre eigenen Dorfheiligen. Dem Auswärtigen Amt liegen bereits Beschwerden in dieser Richtung vor. ${ }^{103}$

Diese Verhaltensweise, sprich dass sich die Albaner meistens eher ihren lokalen Clanchefs als dem Staat verbunden fühlten, verursachte den Deutschen denn auch die größten Probleme bei der Rekrutierung, in der Ausbildung und dem Führen albanischer Einheiten. ${ }^{104}$

Wie bereits im Teil zur Division „Handschar“ gezeigt, setzte die Rekrutierung von Albanern in dieser Region nicht erst für die Aufstellung der „Skanderbeg“, sondern bereits kurz nach dem Balkanfeldzug 1941 ein: Albanienkenner Franz von Scheiger schlug dem Auswärtigen Amt im Herbst 1941 vor, sich diese „islamischen Kreise Albaniens, die zwei Drittel der Bevölkerung ausmachten, zu nutze zu machen“. ${ }^{105}$ Schon zu diesem Zeitpunkt wurde die enge Verbindung mit arabischen Staaten hervorgehoben, insbesondere weil die Albaner, ähnlich wie die Araber, den italienischen Imperialismus als gefährlich empfinden würden. Von Scheigers Bericht sollte für das Auswärtige Amt aufzeigen, wo „starke italienfeindliche Strömungen und Kräfte“ zu finden wären, die für deutsche Zwecke instrumentalisiert werden konnten. ${ }^{106}$

Um schließlich die Albaner als Teil der Waffen-SS erscheinen zu lassen, wurde mehrfach auf ihre Abstammung und ihre soldatischen Eigenschaften

103 Franz Schmidt-Dumont, Abteilung Ausland, Berlin, 1.6.1944, BStU, AS Nr.456/66, Bl. 97.

104 Vgl. Schmidhuber, „Zusammenfassender Bericht“, 2.10.1944, BArchF, RS 3-21/1, S. 3. Vgl. auch Christoph Stamm, Zur deutschen Besatzung Albaniens 1943-1944, in: Militärgeschichtliche Mitteilungen 30 (1981), S. 99-120, hier: S. 110. Kühmel, Deutschland und Albanien, S. 25 f. und Zaugg, Perfekte Krieger?, S. 246.

105 Vgl. Bericht Franz von Scheigers an AA, 25.10.1941, PAAA, Altes Amt, Tirana 4/7, Bl. 255900.

106 Vgl. ebd. 
hingewiesen: So erörterte Berger etwa 1943, dass die „Urkraft“ der Muslime aus dem Sandžak und Nachbargebieten wie Kosovo unbedingt für die WaffenSS zu verwenden sei, da diese „eine ausgezeichnete soldatische Anlage“ aufweisen würden. ${ }^{107}$ Auch rassisch wurden die bisher orientalisierten Albaner nun in ein „nordisches“ Licht gerückt: Die Nordalbaner galten jetzt als eine „besondere Rasse“, die durch die schwere Zugänglichkeit der Region von slawischen Einflüssen frei geblieben sei. ${ }^{108}$ Karl C. Loesch und Wilhelm E. Mühlmann betonten in ihrer 1943 erschienenen Untersuchung „Völker und Rassen Südosteuropas“, dass „frappant nordische Varianten“ bei den Nordalbanern zu finden seien. Bei ihnen würden sich „,nordische Merkmale [...] in nahezu idealtypischer Ausbildung“ zeigen. ${ }^{109}$ Auch „Volkstumsreferent“ Feninger schrieb nach seiner Reise durch die Kosovoregion im Herbst 1941 begeistert über diese „große[n], kräftige[n] Menschen“: „Der Besuch arnautischer Bergbauerndörfer drängt zum Vergleich mit manchen ostmärkischen Alpengebieten, deren Bewohner weitgehende Übereinstimmungen hinsichtlich gewisser Eigenschaften zeigen. “110 Weiter sah er in der „rassischen Reinheit“ der Bevölkerung in Nord- und „Neualbanien“ einen Kontrast zu derjenigen in den Städten, in welchen wohl eine „stärkere Vermischung mit anderen Gruppen“ und somit „fremde Blutsbeimischungen“ stattgefunden hätten. ${ }^{111}$ Die Nord- bzw. „Neualbaner“ wurden damit rassisch sogar auf eine höhere Stufe gestellt als die bosnischen Soldaten der „Handschar“, die zwar „völkisch-rassisch gesehen“ zur „germanischen Welt“, aber dennoch überwiegend zur „dinarischen Rasse“ gezählt wurden. ${ }^{112}$

Bei der Aufstellung der „Skanderbeg“ sollte aufgrund der Meuterei von bosnischen und albanischen Muslimen und Katholiken im September 1943 in der „Handschar“ darauf geachtet werden, ausschließlich Muslime zu rekrutieren: SS-Obersturmführer Talbot von Pistor berichtete noch lange nach Kriegsende,

107 Vgl. Berger an AA, Abt. DVIII, 9.4.1943, PAAA Inland IIg R100998, H297616.

108 Vgl. James Cowles Prichard, Naturgeschichte des Menschengeschlechts, deutsche Übersetzung von Rudolf Wagner, Friedrich Will (Hg.), Leipzig 1942, S. 535.

109 Loesch, Mühlmann, Völker und Rassen, S. 49.

110 Bericht „über die Reise in das Arnautengebiet von Kosovska Mitrovica und Novi Pazar“ des Volkstumsreferenten Dr. Feninger beim Bevollmächtigten des AA in Belgrad, 15.26.10.1941, PAAA, R261153, Bl. 34.

111 Ebd. Feninger sollte gemeinsam mit einem Kriegsberichter seine Studien zum „westbalkanischen Gebirgsmenschen“ vollenden, da die Arbeit für den Reichsführer SS von besonderem Interesse sei, wie Neubacher dem Gesandten Schliep noch im August 1944 mitteilte. Vgl. Neubacher an Schliep, 2.8.1944, PAAA R27305.

112 Vgl. Abschrift eines SS-Hauptsturmführers i. A. Himmlers an das AA vom 19.5.1943, BArchB NS 19/2601, Bl. 245. 
dass „nur mohamedanische Albaner genommen [wurden], keine Christen!“113 Obwohl diese Propaganda, wie am Beispiel von Pistors sichtbar wird, bis in die Nachkriegszeit wirkte, entsprach sie nicht der Realität, denn tatsächlich wurden in die „Skanderbeg“ auch albanische Katholiken aufgenommen. ${ }^{114}$ Somit war sie genauso wenig ein rein muslimischer Verband wie ihre Schwesterdivision „Handschar“.

Die Umsetzung einer ideologischen Schulung wurde in der „Skanderbeg“ aus zwei Gründen erschwert: Zum einen schien Kaesdorf, mehr noch als bei den Bosniern, dass die Albaner den aktuellen Krieg „gar nicht in den großen politischen Zusammenhängen“ wahrnahmen; sie würden „nicht für eine politische Idee [kämpfen], sondern aus angeborener Kampfeslust, aus Erwerbssinn und aus Treuebindung an [ihren] bewährten Führer."115 Zum anderen darf der Zeitpunkt der Aufstellung auch bezüglich der ideologischen Ausbildung nicht außer Acht gelassen werden: Die Alliierten waren in Ost-, Süd- und Westeuropa auf dem Vormarsch, Griechenland stand kurz vor der Räumung. Was also bei der „Handschar“ noch an ideologischer Schulung konzeptualisiert und umgesetzt wurde, hatte für die „Skanderbeg“ kaum mehr Geltung. Kaesdorf war sogar der Meinung, dass die „weltanschauliche Schulung“ verstimmend wirken könnte und daher ganz weggelassen werden sollte. ${ }^{116}$

Auch der Islam als Zentrum einer auf Muslime adaptierten „weltanschaulichen Erziehung“ ist für die „Skanderbeg“ nicht mehr belegt. Als gemeinsames Feindbild wurde nur der Kommunismus bemüht, da für die Kosovo-Albaner ein Sieg der Kommunisten bedeutete, dass ihre Heimat wieder Serbien zugeschlagen würde. ${ }^{117}$ Religion stand, anders als bei anderen muslimischen Verbänden der Waffen-SS, etwa der Schwesterdivision „Handschar“, nicht mehr im Vordergrund. So sind bei der Werbung für die „Skanderbeg“ im Gegensatz zur „Handschar“ keine Einsätze von Imamen belegt. ${ }^{118}$ Oft war es

113 Brief Talbot von Pistor an Vopersal, ohne Datum, BArchF, N756/182b.

114 Vgl. Tom Tushi, E-mail an die Verfasserin, 19.3.2017.

115 „Erfahrungen mit albanischen Soldaten“, Kaesdorf, undatiert, BArchB, NS 31/444, Bl. 28.

116 Vgl. „Erfahrungen mit albanischen Soldaten“, Kaesdorf, undatiert, BArchB, NS 31/444, Bl.

28. Im Gegensatz dazu wäre in den Reihen der Volksdeutschen, die als Rahmenpersonal auch in der „Skanderbeg“ vertreten waren, dringend eine weltanschauliche und politische Erziehung notwendig gewesen. Vgl. Brandt, Persönlicher Stab Reichsführer SS an OKW, 13.10.1942, PAAA R100696, Bl.130288.

117 Vgl. Fernschreiben der 118. Jäg.Div., Abt. Ia vom 5.10.1943, 12.15 Uhr an 297. Inf.Div., Abt. Ia, BArchF, RH26-181/38.

118 Wie bereits erläutert, wurden bei der Werbung für die „Handschar“ gezielt Imame eingesetzt. Vgl. Schreiben des Imams und SS-Hauptsturmführers Hasan Bajralitarovic [Bajraktarević]] an Phleps, undatiert, BArchB, NS 19/2601, Bl. 57. 
Schmidhuber selbst, der auf den Marktplätzen „Neualbaniens“ Werbereden hielt. $^{119}$

In einigen Belangen sollte aber weiterhin auf die Bedürfnisse muslimischer Soldaten eingegangen werden. So wurde etwa für die Köche der Division in Prishtina/Priština ein Halal-Kochlehrgang eingerichtet. ${ }^{120}$ Denn bereits im August 1943 hatte Himmler angeordnet, dass Muslime in der Waffen-SS weder Schweinefleisch essen mussten, noch Alkohol angeboten bekämen. ${ }^{121}$ Dass er damit wohl nicht alle Soldaten zufrieden stellte und diese Aussage eher seine Unkenntnis lokaler Verhältnisse offenbarte, zeigt etwa eine Aussage Schmidhubers, der vom Raki-Konsum der Soldaten berichtete. ${ }^{122}$ Dass hingegen der Fastenmonat Ramadan auch von Angehörigen der „Skanderbeg“ eingehalten wurde, bezeugt der Bericht von Pistors. Er schrieb nach dem Krieg, dass die Ausbilder des SS-Wirtschafts-Bataillons 21, das zu Ausbildungszwecken in Ampermoching stationiert war, deswegen mit Schwierigkeiten $\mathrm{zu}$ kämpfen hatten. ${ }^{123}$

Der Islam stellte im Falle der Ausbildung muslimischer Albaner eher eine Herausforderung als eine Möglichkeit der Einflussnahme dar. Kaesdorf betonte, dass die muslimischen Albaner eine ausgesprochen enge „Bindung an die religiöse Welt des Islam“ hätten und deshalb darauf achten würden, „,wie der „nichtmohammedanischer Führer innerlich über den Islam denkt.“ Dabei würde der Albaner aber

nicht die Großzügigkeit des Bosniaken [zeigen], sondern ist durch eine ironische oder oberflächliche Äußerung seines Führers tief innerlich getroffen. Eine negative Einstellung seines Führers zum Islam zerstört jede Treuebindung und Autorität. Die Verschiedenheit der Religionszugehörigkeit und der Lebensgewohnheiten erschwert die Stellung des deutschen Führers zu seinen albanischen Männern. ${ }^{124}$

An dieser Aussage ist gut zu erkennen, dass die sozialen Strukturen „Neualbaniens“ zwar auf dem gesellschaftlichen Fundament des Islams aufbauten, aber nicht zuletzt in Verbindung mit dem lokalen Gewohntheitsrecht eine spezifische

119 Vgl. Schmidhuber, „Zusammenfassender Bericht“, 2.10.1944, BArchF, RS 3-21/1, S. 3.

120 Vgl. Schreiben Himmler an Berger, 22.7.1943, BArchB, NS 19/2601, Bl. 142. Vgl. auch Brief Talbot von Pistor an Vopersal, ohne Datum, BArchF, N 756/182b. Bereits in der „Handschar“ war mit der Einrichtung einer Großküche und etwa 15-20 Feldküchen auf eine Verpflegung unter „Einhaltung der muslimischen Riten“ geachtet worden. Vgl. Kriegsgefangenenbericht „Bericht über die 13. SS Division „Handschar“, ihre Aufstellung, Gliederung und 1. Einsätze im jugoslawischen Raum“, Walter Eipel, 14.11.1947, VA, HEM.OK.BOJCKA, 72-A/1-a/32.

121 Entwurf Himmler, August 1943, BArchB, NS 19/2601, Bl. 148.

122 Vgl. Schmidhuber, „Zusammenfassender Bericht“, 2.10.1944, BArchF, RS 3/21-1, S. 2.

123 Vgl. von Pistor an Vopersal, undatiert, BArchF, N 756/182b.

124 „Erfahrungen mit albanischen Soldaten“, Kaesdorf, undatiert, BArchB, NS 31/444, S. 25. 
Ausgestaltung fanden, die keine Verbindung zum Nationalsozialismus, wie im Falle von Bosnien gezeigt, zuließ. Entsprechend riet Kaesdorf „dem nichtmuselmanischen Führer“, dass er „sich bei klarem Bekenntnis zu seiner andersartigen Gläubigkeit einer korrekten ritterlichen Haltung zu befleißigen und für seine Person ebenso streng und folgerichtig nach den eigenen inneren Gesetzen zu leben wie es die Albaner ihrerseits tun. Eine saubere kämpferische soldatische Haltung verfehlt ihren Eindruck nie. “125 Im Falle der Rekrutierungen in der Sandžak- und KosovoRegion scheint sich daher eher das deutsche bzw. „volksdeutsche“ Rahmenpersonal den lokalen gesellschaftlich-religiösen Gegebenheiten angepasst zu haben.

\subsubsection{Nicht nur eine „Mobilisierung des Islam“? Zu Inklusionsversuchen serbischer Soldaten in die Waffen-SS}

Deutlicher als bei der Division „Handschar“ zeigt sich am Beispiel der Division „Skanderbeg“, wie oberflächlich und opportunistisch sich die nationalsozialistischen Annäherungen an die Muslime Südosteuropas gestalteten. Denn gleichzeitig zu den Anstrengungen, Verbindungen zwischen Islam und Nationalsozialismus aufzubauen, wurde von deutscher Seite auch versucht, zu serbisch-othodox ausgerichteten Banden eine Brücke zu schlagen, da die Situation in den Grenzgebieten Kosovo und Sandžak eine Zusammenarbeit mit möglichst allen kollaborationswilligen Gruppierungen notwendig machte. In einem geheimen Schreiben zur „Weltanschauliche[n] Führung serbischer Waffenangehöriger der SS“ werden zahlreiche den albanischen diametral gegenüberstehende Interessen aufgeführt, die ebenso der weltanschaulichen Propaganda dienen sollten. Diese unterschieden sich nur in den geografischen Hintergründen und Aufteilungen, boten aber sonst ähnliche Argumente. Denn auch hier galt als „Ziel der weltanschaulichen Führung: Der fanatische Kämpfer für Heimat und Familie, freies Volkstum und staatliche Selbstständigkeit und für ein neues Europa.“126 Zur selben Zeit galt als Erziehungsziel in der weltanschaulichen Schulung ,der willensstarke und tatenfrohe Kämpfer, der bereit ist, für eine neue und bessere europäische Ordnung sein Leben einzusetzen.“127 Und wie der „albanische Soldat“ schien den Deutschen auch „der serbische Soldat“ „sehr gute soldatische Fähigkeiten“ mitzubringen. „Er ist kräftig,

125 „Erfahrungen mit albanischen Soldaten“, Kaesdorf, undatiert, BArchB, NS 31/444, S. 25. 126 „Weltanschauliche Führung serbischer Waffenangehöriger der SS“, ohne Namensangabe, ohne Datum, BarchB, NS31/445, Bl. 36. Im Vergleich dazu der sehr ähnliche Wortlaut bei Himmler bezüglich der albanischen und bosnischen Muslime: „... eine in die Zehntausende gehende Anzahl fanatischer Freiwilliger“. Entwurf Himmler, August 1943, BArchB, NS 19/2601, Bl. 148.

127 „Dienstanweisung für Imame der 13. SS-Freiwilligen b.h.Geb.Div. (Kroatien)“, 15.3.1944, BArchB, NS 19/2601, Bl. 248. 
ausdauernd, anspruchslos, zeigt gute Vertrautheit mit dem Gelände, natürlichen Kampfesmut und Disziplin. Auch der einfache Soldat zeigt Initiative. “128 Das „natürliche Kämpfertum der Serben“ sollte mit Hinweisen auf kämpferische Gestalten und Volkshelden aus der serbischen Geschichte und dem „Appell an die serbische Waffenehre“ gestärkt werden. Dabei sollte auch serbisches Liedgut hinzugezogen und darauf geachtet werden, dass Lieder mit deutschfeindlichem Inhalt durch neue Texte abgeändert würden. ${ }^{129}$ Wichtig schien auch die „Pflege des europäischen Gedankens“, wobei insbesondere auf die Schlacht auf dem Amselfeld von 1389 hingewiesen werden sollte, wo Serbien für Europa geblutet habe. ${ }^{130}$

Unter zahlreichen ähnlichen Argumenten bei Serben und Albanern im Grenzgebiet im und um den Sandžak schient der Anti-Bolschewismus eines der stärksten zu sein: In der nationalsozialistischen Propaganda für die Serben sollte vor allem auf die Verschleppungspolitik der Bolschewisten hingewiesen werden, die bereits 10.000 serbische Kinder verschleppt hätten. Da sich aber „der Serbe [...] als Russe des Balkans, als führende Nation unter den Südslawen“ fühle, dürfe nichts gegen das russische Volk gesagt werden, sondern der Boleschwismus müsse als unrussisch, unslawisch, unreligiös und antinational dargestellt werden. ${ }^{131}$ In der weltanschaulichen Schulung sollte deshalb an das bäuerliche Serbentum, den nationalen Gedanken und die religiösen Kräfte appelliert werden, also die gleichen drei Pfeiler, Tradition, Nation und Religion, die auch in der Ausbildung der albanischen (und bosnischen) Muslime hervorgehoben wurden.

\subsubsection{Die involvierten deutsche Dienststellen}

Ähnlich wie im NDH musste auch in Albanien vordergründig die staatliche Souveränität gewahrt bleiben. Dies wiederum führte dazu, dass es nicht nur zu Spannungen zwischen albanischen und deutschen Dienststellen kam, sondern diese auch untereinander Auseinandersetzungen austrugen, wie im „Bericht

128 „Weltanschauliche Führung serbischer Waffenangehöriger der SS“, ohne Namensangabe, ohne Datum, BarchB, NS31/445, Bl. 36. Im Vergleich: „Soldatische Tugenden“ der Albaner bei Kollegger, Albaniens Wiedergeburt, S. 59-60, „glänzende Soldateneigenschaften“ der Albaner aus Kosovo bei Reichel, AA Inland IIc, 12.4.1943, PAAA Inland IIg R100998, „angeborene Kampfeslust“ der Albaner bei Kaesdorf, „Erfahrungen mit albanischen Soldaten“, undatiert, BArchB, NS 31/444, Bl. 28.

129 „Weltanschauliche Führung serbischer Waffenangehöriger der SS“, ohne Namensangabe, ohne Datum, BarchB, NS31/445, Bl. 36.

130 Ebd., Bl. 37.

131 Ebd. 
zur Entwicklung der militärischen Lage“ nachzulesen ist: „Die Folge war eine sachlich nicht immer glückliche Abhängigkeit von albanischen Interessen unnd Anschauungen, die gelegentlich zu Zwistigkeiten [von deutschen Verwaltungsstellen] mit den militärischen Stellen führten.“132 Direkt an der Aufstellung der „Skanderbeg“ waren vor allem die Dienststellen der SS und Waffen-SS beteiligt. Aus den Quellen wird jedoch sichtbar, dass auch der „Deutsche Bevollmächtigte General Albanien“ (DGA) und der „Sonderbevollmächtigte Südost“ auf die Vorbereitungen und die Durchführung der Aufstellung sowie den Einsatzbereich der Division Einfluss nahmen.

\subsubsection{Die besonderen Stellungen des HSSPF Albanien und SSPF Sandžak}

Die in die Rekrutierung für die „Skanderbeg“ involvierten Stellen der Waffen-SS waren teilweise die gleichen, die bereits bei den Aushebungen für die „Handschar“ in Erscheinung traten, insbesondere im Falle des Sandžaks. Selbstverständlich zeichneten an oberster Stelle auch für die Aufstellung der „Skanderbeg“ Himmler und Berger verantwortlich. Daneben traten lokale Protagonisten der SS bzw. Waffen-SS in den Vordergrund, so der HSSPF Albanien Josef Fitzthum, der SS- und Polizeiführer (SSPF) Sandžak Karl von Krempler, der zum Zeitpunkt der Aufstellung der „Skanderbeg“ vom Oberbefehlshaber Südost zum „Kreiskommandanten Sandžak“ ernannt und direkt dem Militärbefehlshaber Südost unterstellt wurde, ${ }^{133}$ und der spätere SSPF Sandžak Richard Kaaserer. ${ }^{134}$ Da sowohl Fitzthum als auch von Krempler bezüglich der Rekrutierungen von Albanern einen bemerkenswerten Aktivismus entwickelten, sollen ihre Rollen im Folgenden kurz vorgestellt werden. Die sowohl für die Aufstellungsphase als auch die Einsätze der „Skanderbeg“ zentrale Figur des Divisionskommandeurs August Schmidhuber wird im Kapitel zur Aufstellung und Zusammensetzung der Division vorgestellt.

Die Aufgaben der neugeschaffenen Dienststelle des HSSPF Albanien waren nur ungenau definiert und ließen dadurch viel Handlungsspielraum zu. ${ }^{135}$ Der von Himmler für diesen Posten auserwählte Josef Fitzthum traf im Dezember

132 OB Südost, Bericht „Entwicklung der militärischen Lage in Albanien im Herbst 1944“, undatiert, BArchF, RW 40/116a, Bl. 7.

133 Schmider, Partisanenkrieg, S. 369.

134 Vgl. zu Richard Kaaserer auch Kapitel „Ungleichbehandlung, Rassismus und brutale Ausbildungsmethoden“ im Teil zur „Prinz Eugen“.

135 Vgl. allgemein zur Entwicklung von Aufgabenbereichen der HSSPFs und deren sukzessives Eingreifen in Bereiche der Militärbefehlshaber Umbreit, Zur Organisation der Besatzungsherrschaft, S. 53f. 
1943 in Tirana ein. Er war zu diesem Zeitpunkt kein unbeschriebenes Blatt mehr, ${ }^{136}$ sondern durch seine Tätigkeit als Kommandeur von SS-Totenkopfstandarten und SS-Infanterieregimentern sowie als Polizeipräsident Wiens bereits einschlägig bekannt. ${ }^{137}$ So stand er etwa mehrfach unter Anklage, weil er bei „Arisierungen“ Kameraden begünstigt hatte. Selbst seine ehemalige Schwägerin klagte vor Gericht, da er sie nach der Trennung von seinem Bruder willkürlich habe verhaften und in eine Nervenklinik einweisen lassen. ${ }^{138}$ Dieses Verfahren war noch nicht abgeschlossen, als Himmler Fitzthum nach Albanien versetzen ließ. Somit war letzterer weit weg von Wien, „ganz gleich wie das Verfahren gegen Fitzthum ausläuft“, wie Himmler gegenüber Berger und dem Chef des Hauptamtes SS-Gericht, SS-Obergruppenführer und General der Waffen-SS Franz Breithaupt, betonte. ${ }^{139}$

Fitzthums Dienststelle hatte ihren Hauptsitz in Tirana, wo 20 Mann eingesetzt waren. In den Außendienststellen in Shkodër waren acht, in Vlorë und Korçe fünf, sowie in Struga vier Mann eingesetzt. Jeweils mit einem Mann versehen waren weitere Außenposten im Raum Kosovo: in Prizren SS-Oberscharführer Pape, in Pejë/Peć SS-Oberscharführer Jäger, in Kicevo SS-Oberscharführer Joachim Voigt, in Gostivar SS-Hauptscharführer Karl Berger und in Tetovo SSHauptscharführer Karl Nagel. Die Dienststelle Fitzthum hatte eigentlich keine Exekutivgewalt, sondern bestand hauptsächlich aus Kriminalbeamten und war dazu gedacht, „zu beobachten, Nachrichten zu sammeln und diese nach Tirana zu leiten“. Daneben sollte sie Spionageabwehr betreiben und die Verbindung zu den Wehrmachtsdienststellen in Bulgarien, Montenegro sowie den Küstenkommandos aufrechterhalten. ${ }^{140}$

136 Vgl. Birn, Höhere SS- und Polizeiführer, S. 284. Zum Zeitpunkt seines Einsatzes als HSSPF Albanien hatte Fitzthum zuerst den Dienstgrad eines SS-Brigadeführers und Generalmajors der Waffen-SS und ab August 1944 denjenigen eines SS-Gruppenführers und Generalleutnants der Waffen-SS inne.

137 Vgl. Ernst Klee, Das Personenlexikon zum Dritten Reich. Wer war was vor und nach 1945, Frankfurt a.M. 2003, S. 154.

138 Fitzthum hätte ab 1.4.1938 SD-Führer des SS-Oberabschnitts Ost in Berlin werden sollen, wurde aber im März 1938 infolge des Anschlusses Österreichs zum Polizeipräsidenten von Wien ernannt. BArchB, PK (ehemals BDC), Fitzthum, Josef, 14.9.1896, Bl. 1620 f. Vgl. Vernehmungsniederschrift, unterzeichnet von SS-Standartenführer Georg Bilgeri und SS-Standartenführer Tondock, 27.12.1939, BArchB, SSO 210, Fitzthum, Josef, 14.9.1896, Bl. 301. Vgl. zweite Übertragung aus dem Stenogramm, 14.12.1939, BArchB, SSO 210, Fitzthum, Josef, 14.9.1896, Bl. 304.

139 Reichsführer SS an Chef der Sicherheitspolizei und Chef des Hauptamtes SS-Gericht, 12.12.1939, BArchB, SSO 210, Fitzthum, Josef, 14.9.1896, Bl. 308.

140 Abschrift „Verbrechen gegen die Menschlichkeit ausgeführt von Günther Hausding“, 20.10.1960, USHMM/BArchL, B162/2.393, Bl. 2-3. 
Durch seine Funktion als HSSPF Albanien eröffnete sich Fitzthum aber die Möglichkeit, sich neben der Aufstellung bewaffneter Verbände mit „der Verwaltung des Landes zu befassen“ und sich auf diese Weise in die albanische Innenpolitik einzumischen. ${ }^{141}$ Schon bald verfolgte er neben seinen offiziellen Aufgaben, der Reorganisation albanischer Ordnungskräfte (Polizei und Gendarmerie) und dem Aufbau einer albanischen Miliz, das Ziel, die staatliche Souveränität Albaniens endgültig zu brechen. Birn schreibt, dass er sogar am Aufbau einer völlig neuen staatlichen Exekutive gearbeitet habe. ${ }^{142}$ Fitzthum war stets bestrebt, seine Befugnisse nicht nur in militärischer, sondern auch in (innen-)politischer Hinsicht auszubauen. ${ }^{143}$ Er versuchte, Kompetenzen über vorgesetzte Stellen neu zu regeln und zu seinen Gunsten zu verschieben. Damit erreichte er, dass seine Pflichten seit Januar 1944 „in Erweiterung seines vom Reichsführer SS erteilten Auftrages“ nun auch den Aufbau einer staatlichen Exekutive einschlossen. ${ }^{144}$ Durch sein selbstbestimmtes Handeln, der Anordnung von Maßnahmen wie Geiselerschießungen oder Aktionen zur Beschaffung von (Zwangs-)Arbeitskräften - zuweilen ohne Rücksprache mit Vorgesetzten, avancierte Fitzthum im öffentlichen albanischen Bewusstsein bald „zur zentralen Figur der Besatzungspolitik“. ${ }^{145}$

Seit Anfang 1944 beschäftigten ihn auch die Verhandlungen mit der albanischen Regierung über den Aufbau einer albanisch-muslimische Waffen-SS-Freiwilligen-Division „Skanderbeg“. Zusammen mit Deva und Schmidhuber sollte er zu einer der Schlüsselfiguren in der Geschichte der „Skanderbeg“ werden. ${ }^{146}$ Für die Vorbereitungs- und Aufbauphase erhielt er am 24. Januar 1944 Verstärkung durch drei Offiziere, die Himmler nach Albanien sandte: Major der Schutzpolizei Treptow aus Hamburg, Hauptmann Alfred Pursche aus Duisburg und Hauptmann Josef Bendl. ${ }^{147} \mathrm{Zu}$ nennen ist in diesem Zusammenhang auch Fitzthums Erster Generalstabsoffizier (Ia), SS-Hauptsturmführer Christian Wirth, der direkt mit albanischen Behörden bzw. Institutionen, die sich als solche

141 Vgl. OB Südost, Bericht „Entwicklung der militärischen Lage in Albanien im Herbst 1944“, undatiert, BArchF, RW 40/116a, Bl. 8.

142 Vgl. Birn, Höhere SS- und Polizeiführer, S. 284.

143 Vgl. OB Südost, Bericht „Entwicklung der militärischen Lage in Albanien im Herbst 1944“, undatiert, BArchF, RW 40/116a, Bl. 8.

144 Vgl. OB Heeresgruppe F, Generalfeldmarschall Maximilian von Weichs 25.1.1944, Anlage zu DGA Nr. 3046/44 g.v.23.6.1944, BArchF, RH 19-XI/9, Bl. 16.

145 Vgl. Birn, Höhere SS- und Polizeiführer, S. 286.

146 Vgl. Schreiben Neubacher an AA, 29.1.1944, PAAA, R101024, Bl. 020 f.

147 Vgl. Schnellbrief Himmler, 24.1.1944, Nr.304/43, BArchF, N 756/182a. 
ausgaben, wie etwa dem „Nationalen Verteidigungskommando“, über das Rekrutierungsvorgehen und Werbequoten für die „Skanderbeg“ verhandelte. ${ }^{148}$

$\mathrm{Zu}$ den Merkmalen von Fitzthums Aktivismus gehörte auch der seit seiner Ankunft Ende 1943 immer enger werdende Kontakt zu Innenminister Deva. Die beiden pflegten einen freundschaftlichen Umgang, was sich in der Albanienpolitik im letzten Kriegsjahr deutlich niederschlug. ${ }^{149}$ Da Fitzthums Projekte im polizeilich-militärischen Bereich nicht erfolgreich waren - sowohl den Aufbau einer albanischen Miliz als auch der albanischen Gendarmerie betrachtete er im Mai 1944 bereits als gescheitert ${ }^{150}$ - wandte er sich spätestens seit Juli 1944 immer stärker innenpolitischen und militärischen Belangen $\mathrm{zu}$, die außerhalb seiner Kompetenzen lagen. Insbesondere DGA Gullmann sah eigene Kompetenzbereiche durch den Machthunger Fitzthums bedroht. ${ }^{151}$ Gullmanns Ängste waren nicht unbegründet: Ende August 1944 wurde die Funktion des DGA mit derjenigen des HSSPF vereinigt und ,in der Hand des Gruppenführers Fitzthum zusammengefasst“. ${ }^{152}$ Dass die neu geschaffene Stelle des HSSPF Albanien auch von weiteren Dienstellen nicht unbedingt positiv aufgenommen wurde, zeigt die Reaktion Neubachers, der sich dafür aussprach, dass Fitzthum zwar eine beratende Funktion bei der albanischen Regierung für den Aufbau und die Organisation einer albanischen Polizei und Gendarmerie einnehmen, aber keine Befehlsgewalt übernehmen sollte. ${ }^{153}$

Der SSPF Sandžak SS-Standartenführer Karl von Krempler wurde am 26. Mai 1896 im serbischen Pirot geboren. Er war verantwortlich für die Rekrutierungen in der Sandžak-Region und verfügte in der Rekrutierung von Albanern 1944 bereits über mehrjährige Erfahrung: Bevor er sich in der Werbung für die „Skanderbeg“

148 Vgl. Fitzthum an Nationales Verteidigungskommando, z. Hd. Generalstabschef General Gustav von Myrdazc, „Werbung für die Waffen-Gebirgsdivision SS ,Skanderbeg““, 15.4.1944, A. Q.SH., F.160, 1944, D 32, Bl. 5.

149 Vgl. Neubacher an Schliep, 6.3.1944, PAAA, R27305.

150 Vgl. Schreiben, Fitzthum an Himmler, 23.5.1944, BArchB, NS 19/2071, Bl. 14. Nach Kühmel soll es sich allerdings bei der albanischen Wehrmacht insgesamt nur um 1.570 Soldaten gehandelt haben. Vgl. Kühmel, Deutschland und Albanien, S. 311.

151 Vgl. OB Südost, Bericht „Entwicklung der militärischen Lage in Albanien im Herbst 1944“, undatiert, BArchF, RW40/116a, Bl. 8. Vgl. Umbreit, Deutsche Herrschaft, S. $92 \mathrm{f}$.

152 OB Südost, Bericht „Entwicklung der militärischen Lage in Albanien im Herbst 1944“, undatiert, BArchF, RW 40/116a, Bl. 8.

153 Neubacher an Generalkonsulat Tirana (davon Abschrift Schliep an Fehn 20.12.1943), Anlage 3 zu DGA Nr. 3046/44 g. vom 3.6.1944, BArchF, RH 19-XI/9, Bl. 15. Vgl. auch Gullmann an Fitzthum, 9.6.1944, BArchF, RH 19-XI/9, Bl. 2 und Umbreit, Deutsche Herrschaft, S. 93. Fitzthum kam schließlich unter nicht restlos geklärten Umständen bei einem Autounfall in Wien ums Leben. Der Unfall geschah zehn Tage nachdem er sich zu einer Unterredung mit Hitler im Hauptquartier getroffen hatte. Vgl. Karl Berger an Vopersal, 7.11.1975, BArchF, N 756-182b. 
einsetzte, war er verantwortlich für die Rekrutierungen für die „Albanisch-Muselmanische SS-Freiwilligen-Legion“, für die „Handschar“ und weitere Einheiten, wie etwa SS Selbstschutz- und Polizei-Regimenter. ${ }^{154}$ Als „Volksdeutscher“ sprach von Krempler neben seiner Muttersprache Deutsch auch Serbisch und Türkisch. Dies machte ihn zu einer wichtigen Stütze der Deutschen für die Rekrutierungen in diesem Raum. Berger lobte ihn 1943 für seine Art, im Umgang mit den Menschen, was sich positiv auf die Aufstellungen auswirken würde. ${ }^{155}$ Anders erscheint er in den Aussagen Kasches, der dem Auswärtigen Amt berichtete, von Krempler sei durch „äußerst nachteilige Methoden bei der Werbung“ aufgefallen. ${ }^{156}$ In von Kremplers Funktion offenbarte sich nicht zuletzt die Durchlässigkeit der Gebiete: Denn obwohl der Sandžak nicht zu „Großalbanien“ zählte, war von Krempler dennoch in die Rekrutierung von albanischen Muslimen für die „Skanderbeg“ involviert und stand in Austausch mit dieser Division.

\subsubsection{Vertreter der Wehrmacht: Das XXI. Gebirgskorps und der DGA}

Taktisch war die Division „Skanderbeg“ der Heeresgruppe F (OB Südost) bzw. auf nächster Ebene dem Kommandierenden General des XXI. Gebirgskorps unterstellt. Dieser plante somit die Unternehmen, bei welchen die albanische Waffen-SS-Division gemeinsam mit Verbänden der Wehrmacht zum Einsatz kam. Die hohe Frequenz von Personalwechseln auf der Position des Kommandierenden Generals des XXI. Gebirgskorps widerspiegelt die instabile Situation im Südosten Europas: In der relativ kurzen Zeit von September 1943 bis November 1944 waren General der Artillerie Paul Bader, General der Panzertruppe Gustav Fehn, General der Infanterie Ernst von Leyser, Generalleutnant Albrecht Baier und zum Schluss noch einmal von Leyser in dieser Funktion eingesetzt.

Die Unterstellung unter das XXI. Gebirgskorps darf aber nicht darüber hinwegtäuschen, dass auch der DGA versuchte, auf die Aufstellung und die Aufgabenbereiche der „Skanderbeg“ Einfluss zu nehmen. Denn erst Anfang September 1944 ging die vollziehende Gewalt auf den Kommandierenden General über, und somit wurde erst zu diesem Zeitpunkt die eindeutige Unterstellung des DGA vorgenommen. Und erst im Oktober 1944 verfügte der Kommandierende General über die gesamte territoriale Befehlsgewalt, nachdem alle anderen Vertre-

154 Vgl. Zaugg, Albanische Muslime, S. 200.

155 Vgl. Berger an Himmler, „Betr.: Bosniaken-Division“, 29.4.1943, BArchB, NS 19/2601, Bl. 11.

156 Gesandter Kasche an AA, 15.9.1943, PAAA, Inland IIg R100998. 
ter, wie Gstöttenbauer, Fitzthum und der Gesandte Martin Schliep das Land verlassen hatten. ${ }^{157}$

Die Stelle des DGA war das Produkt von Unstimmigkeiten zwischen dem OKW, welches für den albanischen Staat einen „Militärbefehlshaber Albanien“ einsetzen wollte, und Neubacher, der darauf beharrte, diesen zurückzuziehen, da er auch in diesem Fall der Meinung war, dass ein deutscher „Militärbefehlshaber“ nicht gut zur albanischen „Souveränität“ passen würde. Aus diesem Grund einigte man sich darauf, als Vertretung der Interessen der deutschen Wehrmacht bei der albanischen Regierung einen „Deutschen Bevollmächtigten General Albanien“ einzusetzen. ${ }^{158}$ Dem DGA unterstanden keine eigenen Truppen, und er war lediglich mit einem Divisionsstab ausgestattet. ${ }^{159}$ Vom 15. September 1943 bis zum 31. Mai 1944 bekleidete General der Artillerie Theodor Geib die Stelle, im Juni 1944 übernahm sie Generalleutnant Otto Gullmann und ab Ende August 1944 amtierte schließlich SS-Gruppenführer und Generalleutnant der Waffen-SS Josef Fitzthum als HSSPF und DGA in Personalunion. ${ }^{160}$

Dem DGA waren drei Feldkommandanturen in Tirana, Prizren und Struga unterstellt. Diese übten die territoriale Gewalt auf mittlerer Ebene aus. Für die Zusammenarbeit mit der Division „Skanderbeg“ war die Feldkommandantur in Prizren am wichtigsten, da diese für den Raum Kosovo zuständig war, und in Prizren der Divisionsstab der „Skanderbeg“ sowie auch eine Dienststelle Fitzthums stationiert waren. Der Feldkommandantur Tirana waren die Küstengebiete von Vlorë bis zur montenegrinischen Grenze bei Durrës und der Bezirk Elbasan unterstellt; der Feldkommandantur Struga die Grenzgebiete zu Bulgarien. Eine vierte Feldkommandantur war in Korçë, Südalbanien, geplant, wurde aber aufgrund der im Süden bereits viel stärkeren Partisanenbewegung und Auseinandersetzungen an der griechisch-albanischen Grenze nicht mehr umgesetzt. ${ }^{161}$ Auf lokaler Ebene wurden Orts- und Platzkommandanturen eingerichtet.Diese wurden rückblickend als die wichtigsten Institutionen im Land betrachtet, denn ausschließlich sie hatten direkten Kontakt zur Bevölkerung. ${ }^{162}$ Anfang 1944 wurden aufWunsch Neubachers neue Militärverwaltungsbeamte nach Albanien versetzt. Oberrat Dr. West-

157 Vgl. OB Südost, Bericht „Entwicklung der militärischen Lage in Albanien im Herbst 1944“, undatiert, BArchF, RW40/116a, Bl. $8 \mathrm{f}$.

158 Vgl. Führerbefehl, 3.10.1943, BArchF, RW 4/ 885, Bl. 10 sowie Chef OKW Keitel, „Einsetzung eines Deutschen Bev. Generals in Albanien“, BArchF, RW 4/ 885, Bl. 8f. Vgl. Neubacher, Sonderauftrag Südost, S. 110.

159 Vgl. OB Südost, Bericht „Entwicklung der militärischen Lage in Albanien im Herbst 1944“, undatiert, BArchF, RW40/116a, Bl. 5.

160 Vgl. ebd., Bl. 8.

161 Vgl. ebd., Bl. 6.

162 Ebd. 
phal kam zum DGA, Militärverwaltungsrat Heimer zur Feldkommandantur Prizren und Militärverwaltungsrat von Carlowitz nach Struga. Zusätzlich wurden in die jeweiligen Feldkommandanturen auch „einige Bürobeamte und Sonderführer“ entsandt. Eingesetzt wurden solche Militärverwaltungsbeamten eigentlich, um einen möglichen „Zerfall der albanischen Staatsgewalt“ frühzeitig erkennen zu können. Sie entwickelten aber aus eigenem Antrieb eine rege Tätigkeit, da ihr Wirkungsbereich aufgrund „des Fehlens von Befugnissen und von Exekutive außerordentlich schwierig“, und oft reine Interpretationssache war. ${ }^{163}$

\subsubsection{Der „Sonderbeauftragte Südost“ in Albanien}

Auch auf diplomatischer Ebene entfalteten bestimmte Stellen ihren Einfluss in Albanien und auf die Aufstellung und den Einsatz der albanischen Waffen-SSDivision. Der wichtigste Protagonist in dieser Hinsicht war der bereits seit 1940 vom Auswärtigen Amt in anderen südosteuropäischen Staaten wie Rumänien, Ungarn, Bulgarien und Griechenland eingesetzte „Sonderbevollmächtigte Südost“ Hermann Neubacher. Obwohl er Albanien nicht kannte, ließ er sich rasch von dem Albanienexperten Franz von Scheiger über die wichtigsten Eckdaten albanischer Geschichte und Kultur informieren und wurde mit der Bildung eines provisorischen albanischen Regentschaftsrates beauftragt. ${ }^{164}$ Für die Rekrutierungen der Waffen-SS stellte er eine Schlüsselfigur dar, weil er in seiner Funktion seit September 1943 auch für die Koordination sämtlicher außenpolitischer Angelegenheiten in den Gebieten Albanien, Serbien, Montenegro und Griechenland verantwortlich zeichnete. Seine direkten Ansprechpersonen waren der deutsche Generalkonsul Schliep und SA-Oberführer Karl Gstöttenbauer. ${ }^{165}$ Auf Neubachers Verlangen hin wurden die Werbungen von albanischen Muslimen in der Kosovo-Region im September 1943 eingestellt, um die albanische „Neutralität“ nicht zu gefährden. ${ }^{166}$ Bereits im Oktober gab er aber bei einem Treffen mit Eberhard von Thadden zu verstehen, dass Rekrutierungen von Albanern für die Wehrmacht und Waffen-SS unter bestimmten Bedingungen, beispielsweise

163 Ebd., Bl. 7. Vgl. Zaugg, Albanische Muslime, S. $103 \mathrm{f}$.

164 Vgl. Neubacher, Sonderauftrag Südost, S. 105. Vgl. BArchB, SA 4000 72-B, Neubacher, Hermann, 24.6.1893.

165 Vgl. Neubacher, Sonderauftrag Südost, S. 13f. OB Südost, Bericht „Entwicklung der militärischen Lage in Albanien im Herbst 1944“, undatiert, BArchF, RW 40/116a, Bl. 6 f.

166 Vgl. Neubacher, Sonderauftrag Südost, S. 115f. Vgl. auch Zaugg, Albanische Muslime, S. $101 \mathrm{f}$. 
ihrer formellen Unterstellung unter das albanische Innenministerium, dennoch möglich wären. ${ }^{167}$ Dass sich SSPF von Krempler offenbar auch im September nicht an das Rekrutierungsverbot hielt, ist einer Tagesmeldung an die Heeresgruppe F zu entnehmen. Von Krempler sollte darauf hingewiesen werden, dass er „nur Muselmanen im serbischen Kreis Kos.Mitrovica und Sandschak [sic] werben dürfe. “168 Neubacher selbst war gegenüber der Aufstellung einer albanischen Waffen-SS-Division stets kritisch eingestellt, räumte aber ein, dass die Idee bei der albanischen Regierung durchaus positiv aufgenommen worden war. ${ }^{169}$

Wie eng die verschiedenen Stellen ineinander verwoben waren, zeigt sich auch in der Einsetzung einer Dienststelle für Wirtschaft und Finanzen in Albanien. SA-Oberführer Karl Gstöttenbauer, der dieses Amt bekleidete, war in wirtschaftlichen, politischen und administrativen Belangen Neubachers wichtigster Vertreter vor Ort. ${ }^{170}$ Gerade Gstöttenbauer wurde eine übermäßige „Albanienfreundlichkeit“ vorgeworfen, die zu wiederkehrenden Auseinandersetzungen zwischen ihm und militärischen Dienststellen führte. ${ }^{171}$ Kurz vor dem deutschen Rückzug erfolgte dann am 7. Oktober 1944 seine Ernennung zum Chef der Militärverwaltung Albanien und Montenegro in Personalunion - mit dieser Ernennung wechselte er schließlich von der Diplomatie zur Armee. ${ }^{172}$

\subsubsection{Konkurrenzkampf deutscher Dienststellen}

Der albanische Widerstand hielt sich zwar in den ersten Monaten deutscher Besatzung in Grenzen, doch die neue Besatzungsmacht kränkelte an anderer Stelle: Machtkämpfe und Intrigen zwischen den Vertretern deutscher Dienststellen in Albanien prägten das letzte Kriegsjahr von September 1943 bis November 1944 und erschwerten die Zusammenarbeit. ${ }^{173}$ Birn hält fest, dass nicht nur Kompetenzüberschneidungen zu Konflikten führten, sondern sich die Vertreter oft auch der Rollen, die sie zu spielen hatten, nicht sicher, und ihre Funktionen nicht geklärt waren: Der Höhere SS- und Polizeiführer Albanien, der Sonderbevollmächtige

167 Vgl. von Thadden über Treffen mit Neubacher vom 11.10.1943, PAAA, Inland IIg, R100984, H298703.

168 Vgl. Anlage 125/Tagesmeldung an Heeresgruppe F, 27.9.1943, BArchF, RW 40/80.

169 Vgl. Neubacher, Sonderauftrag Südost, S. 116.

170 Vgl. Umbreit, Deutsche Herrschaft, S. 93.

171 Vgl. OB Südost, Bericht „Entwicklung der militärischen Lage in Albanien im Herbst 1944“, undatiert, BArchF, RW 40/116a, Bl. 6-8.

172 Vgl. Schliep an AA, 8.10.1944, PAAA, R27772.

173 Vgl. bspw. OB Südost, Bericht „Entwicklung der militärischen Lage in Albanien im Herbst 1944“, undatiert, BArchF, RW 40/116a, Bl. 7. 
Südost und der Deutsche Kommandierende General Albanien - sie alle hatten spezifische Aufträge und Interessen, die sie verfolgten und umzusetzen versuchten. Jeder dieser deutschen Exponenten beabsichtigte im letzten Kriegsjahr, seinen Einflussbereich so groß wie möglich zu halten. ${ }^{174}$ Da teilweise die Befugnisse deutscher Dienststellen vor Ort überhaupt nicht geregelt waren, ließen sie in ihrer Ausgestaltung einen großen Spielraum zu. ${ }^{175}$

Das Chaos ineinandergreifender Kompetenzen, wie auch ein partielles $\mathrm{Zu}$ sammengehen verschiedener Institutionen je nach Interesse und Situation ${ }^{176}$ war, wie bereits in den Kapiteln zu den beiden anderen Divisionen gezeigt, kein Spezifikum deutscher Albanienpolitik, sondern vielmehr Ausdruck einer zunehmend unüberschaubaren Anhäufung von schriftlich oder mündlich zugesicherten Kompetenzen und Verordnungen, und damit zusammenhängender Überschneidungen in den Bereichen der deutschen diplomatischen und militärischen Administration und Befehlsgebung im Südosten. ${ }^{177}$

Ein erhellendes Beispiel dieser komplizierten Verhältnisse liefert die Ernennung eines „Deutschen Bevollmächtigten Generals in Albanien“ durch Hitler am 3. Oktober 1943. Er reagierte damit auf Neubachers Proteste, der mit der Einsetzung eines „Militärbefehlshabers Albanien“ durch das OKW im „neutralen“ Albanien nicht einverstanden gewesen war. Durch die Umbenennung in „Deutscher Bevollmächtigter General Albanien“, und der Modifikation seiner Funktionen - er hatte nun die Interessen der Wehrmacht bei der albanischen Regierung zu vertreten - sollten Unstimmigkeiten zwischen dem albanischen Staat und dem Dritten Reich vermieden werden. ${ }^{178}$ Doch diese Funktion des DGA befand sich in einem direkten Konkurrenzverhältnis zur Funktion des HSSPF Albanien, der ebenfalls bei der albanischen Regierung für den Aufbau von Polizei, Gendarmerie und Milizverbänden zuständig war. Kleinere und größere Auseinandersetzungen zwischen dem DGA und Vertretern der Wehrmacht auf der einen und den Vertretern der SS und Waffen-SS auf der anderen Seite waren daher vorprogrammiert.

Dass es hinsichtlich der Rekrutierung von „Fremdvölkischen“ für die Waffen-SS nicht nur in Albanien zu Konflikten zwischen deutschen Dienststellen kam, wurde bereits im vorangehenden Kapitel am Beispiel des Gesandten Sieg-

174 Vgl. Birn, Höhere SS- und Polizeiführer, S. 284f. Vgl. auch Kasmi, Deutsche Besatzung in Albanien, S. $21 \mathrm{f}$.

175 Vgl. Zaugg, Albanische Muslime, S. 107-113.

176 Insbesondere Personalmangel forcierte deutsche Institutionen in besetzten Gebieten zur Zusammenarbeit. Vgl. Gerlach, Rivalry and Competition, S. 13.

177 Vgl. Sundhaussen, Improvisierte Ausbeutung, S. 55-75.

178 Vgl. Neubacher, Sonderauftrag Südost, S. 110. 
fried Kasche und den in den Gebieten des NDH aktiven Vertretern der Waffen-SS gezeigt. ${ }^{179}$ Die Konkurrenz um knappe Personalressourcen trat auch in „Großalbanien“ und dem benachbarten Sandžak zutage: Bereits am 11. Oktober 1943, nur einen Monat nach der Kapitulation der Badoglio-Regierung, empörte sich Gottlob Berger bereits, dass sich die Wehrmacht nicht an das auf Druck Neubachers vom Auswärtigen Amt durchgesetzte Rekrutierungsverbot von Albanern gehalten und schon fünf Bataillone mit insgesamt 4.800 Mann rekrutiert hätte: „Die Doppelspurigkeit ist damit wieder - ich betone ausdrücklich leider - vorhanden. “180 $\mathrm{Da}$ sich die Wehrmacht nicht daran hielt, wollte auch er das Rekrutierungsverbot umgehen und 6.000 bereits zusammengezogene „,Volksalbanesen“ (serbische Staatsbürger) - 2/3 im Sandzak, 1/3 im Kosovogebiet“ - in den Verbänden der Waffen-SS einsetzen. ${ }^{181}$ Einige der für Albanien relevanten Auseinandersetzungen sollen im Folgenden näher erläutert werden, da sie einen Einblick in die impovisierte Situation vor Ort geben und aufzeigen, weshalb das Projekt „Skanderbeg“ auch in den Reihen der Deutschen nicht nur Unterstützer fand.

Bereits kurz nachdem Fitzthum in Tirana eingetroffen war, meldete sich DGA Gullmann, der selbst erst zwei Monate im Land war, zu Wort, indem er zwar die Weisungen Himmlers hinsichtlich der Überwachung des „gesamten politischen, wirtschaftlichen und kulturellen Lebens“ durch Fitzthum akzeptierte, aber darauf beharrte, der HSSPF müsse in militärischer Hinsicht in die Schranken gewiesen werden. Ihm sei nicht bekannt, dass durch die Einsetzung eines HSSPF Albanien „die Aufgaben und Pflichten des territorialen Befehlshaber irgendwie eingeschränkt worden sind. “182 Auch Generalfeldmarschall Maximilian von Weichs sah sich veranlasst, dazu Stellung zu nehmen: Der Kommandierende General des XXI. Gebirgskorps sollte gegenüber Fitzthum bezüglich Rekrutierungsorten und -zeiten der militärischen Verbände, somit auch der „Skanderbeg“, das Weisungs- und ein Vetorecht gegenüber Organisationsmaßnahmen behalten, die den Interessen der Landesverteidigung zuwiderliefen. Weiter legte von Weichs fest:

179 Vgl. bspw. Sauberzweig an Berger, 30.9.1943, BArchB, NS 19/2601, Bl. 28. Vgl. Phleps an Chef des SS-Führungshauptamt, SS-Gruppenführer Jüttner, „Zwischenbericht über Werbeaktion muselmanischer Freiwilliger“, 19.4.1943, BArchB, NS 19/2601, Bl. 8.

180 Berger an Reichel, 11.10.1943, PAAA, R100984, Inland IIg, H298706. Zu Rekrutierungen von Albanern in Polzeiformationen innerhalb der Waffen-SS vgl. Tenente Danilo Marchione, 30.10.1943, AUSSME I3/b13/f1, S. 4.

181 Berger an Reichel, 11.10.1943, PAAA, R100984, Inland IIg, H298706.

182 Gullmann an Fitzthum, 9.6.1944, BArchF, RH 19-XI/9, S. 2. Auch Umbreit beschreibt die Verhältnisse in Albanien als wirr, konzeptlos und das Vorgehen als hastig. Umbreit, Deutsche Herrschaft, S. $91 \mathrm{f}$. 
Er [der Kommandierende General] übt über die einsatzfähige alban[ische] Exekutive in allen Fragen des Einsatzes der albanischen Truppenteile usw. gegen den äußeren und inneren Feind die uneingeschränkte und alleinige Befehlsgewalt aus. Der Beauftragte des Reichsführer SS wird ihm in dieser Hinsicht unterstellt. ${ }^{183}$

Obwohl diese Weisung Fitzthum in die Schranken wies, sah DGA Gullmann seine Stellung durch Fitzthums Aktivitäten weiterhin bedroht und wollte daher seine und die Funktion des HSSPF geklärt wissen. Letzterer sollte von vorgesetzter Stelle dazu aufgefordert werden, den DGA persönlich über sämtliche Tätigkeiten und deren Ergebnisse zu unterrichten, wie Gullmann im Juni 1944 an den Chef des Generalstabes der Heeresgruppe F, Generalmajor August Winter schrieb. ${ }^{184}$ Außerdem sei Fitzthum, so Gullmann,

im Dezember [19]43 als Beauftr[agter] RFSS in die Dienststelle Tirana des Sonderbevollmächtigten Südost entsandt worden. Er ist vom Sonderbevollmächtigten Südost der albanischen Regierung als Berater für die Organisation der Polizei und Gendarmer[ie] zur Verfügung gestellt worden, ohne eine Befehlsgewalt zu übernehmen. ${ }^{185}$

Durch den Aufbau der Division „Skanderbeg“ befürchteten die über 80 Dienststellen und Einheiten der Wehrmacht, ihrer bisherigen Aufgabenbereiche enthoben zu werden, wie Hennig aus der Feldkommandantur Prizren berichtete. ${ }^{186}$ Fitzthum hingegen sah durch die Weisung 931/44 nun auch seinen Einflussbereich bedroht, da diese den Feldkommandanturen der Wehrmacht auch politische Aufgaben übertrug. Anfang Juni 1944 meldete er Gullmann, dass die „Überwachung des Landes in politischer Hinsicht“ sowie „die Anregung für die Beeinflussung der Bevölkerung“ nur „durch entsprechend geschulte und erfahrene Kräfte [der SS] durchgeführt werden“ könnten und es der Dienststelle des HSSPF obliegen würde, „die Überwachung des gesamten politischen, wirtschaftlichen und kulturellen Lebens, mit dem Ziel, alle Einflüsse, Widerstandsbewegungen usw., die der durch den deutschen Gesandten gelenkten Reichspolitik abträglich erscheinen, zu bekämpfen bezw. auszuschalten. “187 Er forderte daher, dass die genannte Weisung berichtigt würde und die Feld-

183 OB Heeresgruppe F, Generalfeldmarschall Maximilian von Weichs 25.1.1944, Anlage zu DGA Nr. 3046/44 g.v. 23.6.1944, BArchF, RH 19-XI/9, Bl. 16.

184 Vgl. Gullmann an Chef des Generalstabes der Heeresgruppe F, Generalmajor August Winter, 23.6.1944, BArchF, RH 19-XI/9, S. 7.

185 Ebd. S. 5. Hervorhebung im Original.

186 Vgl. Feldkommandantur 1039 Hennig an DGA Gullmann, 28.5.1944 (Anlage 7 zu DGA Nr. 3046/44/geh.v.23.6.1944), BArchF, RH 19-XI/9, Bl. 20.

187 Fitzthum an DGA Gullmann, Abschrift „Betr.: Politische Aufgaben der Feldkommandanturen in Albanien“, 3.6.1944 (Anlage 2 zu DGA Nr.3046/44 g. vom 23.6.1944), BArchF, RH 19-XI/9, Bl. 14. 
kommandanturen der Wehrmacht auch in Zukunft keine politischen Aufgaben wahrnähmen. ${ }^{188}$

Dass sich auch Schmidhuber, ähnlich wie Fitzthum, in seiner Funktion als Divisionskommandeur der „Skanderbeg“ über übliche Dienstwege hinwegsetzte, führte $\mathrm{zu}$ weiteren Auseinandersetzungen: Im Kosovo hatte er bereits im Mai 1944 Personenerfassungen und das Ausstellen von Waffenscheinen angeordnet, ohne die zuständigen Stellen der Wehrmacht darüber informiert zu haben. ${ }^{189}$ Dies führte zu einer Beschwerde Hennigs beim DGA, da sich Schmidhuber unter Umgehung der Feldkommandanturen direkt an die Präfekten von Prizren, Prishtina/Priština und Pejë/Peć gewandt hatte. ${ }^{190}$ DGA Gullmann ließ Schmidhuber über Fitzthum ausrichten, dass solche Weisungen an Präfekten und andere albanische Regierungs- und Verwaltungsstellen in Zukunft zu unterbleiben hätten und eindeutig dem Aufgabenbereich der territorialen Dienststellen der deutschen Wehrmacht unterstehen würden. ${ }^{191}$

Obwohl diese Machtkämpfe im Laufe des Sommers 1944 an Intensität zunahmen, war Gullmann der Meinung, dass gegenüber den albanischen Regierungsund Verwaltungsstellen der Schein einer reibungslosen Zusammenarbeit deutscher Dienststellen gewahrt werden sollte. ${ }^{192}$ Diese hatten nämlich bereits in der Vergangenheit versucht, „Zwiespältigkeiten im deutschen Lager für ihre Zwecke auszunutzen“, da sie „mit feinem Spürsinn diesen Mangel einer einheitlichen Ausrichtung der deutschen Politik“ erkannt hatten. ${ }^{193}$ Als Sieger im Kampf um die Macht in militärischen Belangen ging im Herbst 1944 Fitzthum hervor, der schließlich in Personalunion auch die Funktion des DGA übernahm. Als erste Amtshand-

188 Ebd.

189 Schmidhuber an die Präfekten von Prizren, Priština und Peja, „Betr.: Personenerfassung und Waffenscheine im Kosovo-Gebiet“, 25.5.1944, (Abschrift, Anlage 10 zu DGA Nr. 3046/44/ geh.v.23.6.1944), BArchF, RH 19-XI/9, Bl. 26.

190 Vgl. Feldkommandantur 1039 Hennig an DGA Gullmann, 30.5 .1944 (Anlage 10 zu DGA Nr. 3046/44/geh.v.23.6.1944), BA-MA, RH 19-XI/9, Bl. 25. Vgl. hierzu auch Schmidhuber an die Präfekten von Prizren, Priština und Peja, „Betr.: Personenerfassung und Waffenscheine im Kosovo-Gebiet“, 25.5.1944, (Abschrift, Anlage 10 zu DGA Nr. 3046/44/geh.v.23.6.1944), BArchF, RH 19-XI/9, Bl. 26.

191 Vgl. Gullmann an Fitzthum, 9.6.1944, BArchF, RH 19-XI/9, S. 3.

192 DGA Gullmann, Abschrift „Gesichtspunkte für Dienstregelung“, 5.6 .1944 (Anlage $1 \mathrm{zu}$ DGA Nr. 3046/44 g. vom 23.6.1944), BArchF, RH 19-XI/9, Bl. 11.

193 OB Südost, Bericht „Entwicklung der militärischen Lage in Albanien im Herbst 1944“, undatiert, BArchF, RW 40/116a, Bl. 18. 
lung löste er die Feldkommandanturen der Wehrmacht auf und vereinigte sie in der „Dienststelle des Deutschen Feldkommandanten in Albanien“. ${ }^{194}$

\subsection{Ausgangslage und Absichten auf albanischer Seite}

Das letzte Kriegsjahr in Albanien war nicht nur auf deutscher Seite geprägt von Intrigen und Machtkämpfen. Auch die Exponenten der lokalen Eliten und nationalen Politik paktierten oder bekämpften sich - oder wechselten zwischen diesen beiden Verhaltensweisen. ${ }^{195}$ Der Autor des Wehrmachtsberichts zur „Entwicklung der militärischen Lage in Albanien“ wähnte sich daher in einem Land „der ewigen inneren Fehden“. ${ }^{196}$ Jede Fraktion hatte neben übergeordneten nationalen auch regionale, lokale und manchmal nur persönliche Interessen, die es zu befriedigen galt. Um diese umzusetzen, wählten die verschiedenen Gruppierungen verschiedene Vorgehen: Einige unterstützten die deutschen Besatzer, andere bekämpften sie. Ein weiteres Lager wechselte zwischen neutralem Abwarten, Zusammenarbeit mit den Deutschen und Verhandlungen mit den Alliierten. Für dieses opportunistische Verhalten zeigten die deutschen Vertreter wenig Verständnis, denn es erschwerte die Umsetzung ihrer Aufgaben vor Ort. ${ }^{197}$ Auch der Historiker Neuwirth schreibt, „dass eine parteipolitische Zuordnung“ hinsichtlich „Kollaboration und Widerstand sehr am tatsächlichen Verhalten der Albaner vorbeigehen würde“. ${ }^{198}$ Bezeichnend hierfür ist die Dachorganisation des nationalen Widerstands, der „Balli Kombëtar“, wo sich sowohl Kollaborationswillige als auch Gegner der Deutschen einfanden. Ein gutes Beispiel liefert auch Abaz Kupi, ein Anhänger Zogus, der während des Krieges mehrmals die Seiten wechselte. ${ }^{199}$ Nach dem Krieg wurde aber die Dachorganisation „Balli Kombë-

194 Vgl. OB Südost, Bericht „Entwicklung der militärischen Lage in Albanien im Herbst 1944“, undatiert, BArchF, RW 40/116a, Bl. 9.

195 Vgl. Neubacher, Sonderauftrag Südost, S. 107f., 117. Vgl. auch OB Südost, Bericht „Entwicklung der militärischen Lage in Albanien im Herbst 1944“, undatiert, BArchF, RW 40/116a, Bl. 13-15.

196 OB Südost, Bericht „Entwicklung der militärischen Lage in Albanien im Herbst 1944“, undatiert, BArchF, RW 40/116a, Bl. 11.

197 Vgl. Schmidhuber, „Zusammenfassender Bericht“, 2.10.1944, BArchF, RS 3-21/1, S. 3. Vgl. OB Südost, Bericht „Entwicklung der militärischen Lage in Albanien im Herbst 1944“, undatiert, BArchF, RW 40/116a, Bl. 13.

198 Neuwirth, Widerstand und Kollaboration, S. 39.

$199 \mathrm{Vgl}$. Zaugg, Resistance and Its Opponents in the Region of Sandžak and Kosovo, in: Les Cahiers Sirice, 1(2019), S. 96. Vgl. OB Südost, Bericht „Entwicklung der militärischen Lage in Albanien im Herbst 1944“, undatiert, BArchF, RW 40/116a, Bl. 15 f. 
tar“ ohne Differenzierung den Kollaborateuren zugerechnet - eine Annahme, die auch Marie-Janine Calic in ihrem Buch zur Geschichte Jugoslawiens des 20. Jahrhunderts unkritisch übernimmt. ${ }^{200}$ In diesem Kapitel, das sich verschiedenen Ausgangslagen und Absichten auf albanischer Seite widmet, ist es daher wichtig, ebenso zwischen den nord- und südalbanischen Eliten, wie auch zwischen Eliten und einfachen Bürgern zu unterscheiden.

\subsubsection{Die albanische Regierung im Schatten der „Zweiten Liga von Prizren“}

Die Gründung der „Zweiten Liga von Prizren“ ging auf eine Versammlung verschiedener Notabeln in Prizren vom 16. bis 20. September 1943 zurück. Sie war in erster Linie das Werk Devas und Pejanis, die den Aufbau der „Zweiten Liga“ mit Hilfe Franz von Scheigers vorbereitet hatten. Die Wahl des Namens steht in engem Zusammenhang mit der „Liga von Prizren“ 1878 bis 1881, als deren Nachfolger sich die Mitglieder der „Zweiten Liga“ sahen. Die „Erste Liga“ hatte das Bestreben, gegen den Vertrag von San Stefano und die Beschlüsse des Berliner Kongresses hinsichtlich der albanisch bewohnten Gebiete vorzugehen, letztlich mit der Intention, einen eigenen albanischen Nationalstaat $\mathrm{zu}$ gründen. ${ }^{201}$ Entsprechend ist auch in den Statuten der „Zweiten Liga“ nachzulesen, dass ihr primäres Ziel darin bestand, „Großalbanien“ bzw. die „befreiten Gebiete und weitere (albanisch bewohnte) Territorien des früheren Jugoslawiens“ zu verteidigen und sie gegen Übergriffe der angrenzenden Länder Serbien, Montenegro und Bulgarien zu schützen. ${ }^{202}$ Die anfänglich 45 Mitglieder setzten ein Exekutivkomitee ein, dessen Vorsitz Rexhep Mitrovica übernahm. ${ }^{203}$ In Spitzenzeiten soll die „Zweite Liga“ zwischen 12.000 und 15.000 Mitglieder gezählt haben. Sie war eine nationalistische und antikommunistische, aber keine per se pro-faschistische Organisation, wie der Albanologe Elsie betont. Hinter der Kollaborationsbereitschaft stand in erster Linie

200 Vgl. Calic, Geschichte Jugoslawiens, S. 180.

$201 \mathrm{Vgl}$. Elsie, Historical Dictionary of Kosovo, S. 175f.

202 Vgl. ebd., S. 251. Vgl. auch Kasmi, Deutsche Besatzung in Albanien, S. 15.

203 Rexhep Mitrovica ließ sich als „Kossow[sic]-Emigrant in Albanien nieder und galt bei den Deutschen als einer der Begründer der „Kossowo[sic]-Irrendenta“-Bewegung. Er war zunächst ein Befürworter Zogus, ab 1924 allerdings in der Opposition und von Ende 1924 bis zur italienischen Besetzung des Landes im Exil. Geldnöte hätten ihn „in das Fahrwasser der italienischen Politik getrieben“. Vermerk von Scheiger an AA, 2.4.1942, PAAA, Altes Amt, Tirana 4/6. 
die Absicht, durch eine Zusammenarbeit mit den Deutschen Kosovo und angrenzende albanisch bewohnte Gebiete als Teil „Großalbaniens“ zu erhalten. ${ }^{204}$

Da die „Zweite Liga von Prizren“ im Kosovo seit ihrer Gründung im September 1943 die Rolle einer staatlichen Institution bzw. einer Parallelregierung zur Regierung in Tirana übernahm, war sie in allen Belangen der Rekrutierungen für die Waffen-SS die erste Ansprechpartnerin und entscheidend für die Ausgestaltung der Division „Skanderbeg“ mitverantwortlich. Fitzthum, Schmidhuber und ihre Vertreter, etwa Fitzthums Erster Generalstabsoffizier, SS-Hauptsturmführer Christian Wirth, verhandelten daher in erster Linie mit dem jeweiligen Präsidenten der „Zweiten Liga“, der Reihenfolge nach Mitrovica, Pejani und Deva, bzw. einem „Nationalen Verteidigungskommando“, das aber ebenfalls von diesen Personen dominiert wurde, über Kontingente und Rekurtierungsarten, und erst in zweiter Linie mit der Regierung in Tirana. Bei Mitrovica und Deva handelte es sich dabei sogar um dieselben Verhandlungspartner, da beide sowohl Mitglieder der „Zweiten Liga“ als auch der albanischen Regierung waren. ${ }^{205}$

Als Rexhep Mitrovica im Januar 1944 zum Ministerpräsidenten Albaniens gewählt wurde, ersetzte ihn Pejani als Präsident der „Zweiten Liga“. ${ }^{206}$ Da zur gleichen Zeit auch Deva als Innenminister Teil der Regierung wurde, avancierte das Trio Pejani, Deva und Mitrovica zu den wichtigsten Protagonisten in der Aufbauphase der Division „Skanderbeg“. Sie alle waren Mitglieder der „Zweiten Liga“ und zwei von ihnen konnten die Anliegen der Waffen-SS bezüglich der Rekrutierung von Albanern direkt in die albanische Regierung einbringen. Es fällt auf, dass alle drei im bei Serbien verbliebenen Teil beheimatet und zu diesem Zeitpunkt genau genommen keine albanischen Staatsbürger waren. ${ }^{207}$ Alle drei hatten sich zudem kurz nach dem Sieg der Deutschen im Balkanfeldzug 1941

204 Vgl. Elsie, Historical Dictionary of Kosovo, S. 251-252. Vgl. zu den wachsenden Mitgliederzahlen der „Zweiten Liga“ auch Malcolm, Kosovo, S. $305 \mathrm{f}$.

205 Vgl. bspw. „Werbung für die Waffen-Gebirgsdivision SS ,Skanderbeg““, Fitzthum an das Nationale Verteidigungskommando, z. Hd. Generalstabschef General Gustav von Myrdazc, 15.4.1944, A.Q.SH., F.160, 1944, D 32, Bl. 5.

206 Vgl. Elsie, Historical Dictionary of Kosovo, S. 252.

207 Rexhep Mitrovica und Xhafer Deva stammten aus Mitrovica, Bedri Pejani aus Vushtrii. Noch heute tragen Straßen in den beiden Städten in Erinnerung an ihre Verdienste um „Großalbanien“ ihre Namen. Bezeichnend für alle drei Exponenten ist, dass es sich um Angehörige lokaler Eliten handelte, die im Ausland studiert oder gearbeitet oder gezwungenermaßen eine Zeit im Exil verbracht hatten: Xhafer Deva hatte in Istanbul und Wien studiert; Rexhep Mitrovica war ursprünglich Lehrer, weilte während der Herrschaft Zogus im Exil und kehrte, nachdem die Italiener Albanien annektiert hatten, zurück. Bedri Pejani war Herausgeber der Zeitung „Populli“ in Skhoder, musste ebenfalls unter Zogu ins Exil und war Mitglied der Exilorganisation Komiteti Nacional Revolucionar (Konare). 
im „Komitee für die Verteidigung des Kosovo“ eingefunden und bereits bei früheren Rekrutierungen für die Waffen-SS in Nordkosovo und der Sandžak-Region eine wesentliche Rolle gespielt. ${ }^{208}$

Pejani, seit Januar 1944 Präsident der „Zweiten Liga“, hatte den Ruf, erbarmungslos gegen alle Nicht-Albaner und „untreuen Elemente“ vorzugehen. Mit Massakern und Plünderungen verfolgte die von ihm präsiderte Organisation das Ziel, proitalienisch eingestellte Bürger, vor allem aber serbische Siedler, die nach 1918 eingewandert waren, zu vertreiben. ${ }^{209}$ Auf der anderen Seite war er es, der die Art der Rekrutierungen und Rekrutierungskontingente der WaffenSS im Frühjahr 1944 wesentlich beeinflusste, wie noch zu zeigen sein wird. ${ }^{210}$ Alleine in diesem halben Jahr seiner Amtszeit sollen nach Elsie rund 40.000 Serben und Montenegriner aus dem Kosovo vertrieben worden sein. ${ }^{211}$ Neubacher gelang es schließlich im Sommer 1944, den von ihm als „wahnsinnig“ bezeichneten Pejani abzusetzen.

Nach Pejani übernahm Deva den Vorsitz. Er versprach Neubacher, die Serbenvertreibungen einzustellen, was allerdings nicht passierte. ${ }^{212}$ Deva bildete das wichtigste Element bei der Aufstellung der „Skanderbeg“. Als Innenminister und neuer Vorsitzender der „Zweiten Liga“ wurde er zum Dreh- und Angelpunkt für die Rekrutierungsmaßnahmen der Waffen-SS im Kosovo. Oder wie im Bericht zur „Entwicklung der militärischen Lage in Albanien“ nachzulesen ist: „Deva als Innenminister verfügte [...] über die notwendige Tatkraft und Energie, um beim richtigen Ansetzen ein wirklich wertvolles Instrument der deutschen Politik zu werden“. ${ }^{213}$ Schon am 19. April 1944 bemerkten daher die Italiener: „Diese Schöpfung [die Division ,Skanderbeg`] ist das Werk des Innenministers

208 Vgl. Volkstumsreferent Dr. Feninger beim Bevollmächtigten des AA in Belgrad, Bericht „über die Reise in das Arnautengebiet von Kosovska Mitrovica und Novi Pazar“, 15.-26.10.1941, PAAA, R261153, Bl. 48. Vgl. Zaugg, Albanische Muslime, S. 143. Vgl. zu Deva und Pejani auch Malcolm, Kosovo, S. 297, 305, 309.

209 Vgl. Bericht an das italienische Außenministerium, ohne Namensangabe, 19.4.1944, ASD, RSI, Aff. Pol., Busta 51, fasc. Alb. 1/1, S. 2. Vgl. Volkstumsreferent Dr. Feninger beim Bevollmächtigten des AA in Belgrad, Bericht ,über die Reise in das Arnautengebiet von Kosovska Mitrovica und Novi Pazar“, 15.-26.10.1941, PAAA, R261153, Bl. 40.

210 Vgl. Schreiben der „II. albanischen Liga von Prizren“ an Hitler, 29.3.1944, BArchB, NS 19/ 2071, Bl. 7.

211 Vgl. Elsie, Historical Dictionary of Kosovo, S. 252.

212 Vgl. Neubacher, Sonderauftrag Südost, S. 116.

213 Vgl. OB Südost, Bericht „Entwicklung der militärischen Lage in Albanien im Herbst 1944“, undatiert, BArchF, RW 40/116a, Bl. 14. 
Deva, Vertrauensmann der Deutschen.“214 Nicht zuletzt pflegte er mit HSSPF Fitzthum auch privat ein freundschaftliches Verhältnis. ${ }^{215}$

Als Deva in traditioneller Weise seinem Ruf als Innenminister nach Tirana folgend eine kleine Privatarmee aus Kosovaren mit in die Hauptstadt nahm, demonstrierte er damit auch öffentlich, dass er die staatlichen albanischen Insitutionen nicht anerkannte. Die Größe dieser Privatarmee betrug nach Neubacher rund 1.000 Mann aus Peja/Peć, Prishtina/Priština und Prizren. ${ }^{216}$ Im Wehrmachtsbericht zur „Entwicklung der militärischen Lage in Albanien“ ist nachzulesen, dass „diese halbwilden Bergbewohner [...] in der Hauptstadt ein für europäische Begriffe ziemlich unmögliches Willkürregiment aus[übten]““. ${ }^{217}$ Bezeichnenderweise ging aber der Autor des Berichts davon aus, dass sich diese Privatarmee der albanischen Regierung ,in landesüblicher Form“ durch Terror die fehlende Autorität verschaffte. ${ }^{218}$ Auch Neubacher bestätigt, dass die Parole der Privatarmee Devas „Terror gegen Terror“ gelautet habe. ${ }^{219}$ Rudolf Vogel, während des Krieges als Soldat in Tirana eingesetzt, beschreibt in seinen Memoiren, wie diese „Horde wilder bewaffneter Kosovaren“ in der Hauptstadt auf regelrechte Plünderungsstreifzüge ging. ${ }^{220}$ Jenes „teilweise wirklich wüste Treiben“ sorgte sogar bei deutschen Dienststellen für Empörung. ${ }^{221}$ Auch als die Regierung Mitrovica in Tirana mit Deva als Innenminister ihre Unterstützung für die „Skanderbeg“ an die Bedingung knüpfte, dass alle aus dem Kosovo und Metohija stammenden männlichen Serben zwischen 17 und 45 Jahren nach Deutschland deportiert würden, befremdete dies die deutschen Dienststellen. Werner Junker, Vortragender Legationsrat bei der Dienststelle des Sonderbevollmächtigten des Auswärtigen Amtes für den Südosten in Belgrad, berichtete, dass drei Serben, die sich der Deportation ver-

214 „È stata creata una milizia composta di Kossovari. Detta creazione è opera del Ministro dell'Interno Deva, uomo di fiducia della Germania“ Bericht an das italienische Außenministerium, ohne Namensangabe, 19.4.1944, ASD, Albania, Busta 51, fasc. Alb. 1/1, S. 2.

215 Vgl. Schreiben Neubacher an Schliep bez. Fitzthums Rekrutierungsanstrengungen in „Neualbanien“ und seiner „guten Kameradschaft“ mit Deva, 6.3.1944, PAAA, R27305, Telegramm 78.

216 Vgl. Neubacher, Sonderauftrag Südost, S. 119.

217 OB Südost, Bericht „Entwicklung der militärischen Lage in Albanien im Herbst 1944“, undatiert, BArchF, RW 40/116a, Bl. 14.

218 Ebd.

219 Vgl. Neubacher, Sonderauftrag Südost, S. 119.

220 Vgl. Vogel, Erinnerungen, Bd. 1, Unter Skipetaren - Albanische Erinnerungen 1943/44, unveröffentlicht 1989, S. $181 \mathrm{f}$.

221 OB Südost, Bericht „Entwicklung der militärischen Lage in Albanien im Herbst 1944“, undatiert, BArchF, RW 40/116a, Bl. 14. Durchgestrichen im Original. 
weigert hätten, in der Nähe von Prishtina/Priština „geschlachtet und enthäutet worden" wären. 222

Welchen Stellenwert Innenminister Deva für das Gelingen des Projekts „Skanderbeg“ hatte, zeigte sich im Sommer 1944, als er kurzerhand aus der neuen, von „Altalbanern“ dominierten Regierung ausgeschlossen wurde. ${ }^{223}$ Fitzthum sah dadurch die zugesicherte offizielle Aushebung bestimmter Jahrgänge für den Dienst in der Waffen-SS gefährdet:

Wenn Deva nicht Innenminister bleibt, wird [die] Division Skanderbeck [sic] nicht Wirklichkeit, da nur die Gestellung erforderlicher Jahrgänge zum Ziel führt. Dazu aber ist nur Deva bereit. Er kann dies als Innenminister, nicht aber als Privatmann, es sei denn, dass wir [den] Bruch des Kosovo mit Altalbanien hinnehmen. Anfänge [sind] bereits vorhanden. ${ }^{224}$

Auch Himmler erkannte, „dass [die] heutige Regierung uns keine Freiwilligen und keine Truppen bringen“ würde, und kontaktierte am 27. Juli 1944 aufgrund der sich rasch verschlechternden Situation in Südosteuropa mit dem Vermerk „dringend“ Kaltenbrunner. ${ }^{225}$ Die „Altalbaner“ wären erst dann bereit, für die „Skanderbeg“ Soldaten zu stellen, wenn der deutsche „Sieg klar erkennbar“ würde, war sich Fitzthum sicher. Daher kam er zum Schluss, dass die „Skanderbeg“ nur im Kosovo unter der Schirmherrschaft der „Zweiten Liga“ und mit Hilfe Devas aufgestellt werden konnte. ${ }^{226}$ Obwohl Neubacher Deva persönlich nicht sympathisch fand, war auch er der Meinung: „Auf Djaver Deva können wir nicht verzichten. Bitte die Forderung zu vertreten, dass Djaver Deva Innenministerium behält.“ 227

Der Einfluss der Regierung war aus deutscher Sicht durch die Struktur der Stammesherrschaft im Norden von Anfang an stark eingeschränkt. Die Macht und weitreichende Einflussnahme der Bajraktare, der Clanchefs, hatten die Deutschen unterschätzt. ${ }^{228}$ Über die Regierung in Tirana hieß es nur: „Die wechselnden Regierungen im Laufe der deutschen Besatzung einzeln aufzuzählen, hieße ihnen eine Bedeutung beimessen, die sie in Wirklichkeit niemals für das Land und für Deutschland besessen haben.“‘229

222 Schreiben Junkers an Neubacher vom 17.6.1944, PAAA, R27305, Telegramm Nr. 176.

223 Vgl. Fernschreiben Fitzthum an Himmler, undatiert, BArchB NS 19/1488, Bl. 1 f.

224 Fernschreiben Fitzthum an Himmler, undatiert, BArchB, NS 19/1488, Bl. 1.

225 Fernschreiben Himmler an Kaltenbrunner, 27.7.1944, BArchB, NS 19/1488, Bl. 2.

226 Vgl. Fernschreiben Fitzthum an Himmler, undatiert, BArchB NS 19/1488, Bl. 1 f.

227 Neubacher and die deutschen Gesandtschaften in Tirana und Belgrad, 25. Juli 1944, PAAA, R27305.

228 Vgl. OB Südost, Bericht „Entwicklung der militärischen Lage in Albanien im Herbst 1944“, undatiert, BArchF, RW 40/116a, Bl. 26.

229 Vgl. ebd., Bl. 13. 
Fitzthum hatte richtig erkannt, dass sich der Antagonismus zwischen Nordund Südalbanien im Sommer 1944 verstärkte: Mehdi Bey Frashëri herrschte im Süden, Deva im Norden, wie Neubacher die Situation rückblickend beschrieb. ${ }^{230}$ Fitzthum konnte zwar via Kaltenbrunner und Neubacher über Himmler erreichen, dass Deva kurzfristig noch einmal auf seinen Posten als Innenminister zurückkehrte. ${ }^{231}$ Als Deva aber diesen Posten endgültig verlor, bedeutete dies nicht etwa das Ende seiner Karriere. Vielmehr widmete er sich nun ganz der „Zweiten Liga" und konzentrierte sich darauf, seine Stellung im Kosovo zu festigen. ${ }^{232} \mathrm{Er}$ solle sogar daran gearbeitet haben, im Kosovo eine eigene nordalbanische Regierung aufzubauen. ${ }^{233}$ Hinsichtlich der Division „Skanderbeg“ begann er, über das „Komitee zur Verteidigung des Kosovo“ Mitte August 1944 sogar auf ganz alltägliche organisatorische Belange wie etwa die Truppenverpflegung Einfluss zu nehmen. ${ }^{234}$ Er war es auch, der ein letztes - von den Deutschen unterstütztes Aufgebot in der Region Kosovo aushob und befehligte, worunter sich auch Entlassene aus der Division „Skanderbeg“ befanden. ${ }^{235}$

\subsubsection{Sympathien für „Großdeutschland“ und das Projekt „Großalbanien“}

Ähnlich wie in Bosnien war auch in Albanien die Sympathie für Deutschland eng an Erinnerungen an die Österreicher gekoppelt. Der Kriegsberichter Willibald Kollegger beschrieb diese Sympathie bereits 1942 anhand einer Begegnung in Boga, im gebirgigen Nordalbanien:

Hier oben treffen wir den Bruder eines albanischen Ministers, der hocherfreut ist, einen Deutschen zu treffen. Als er erfährt, dass sein Deutscher dem ehemaligen Österreich entstammt, kennt seine Begeisterung keine Grenzen mehr. ,Ja, die Österreicher, die haben wir in guter Erinnerung', sagt er in gebrochenem Deutsch, das er noch aus der Weltkriegszeit her beherrscht, als die k.u.k. Armeen die Hälfte Albaniens besetzt hielten. Die Sympathie für eine ehemalige Okkupationsmacht ist so außergewöhnlich, dass sie erläutert

230 Neubacher, Sonderauftrag Südost, S. 117.

231 Vgl. Schreiben Neubacher an Tirana und Belgrad, 25.7.1944, PAAA R27305. Vgl. Fernschreiben Kaltenbrunner an Himmler, „Geheime Kommandosache“, 28.7.1944, BArchB, NS 19/1488, Bl. 3.

232 Vgl. Schmidhuber, „Zusammenfassender Bericht“, 2.10.1944, BArchF, RS 3-21/1, S. 3. Neubacher, Sonderauftrag Südost, S. 117.

233 Vgl. OB Südost, „Lagebild Südost vom 9.10.1944“, 10.10.1944, BArchF, RH 19/XI-22, Bl. 224.

234 Vgl. Meldekopf Rožaje, Hoffmann an Hauptmann Bendl, 14.8.1944, VA HEM.OK.BOJCKA, 9/6/29.

235 Vgl. Zaugg, Albanische Muslime, S. 284. 
werden muss, und zwar anhand albanischer Erklärungen, die dem Verfasser auch an anderen Orten gegeben wurden. Die Österreicher haben sich in Albanien deshalb so beliebt gemacht, weil die Albaner sofort den Eindruck hatten, dass man ihnen von dieser Seite her nur Gutes wolle. Man baute ihnen Häuser, Strassen und Brücken und schulte die albanischen Behörden so lange, bis sie fähig waren, ihr eigenes Land im aufbauenden Sinne zu regieren. Die sogenannten Berater waren keine Schnüffler, sondern Helfer. ${ }^{236}$

Auch der Autor des Berichts zur „Entwicklung der militärischen Lage in Albanien“ betont, dass ,die deutsche Politik zwei feste Aktivposten vor[fand], die brauchbare Anknüpfungspunkte für eine Beeinflussung der Entwicklung boten““.237 Zum einen war dies die „erstaulich weit verbreitete Sympathie“ für Deutschland, die auch laut ihm vor allem der früheren österreichisch-ungarischen Albanienpolitik geschuldet war. ${ }^{238}$ Zum anderen war es das Projekt „Großalbanien“, welches die nordalbanischen Eliten um jeden Preis über das Kriegsende hinwegretten wollte. ${ }^{239}$

Ein dritter, wesentlich erscheinender Punkt, der die albanischen Eliten zur Zusammenarbeit mit den Deutschen bewegte, war deren Versprechen, den Status Quo der albanischen Eliten, Begs im Süden und Bajraktare im Norden, nicht anzutasten. ${ }^{240}$ Dies stellte einen Gegensatz zu den Absichten anderer in- und ausländischer Akteure dar, so etwa derjenigen der albanischen und jugoslawischen Kommunisten, die eine radikale Umwälzung bestehender Verhältnisse forderten und eine „kleinalbanische“ Lösung anstrebten, oder die Briten, welche ihre Unterstützung ebenfalls an bestimmte Bedingungen knüpften. ${ }^{241}$

Die Kommunikation mit den potentiellen Kollaborateuren gestaltete sich auf zwei Ebenen einfach: Einerseits sprachen viele von ihnen Deutsch oder eine andere Fremdsprache fließend, da sie zumeist im Ausland studiert hatten, andererseits sahen die lokalen Eliten klare Vorteile in der deutschen Albanienpolitik, die Albanien vordergründig als „neutralen Staat“ respektierte. ${ }^{242}$ Somit ging die albanische Elite im Herbst 1943 davon aus, dass sie ,in der deutschen Wehrmacht einen unangreifbaren Schützer ihrer mittelalterlichen wirtschaftlichen

236 Kollegger, Albaniens Wiedergeburt, S. 38.

237 OB Südost, Bericht „Entwicklung der militärischen Lage in Albanien im Herbst 1944“, undatiert, BArchF, RW 40/116a, Bl. 12.

238 Vgl. ebd, Bl. 17.

239 Vgl. ebd.

240 Vgl. Neuwirth, Widerstand und Kollaboration, S. $124 \mathrm{f}$.

241 Vgl. detailliert Zaugg, Resistance and Its Opponents in the Region of Sandžak and Kosovo, in: Les Cahiers Sirice, 1(2019), S. 85-99. Vgl. Kühmel, Deutschland und Albanien, S. 52f. Vgl. auch Schmidhuber, „Zusammenfassender Bericht“, 2.10.1944, BArchF, RS 3-21/1, S. 7.

242 Vgl. OB Südost, Bericht „Entwicklung der militärischen Lage in Albanien im Herbst 1944“, undatiert, BArchF, RW40/116a, Bl. 6. 
Vorherrschaft gefunden“ hätte. ${ }^{243}$ Schmidhuber bestätigt in seinem Schlussbericht die soziale Situation, nämlich, dass in Albanien noch 85-90 Prozent der Landbevölkerung unter der „mittelalterlichen Feudealherrschaft dieser Begs [Beys] und Agas“ stand. 244

Da die deutschen Besatzer versprachen, diese bestehenden Herrschaftsverhältnisse nicht zu verändern, waren viele Vertreter insbesondere der nord- und „neualbanischen“ Eliten bereit, ihrerseits die deutschen Interessen zu unterstützen. Doch auch aus der Angst, „Großalbanien“ zu verlieren, ließ sich Kapital schlagen und die Unterstützung der albanischen Kreise sichern, denn

die außenpolitische Lage Albaniens im Balkan [ließ] Deutschland allen einsichtigen politischen Kreisen als den einzig möglichen uneigennützigen Verbündeten und Beschützer erscheinen. Infolge der deutschen Eroberung des Balkans war die Schaffung Groß-Albaniens [sic] durch den Hinzutritt des fruchtbaren Kosovo-Gebietes ermöglicht worden. Erst durch diese Heimkehr Kosovos erhielt der Staat eine halbwegs tragbare wirtschaftliche Grundlage, welche es ermöglichte, ein eigenstaatliches Leben ohne dauernde Abhängigkeit vom Auslande zu fristen. Jedem halbwegs klar Denkenden musste es unzweifelhaft sein, dass diese Ordnung nur dann von Dauer sein konnte, wenn Deutschland die ausschlaggebende Macht auf dem Balkan blieb. ${ }^{245}$

Ende April 1941, nach Beendigung des Balkanfeldzugs, war unter italienischer Herrschaft ein „großalbanischer“ Staat entstanden, der die Bevölkerung Albaniens mit einem Schlag beinahe verdoppelte. $\mathrm{Zu}$ „Großalbanien“ gehörten nun auch Kosovo und Metohia, die Region um Plav und Gusinje im heutigen Montenegro sowie die westmazedonischen Gebiete um Debar, Tetovo, Gostivar und Kičevo. ${ }^{246}$ Als die Italiener und Deutschen im April in diese von Albanern bewohnten Gebiete einmarschierten, wurden sie, ähnlich im Falle der „volksdeutschen“ Bevölkerung im Banat, als Befreier gefeiert und mit Umzügen und Fahnen begrüßt. ${ }^{247}$ Der italienische Außenminister Galeazzo Ciano war damals überzeugt, dass durch das Projekt „Großalbanien“ die Aufmerksamkeit der anderen Balkanstaaten weg von den Aktivitäten der Achsenmächte auf dieses innerbalkanische Problem, Kosovogebiet und angrenzende Gebiete, gelenkt werden konnte. ${ }^{248}$ Seit April 1941 bildete „Großalbanien“ daher das stärkste Argument

243 Ebd., Bl. 12.

244 Schmidhuber, „Zusammenfassender Bericht“, 2.10.1944, BArchF, RS 3-21/1, S. 1.

245 OB Südost, Bericht „Entwicklung der militärischen Lage in Albanien im Herbst 1944“, undatiert, BArchF, RW 40/116a, Bl. 17.

246 Pavle Dželetović Ivanov, 21. SS Divizija Skenderbeg, Belgrad: Nova knjiga 1987, S. 39.

247 Vgl. ebd., S. 42, 52, 78.

248 Vgl. Ciano, Tagebücher, 21.4.1939, S. 78. Vgl. zu dieser Strategie und ihrem Scheitern auch Sundhaussen, Improvisierte Ausbeutung, S.59f. 
für eine Zusammenarbeit von Nordalbanern, Kosovaren und den albanischen Bewohnern des Sandžaks mit den Achsenmächten und letztlich auch für die Rekrutierungen in die Waffen-SS. ${ }^{249}$

Die Wahrscheinlichkeit schien nämlich groß, dass nach einem Ende der italienischen - bzw. nach September 1943 der deutschen - Herrschaft Kosovo wieder unter serbische Regierungsgewalt kommen würde. Dieser Konfliktpunkt um ein „Großalbanien“ mit, oder ein kleineres Albanien ohne Kosovo verhinderte im Spätsommer/Frühherbst 1943 auch ein Zusammengehen des inneralbanischen Widerstands und stärkte damit vorerst die Position der Deutschen. ${ }^{250}$ Die militärische Unterstützung durch die Albaner erfolgte auf zwei Ebenen: Einerseits sollten Familienvorstände und Clanchefs mit sogenannten „nationalen Banden“ Hilfstruppen für die Deutschen stellen, andererseits auch die Rekrutierungen für die Waffen-SS unterstützen. $^{251}$

In der angrenzenden Nordkosovo- und der Sandžak-Region, die seit April 1941 wie das übrige Serbien unter deutscher Militärherrschaft standen, lassen sich auch Parallelen zur Situation in Bosnien finden: Schon am 30. Mai 1941 meldete Kasche aus Agram, dass ihm von Dr. Asim Muftić ein von mehreren Muslimen unterzeichnetes Memorandum überbracht worden war, mit der Bitte, nicht nur Bosnien und Herzegowina, sondern auch den Sandžak als deutsches Protektorat anzuerkennen. ${ }^{252}$ Gerade in diesem Gebiet führte die Aussicht auf politische Selbstbestimmung in den Folgejahren zu einem Anstieg der Rekrutierungsquoten: Lange vor den einsetzenden Rekrutierungen für die „Handschar“ und die „Skanderbeg“ schrieb Günther Hausding in einem Lagebericht über Nordkosovo und den Sandžak:

Im Gegensatz zur ablehnenden Haltung der serbischen Volksgruppe steht das muselmanisch-albanische Element in diesem Bezirk. So wurde beispielsweise in den Moscheen für den Sieg der deutschen Sache gebetet. Um objektiv zu bleiben, muss jedoch klar erkannt werden, dass die Albaner mit ihrer immer wieder besonders betonten Deutschfreundlichkeit sich um Auflagen in wirtschaftlicher Hinsicht herumdrücken. ${ }^{253}$

Mitrovica und die umliegenden Gebiete erhielten aufgrund der sehr angespannten ethnischen Situation sogar einen politischen und administrativen Autonomiestatus. Die politischen Vertreter konnten auf diese Weise gewisse Entscheidungen

249 Vgl. Dželetović, 21. SS Divizija Skenderbeg, S. 53.

250 Vgl. Zaugg, Albanische Muslime, S. $72 \mathrm{f}$.

251 Siehe zu den „nationalen Banden“ detailliert ebd., S. 229-234.

252 Kasche an AA, „Muselmanen in Bosnien“, 30.5.1941, PAAA, R103345, Bl. 182.

253 Lagebericht des Außenkommandos Kosovska-Mitrovica für August 1942, Hausding, 27.8.1942, USHMM/BArchL, B162/15.668, Bl. 41. 
unabhängig von Belgrad treffen. ${ }^{254}$ Zudem hatten Albaner in diesem Gebiet bereits 1942 eine eigene Gendarmerie mit eigenen Uniformen gefordert. Diese wurde aber nicht nur abgelehnt, vielmehr sollten von der serbischen Regierung 500 serbische Beamte in diesen Teil des Kosovo-Gebiets und die Sandžak-Region geschickt werden. Für Hausding war bereits klar, dass eine solche Maßnahme zu einer „Verschärfung der Gegensätze zwischen Serben und Arnauten führen“ würde. ${ }^{255}$ Außerdem warnte er schon 1942 davor, dass auch die Stimmung innerhalb der albanischen Bevölkerung jederzeit umschlagen und sich nicht nur gegen Serben, sondern auch gegen die deutschen Besatzer richten könnte und sich durch Mundzu-Mund-Propaganda sehr rasch verbreiten würde. ${ }^{256}$

\subsubsection{Eine Nationalarmee für den albanischen Staat}

Divisionskommandeur Schmidhuber berichtete im Oktober 1944, Albanien habe vor der Aufstellung der Division „Skanderbeg“ „noch über keine reguläre Truppe im deutschen Sinne“ verfügt. Vielmehr habe es sich bei den bisherigen Verbänden, auch denjenigen, die unter den Italienern aufgestellt worden waren, nur „nach ihrer äußeren Uniformierung“ um „militärähnliche Gebilde“ gehandelt. ${ }^{257}$ Entsprechend groß schien der Wunsch der Regierung und der „Zweiten Liga von Prizren“ gewesen zu sein, endlich über eine eigene Armee zu verfügen. Aus diesem Grund sah die Regierung „die Aufstellung einer solchen [Waffen-SS-]Division nicht ungern, weil sie von ihr die Schaffung eines gut ausgebildeten Grundstocks für eine nationale Wehrmacht und Gendarmerie erhoffte.“258

Obowohl Neubacher wie erwähnt noch im September 1943 über Kaltenbrunner erreichte, dass die Werbungen für die Waffen-SS auf dem Gebiet „Neualbaniens“ und angrenzender Gebiete wie dem Sandžak eingestellt wurden, stimmte

254 Vgl. Bericht an das italienische Außenministerium, ohne Namensangabe, 19.4.1944, ASD, RSI, Aff. Pol., Busta 51, fasc. Alb. 1/1, S. 1.

255 Vgl. Lagebericht des Außenkommandos Kosovska-Mitrovica für August 1942, Hausding, 27.8.1942, USHMM/BArchL, B162/15.668, Bl. 41.

256 Vgl. ebd. Bis heute halten sich „großalbanische“ Träumereien, unlängst sogar vom aktuellen Präsidenten Hashim Thaçi geäußert, obwohl längst klar ist, dass sich Kosovo, Albanien und die albanischen Teile Mazedoniens durch jahrzehntelange Trennung, ihre geographische Lage und ihre spezifische politische Situation unterschiedlich entwickelt haben. Vgl. https:// www.welt.de/politik/ausland/article165855190/Der-riskante-Traum-von-Grossalbanien.html (Stand: 4.4.2018). Vgl. Andreas Ernst, Kosovos Präsident Thaci provoziert mit seinen Plänen für Grossalbanien die EU, in: NZZ, 4.6.2019 (Stand: 7.7.2019).

257 Schmidhuber, „Zusammenfassender Bericht“, 2.10.1944, BArchF, RS 3-21/1, S. 1.

258 Neubacher, Sonderauftrag Südost, S. 116. 
er bereits einen Monat später Rekrutierungen in diesem Gebiet unter bestimmten Bedinungen $\mathrm{zu}$ - aus Angst, die Briten könnten den Deutschen zuvorkommen. ${ }^{259}$ Die zwei wichtigsten Bedingungen waren, dass die geworbenen Albaner nicht außerhalb Albaniens eingesetzt und „die mit Albanern aufgestellten Verbände [...] wenigstens formell dem albanischen Innenministerium unterstellt“ werden sollten. ${ }^{260}$ Damit wollte Neubacher der albanischen Regierung entgegenkommen, um den erwähnten Grundstock für eine eigene Armee auszuheben.

Wie den Schreiben Fitzthums und Altenburgs zu entnehmen ist, waren $\mathrm{zu}$ diesem Zweck ursprünglich sogar zwei Divisionen geplant. ${ }^{261}$ Diese sollten sowohl Nordalbanien und Kosovo („Neualbanien“), als auch Mittel- und Südalbanien („Altalbanien“) abdecken. Auch Graf gab später in Kriegsgefangenschaft zu Protokoll, dass das eigentliche Ziel dieser beiden Divisionen die Grundsteinlegung einer albanischen Nationalarmee gewesen wäre. ${ }^{262}$ Ende März 1944 forderte Pejani Hitler auf, die Aufstellung einer solchen Armee in die Wege zu leiten, dann würde das „Zentralkomitee“ für ihren Aufbau 120.000 bis 150.000 Soldaten aus den „neualbanischen“ Gebieten bereitstellen. Er forderte weiter, dass die zukünftige albanische Armee vorerst durch deutsche Offiziere und Unteroffiziere ausgebildet und kommandiert werden, und die Bewaffnung und sonstige Ausrüstung aus deutschen Beständen erfolgen sollte. ${ }^{263}$

Noch ein weiteres Indiz weist darauf hin, dass auf eine nationale Armee hingearbeitet wurde: Am 23. Mai 1944 meldete Pejani dem Ministerpräsident Mitrovica, dass für die Division „Skanderbeg“ keine Freiwilligenwerbung wie noch ein Jahr zuvor in Mitrovica stattfinden sollte, sondern die Rekrutierungen mittels einer regulären Mobilisierung durchgeführt durchzuführen seien:

Eine Rekrutierung auf freiwilliger Basis könnte aus mehreren Gründen scheitern, während eine Rekrutierung auf Grund unserer militärischen und nationalen Gesetze den absoluten Vorteil hätte, uns eine der besten Divisionen weltweit durch einen ganz zweckmäßigen Aufwand ohne jegliche Komplikationen zu bescheren. ${ }^{264}$

259 Vgl. von Thadden über Treffen mit Neubacher vom 11.10.1943, PAAA, Inland IIg, R100984, H298703.

260 Vgl. ebd.

261 Vgl. Fitzthum an Himmler, undatiert, BArchB, NS 19/1488, Bl. 1. Vgl. Altenburg an AA, z. Hd. Botschafter Ritter, 12.5.1944, PAAA, R27772.

262 Vgl. SS-Obersturmbannführer Alfred Graf, Kriegsgefangenenbericht, 9.11.1948, VA, HEM. OK.BOJCKA, 72/2-1/32.

263 Vgl. Schreiben der „II. albanischen Liga von Prizren“ an Hitler, 29.3.1944, BArchB, NS 19/ 2071, Bl. 7 f. Vgl. hierzu auch Schreiben an Militärbefehlshaber Südost mit der Bitte um Stellungnahme, i. A. gez. Poleck OKW/WFSt./Qu.2 (Süd/Südost), 3.5.1944, BArchF, RH 19-XI/10b, B1. 99. Vgl. auch Schreiben Pejanis an Mitrovica, 14.2.1944, A.Q.SH. F.149, 1944, D I-1317, Bl. 1. 264 Pejani an Ministerpräsident Mitrovica, 23.5.1944, A.Q.SH. F.147, 1944, D I-165, Bl. 16. 


\subsubsection{Schutz vor Übergriffen und Entlassung aus der Kriegsgefangenschaft}

Bei zahlreichen Bewerbern für die Waffen-SS stellten, wie bereits für die beiden anderen Division gezeigt wurde, die zahlreichen und oft tödlichen Übergriffe durch ethnisch-religiöse bzw. politische Gegner, wie etwa Četniks oder kommunistische Partisaneneinheiten, einen der wichtigsten Gründe für einen Beitritt dar. SSBrigadeführer und Generalmajor der Waffen-SS Ernst Fick beschrieb im März 1944 diese Situation in einem Brief an Himmler: „Die Mohamedaner, die im Allgemeinen von Cetniks [sic] und Ustaschas bekämpft wurden, gehen z. T. zwangsläufig zu den Freiw[illigen] Verbänden der SS oder den Partisanen, um nicht weiterhin von Ustaschas, Cetniks [sic] und Partisanen gemordet zu werden.“265

Diese interenthnische Gewalt nahm bereits kurz nach dem Balkanfeldzug an Intensität zu, wie etwa dem ausführlichen Bericht Feningers durch „das Arnautengebiet von Kosovska Mitrovica und Novi Pazar“ von Herbst 1941 zu entnehmen ist. ${ }^{266} 1942$ beschrieb auch Hausding vom Außenkommando Kosovska Mitrovica den von Gewalt geprägten Alltag anhand einiger Vorfälle, die sich in der zweiten Augusthälfte zugetragen hatten: Nachdem ein Albaner am 19. August von einem Serben erschossen worden war, schlossen die Albaner in ganz Vushtrri/Vučitrn „spontan und demonstrativ“ für einen Tag ihre Läden und legten ihre Arbeit nieder. Die Erregung sei sehr groß gewesen, obwohl in diesem Fall nach den Informationen, die Hausding besaß, die Schuld beim getöteten Albaner gelegen habe. ${ }^{267}$ Ob dieser Mord in Zusammenhang mit den kurz zuvor von Albanern an der serbischen Grenzwache begangenen brutalen Übergriffen stand, wobei „ein serbischer Feldwebel in viehischster Weise ermordet und verstümmelt" worden war, kann nicht mit Sicherheit festgestellt werden. ${ }^{268}$

Um solche Ängste vor Übergriffen für die bevorstehenden Rekrutierungen zu nutzen, wurden gezielt entsprechende Augenzeugenberichte in Umlauf gebracht, so etwa die Erlebnisse eines „Sandschak-Muselmanen“, der „die Abschlachtung der Muselmanen im Sandžak und Ostbosnien“ in detailreicher Sprache schilderte. Die Argumentation blieb dabei stets dieselbe: Der einzige Weg dieser Gewalt Herr zu werden, waren die Bewaffnung, Ausbildung und Unterstützung

265 SS-Brigadeführer und Generalmajor der Waffen-SS Ernst Fick an Himmler, 16.3.1944, BArchB, NS 19/2601, Bl. 82.

266 Vgl. Bericht ,über die Reise in das Arnautengebiet von Kosovska Mitrovica und Novi Pazar“ des Volkstumsreferenten Dr. Feninger beim Bevollmächtigten des AA in Belgrad, 15. 26.10.1941, PAAA, R261153, Bl. 32, 53.

267 Vgl. Lagebericht des Außenkommandos Kosovska-Mitrovica für August 1942, Hausding, 27.8.1942, USHMM/BArchL, B162/15.668, Bl. 41.

268 Ebd. 
durch die deutschen Besatzer. ${ }^{269}$ Hausding meldete, dass „zur Abstellung und Verhinderung weiterer Gewalttaten und schließlich zur Eindämmung der Blutrache“ im Grenzbezirk des deutschen Einflussbereichs bei Podujevo/Besianë sogar ein „allgemeiner Landfriede“ (Besa) auf Basis des in dieser Region üblichen Gewohnheitsrechts abgeschlossen worden war. ${ }^{270}$ Dass dieses Gebiet einen Hotspot interethnischer Konflikte darstellte, zeigen auch die Namen zahlreicher in Besianë/Podujevo und Umgebung rekrutierter Albaner für deutsche Waffen-SS und Polizei-Einheiten. ${ }^{271}$ Die Gefahr, Opfer eines ethnisch motivierten Übergriffs zu werden, hatte sich in den Jahren zwischen 1941 und 1944 in der ganzen Region verschärft, da beide Besatzungsmächte den gegenseitigen Hass zwischen Serben und Albanern teilweise gezielt geschürt hatten - einerseits, um die Lage für die kommunistischen Partisanen so instabil wie möglich zu halten, andererseits auch, um dem Achsenpartner zu schaden. ${ }^{272}$

Wenig Spielraum bei ihrer Entscheidung, der Division „Skanderbeg“ beizutreten, hatten auch die Albaner, die im Frühjahr 1941 als jugoslawische Soldaten in deutsche Kriegsgefangenschaft geraten waren. Am 12. Februar 1944 wandte sich Keitel an den Chef des Allgemeinen Wehrmachtsamtes (AWA), Hermann Reinecke, und bat ihn, Himmlers Forderung, 4.000 albanische Kriegsgefangene freizulassen, nachzukommen, da Hitler die Aufstellung der Division „Skanderbeg“ nun bewilligt habe. ${ }^{273}$ Nachdem die Gefangenen aber Anfang März 1944 nicht in „Neualbanien“ und im Sandžak eingetroffen waren, meldete Neubacher, dass die „Nichtfreilassung albanischer Kriegsgefangener aus ehemalig serbischem Raum“ die kosovarische Bevölkerung zunehmend beunruhigen würde. ${ }^{274}$

269 Vgl. Bericht eines „Sandschak-Muselmanen“ an AA, Februar 1943 (Datum nicht genau angegeben), PAAA Inland IIg R100998.

270 Lagebericht des Außenkommandos Kosovska-Mitrovica für August 1942, Hausding, 27.8.1942, USHMM/BArchL, B162/15.668, Bl. 42.

271 Vgl. AJ 110, F 692-730, bspw. Suleiman, Barhin, F 697 oder Smali, Mustafa, F 727, die zuerst für die „Handschar“ geworben, später zur „Skanderbeg“ versetzt wurden.

272 Vgl. hierzu detailliert Zaugg, Albanische Muslime, S. 77-85. Bereits kurz nach der italienischen Invasion in Albanien schrieb der italienische Außeniminister Galeazzo Ciano: „Es scheint, dass die Serben eine panische Angst vor ihnen [den Albanern] haben. Heute darf noch nicht einmal der Gedanke daran aufkommen, dass wir diesem Problem unsere Aufmerksamkeit zuwenden. Im Gegenteil, wir müssen die Jugoslawen einschläfern. Aber in Zukunft müssen wir eine Politik lebhafter Anteilnahme an Kossowa [sic] einschlagen. Das wird ein irredentistisches Problem im Balkan lebendig erhalten, die Aufmerksamkeit der Albaner fesseln und einen in den Rücken Jugoslawiens gezückten Dolch darstellen.“ Ciano, Tagebücher, 21.4.1939, S. 78.

273 Keitel an AWA/Chef KGF, Hermann Reinecke, den OB Südost, Fegelein und Rohde, 12.2.1944, PAAA R100984, Bl. H298851.

274 Telegramm Neubacher über AA an Himmler, 5.3.1944, PAAA, R1000984, Bl. H298867. 
Am 7. April 1944 gab die Reichsregierung auf Anfrage des ehemaligen albanischen Ministerpräsidenten Frashëri bezüglich der „Freilassung der ehemaligen jugoslawischen Kriegsgefangenen albanischer Staatsangehörigkeit zwecks Einsatz zum Kampf gegen den Bolschewismus“ schließlich grünes Licht. ${ }^{275}$

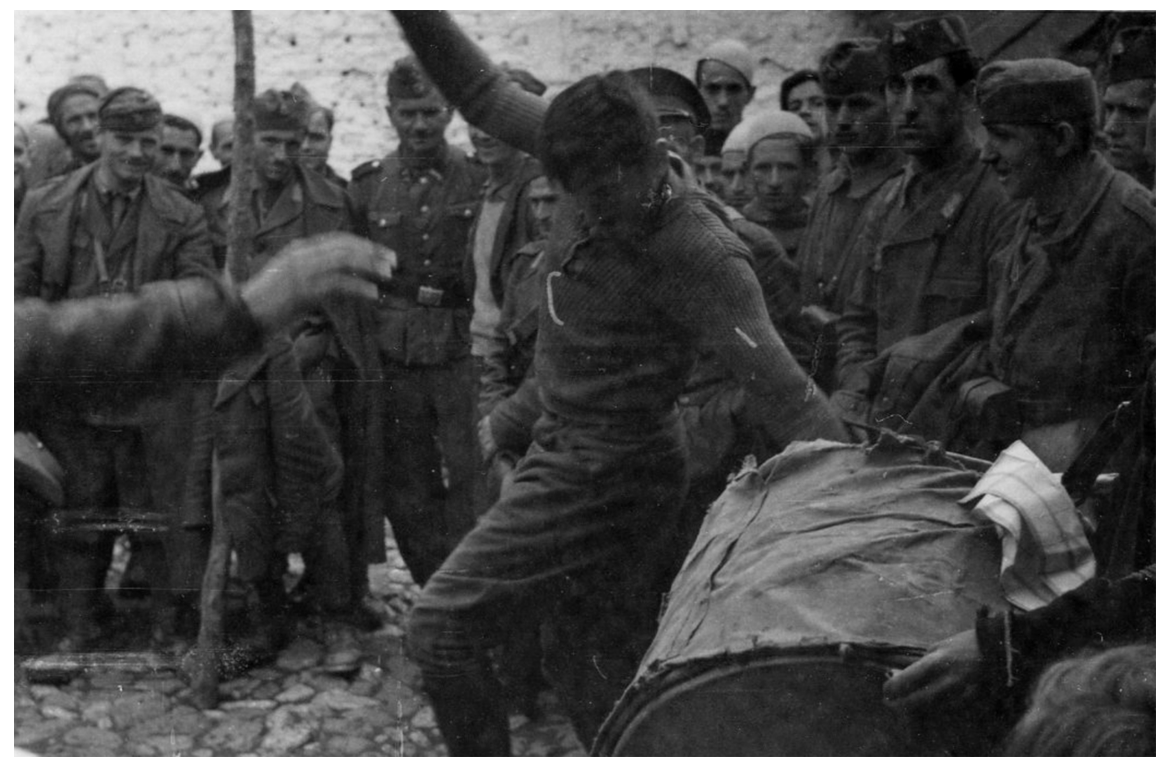

Abb. 28: Propagandistischer Empfang der für die „Skanderbeg“ bestimmten, entlassenen Kriegsgefangenen. ${ }^{276}$

Diese trafen im Mai 1944 im Gebiet Kosovo ein. Sie wurden feierlich empfangen und ihre Ankunft durch Kriegsberichter Westermann auch photographisch festgehalten. ${ }^{277}$ Fitzthum teilte Berger begeistert mit: „Großteil wird bereitwillig in der Div. ,Skanderbeg“ dienen!“²78 Karl Berger, ein ehemaliger Divisionsangehö-

275 Hencke über Staatssekretär an RAM, 7.4.1944, PAAA R100649, Inland IID, Bl.000008.

276 Propagandistischer Empfang der für die „Skanderbeg“ bestimmten, entlassenen Kriegsgefangenen, 28.5.1944, Kriegsberichter Westermann, NARA, Nr. 23A.

277 Vgl. NARA, Kriegsberichter Westermann, Bild 23A.

278 Schreiben Fitzthum an Berger, 5.5.1944, PAAA R101024, Bl.027. Vgl. Schreiben Wilhelm Keitels, Chef OKW an Hermann Reinecke, Alexander Löhr, Hermann Fegelein und Werner Rohde, Betr.: Freilassung albanischer Kriegsgefangener für die Waffen-SS, 12.2.1944, PAAA, R100984, Bl. H298850. 


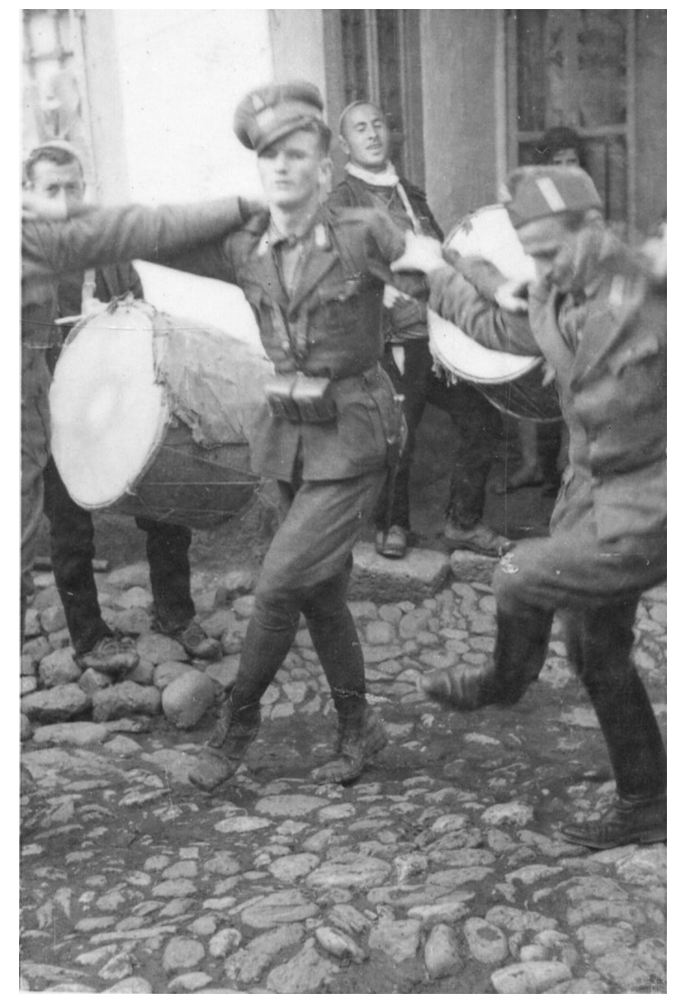

Abb. 29: Propagandistischer Empfang der für die „Skanderbeg“ bestimmten, entlassenen Kriegsgefangenen. ${ }^{279}$

riger, schrieb Vopersal aber rückblickend, dass von 15.000 freigelassenen albanischen Krieggefangenen tatsächlich nur rund 3.500 die Divisionsstandorte Prizren, Prishtina/Priština und Tetovo-Gostivar erreichten. ${ }^{280}$ Alfred Graf, Kommandeur des Regiments „Skanderbeg“ ging zwar davon aus, dass „das Gros der Rekruten

279 Propagandistischer Empfang der für die „Skanderbeg“ bestimmten, entlassenen Kriegsgefangenen, 28.5.1944, Kriegsberichter Westermann, NARA, Nr. 23A.

280 Vgl. Brief Karl Berger an Vopersal, 18.12.1975, BArchF, N 756/182b. Fischer geht nur von rund 1.500 Kriegsgefangenen aus, die in der "Skanderbeg“ Dienst taten. Vgl. Fischer, Albania at War, S. 185. Abweichende Zahlen finden sich bei Vopersal: Auf Nachfrage hätten ältere Albaner aus den Reihen des Balli Kombëtar erzählt, dass bei der Dienststelle Fitzthum bereits im November 194320.000 Albaner aus deutscher Kriegsgefangenschaft eingetroffen wären. Diese Aussagen stimmen nicht mit dem Umstand überein, dass Fitzthum seinen Dienst in Albanien erst im Dezember 1944 antrat und 20.000 Freigelassene verglichen mit anderen Angaben viel zu hoch scheinen. Aufzeichnungen Vopersal, BArchF, N 756/182a. 
[...] aus ehemaligen Kriegsgefangenen der jugoslavischen [sic] Armee“ bestanden hätte, die man unter der Voraussetzung, dass sie sich „freiwillig“ zum Dienst in der Division „Skanderbeg“ melden würden, in deutschen Kriegsgefangenenlagern aussortiert und in einem Sammeltransport nach Prizren gebracht hatte. Davon seien aber letztlich nur etwa 30 Prozent auch wirklich zum Dienst erschienen. ${ }^{281}$

Divisionskommandeur Schmidhuber lobte nach dem Unternehmen „Draufgänger“ Ende Juli 1944 den Einsatz der ehemaligen Kriegsgefangenen. ${ }^{282}$ Selbst im Bericht von Anfang Oktober, in welchem Schmidhuber vor allem kritische Töne anschlug, äußert er sich positiv zu den ehemaligen Kriegsgefangenen, die sich „ausgezeichnet geschlagen“ hätten. ${ }^{283}$ Auch „volksdeutsche“ Führer und Unterführer, ebenfalls ehemalige Soldaten aus der jugoslawischen Armee, wurden aus der Kriegsgefangenschaft entlassen, um in der „Skanderbeg“ zu dienen. Sie wurden ihren früheren Funktionen entsprechend eingesetzt: „Ehemalige [volks]deutsche Unteroffiziere wurden Zug- und Kompanieführer. Einzelne Offizier[e] Bat[aillons-] und Reg[iments-]Führer. Alles in ihrer ehemaligen jugoslawischen Kleidung.“ ${ }^{284}$

\subsubsection{Konkrete Wünsche: Persönliche Bereicherung}

Im März 1944 waren die Clanchefs in „Neualbanien“ durch die „Zweite Liga von Prizren“ über die geplanten Rekrutierungsvorhaben der Deutschen für die 21. Waffen-Gebirgs-Division der SS informiert worden. Viele von ihnen waren selbst Mitglied der „Zweiten Liga“ und über deren Politik im Bilde. Doch trotz der oben erwähnten Absicht Pejanis, zu dieser Zeit Präsident der „Zweiten Liga“, den Dienst in der albanischen Waffen-SS-Division als regulären Militärdienst zu betrachten, waren sie oft nur dann bereit, aus ihrer Gefolgschaft Rekruten aufzubieten, wenn ihnen daraus ein persönlicher finanzieller, politischer oder gesellschaftlicher Vorteil erwuchs. „Bakschisch“, Schmiergeld, zählte in Albanien zu den üblichen Ver-

281 Vgl. Graf an Vopersal, 1973, BArchF, N 756/182b Bl. 3. Auch im Interview mit Tush Mark Ndou wird deutlich, dass zahlreiche der Freigelassenen nicht bei der Division erschienen, sondern bei ihren Familien in den Dörfern blieben bzw. zu den Partisanen gingen. Vgl. Interview mit Tush Mark Ndou (geführt von Franziska Zaugg), 7.6.2017.

282 Vgl. Abschließender Gefechtsbericht des Unternehmens „Draufgänger“ vom 18. bis 28. Juli 1944, Schmidhuber, NARA, T314/664, F. $293 \mathrm{f}$.

283 Vgl. „Zusammenfassender Bericht“ Schmidhuber, 2.10.1944, BArchF, RS 3-21/1, S. 5.

284 Vgl. Brief von von Pistor an Vopersal, undatiert, BArchF, N 756/182b. 
handlungsmitteln jener Zeit. ${ }^{285}$ So warben auch die Briten mit Gold und Waffen um Personal für die von ihnen unterstützten Partisanenverbände. ${ }^{286}$ Auch Divisionskommandeur Schmidhuber war der Überzeugung, dass das passive Verhalten der Stammesvorsteher und lokaler Verwaltungsstellen nur mithilfe von Schmiergeldern hätte überwunden werden können: „Die Aufstellung der Division in dem geplanten Umfange wäre vielleicht am ehesten möglich gewesen, wenn der Divisions-Kommandeur mit einem Sack Gold angerückt wäre und es unter die maßgeblichen Begs verteilt hätte. Dann wären ihm von diesen die Rekruten aus ihrer Pächterschar zugetrieben worden. “287

Doch trotz seiner mehrjährigen Erfahrung in südosteuropäischen WaffenSS-Verbänden war Schmidhuber der Umstand, dass bei der lokalen Elite Militärdienste erkauft werden mussten, neu: „Wer in Albanien Freundschaft anbietet, wird zuerst gefragt: ,Wieviel Gold gibst du mir?` Der Witz ist einfach der, dass gewisse Leute mit der Aufstellung einer albanischen Division ein Geschäft machen wollten. “288 Da jedoch aufgrund der limitierten eigenen finanziellen Mittel im Frühjahr und Sommer 1944 solche Zahlungen nicht geleistet werden konnten, blieb die Unterstützung der Clanchefs aus. Schmidhuber schien es im Gegenteil sogar, als hätten sie durch ihren Einfluss die Aufstellung der Division behindert: „Die Aufstellung der Division stieß vor allem auf den unsichtbaren Widerstand der Begs und Agas [gemeint sind hier aber die Bajraktare], der sich in der Passivität der beghörigen Präfekten und Bürgermeister und einer aufstellungsfeindlichen Flüsterpropaganda auswirkte.“289

Zur persönlichen Bereicherung ist auch das Plündern zu zählen, welches in Albanien als Teil des Kriegsdienstes angesehen wurde. ${ }^{290}$ Dass in Albanien Plündern auch von italienischer Seite als Teil der Kriegführung betrachtet wurde, bestätigt etwa Pfeiffer, der im Herbst 1941 an die Deutsche Botschaft in Rom schrieb, dass von italienischen Seite den Soldaten in den albanisch-monte-

285 Vgl. OB Südost, Bericht „Entwicklung der militärischen Lage in Albanien im Herbst 1944“, undatiert, BArchF, RW 40/116a, Bl. 33.

286 Vgl. Vogel, Erinnerungen, Bd. 1, Unter Skipetaren - Albanische Erinnerungen 1943/44, unveröffentlicht 1989, S. 177, 215. Vgl. OB Südost, Bericht „Entwicklung der militärischen Lage in Albanien im Herbst 1944“, undatiert, BArchF, RW 40/116a, Bl. 17.

287 Schmidhuber, „Zusammenfassender Bericht“, 2.10.1944, BArchF, RS 3-21/1, S. 3.

288 Ebd.

289 Ebd.

290 Plündern war in Europa seit der Antike als Teil der Kriegführung weit verbreitet - oft auch als Ersatz für Sold. Vgl. Horst Carl, Hans-Jürgen Bömelburg, Lohn der Gewalt. Beutepraktiken von der Antike bis zur Neuzeit, Paderborn: Schöningh 2011. 
negrinischen Grenzgebieten nach der Niederschlagung von Unruhen „fünf Tage freie Hand gegeben worden [war] für Plünderung und Vergewaltigung““ ${ }^{291}$

Schmidhuber empfand die eigenmächtigen Plünderungen seiner Soldaten als störend, da so in keiner Weise die Disziplin gehalten werden konnte und meinte daher vernichtend: „Im Angriff geht er [der albanische Soldat] nur soweit mit, bis er etwas zum Stehlen oder Plündern findet. Hat er eine Ziege, eine Pflugschar oder ein Nähmaschinenrad erbeutet, dann ist für ihn der Krieg aus, und er geht eigenmächtig nach Hause.“292 Auch Kaesdorf wies darauf hin, es komme nicht selten vor, dass die Männer von sich aus in Häuser verschwinden würden, um Proviant zu besorgen, ${ }^{293}$ und Rudolf Vogel erwähnt die Alltäglichkeit von Plünderungen in seinen Memoiren ebenfalls. ${ }^{294}$ Er schreibt hierzu, „ihre Plünderungen fielen automatisch uns zur Last, weil sie ja in unseren Diensten standen.“295 Aufgrund der angespannten Ernährungssituation wurden aber Konfiszierungen von vorgesetzter Stelle mitunter auch angeordnet. SS-Untersturmführer Sulejman Daca meldete dem Ia der „Skanderbeg“ Mitte Juni 1944, dass der „Zweck der jetzigen Kämpfe [...] die Plünderung“ sei, und „ohne Rücksicht auf Verluste“ Getreide aus Häusern geholt werden sollte. ${ }^{296}$

Da Plünderungen in „Neualbanien“ demnach zum Alltag gehörten, fürchtete Schmidhuber im Herbst 1944 um seine eigenen Einheiten: Er war überzeugt, dass die Albaner nur darauf warten würden, „sich plündernd auf eine sich auflösende deutsche Wehrmacht zu stürzen, um ihre Waffen- und Munitionsbestände aufzubessern, wie sie es vom Falle Jugoslawiens oder Italiens her gewöhnt waren.“297

291 Pfeiffer an Deutsche Botschaft in Rom, 14.10.1941, Altes Amt, Tirana 4/3, Bericht Nr. 1007. Hierzu führt Mantelli aus, dass der frühere italienische Kommandierende General des H.Q. in Albanien nun in Montenegro, Alessandro Pirzio Biroli, 1941 eine „carte blanche“ erhielt: Er ließ seine Soldaten wissen, dass sie für keine Handlung, die sie im Lauf der Niederschlagung des Aufstandes begingen, später zu Rechenschaft gezogen würden. Vgl. Mantelli, Italiener auf dem Balkan, S. 67.

292 Schmidhuber, „Zusammenfassender Bericht“, 2.10.1944, BArchF, RS 3-21/1, S. 2.

293 Kaesdorf, „Erfahrungen mit albanischen Soldaten“, undatiert, BArchB, NS 31/444, S. 26.

294 Vgl. Vogel, Erinnerungen, S. $181 \mathrm{f}$.

295 Vgl. ebd., S. 216.

296 SS-Ustuf. Daca an Ia, BArchF RS 3-21/2, 15.6.1944, Bl. 96.

297 Schmidhuber, „Zusammenfassender Bericht“, 2.10.1944, BArchF, RS 3-21/1, S. 6. 


\subsubsection{Konkrete Wünsche: Nahrung, Sold, Bewaffnung}

In den unteren Bevölkerungsschichten, die nicht der Elite angehörten, aber relativ frei entscheiden konnten, ob sie sich der „Skanderbeg“ anschlossen, waren konkrete Bedürfnisse wie Nahrung, Sold und Bewaffnung zur Verteidigung der eigenen Dörfer wichtige Motive. Die Familienunterstützung war, wie bereits bei den anderen beiden Divisionen erwähnt, ein Novum. Wie die Akten aus dem Arhiv Jugoslavije und dem Archiv in Prishtina/Priština zeigen, wurde die Möglichkeit auf Beantragung von Familienunterstützung von der lokalen Bevölkerung oft wahrgenommen. Ein anschauliches Beispiel liefert der Albaner Husen Salli (Jahrgang 1921) aus dem serbischen Kruševac, der sich als Rottwachtmeister für das Polizei-Freiwilligen Regiment 1 rekrutieren ließ und beim Fürsorgeoffizier der SS in Serbien einen Antrag auf Familienunterhalt stellte. ${ }^{298}$ Schmidhuber stellte rückblickend aber klar, „dass bei einem Massenandrang zur Division“ die zur Verfügung stehenden Geldmittel für die Besoldung und Familienunterstützung nicht ausgereicht hätten. ${ }^{299}$

Dass die Aussicht auf Nahrung und Bewaffnung für den Entscheid zum Beitritt zur „Skanderbeg“ wesentlich war, zeigen auch die zahlreichen Desertionen, die einsetzten, als sich sowohl die Nahrungs- als auch die Bewaffnungssituation im Sommer 1944 rapide verschlechterte. In seinem „Zusammenfassenden Bericht“ erwähnte Schmidhuber, dass die Versprechen auf Bewaffnung und militärische Ausbildung von Anfang an nicht eingehalten worden wären, denn „die ersten Einsätze erfolgten bereits nach 6-wöchentlicher Ausbildung bei unzureichender Bewaffnung [...].“300 Die Ausrüstung mit Waffen und Munition war schließlich so knapp, dass die albanischen Soldaten der „Skanderbeg“ beim Unternehmen „Fuchsjagd“ Mitte August mit nur je 30 Schuss pro Gewehr und ohne jegliche Handgranaten in den Kampf geschickt wurden. ${ }^{301}$ Dass die Versorgungslage der „Skanderbeg“ knapp bis prekär war, zeigt auch die Tatsache, dass die Aus-

298 Vgl. Fall Husen Salli, AJ, 110-723-262.

299 Vgl. Schmidhuber, „Zusammenfassender Bericht“, 2.10.1944, BArchF, RS 3-21/1, S. 4.

300 Schmidhuber, „Zusammenfassender Bericht“, 2.10.1944, BArchF, RS 3-21/1, S. 5.

301 Vgl. Gen.Kdo. XXI. Geb.A.K., von Leyser an „Skanderbeg“, 25.8.1944, NARA, T314/664, F. 594. Als weitere Beispiele sind folgende zu nennen: Ia der „Skanderbeg“ an Hauptsturmführer Bormann meldete Mitte Juni 1944: „Keine Pak mehr zur Verfügung. In Pristina [sic] nur noch eine Kanone mit defekter Höhenrichtmaschine.“ Stab „Skanderbeg“ Ia an Hstuf. Bormann, 15.6.1944, BArchF, RS 3-21/2, S. 10. Einen Monat später wurde dringend um Handgranaten gebeten. Vgl. Meldekopf Rožaje, Hoffmann an Bendl, 11.7.1944, BArchF, RS 3-21/2, S. 15. 
rüstung der im Mai 1944 aufgelösten Albanischen Miliz direkt an die Division „Skanderbeg“ übergehen sollte. ${ }^{302}$

\subsubsection{Antikommunistische Einstellung, sozialer Druck und Drohungen}

Eine antikommunistische Einstellung war vor allem bei denjenigen Bevölkerungsteilen verbreitet, die durch eine kommunistische Umstrukturierung von Gesellschaft und Besitzverhältnissen viel zu verlieren hatten oder tief in traditionellen Strukturen verwurzelt waren. Die Kommunisten konnten ihren größten Zulauf in Süd- und Mittelalbanien verzeichnen, wo Großgrundbesitzer herrschten und in den Städten Intellektuelle zu finden waren:

Da sie den Bauern freies Eigentum ihrer Höfe, dem ziemlich zahlreichen geistigen Proletariat, vor allem der Lehrerschaft, Lebensgrundlagen und Einfluss, dem Armen die Güter der Reichen und der in erstarrter Tradition eingezwängten Jugend geschlechtliche Freiheit versprachen, liefen ihnen die Anhänger in hellen Scharen zu. ${ }^{303}$

Im Norden und in „Neualbanien“ sahen die Voraussetzungen anders aus: Die Dorfgemeinschaften und erweiterten Familienverbände waren streng hierarchisch und sehr traditionell aufgebaut. Oft oblag es der Entscheid des Clanchefs, ob mit den Deutschen zusammengearbeitet wurde oder nicht, und diesem hatten sich die Angehörigen eines Clans bzw. einer Großfamilie zu beugen. ${ }^{304}$ Schmidhuber beschrieb diesen Zustand mit folgenden Worten: „Sie kennen noch kein ausgeprägtes Volks- und Staatsbewusstsein, sondern leben noch, wie einst die Germanen, im Sippen- und Stammesdenken. “305 Aus diesen Gründen schien ihm die Bevölkerung in Nord- und „Neualbanien“ instinktiv antikommunistisch eingestellt zu sein. ${ }^{306}$ So war der „Kampf gegen den Bolschewismus“ auch bei der Rekrutierung der freigelassenen albanischen Kriegsgefangenen der ehemaligen jugoslawischen Armee ein wesentliches Argument. ${ }^{307}$

Doch nicht nur eine antikommunistische Grundeinstellung förderte die Rekrutierung in deutsche Einheiten. Bereits seit Anfang 1943 griff der „Balli Kombëtar“

302 Schreiben Kommandeur Nationale Verteidigung General Prenk Pervizi an Kdo.st. Abt. Kos. und weitere, 20.5.1944, A.Q.SH. F.160, 1944, D 32, Bl. 31.

303 Vgl. OB Südost, Bericht „Entwicklung der militärischen Lage in Albanien im Herbst 1944“, undatiert, BArchF, RW 40/116a, Bl. 16.

304 Vgl. Zaugg, Perfekte Krieger?, S. 245f. Vgl. Holm Sundhaussen, Dorf, Religion und Nation, S. 90-92.

305 Schmidhuber, „Zusammenfassender Bericht“, 2.10.1944, BArchF, RS 3-21/1, S. 1.

306 Vgl. Schmidhuber, „Zusammenfassender Bericht“, 2.10.1944, BArchF, RS 3-21/1, S. 7.

307 Hencke über Staatssekretär an RAM, 7.4.1944, PAAA R100649, Inland IID, Bl.000008. 
bei den Rekrutierungen auch zu Zwangsmitteln, ${ }^{308}$ und selbst die albanischen Kommunisten rekrutierten gelegentlich unter Androhung drakonischer Strafen. ${ }^{309}$ Somit waren die jungen albanischen Muslime in den Grenzgebieten oft gezwungen, sich von einer dieser drei Fraktionen rekrutieren $\mathrm{zu}$ lassen, um mit dem Leben davon zu kommen. ${ }^{310}$

Folgendes Flugblatt soll einen Einblick in die antikommunistische Propaganda geben, die den Kommunismus als etwas „Fremdes“, Nicht-Genuines definiert:

\section{Kommunisten!}

Irregeleitet durch landfremde Agenten, [sic] wolltet Ihr mit dieser Aktion Unruhe und Uneinigkeit stiften und den Zusammenschluss des freien Albanien unter einer starken nationalen Regierung verhindern.

Aber gerade die gegenteilige Wirkung habt Ihr hervorgerufen. Eure Tätigkeit hat allen guten Albanern die Augen geöffnet und ihnen gezeigt, welche Gefahr dem Lande durch den Bolschewismus droht. Deshalb haben sich alle zur Nationalversammlung bekannt. [...]

Albanien braucht zu seiner Wiedererstarkung nichts notwendiger als Ruhe und Ordnung. Alle müssen sich zum Besten des Ganzen hinter die rechtmäßige, vom Volke gewählte Staatsgewalt stellen; denn nur durch Einigkeit sowie positive und friedliche Arbeit wird die eben erst errungene Freiheit Albaniens erhalten und gesichert. Wer das nicht erkennt und heute abseits steht oder sich sogar mit der Waffe in der Hand gegen seine Brüder stellt, hat für alle Zeiten das Recht verwirkt, bei der Neuordnung des freien nationalen Albaniens je noch ein Wort mitreden zu können. ${ }^{311}$

\subsection{Werbung und Aufstellung}

Während SS-Obersturmbannführer Alfred Graf, ehemaliger Regimentskommandeur in der Division „Skanderbeg“, noch nach dem Krieg zu Protokoll gab, dass die Rekrutierungen für die „Skanderbeg“ auf der Grundlage von Freiwilligkeit durchgeführt worden seien, ${ }^{312}$ zeichnen die untersuchten Dokumente ein anderes Bild: Von 1941 bis 1943 kann zwar zumindest in Teilen von „Freiwilligkeit“ gesprochen werden, doch 1944 trat wohl der größte Teil der Soldaten den Dienst in

308 Vgl. Neuwirth, Widerstand und Kollaboration, S. 104, 116f. Vgl. Notizie varie, 11.1.1944, AUSSME I3/b13/f1, S. 5.

309 Vgl. Neuwirth, Widerstand und Kollaboration, S. 199. Vgl. auch Meldung SS-Untersturmführer Daca an Ia, 15.6.1944, BArchF, RS 3-21/2, Bl. 95.

310 Vgl. SS-Brigadeführer und Generalmajor der Waffen-SS Ernst Fick an Himmler, 16.3.1944, BArchB, NS 19/2601, Bl. 82.

311 Februar bis Juli 1944, Gen.Kdo. XXI.Geb.AK, Ia Nr. 4633/44 geh., Flugblatt undatiert, BArchF, RH26-181/38.

312 Vgl. Kriegsgefangenenbericht Graf, VA, HEM.OK.BOJCKA, 72/2-1/32. 
der „Skanderbeg“ als regulären, vom Staat verordneten Militärdienst an. ${ }^{313} \mathrm{Zu}$ sätzlich verstärkten sogenannte „nationalen Banden“ die Division. Solche waren nicht nur im Zweiten Weltkrieg in Südosteuropa zu finden, sondern in sämtlichen von Großmächten geführten Kriegen in dieser Region. ${ }^{314}$

Die Rekrutierungen von Albanern in Verbände der Waffen-SS oder zumindest in Einheiten, die durch die Waffen-SS rekrutiert wurden, gliedern sich in drei Phasen. Erste unkoordinierte Rekrutierungen begannen bereits während des Balkanfeldzuges im April 1941, in welchem albanische Freischärler als Hilfstruppen den deutschen Verbänden angegliedert wurden. ${ }^{315}$ Ende 1941 meldete Wegener aus der deutschen Gesandtschaft Tirana bereits konkrete Pläne zur Aufstellung zweier albanischer Freiwilligenbataillone. ${ }^{316}$ Die zweite Phase dauerte von Spätherbst 1942 bis Herbst 1943 - sie schließt mit dem von Neubacher via Kaltenbrunner angeregten Rekrutierungsstopp im September 1943. ${ }^{317}$ Diese Phase war gekennzeichnet von einer relativ hohen Anzahl freiwilliger Beitritte, wobei dieses Interesse vor allem der militärischen Unterlegenheit der Albaner ihren lokalen Gegnern gegenüber geschuldet war. ${ }^{318}$ Dennoch muss angenommen werden, dass bereits in dieser Phase auch „Volksgruppenführer“, beispielsweise Ali Beg Draga, Druck auf die Albaner im Sandžak, Nordkosovo und „Neualbanien“ ausübten. ${ }^{319}$

Trotz des im September 1943 verhängten Rekrutierungsstopps setzten sich aber die Rekrutierungen unter Neubachers Bedingung, dass die rekrutierten Albaner für Verbände der Waffen-SS und Wehrmacht nicht außerhalb Albaniens eingesetzt und diese Verbände formell dem albanischen Innenministerium unterstellt würden, fort. ${ }^{320}$ Im Januar 1944 meldete Neubacher dem Auswärtigen Amt, dass die „besonders dankbar ergebene[n] Neu-Albaner (Kossowaner [sic])“ bereit seien, gemeinsam „gegen [den] äußeren Feind“ vorzugehen. ${ }^{321}$

313 Vgl. Bedri Pejani an Ministerpräsident Rexhep Mitrovica, 23.5.1944, A.Q.SH. F.147, 1944, D I-165, Bl. 16.

314 Dmitar Tašić, Repeating Phenomenon: Balkan Wars and Irregulars, 25.

315 Vgl. Kollegger, Albaniens Wiedergeburt, S. 66.

316 Vgl. Wegener an AA, 13.11.1941, Altes Amt, Tirana 4/3.

317 Neubacher, Sonderauftrag Südost, S. $115 \mathrm{f}$.

318 Neumeister schreibt, dass die nationalistischen Serben „in dieser Voraussicht [...] sehr erhebliche Niederlagen von Waffen und Kriegsmaterial im Berglande errichtet“ hätten. Vgl. „Lage in Albanien im Mai 1943“, Auswertestelle Süd, 24.8.1944, unterzeichnet vom Chef der Heeresarchive Oberstleutnant Neumeister, 31.8.1944, BArchF, RH 18/407.

319 Vgl. Kriegsgefangenenbericht II, Schmidhuber, 19.8.1945, VA HEM.OK.BOJCKA, 72/1/2/3.

320 Vgl. Von Thadden über Treffen mit Neubacher vom 11.10.1943, PAAA, Inland IIg, R100984, H298703.

321 Vgl. Schreiben Neubacher an AA, 29.1.1944, PAAA, R101024, Bl. 020 f. In jene Zeit fiel auch die Abkommandierung von rund 90 Tadschiken und 50 Turkmenen in die Region Kosovo, die 
Die dritte Phase setzte im Frühjahr 1944 ein. Hitler hatte Himmlers Vorschlag, eine albanisch-muslimische Waffen-SS-Division aufzubauen, zugestimmt: „Der Reichsführer-SS, der von de[n] berühmten k.u.k. - bosnischherzegowinischen Elite-Regimentern der Donau-Monarchie viel gehört hatte, kam schließlich doch zum Ziel: er ließ sich 1944 von Hitler bevollmächtigen, in Albanien für den lokalen Partisanenkrieg innerhalb der Grenzen des Landes eine Waffen-SS-Gebirgsdivision „SkanderBeg“ [sic] aufzustellen.“322 Berger und Himmler versuchten, auch die Karte der nationalen Unabhängigkeit auszuspielen - mit mäßigem Erfolg. Durch die Benennung der Division „Skanderbeg“ wollte man eine Brücke zum albanischen Nationalhelden Iskander Beg bzw. Georg Kastrioti, schlagen. Der Katholik, der in der zweiten Hälfte des 15. Jahrhunderts 25 Jahre lang gegen die Osmanen gekämpft hatte, diente nun als Namensgeber für diesen muslimischen Verband des Dritten Reichs. ${ }^{323}$ Auch in den Rekrutierungsbüros, etwa in Prizren, wurde darauf geachtet, dass das Bild des Nationahelden Skanderbeg gleichberechtigt neben dem Porträt des Führers an der Wand hing. ${ }^{324}$ Der sogenannte „Skanderbeg“-Orden, der ebenfalls im Rahmen dieser Politik der nationalen Symbole zu sehen ist, sollte Männer auszeichnen, die sich im Kampf um den europäischen Sieg des Nationalsozialismus verdient gemacht hatten. ${ }^{325}$ Doch wie bereits im Teil zur Division „Prinz Eugen“ gezeigt, war die Idee einer solchen „nationalen“ Namensgebung nicht neu. Den Namen „Skandereg“ hatten zudem bereits die Italiener für militärische Zwecke genutzt: Zwischen 1939 und 1943 integrierten sich die im „Gruppo Skanderbeg“ gesammelten Einheiten der Milizia Fascista Albanese (MFA) in das italienische Heer. ${ }^{326}$

\subsubsection{Vorgängereinheiten}

Die Rekrutierung von Albanern in deutsche Einheiten der Wehrmacht und WaffenSS und als Hilfstruppen setzte bereits 1941 ein: Schon während des Balkanfeldzugs kämpften albanische Freischärler an der Seite der Deutschen gegen jugoslawische

als sowjetische Kriegsgefangene in den deutschen Militärdienst übernommen wurden und als Muslime die Albaner gegenüber Wehrmacht und Waffen-SS positiv stimmen sollten. Frolov, Pod barjakom Skenderbega, S. 43.

322 Neubacher, Sonderauftrag Südost, S. 116.

323 Vgl. Zaugg, Albanische Muslime, S. 35. Zu Iskander Beg/Georg Kastrioti ausführlich: Oliver Jens Schmitt, Skanderbeg. Der neue Alexander auf dem Balkan. Regensburg: Friedrich Pustet 2009. 324 Vgl. Rekrutierungsbüro für die Waffen-SS in Prizren, BArchF, N765/182b, Bl. 2.

325 Vgl. Persönlicher Stab Reichsführer SS, 14. 7.1944, NS19/3426, S. 4 f., 7.

326 Vgl. Kollegger, Albaniens Wiedergeburt, S. 60. Zur MFA ausführlich: Zaugg, Albanische Muslime, S. 59-64. 
Truppen, wie der deutsche Kriegsberichter Willibald Kollegger ein Jahr später dokumentierte. ${ }^{327}$ Im Oktober 1941 regten auch Feninger und von Scheiger in ihren Berichten an, Albaner zu rekrutieren, da aufgrund ihrer Einschätzung ein großer Teil der nord- bzw. „neualbanischen“ Bevölkerung den Deutschen Besatzern positiv gegenüber stehen würde. ${ }^{328}$ Im November 1941 wurde daher die Aufstellung zweier albanischer Freiwilligenbataillone in dieser Region diskutiert. Wegener meldete Mitte November 1941, dass sich bereits einige tausend Freiwillige zum Dienst gemeldet hatten und merkte an, dass mangels geeigneten Führungspersonals auch Flüchtlinge aus „Altalbanien“ rekrutiert würden. ${ }^{329}$ Auch Weizsäcker schrieb Ende November 1941 an den Gesandten Curt Heinburg von der Planung einer lokalen albanischen Miliz, die unter deutsches Kommando gestellt werden sollte. ${ }^{330}$ Dennoch wies er Heinburg an, Cianos Vorwurf, „dass die aus Albanern zusammengestellte Miliztruppe demnächst auf den Führer vereidigt werden solle“ zurückzuweisen. ${ }^{331}$ Um weiteren Auseinandersetzungen mit den Italienern vorzubeugen, regte der Bevollmächtigte Kommandierende General und Befehlshaber in Serbien, General der Infanterie Franz Böhme, im Dezember 1941 an, dass für solche Einheiten - zumindest offiziell - nur im unter deutscher Militärherrschaft stehenden Teil Kosovos und dem Sandžak, geworben werden sollte. Die Rekrutierung von Flüchtlingen aus „Großalbanien“ sollte soweit möglich vermieden werden. ${ }^{332}$

Seit 1942 waren die Italiener dennoch über die deutschen Rekrutierungsabsichten in der albanischen Bevölkerung dieser Region informiert, wie Akten belegen. ${ }^{333}$ In dieser Zeit entstanden unter der Schirmherrschaft albanischer Organisationen verschiedene Formationen, die schließlich 1944 in die Division „Skanderbeg“ mündeten. Neben den Rekrutierungen im Sandžak, die von Krempler durchführte, wurde wiederholt auch in angrenzenden Regionen rekrutiert. Interethnische Spannungen zwischen Serben und Albanern führten zu einem steigenden Interesse der albanischstämmigen Bevölkerung nach Bewaffnung und mi-

327 Vgl. Kollegger, Albaniens Wiedergeburt, S. 66.

328 Vgl. Bericht Franz von Scheigers an AA, 25.10.1941, PAAA, Altes Amt, Tirana 4/7, Bl. 255900. Vgl. Bericht „über die Reise in das Arnautengebiet von Kosovska Mitrovica und Novi Pazar“ des Volkstumsreferenten Dr. Feninger beim Bevollmächtigten des AA in Belgrad, 15. 26.10.1941, PAAA, R261153.

329 Vgl. Wegener an AA, 13.11.1941, Altes Amt, Tirana 4/3.

330 Vgl. Weisäcker an Gesandten Heinburg, 29.11.1941, PAAA, BA 61153, S. 104.

331 Vgl. ebd.

332 Vgl. Schreiben „Italienische Wünsche bezüglich Kos. Mitrovica“, Bevollmächtigter Kommandierender General und Befehlshaber in Serbien, General der Infanterie Franz Böhme, an Wehrmachtbefehlshaber Südost, General der Pioniere Walter Kuntze, 9.12.1941, BArchF, RW 40/23, 24.

333 Schreiben des Gabinetto Diplomatico an das Ministero degli Affari Esteri zur Situation in Serbien, 7.12.1942, ASD, AG, 1923-1943, Busta 1492, AG-Serbia 2. 
litärischer Ausbildung nach westeuropäischen Standards. Somit dienten die seit 1942 aufgestellten „Selbstschutzeinheiten“ (als Namen waren zuerst SS-,,Kosovo“und SS-,,Sandžak“-Wacht vorgesehen) schließlich als „Albanisch Muselmanische SS-Freiwilligen-Legion“ vordergründig als Schutz für die lokale Bevölkerung und gleichzeitig für die deutschen Besatzer zur Befriedung umkämpfter Grenzgebiete und als Speerspitze im Partisanenkrieg. ${ }^{334}$ Ali Draga wie auch Deva und Lufti waren, wie bereits gezeigt, zu diesem Zeitpunkt bereits seit längerem in die Werbung Freiwilliger involviert, die unter Aufsicht des HSSPF Serbien, SSGruppenführer August Meyszner durchgeführt wurde. ${ }^{335}$

Gerade aus italienischen Quellen wird ersichtlich, dass auch bei diesen frühen Rekrutierungen bereits Druck ausgeübt oder Beitritte sogar erzwungen wurden: Die Rekrutierungen für sogenannte „Freiwilligenverbände“ unter deutschem Kommando, die verwendet werden sollten, „um der Situation in Serbien zu begegnen“, betrafen die gesamte männliche muslimische Bevölkerung der Region zwischen 18 und 40 Jahren. Die italienischen Behörden gingen davon aus, dass sie zum größten Teil auf der Basis von Zwang durchgeführt wurden; so musste sich bei einer Familie mit mehreren Söhnen mindestens einer der Söhne rekrutieren lassen. Dieses Vorgehen der Deutschen hätte in der ansässigen albanischen Bevölkerung und sogar bei den deutschen Dienststellen in Belgrad zu Protesten geführt. ${ }^{336}$ Aus einem anderen Bericht der italienischen Armee geht hervor, dass in den Jahren bis zur italienischen Kapitulation im September 1943 auf breiter Basis rekrutiert wurde: „Viele Kosovaren sind rekrutiert und als Polizeikräfte regulär in das deutsche Heer inkorporiert worden.“337 Es ist naheliegend, dass damit nicht nur die der Waffen-SS angegliederten Polizeieinheiten gemeint sind, sondern auch Einheiten der Waffen-SS. Dass in dieser Periode viele Albaner nicht nur für militärische, sondern insbesondere auch für Polizeieinheiten rekrutiert wurden, zeigen Stammkarten albanischer Angehöriger von „Freiwilligen-PolizeiBataillonen“ in den Archiven von Prishtina/Priština und Belgrad. ${ }^{338}$

334 Vgl. hierzu detailliert Zaugg, Albanische Muslime, S. 180-184. Zur Namensgebung Letsch an Berger, 8.10.1943, BArchB, NS 19/1660, Bl. 2.

335 Vgl. Bevollmächtigter des AA beim Militärbefehlshaber Serbien Benzler an AA, „Italienische Beschwerde über die Betätigung Xhafer Devas im Mitrovica-Gebiet“, 31.3.1943, PAAA, R100998 H297622. Vgl. Bevollmächtigter des AA beim Militärbefehlshaber Serbien Benzler an AA, „Aufstellung eines muselmanischen Freiwilligenkorps“, 13.4.1943, PAAA, R100998.

336 Generalstatthalter Albanien, Gabinetto Diplomatico an das Ministero degli Affari Esteri zur Situation in Serbien, 7.12.1942, ASD, Archivio del Gabinetto, 1923-1943, Busta 1492 (AG Serbia 54). 337 Vgl. Relazione politica sull'Albania, 30.10.1943, Uff. Stor. I3/b13/f1, S. 4.

338 Vgl. Arkivi Kosoves, F: Dosjete robërve të luftës në Gjermani, V: 1940-1945, K: 1 und AJ 110, F 692-730. 
Insbesondere die instabile politische Situation mit wiederkehrenden, extrem gewalttätigen Auseinandersetzungen zwischen den einzelnen Bevölkerungsgruppen ließen im SS-Hauptamt 1943 den Wunsch nach Abklärung weiterer Möglichkeiten zur Erhaltung von Ruhe und Ordnung und der „Heranziehung der muslimischen Bevölkerung zu militärischen Zwecken“ aufkommen. Mit konkreten Vorschlägen zu solchen Rekrutierungen sollte an das Auswärtige Amt herangetreten werden, wie aus Reichels Bericht hervorgeht. ${ }^{339}$ Auch Berger betonte gegenüber dem Auswärtigen Amt, dass die Aufstellung von „Selbstschutzeinheiten“ in der Sandžak- und Kosovoregion vor allem deshalb notwendig sei, um die albanische Bevölkerung vor Četniks zu schützen. ${ }^{340}$ Legationsrat Reichel wies darauf hin, dass sich die Muslime in einer schwierigen Lage befänden, da sie bisher im Unterschied etwa zu den Četniks unbewaffnet waren. ${ }^{341}$ Es sollte zunächst ein Regiment aus Freiwilligen aus den Gebieten Kosovska Mitrovica und Novi Pazar aufgestellt werden. Die Deutschen rechneten mit rund 12.000 Kriegsfreiwilligen, die eigentlich für die Wehrmacht vorgesehen gewesen waren, jetzt aber für die Waffen-SS eingesetzt werden sollten. ${ }^{342}$ Der Chef des Generalstabs des Kommandierenden Generals und Befehlshabers Serbien, Oberst der Reserve Kurt von Geitner, rechnete in den nächsten Monaten mit blutigen Zusammenstößen zwischen montenegrinischen Četniks und der muslimischen Bevölkerung im SandžakGebiet. $^{343}$

Dass die Rekrutierungen nach einer kurzen Unterbrechung im September auch im Oktober 1943 nicht abrissen, zeigt ein Schreiben Bergers, der der Meinung war, dass mit Hilfe Meyszners und des Hauptamts Ordnungspolizei durch die Erfassung von 12.000 bis 15.000 „Volksalbanesen“ in Bezug auf die interethnischen Konflikte „sehr viel Blut gespart“ und „tadellose Einheiten“ gebildet werden könnten. ${ }^{344}$ Selbst kurz vor dem eigentlichen Aufstellungsbeginn der Division „Skanderbeg“ wurde von deutscher Seite in dieser Region geworben,

339 Vgl. Bericht Reichel, AA Inland IIc, 12.4.1943, PAAA, Inland IIg, R100998.

340 Vgl. Berger an das AA, „Betreff: Freiwillige für die 13. (kroatische) SS-Division aus dem Sandžakgebiet“, 9.4.1943, PAAA, R100998, H297616.

341 Vgl. Bericht Legationsrat der Abteilung Inland IIc, SS-Sturmbannführer Eberhard Reichel, AA Inland IIc, 12.4.1943, PAAA R100998.

342 Vgl. Bevollmächtigter des AA beim Militärbefehlshaber Serbien Benzler an AA, 13.4.1943, PAAA, Inland IIg, R100998.

343 Vgl. Chef des Generalstabs, von Geitner an Königl. Ital. Verbindungsstab beim Kdr. Gen. u. Bfh. in Serbien, 5.4.1943, ASD, AG, 1923-1943, Busta 1492, Serbia 4.

344 Berger an das Hauptamt Ordnungspolizei (OrPo) zur „Albanien-Aktion“ am 11.10.1943, BArchB, NS19/1660, Bl. 5. 
wie zwei Battaillone bestehend aus 800 Muslimen belegen, die von Krempler im Sandžak bereits Ende Februar 1944 ausgehoben hatte. ${ }^{345}$

\subsubsection{Rekrutierungs- und Einsatzräume in den Grenzgebieten „Großalbaniens“}

In der Region „Neualbanien“ und angrenzenden Gebieten hofften die Vertreter des Dritten Reiches beidseitig der Demarkationslinie auf eine prodeutsche Einstellung der zu großen Teilen albanischstämmigen Bevölkerung. HSSPF Albanien Fitzthum und HSSPF Serbien Meyszner waren beide der Überzeugung, dort eine ausgeprägte „Deutschfreundlichkeit“ vorzufinden; die Menschen in diesen Gebieten würden die Deutschen erwarten, um nach der absehbaren italienischen Kapitulation nicht mit den Alliierten zusammenarbeiten zu müssen. ${ }^{346}$ Die Bevölkerung war meist stark nationalistisch und entsprechend antiserbisch, antimontenegrinisch, antibulgarisch, antigriechisch und antikommunistisch eingestellt. ${ }^{347}$ Diese Einstellungen aufgreifend lehnte sich auch die deutsche Rhethorik an diese Tendenzen an, wie Malcom schreibt: „The German policy towards the newly acquired territory of Kosovo and Albania was to court the sympathy of the population by using the rhetoric of Albanian nationalism and Albanian independence [...].“348

Dass den Rekrutierungen auf albanischer Seite die Absicht eines ethnisch reinen Nationalstsaates und auf deutscher Seite der Instrumentalisierung ethnischer Konflikte zugrunde lag, zeigt ein Blick auf die Rekrutierungsräume. Im Kernland Albaniens konnte die Waffen-SS kaum Anhänger finden; ${ }^{349}$ die Rekrutierungen fanden an den Grenzen statt, wo Konflikte seit Jahrzehnten schwelten und bei jeder neuen Gelegenheit wieder aufflammten. ${ }^{350}$ Ausgehend von dieser Situation erklärte Fitzthum Himmler, dass die „Division Skanderbeck [sic] und weitere Divisionen [...] nur in [der Region] Kosovo aufgestellt werden [können].“351

345 Vgl. Besprechung Generalleutnant Meyszner, 21.2.1944, BArchF RW40/85, Bl. 104.

346 Vgl. Fernschreiben Fitzthum an Himmler, undatiert, BArchB, NS 19/1488, Bl. 1. Meyszners Aussage bezieht sich klar auf die Bewohner Nord- und „Neualbaniens“. Funkspruch Außendienststelle des BdS Cos.-Mitrovica, HSSPF Serbien SS-Gruppenführer Meyszner an Persönlicher Stab Reichsführer SS, 3.8.1943, BArchB, NS 19/2071, Bl. 1.

347 Vgl. Malcolm, Kosovo, S. $294 \mathrm{f}$.

348 Ebd., S. 304.

349 Vogel schreibt, dass er in Tirana kaum albanische Übersetzer für deutsche Dienste fand, da diese Anschläge fürchteten. Vgl. Vogel, Erinnerungen, S. $209 \mathrm{f}$.

350 Vgl. hierzu Zaugg, Albanische Muslime, S. 148-177.

351 Fitzthum an Himmler, undatiert, BArchB, NS 19/1488, Bl. 1. 
Einerseits handelt es sich dabei um die Teile Kosovos und des Sandžaks, die im April 1941 unter deutscher Militärherrschaft bei Serbien verblieben waren. Hier setzten die Rekrutierungen für Einheiten der Waffen-SS und Polizei am frühesten ein und waren am erfolgreichsten. Andererseits fanden in dieser Periode auch Rekrutierungen von Albanern aus den Teilen Kosovos statt, die 1941 als „neualbanische“ Gebiete in den „großalbanischen“ Staat unter italienischer Herrschaft eingegliedert worden waren. Weitere Rekrutierungen fanden aber auch in anderen Grenzregionen statt, die ebenfalls eine starke ethnische Durchmischung und anhaltende Konflikte aufwiesen, so etwa in von Albanern bewohnten montenegrinischen, mazedonischen und griechischen Grenzgebieten. Gute Erfolge für Verbände der Waffen-SS und Polizei erzielten die Werber beispielsweise in Kastoria in Nordgriechenland, ${ }^{352}$ denn „der südlichste Zipfel des Landes [Albanien], [war] schon vor dem griechisch-albanischen Krieg her ein fortdauernder Brandherd" und bot somit für Rekrutierungen eine geeignete Ausgangslage. ${ }^{353}$ Auch in Plevlja, einem Bezirk im montenegrinischen Teil des Sandžaks, wurde fleißig rekrutiert. ${ }^{354}$

Nebst der Abneigung gegenüber anderen Bevölkerungsgruppen und dem Nationalismus sollte die bereits 1941 von „Volkstumsreferent“ Feninger und Albanienkenner von Scheiger dokumentierte antiitalienische Einstellung im Kosovo-Gebiet und dem angrenzenden Sandžak ${ }^{355}$ nach Möglichkeit für deutsche militärische Zwecke genutzt werden. Rekrutierungen, die beidseitig der Demarkationslinie stattfanden, hatten heftige Auseinandersetzungen zwischen deutschen und italienischen Dienststellen zur Folge. ${ }^{356}$ Der italienische Botschafter in Berlin, Dino Alfieri, vermutete in Mitrovica gar ein „centro d'intrighi“, und auch Ciano ließ über den deutschen Botschafter in Rom Hans Georg von Ma-

$352 \mathrm{Zu}$ dieser Region finden sich zahlreiche Personendaten zur Rekrutierung durch die Waffen-SS im Archiv Prishtina. Vgl. Arkivi Kosoves, F: Dosjete robërve të luftës në Gjermani, V: 1940-1945, K: 1.

353 OB Südost, Bericht „Entwicklung der militärischen Lage in Albanien im Herbst 1944“, undatiert, BArchF, RW40/116a, Bl. 6.

354 Vgl. zu Rekruten aus Plevlja bspw. in AJ F 110, Box F694/J746, Box F699/J751, F702/J754, Box F704/J756, Box F723/J755, Box F729/781, F730/J782.

355 Vgl. Bericht ,über die Reise in das Arnautengebiet von Kosovska Mitrovica und Novi Pazar“ des Volkstumsreferenten Dr. Feninger beim Bevollmächtigten des AA in Belgrad, 15.-26.10.1941, PAAA, R261153, Bl. 50. Vgl. Bericht Franz von Scheigers an AA, 25.10.1941, PAAA, Altes Amt, Tirana 4/7, Bl. 255900 .

356 Vgl. bspw. Zur Rekrutierung von Albanern auch im italienischen Teil Kosovos: Berger an das AA, „Betreff: Freiwillige für die 13. (kroatische) SS-Division aus dem Sandžakgebiet“, 9.4.1943, PAAA, R100998, H297616. Ausführlich zu den Spannungen zwischen italienischen und deutschen Dienststellen im Kosovo- und Sandžak-Gebiet vgl. Zaugg, Albanische Muslime, S. 77-85. 
ckensen ausrichten, dass er im serbischen Teil Kosovos die deutsche Unterstützung einer albanischen Irredenta-Bewegung vermutete. ${ }^{357}$ Auch die Deutschen sparten nicht mit Vorwürfen und unterstellten den Italienern, im gleichen Gebiet Četnik-Verbände zu unterstützen, wie das deutsche Generalkonsulat in Tirana über Wegener ausrichten ließ:

Die Italiener verbreiten hier immer wieder Gerüchte, Deutschland wolle in Albanien Unruhen und italienfeindliche Demonstrationen hervorrufen [...]. In Mitrovitza [sic] bestehe Eindruck, dass Tschetniken [sic], die von albanischem und montenegrinischem Gebiet aus gegen Novipazar und Mitrovitza operieren, insgeheim von Italienern unterstützt wären. Dies ist hier nicht nachprüfbar und könnte, wenn zutreffend, gleichfalls Grund für uns verdächtigende Unterstellungen von Seiten der Italiener als Ausdruck ihres schlechten Gewissens sein. ${ }^{358}$

Von Bülow wandte sich schließlich in einem Schreiben an Ribbentrop, da „die Gefahr, dass aus dem Mitrovitza-Gebiet [sic] eine Quelle deutsch-italienischer Missverständnisse und Reibungen wird, [...] schon im Hinblick auf die unter den heutigen Verhältnissen im Balkan doppelt notwendige militärische und politische Zusammenarbeit mit den Italienern unter allen Umständen abgewendet werden“ musste. ${ }^{359}$ Im Bewusstsein, „mit unserem Bundesgenossen Italien auf Gedeih und Verderb verbunden“ zu sein, ließ der Bevollmächtigte Kommandierende General in Serbien Franz Böhme durch Major Parzer allen Offizieren der in der Region Kosovska Mitrovica liegenden Einheiten Befehle zum zukünftigen Verhalten gegenüber den italienischen Soldaten wie auch gegenüber den Albanern überbringen: Albaner etwa, die aus „Neualbanien“ in den serbischen Teil Kosovos zugewandert waren, sollten nicht mehr für militärische Einheiten geworben, sondern in den italienischen Teil Kosovos zurückgebracht werden. Im serbischen Teil Kosovos sollten zudem die Albaner dazu angehalten werden, ihren „disziplinlose[n] und wilde[n] Hass gegen alles, was nicht albanisch sei“,

357 Bericht italienischer Botschafter in Berlin, Dino Alfieri, an das italienische Außenministerium, 5.11.1941, ASD, AP, 1931-1945, Bulgaria, Busta 28, sottofasc. 2 „incidenti vari al confine“. Abschrift von Referent Geheimrat von Bülow an RAM Ribbentrop zur Vorlage, 20.11.1941, PAAA, R101024, Bl. 4.

358 Deutsches Generalkonsulat Tirana, in Vertretung: Wegener an Deutsche Botschaft in Rom, 12.11.1941, PAAA, Altes Amt, Tirana 4/3.

359 Abschrift von Aufzeichnung Ref.: G.R.v. Bülow an Ribbentrop, 20.11.1941, PAAA, R101024, Bl. 006. Die italienischen Anschuldigungen gegen das deutsche Vorgehen in Mitrovica 1941/ 1942 und der Unterstützung der dortigen antiitalienischen Bewegung rissen auch nach der italienischen Kapitulation nicht ab. Vgl. Bericht an das italienische Außenministerium, ohne Namensangabe, 19.4.1944, 19.4.1944, ASD, Albania Busta 51, fasc. Alb. 1/1, S. 2. 
abzubauen. Persönliche Kontakte zu italienischen Offizieren jenseits der Grenze sollten unterbunden, private Einladungen abgelehnt werden. ${ }^{360}$

Wie bereits gezeigt, rekrutierten die Deutschen in diesen Grenzregionen nicht nur Albaner, sondern auch Serben für ihre Dienste, unter anderem für das Serbische Freiwilligenkrops, die Serbische Staatswache (SSW) oder die Serbische Grenzwache. ${ }^{361}$ Teile des SFK wurden ebenfalls im Raum Nordkosovo/Sandžak rekrutiert, wo sie auch Verbrechen an Zivilisten begingen. Der Historiker Noel Malcolm erwähnt allerdings, dass die Angehörigen des SFK nicht allzu motiviert waren, in den Reihen der Deutschen zu kämpfen. So wären etwa von 200 „Freiwilligen“, die in Podujevo rekrutiert worden waren, auf dem Marsch nach Vushtrri/Vuçitrn 50 desertiert. ${ }^{362}$ Malcolm geht davon aus, dass sich bis Anfang 1943 ungefähr 25.000 Serben zu deutschen Kollaborationseinheiten gemeldet hatten, also zum SFK, der Serbischen Grenzwache oder der SSW. ${ }^{363}$ Im September 1943 meldete der Oberbefehlshaber Südost Felber nicht nur zahlreiche Desertionen aus der Serbischen Grenzwache und der Serbischen Staatswache, sondern auch Zusammenstöße zwischen Serbischer Grenzwache und der Albanischen Miliz im serbisch-albanischen Grenzgebiet in der Sandžak- und Kosovoregion:

Die Desertationen und Überläufe von Posten der Serbischen Staatswache und Serbischen Grenzwache haben in den letzten Tagen ein nicht mehr vertretbares Ausmaß angenommen. Außerdem ist es zu Zusammenstößen zwischen Serbischer Grenzwache und deutschen Zollbeamten einerseits und albanischer Miliz andererseits gekommen, die bei den gegenwärtigen Beziehungen zu Albanien vermieden werden müssen. ${ }^{364}$

Wenig später fürchteten die Deutschen, dass sich die Führer der SSW mit den Četniks verbünden könnten, was eine Zusammenarbeit mit beiden Gruppen in diesen Grenzgebieten weiter erschweren würde. ${ }^{365}$

Da man aus den Fehlern bei der Aufstellung der „Handschar“ gelernt hatte, sollten die Angehörigen der Division „Skanderbeg“ ihre Heimat nie verlassen und stattdessen in ihrer Herkunftsregion rekrutiert, ausgebildet und auch in diesem bürgerkriegsähnlichen Konflikt gegen ihre direkten Feinde, die Četnik-

360 Vgl. „Durchführung des Sonderauftrags des Bevollm. Kdr. General in Serbien an Major Parzer“, Parzer, 4.12.1941, BArchF, RW 40/23, 25 f.

361 Vgl. zum Serbischen Freiwilligenkorps (SFK) Malcolm, Kosovo, S. 295.

362 Vgl. Malcolm, Kosovo, S. 295.

363 Vgl. ebd., S. 297.

364 Militärbefehlshaber Südost, Felber an HSSPF und Verb.Beamter beim Zollgrenschutz, 13.9.1943, BArchF, RW40/80, Bl. 100.

365 Vgl. Militärbefehlshaber Südost, Abt. Ia, i.V. General der Artillerie an Höhere SS- und Polizeiführer, 11.2.1944, BArchF, RW40/85, Bl. 59. 
und kommunistische Partisanen-Verbände, eingesetzt werden. Man ging nämlich davon aus, dass die Rekrutierungsquoten in Bosnien so stark zurückgegangen waren, weil sich in der Bevölkerung das Gerücht verbreitet hatte, die SS-Freiwilligen würden ihre Heimat nie wieder sehen, sondern auf den Schlachtfeldern Russlands oder Frankreichs sterben. ${ }^{366}$ Der Rekrutierungs- sowie später der Divisionsstab der „Skanderbeg“ wurden schließlich in Prizren aufgebaut. Neubacher berichtete nach dem Krieg, dass auch eine Verlegung der Division nach Mitrovica zur Diskussion gestanden hätte, er diese aber verhinderte, ,weil ich Ausschreitungen gegen die serbische Bevölkerung befürchtete. Serben und Skipetaren lieben sich nicht. “367

Bei den Werbungen sollte es sich nicht in erster Linie um eine Freiwilligenwerbung handeln, sondern der Dienst in der Waffen-SS sollte vielmehr als regulärer Militärdienst dargestellt werden. Das „Zentralkomitee zur Verteidigung Kosovos“ bat daher, „das Wort ,Freiwillige“ aus dem Vokabular unserer militärischen Organisation zu löschen“. ${ }^{368}$ Das „Komitee“ versicherte außerdem, die Bevölkerung Kosovos hätte grundsätzlich akzeptiert, dass alle männlichen Einwohner zwischen 15 und 60 Jahren mobilisiert werden sollten. Von einer Rekrutierung auf freiwilliger Basis sollte deshalb abgesehen werden, da den Vertretern des „Komitees“ eine angeordnete Einberufung auf nationaler Basis mit weniger Aufwand mehr Erfolg versprach. ${ }^{369}$ Pejani wollte damit außerdem vermeiden, dass sich nur „gesellschaftlicher Abschaum“ zum Dienst meldete. ${ }^{370}$

Nach einer Besprechung zwischen Fitzthums Erstem Generalstabsoffizier, SS-Hauptsturmführer Christian Wirth, und dem „Nationalen Verteidigungskommando“ wurden in der Folge die Jahrgänge 1918, 1919 sowie 1922 bis 1927 für die Rekrutierungen vorgesehen. Der Jahrgang 1920 wurde ebenfalls zur Werbung freigegeben, soweit dieser nicht bereits unter Waffen stand. ${ }^{371}$ Das „Zentralkomitee“ entschied, dass „die Gründung dieser Division durch die von unserem

366 Salihbegovic, „Bericht zur Lage“, 25.9.1943, BArchB, NS 19/2601, Bl. 31.

367 Neubacher, Sonderauftrag Südost, S. 116. Vgl. Schreiben Colonel Qazim Komani, 29.03.1944 A.Q.SH., F. 160, V. 1944 D 32, S. 1.

368 Sitzung des „Zentralkomitees zur Verteidigung Kosovos“, Nr. 14, 30.03.1944 A.Q.SH., F. 147, V. 1944 D I-165, S. 15.

369 Ebd.

370 Vgl. Bedri Pejani an Ministerpräsident Rexhep Mitrovica, 23.5.1944, A.Q.SH. F.147, 1944, D I-165, Bl. 16.

371 Vgl. „Werbung für die Waffen-Gebirgsdivision SS ,Skanderbeg““, Fitzthum an das Nationale Verteidigungskommando, z. Hd. Generalstabschef General Gustav von Myrdazc, 15.4.1944, A.Q. SH., F.160, 1944, D 32, Bl. 5. Vgl. Schreiben Reichels, Referat Inland IIc, 6.4.1944, PAAA, R100984, Bl. H298869. In einem Schreiben von Reichels ist hingegen nur von den Jahrgängen 1920-1924 die Rede. Vgl. Schreiben Reichels, Referat Inland IIc, 6.4.1944, PAAA, R100984, Bl. H298869. 
Rekrutierungsbüro angewandten Vorgehen, auf dieselbe Weise wie auch die Regimenter unserer nationalen Armee aufgebaut wurden, oder auf sonstigen in der Verfügung des Ministeriums für Inneres Nr. 771 vom 24. März 1944 festgelegten Wegen, d.h. durch die Rekrutierung von Freiwilligen“ aufgebaut werden sollte. ${ }^{372}$

Auf Druck der „Zweiten Liga“ und des „Zentralkomitees zur Verteidigung Kosovos“ beschloss die albanische Regierung, den Dienst in der „Skanderbeg“ als regulären Militärdienst zu betrachten. Basierend auf dieser Entscheidung wurden auch die Angehörigen der Albanischen Miliz, nachdem diese im Frühsommer 1944 aufgelöst worden war, als „Freiwillige“ der „Skanderbeg“ zugeführt. ${ }^{373}$ In einem Schreiben des Kommandierenden Generals der „Nationalen Verteidigung“ Prenk Pervizi heisst es, dass diesen Soldaten ein freiwilliger Übertritt in die „Skanderbeg“ nahegelegt wurde. Stimmten sie diesem nicht zu, sollten sie ganz aus dem Dienst entlassen werden. ${ }^{374}$

Dass es noch im Juni 1944 auch echte Freiwillige gab, zeigt ein Schreiben Neubachers an das Auswärtige Amt: Muslime aus dem Grenzgebiet des von Bulgarien besetzten Mazedonien baten um Aufnahme in die Division „Skanderbeg“. ${ }^{375}$ Selbst im Herbst 1944 rapportierte Schmidhuber noch, dass durch „das Verhalten der kommunistischen Banden, welche unklugerweise über bisher gleichermaßen deutsch- und kommunistenfeindliche Banden hergefallen sind und ihre Dörfer niedergebrannt haben“, sowie durch die Zurücknahme der Etappen-Einrichtungen aus dem Raum Kosovo die Rekrutierungsbereitschaft in der albanischen Bevölkerung in den letzten Monaten deutscher Besatzung noch einmal gestiegen sei. ${ }^{376}$

372 Sitzung des „Zentralkomitees zur Verteidigung Kosovos“, Nr. 14, 30.03 .1944 A.Q.SH., F. 147, V. 1944 D I-165, S. 15.

373 Schreiben Kommandeur Kommandeur Nat. Vert. General Prenk Pervizi an Kdo.st. Abt. Kos. und weitere, 20.5.1944, A.Q.SH. F.160, 1944, D 32, Bl. 31.

374 Schreiben Kdr. Nat. Vert. General Prenk Pervizi an Kdo.st. Abt. Kos. und weitere, 20.5.1944, A. Q.SH. F.160, 1944, D 32, Bl. 31. Vgl. auch Schreiben von Myrdacz und Pervizi, unterzeichnet und durch Major Haki Kaziaj (i. A. Leiter der Mobilisierungsstelle) beglaubigt, an Oberst Hamid Tirana, Leiter der Mobilisierungsstelle, 8.5.1944, A.Q.SH., F.160, 1944, D 32, Bl. 22.

375 Vgl. Neubacher an AA, 30.6.1944, PAAA Inland IIg R100696. Ein Beispiel liefert auch der Fall von Kadri Rexhep Abdullahu, der aus der albanischen Wehrmacht entlassen werden wollte, um in den Verbänden der Waffen-SS zu kämpfen. Als ihm die Entlassungsprozedur zu lange dauerte, floh er und meldete sich in der Kaserne der SS in Peć. Vgl. Schreiben des Kommandeurs Lagers des 1. Reg., Major Neshet Hasho an Kommandostelle Abt. Kos. Prizren, zur Kenntnisnahme an Rekrut.st. 6 Prizren, Rekr.st. Pristina, 7.6.1944, A.Q.SH., F.160, 1944, D 32, Bl. 18. 376 Schmidhuber, „Zusammenfassender Bericht“, 2.10.1944, BArchF, RS3-21/1, S. 6. Vgl. ebd., S. 8. 
Obwohl sich die Rekrutierungsanstrengungen grundsätzlich auf „Neualbanien“ und die angrenzenden Gebiete beschränkten, sind auch Freiwilligenzugänge aus „Altalbanien“ belegt: so zum Beispiel Schmidhubers Übersetzer, SS-Hauptsturmführer Thela Decg, Sohn einer Österreicherin und aus einer Großgrundbesitzerfamilie in Südalbanien stammend, der in Wien studiert hatte. ${ }^{377}$ Auch Erhard Hoffmann erwähnte in einem Funkspruch an Backhausen die Ankunft von Freiwilligen aus „Altalbanien“, und informierte darüber, dass es „sich durchwegs um junge, mutige, antikommunistisch eingestellte Männer aus Altalbanien [handelte], die sich außerordentlich gut bewähren werden“. ${ }^{378}$

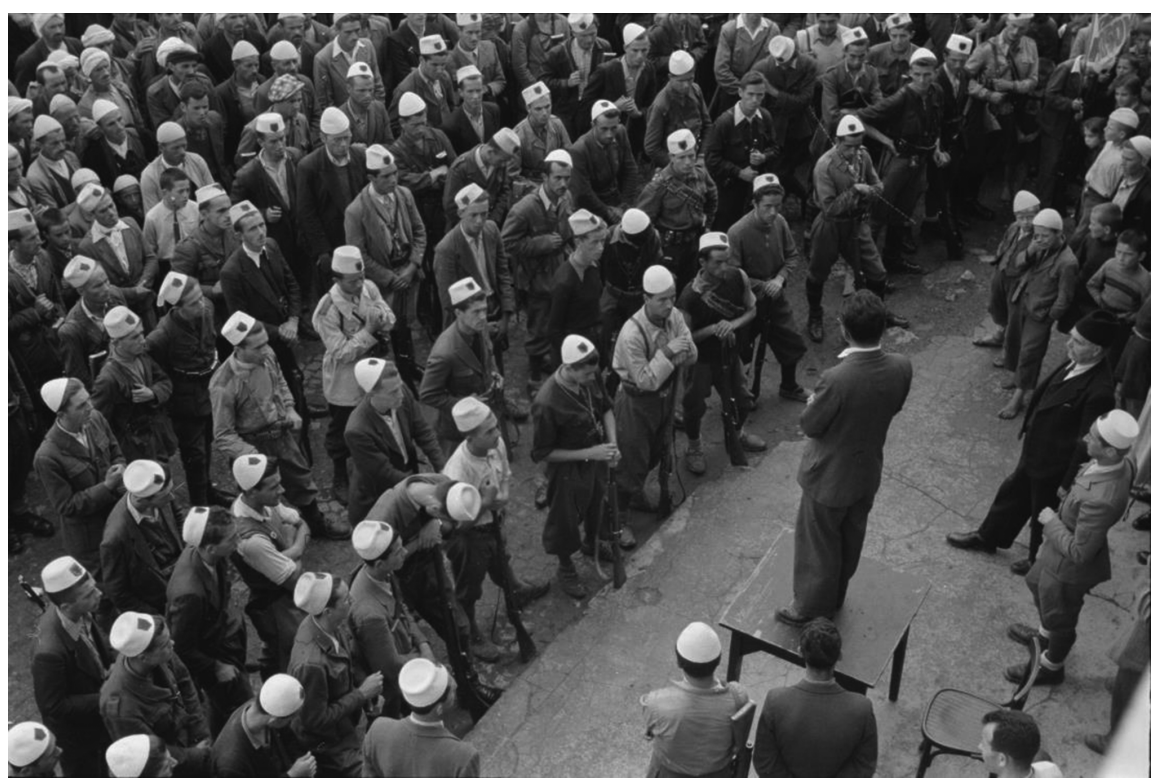

Abb. 30: Rekrutierung in Mitrovica, Xhafer Deva spricht zu den Rekruten. ${ }^{379}$

377 Vgl. Brief Kopf an Vopersal, 4.7.1976, BArchF, N 756-182a.

378 Funkspruch Meldekopf Rožaje, Hoffmann an Backhausen, Abschrift an Bendl, 11.7.1944, BArchF, R S3-21/2, Bl. 16. Auch Kühmel bestätigt den Beitritt von Freiwilligen aus „Altalbanien“ in die "Skanderbeg“, obwohl dies von der albanischen Regierung abgestritten worden sei. Vgl. Kühmel, Deutschland und Albanien, S. 310. Vgl. auch Zaugg, Albanische Muslime, $204 \mathrm{f}$.

379 ECPAD, LFT SO F2684 L03. 


\subsubsection{Werbung durch Flugblätter, Pamphlete und Karikaturen}

In der oft antikommunistisch eingestellten Bevölkerung Nord- und „Neualbaniens“ hofften die Deutschen, durch gezielte antikommunistische Propaganda willige Helfer $\mathrm{zu}$ finden. Ein Mitarbeiter im Stab des DGA, Rudolf Vogel beklagte später, dass den britischen Verbindungsoffizieren pro Person für Werbung und Propaganda 10.000 englische Goldpfund zur Verfügung standen, während den deutschen Stellen „für die gesamte gedruckte Propaganda [...] auf deutscher und albanischer Seite ein Monatsbetrag von lächerlichen 50.000 albanischen Papierfranken bewilligt“ wurde. ${ }^{380}$ Im Folgenden sollen einige Beispiele von Flugblättern und Plakaten die Werbeanstrengungen der Deutschen veranschaulichen:

Flugblatt Nr. 1

Albaner!

Landfremde Agenten haben sich bei Euch eingenistet und wollen Eure Seelen mit verlogenen Phrasen vergiften und Euren Verstand mit betrügerischen Verbrechen einnebeln. Der Bolschewismus, der die ganze Welt einnehmen will, hat seine Fühler auch nach Albanien ausgestreckt. Wir deutschen Soldaten, die wir an der Ostfront die europäische Kultur gegen Sowjethorden schützen, können euch aus eigener Anschauung einiges über den Bolschewismus sagen, was Ihr unbedingt wissen müsst.

Der Bolschewismus bedeutet die Vernichtung der nationalen Freiheit. Jedes nationale Fühlen und Denken wird von der berüchtigten Sowjetpolizei durch Mord und Terror ausgelöscht.

[...]

Albaner!

Auch mit Euch würden die Bolschewisten keine Ausnahme machen, wenn sie über Albanien herrschen würden.

Ihr würdet Eure nationale Unabhängigkeit verlieren. Moskauer Funktionäre würden Euch nach Moskauer Gesetzen regieren. Die albanische Sprache, Sitte und Kultur würden in kurzer Zeit verschwinden. [...]

unterzeichnet, Deutscher Bevollm. Gen. Albanien“381

380 Vogel, Erinnerungen, S. 211.

381 Ohne Unterschrift, Fernschreiben der 118. Jäg.Div.Abt. Ia vom 5.10.1943, 12.15 Uhr an 297. Inf.Div. Abt. Ia, BArchF, RH26-181/38. 


\section{Flugblatt Nr. 2}

Churchill und Stalin wollen bis zum letzten Albaner kämpfen! Es ist eine alte englische Methode, andere für sich kämpfen zu lassen. So hat England die Polen, Holländer, Belgier, Franzosen und Serben in den Krieg gegen Deutschland gehetzt.

Ständig sucht es nach neuen Blutspendern und Opfern. Auch Albanien soll vor den englischen Kriegswagen gespannt werden und den britischen Weltbeherrschungsplänen dienen. Daher überschwemmt London Albanien mit Lügenpropaganda.

[...]

Albaner! Ihr habt bewiesen, dass Ihr politisch zu denken versteht. Hättet Ihr den englischen und bolschewistischen Aufforderungen Folge geleistet, das Ergebnis wäre Not, Tod und Elend für Euch gewesen.

Die deutsche Wehrmacht schlägt jeden Aufstand nieder.

Denkt an Kruja! In Kruja haben die Rebellen erfahren, was es heißt, sich gegen die deutsche Wehrmacht zu erheben.

Mischt Euch nicht in die Auseinandersetzungen zwischen Deutschland und seinen englisch-bolschewistischen Gegner ein. Deutschland ist Euer bester und aufrichtigster Freund. Ihr seid jetzt ein freier und unabhängiger Staat. Das wird Albanien bleiben, wenn Ihr Ruhe und Ordnung im Lande haltet und Deutschland in seinem Kampfe gegen England und die Sowjetunion, die auch Eure Feinde sind, nicht stört.

Wenn Ihr dagegen feindliche Aktionen gegen die deutsche Wehrmacht unternehmt, so werdet Ihr schwer dafür büßen müssen.“382

382 Übersetzung Flugblatt, ohne Datierung, ohne Unterschrift, Fernschreiben der 118. Jäg.Div. Abt. Ia vom 5.10.1943, $12.15 \mathrm{Uhr}$ an 297. Inf.Div. Abt. Ia, BArchF, RH26-181/38. 


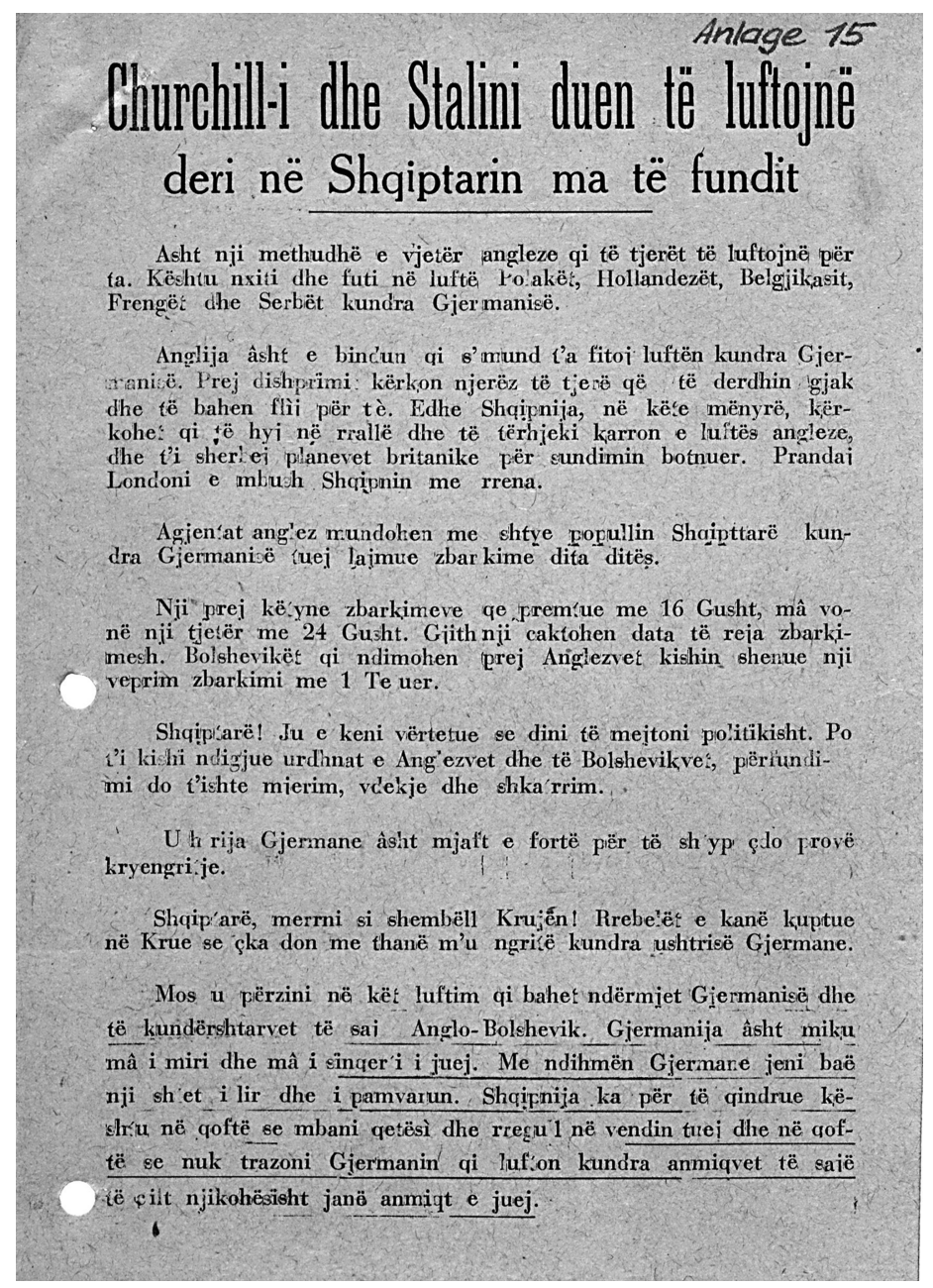

Abb. 31: Flugblatt Nr. 2 „Churchill und Stalin wollen bis zum letzten Albaner kämpfen““.383

383 Original des Flugblatts Nr. 2, ohne Datierung, ohne Unterschrift, Fernschreiben der 118. Jäg.Div.Abt. Ia vom 5.10.1943, 12.15 Uhr an 297. Inf.Div. Abt. Ia, BArchF, RH26-181/106. 


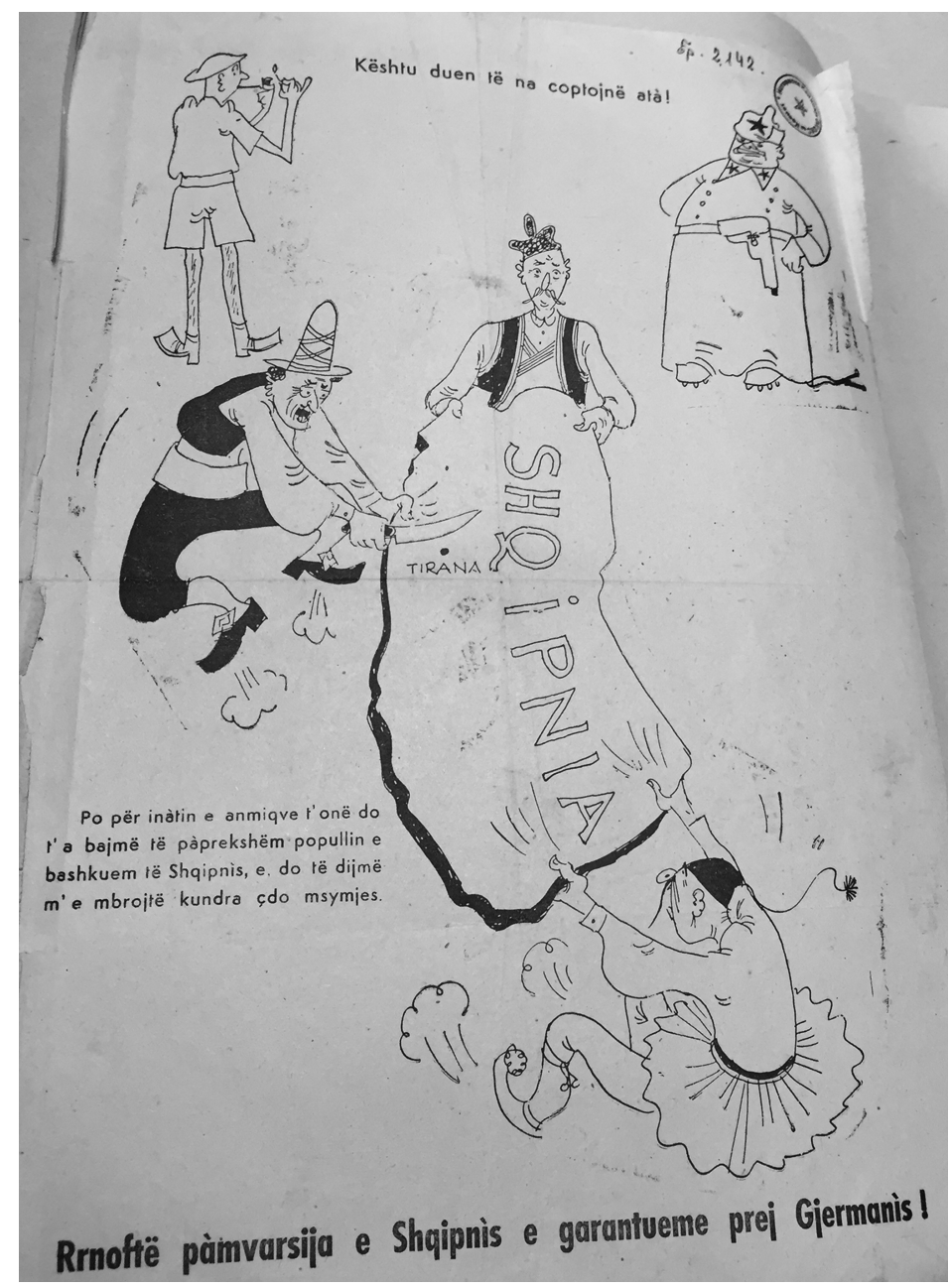

Abb. 32: Flugblatt Nr. 3 „So wollen sie es auseinanderreissen!“ - „Erhöht die Unabhängigkeit Albaniens, die von Deutschland garantiert wird!.“384

384 Arkivi Kosoves, F: Njësit dhe Brigadat, V: 1941-1945, K: 37, fl. 2142. 
Flugblatt Nr. 4

Mit Hilfe Deutschlands erlangt Albanien seine Freiheit wieder. Das Große Deutsche Reich garantierte die Unabhängigkeit Albaniens.

Freiheit ist das Kostbarste für Albanien!

Diese Freiheit muss zunächst von den Albanern selbst vor dem inneren Feind geschützt und gestärkt werden.

Der gefährlichste Feind der albanischen Freiheit ist der Bolschewismus!

Dieser versucht unter dem Deckmantel nationaler Ideale und mit falschen Versprechungen, Macht und Freunde für seine wahren Ziele und Bestrebungen zu gewinnen.

Albaner, ihr kennt den Bolschewismus immer noch nicht gut.

Der Bolschewismus in Albanien würde die Menschen, die Familien, den Glauben und die Bräuche zerstören, Albanien zu einer Provinz Russlands machen und unter die Hufe Moskaus stellen. Dies ist es, was die kommunistischen Agenten und Führer, die heute von Moskau bezahlt werden, vor euch verstecken, die alle echten Albaner gegen sich selbst hätten, wenn sie es auch nur indirekt gezeigt hätten. Sie werden als Werkzeuge des Kommunismus gegen die Ruhe und Sicherheit Albaniens eingesetzt und stiften zum Brudermord und gegen die Freiheit Albaniens an.

Macht deshalb alle aufmerksam, die nicht wissen, warum sie Kommunisten sind und warum sie sich von Moskau wie blinde Werkzeuge täuschen lassen.

Stellt euch hinter eure Nationalversammlung, hinter die Männer, die jeden Teil eures Landes vertreten, damit das Schicksal der Albaner in den Händen albanischer Führer liegt. Identifiziert und eliminiert die wirklichen Kommunisten, zeigt uns die Verstecke und ihre Zentren, damit wir die bolschewistische Cholera ausmerzen können. 


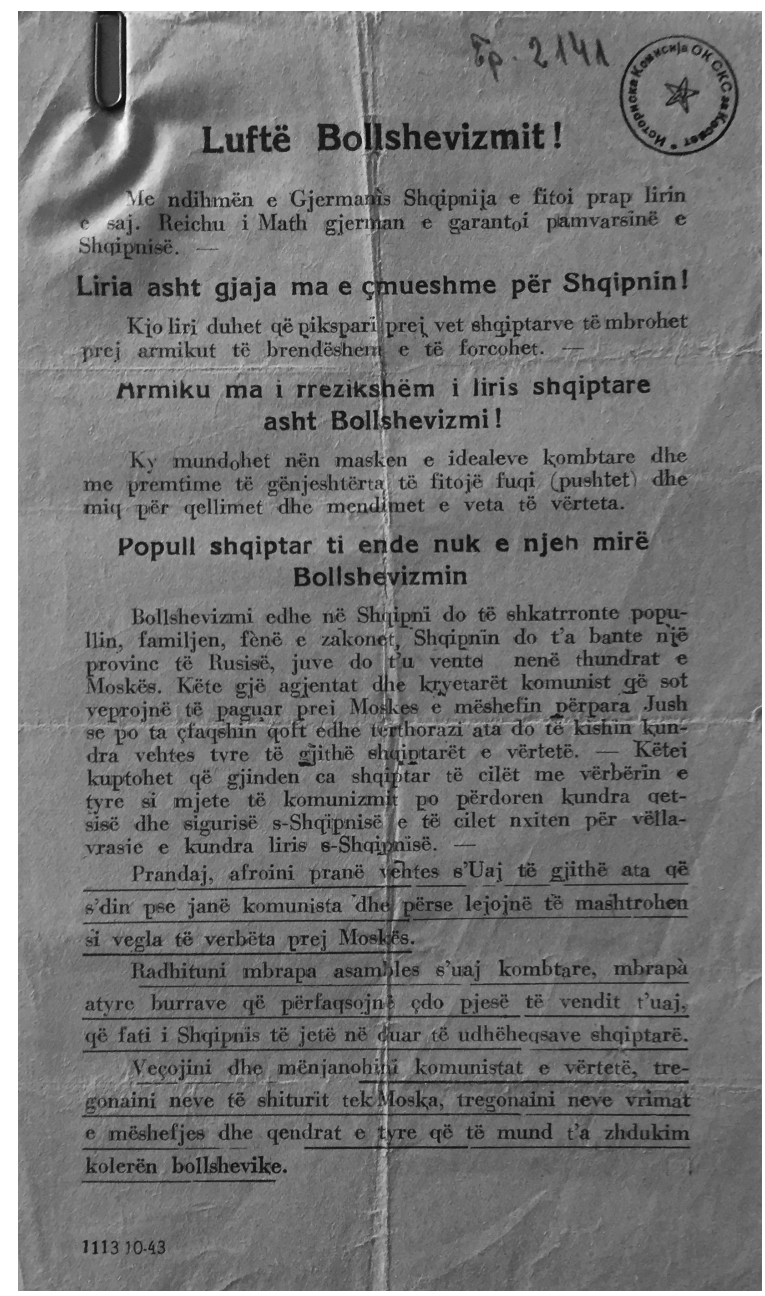

Abb. 33: Flugblatt Nr. 4 „Krieg dem Bolschewismus!“, Oktober 1943. ${ }^{385}$

385 Arkivi Kosoves, F: Njësit dhe Brigadat, V: 1941-1945, K: 37, fl: 2141. 


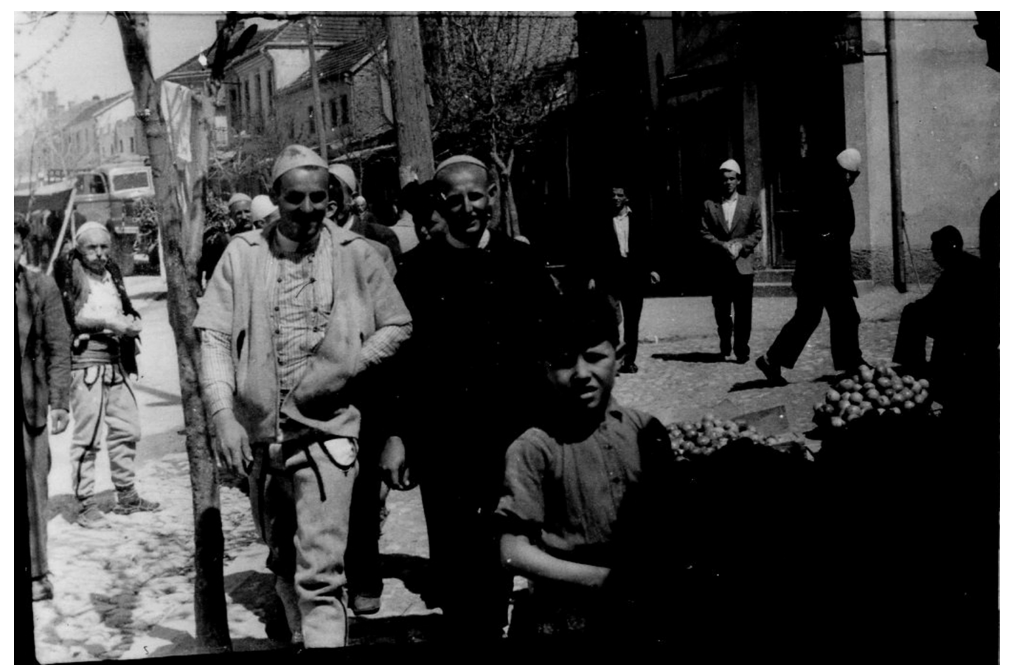

Abb. 34: Zwei Rekrutierungswillige werden von Kriegsberichter Westermann bei ihrem Gang zum Rekrutierungsbüro aufgenommen, Mai $1944 .{ }^{386}$

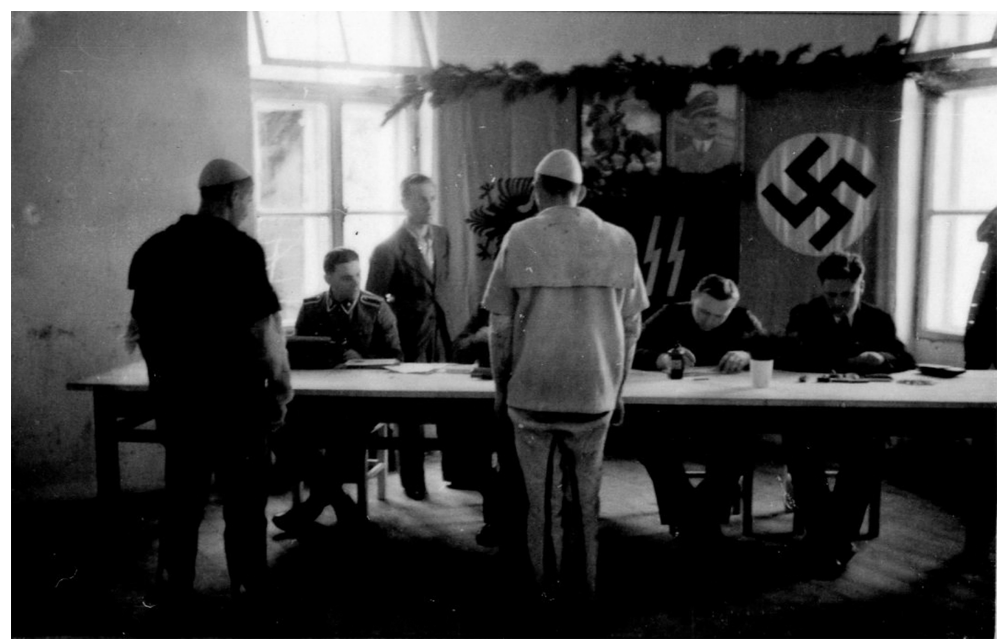

Abb. 35: Die beiden Rekrutierungswilligen im Rekrutierungsbüro Prizren. ${ }^{387}$

386 Kriegsberichter Westermann, NARA, Nr. 39A.

387 Kriegsberichter Westermann, NARA, Nr. 17A. Vgl. auch Nachlass Vopersal, BArchF, N 756/182b. 


\subsubsection{Probleme bei der Werbung und die Rolle der „Zweiten Liga“ dabei}

Trotz Himmlers und Bergers Maßnahmen, die Division „Skanderbeg“ mit nationalen Symbolen zu schmücken und der von staatlicher Seite angeordneten Einberufung bzw. der Idee, den Dienst in der Waffen-SS als regulären Militärdienst zu deklarieren, blieb die Division weit hinter ihrem Soll zurück. Dreieinhalb Monate nach Beginn der Rekrutierungen, Mitte August 1944, stellte der Chef des Generalstabes des XXI. Gebirgskorps, Oberst Franz von Klocke fest, dass die „Skanderbeg“ immer noch in der Aufstellung begriffen sei. Bis auf das StammBataillon mit den Albanern aus der „Handschar“ hätte sie noch keinen Kampfwert und würde zur Zeit noch mit „große[n] personelle[n] und materielle[n] Schwierigkeiten“ kämpfen. ${ }^{388}$ Bis zum 25. September 1944 wurden insgesamt nur 11.398 Männer gemustert. 9.275 davon wurden als tauglich befunden und einberufen. Davon rückten letztlich nur 6.491 Mann ein. ${ }^{389}$ Auch die vom „Zentralkomitee“ unter der Führung Pejanis zugesicherte Rekrutierungsquote von 10.000 Mann per 1. Mai 1944 wurde nicht eingehalten, ${ }^{390}$ weil die Deutschen die von Pejani gestellten Forderungen - vor allem diejenige nach einer erneuten „Berichtigung“ des Grenzverlaufs zugunsten „Großalbaniens“ - nicht erfüllen konnten. ${ }^{391} \mathrm{Da}$ nun weder die albanischen Behörden noch das „Komitee“ aktiv wurden, musste Schmidhuber die Bevölkerung ,persönlich in öffentlichen Reden auf den Wochenmärkten aller Städte Kosovos“ „über den Zweck und das Ziel der Aufstellung einer albanischen SS-Division“ aufklären. ${ }^{392}$ Ein Bericht der Polizeipräfektur des Kreises Prizren bestätigt, dass Schmidhuber am 31. Mai 1944 auf dem Hauptplatz von Prizren eine Rede für die zum Einkaufen auf dem Markt anwesende Menge gehalten habe, in der er die Gründe für den Aufbau einer SS-Division darlegte. ${ }^{393}$

388 Chef des Generalstabes des XXI. Geb.AK, Oberst von Klocke, 15.8.1944, NARA, T314/664, Bl. 565.

389 „Zusammenfassender Bericht“ Schmidhuber, 2.10.1944, BArchF, RS 3-21/1, S. 3f. Die Partisanen der kommunistischen albanischen „Nationalen Befreiungsfront“ hingegen verfügten nach offiziellen Angaben am Ende des Krieges über 70.000 Mann. Vgl. Neuwirth, Widerstand und Kollaboration, S. 203. Auch Titos Partisanenverbände waren bereits zur Jahreswende 1943/ $44 \mathrm{zu}$ einer Gesamtstärke von fast 250.000 Mann angewachsen. Vgl. Schmider, Der jugoslawische Kriegsschauplatz, S. 1028.

390 Vgl. „Zusammenfassender Bericht“ Schmidhuber, 2.10.1944, BArchF, RS 3-21/1, S. 3 f.

391 Vgl. Pejani, Forderungen der „2. Liga von Prizren“, 14.2.1944, A.Q.SH. F.149, 1944, D I1317, Bl. 1. Vgl. Verschiedene Schreiben zu den Forderungen der „2. Liga von Prizren“, Mai 1944, BArchF, RH 19-XI/10b, Bl. 99-106.

392 „Zusammenfassender Bericht“ Schmidhuber, 2.10.1944, BArchF, RS 3-21/1, S. 3.

393 Vgl. Bericht der Polizeidirektion des Kreises Prizren vom Mai 1944, 1944, A.Q.SH. F.153, 1944, D 141, Bl. 11. 
Hausding erwähnte außerdem, dass bei der zumeist analphabetischen Bevölkerung jede Nachricht durch „Mund zu Mund Propaganda“ verbreitet werden musste, und eine Verbreitung wichtiger Neuigkeiten somit hauptsächlich auf Märkten stattfand. ${ }^{394}$

Die Passivität öffentlicher Institutionen ging noch weiter: Musterungstermine wurden nicht eingehalten, und Schmidhuber beschwerte sich, dass die Behörden „nur mittelmäßiges und unansehnliches Menschenmaterial“ zu den Aushebungen schicken würden. ${ }^{395}$ Obwohl die Rekrutierungen vordergründig von staatlicher Seite angeordnet worden waren, erklärte Schmidhuber rückblickend, dass die Repräsentanten staatlicher Institutionen auf Gemeindeebene nichts unternahmen, um Männer, die sich der Einberufung widersetzen, zu verhaften und der Truppe zuzuführen.

Eine solche Passivität der Präfekten und Bürgermeister musste natürlich für die Masse der Bevölkerung eine stillschweigende Aufforderung bedeuten, ihrerseits die Aufstellung der Division ebenfalls als eine inoffizielle Nebensächlichkeit $\mathrm{zu}$ betrachten und sie entsprechend zu ignorieren. ${ }^{396}$

Das städtische Großbürgertum und die ländlichen Eliten, organisiert in der „Zweiten Liga“, hatten zudem ihre eigenen Pläne: Zwar unterstützten sie den Aufbau einer albanischen Waffen-SS-Division als Grundlage einer albanischen Nationalarmee, ihre eigenen Söhne wollten sie aber nicht in die „Skanderbeg“ schicken: „Wo Interesse hierfür [die Rekrutierung] bestand, schuf es Erbitterung, dass nur die Armen einberufen wurden, während die Söhne der Begs [Bajraktare] und der städtischen Kaufleute sich durch Beziehungen und Bestechungen vom Wehrdienst freimachten. “397

Im Frühling 1944 war es weit schwieriger, albanische „Freiwillige“ $\mathrm{zu}$ finden als noch ein oder zwei Jahre zuvor. Die Situation hatte sich grundlegend verändert: Lebensmittel, Bekleidung, aber auch Bewaffnung und Ausrüstung waren nur noch beschränkt vorhanden und nur unter Schwierigkeiten und in unzureichenden Mengen zu beschaffen. Schließlich blieben auch Sold und Familienzulagen aus. ${ }^{398}$ Somit fielen jetzt wesentliche Motivationsgrundlagen, die einen Eintritt in die Waffen-SS förderten, weg.

394 Lagebericht des Außenkommandos Kosovska-Mitrovica für August 1942, Hausding, 27.8.1942, USHMM/BArchL, B162/15.668, Bl. 41.

395 „Zusammenfassender Bericht“ Schmidhuber, 2.10.1944, BArchF, RS 3-21/1, S. 3.

396 Ebd.

397 Ebd.

398 Vgl. „Betreff: Freiwillige für die 13. (kroatische) SS-Division aus dem Sandžakgebiet“, Schreiben Berger an das AA, 9.4.1943, PAAA, R100998, Bl. H297616. Vgl. „Zusammenfassender Bericht“ Schmidhuber, 2.10.1944, BArchF, RS 3-21/1, S. 4. 
Ein weiteres wesentliches Merkmal hebt die Division „Skanderbeg“ bei den Werbungen von ihrer Schwesterdivision „Handschar“ ab: die fehlende Präsenz des Großmufti. Sind sein Werben und Walten, seine Einsprüche und sein Mitgestalten für die Division „Handschar“ mannigfaltig belegt, so fehlt sein Auftreten bei der „Skanderbeg“ ganz. Natürlich ist der Schluss naheliegend, dass bloß die Belege fehlen, da die Dokumentation der Geschichte der „Skanderbeg“ als lückenhaft $\mathrm{zu}$ bezeichnen ist und auch Akten willentlich vernichtet wurden. ${ }^{399}$ Allerdings gibt es auch Aussagen, welche die Annahme bestätigen, dass die Nationalsozialisten bewusst auf die Zusammenarbeit mit al-Huseini in Albanien verzichteten. So schrieb beispielsweise Dr. Franz Schmidt-Dumont im Juni 1944, dass Werbungen, bei welchen der Großmufti als Galionsfigur involviert wäre, an den „kaum vernarbten Wunden“ der osmanischen Besatzung rühren würden. ${ }^{400} \mathrm{Au}$ ßerdem machte Vizeaußenministers Mehdi Bej Frashëri die deutschen Besatzer darauf aufmerksam, dass Albanien als säkularisierter Staat zu sehen sei, in welchem Religion eine untergeordnete Rolle spielte. ${ }^{401}$

\subsection{Ausbildung}

Sowohl Schmidhuber als auch von Pistor machten vor allem die viel zu kurze und nur oberflächliche Ausbildung für die hohen Verluste innerhalb der Division „Skanderbeg“ verantwortlich. ${ }^{402}$ Die Rekrutierten wurden bereits Mitte Juli 1944, nach nur sechs Wochen Ausbildung, in die ersten Einsätze geschickt. ${ }^{403}$ Nur diejenigen Soldaten, die vorher bereits in der Division „Handschar“ oder in der jugoslawischen Armee gedient hatten, verfügten über eine fundiertere Ausbildung. ${ }^{404}$

Für das Scheitern der Ausbildung und der Diszplinierung der Soldaten führt Schmidhuber zwar einerseits den Zeitdruck und den Mangel an geeigneten Ausbildern an, argumentiert aber andererseits auch anhand völkisch-rassischer bzw.

399 So schreibt der Divisionsangehörige Arnemann rückblickend: „Wir übernahmen die Sicherung der Ortschaft, während im Laufe des Tages vom Stammpersonal ,Skanderbeg‘ schriftl [iches] Material vernichtet wurde.“ Arnemann an Vopersal, 19.1.1982, BArchF, N 756/182a.

400 Vgl. Abteilung Ausland, Schmidt-Dumont, Aufzeichnung, Berlin, 1. Juni 1944, BStU, AS Nr.456/66, Bl. 97.

401 Vgl. Andor Hencke, Leiter Politische Abteilung an das AA, Inland IIc, 4.3.1944, PAAA, R100649, Bl. 000022.

402 Vgl. Brief von Pistor an Vopersal, undatiert, BArchF, N 756/182b.

403 Vgl. „Zusammenfassender Bericht“ Schmidhuber, 2.10.1944, BArchF, RS 3-21/1, S. 5.

404 Vgl. hierzu die Aussage Schmidhubers, der den ehemaligen Kriegsgefangenen aus der jugoslawischen Armee einen guten Kampfwert attestierte. Schmidhuber, Abschließender Gefechtsbericht des Unternehmens „Draufgänger“ vom 18. bis 28. Juli 1944, NARA, T314/664, F. 293 f. 
kolonialistischer Erklärungsmuster. Er war schließlich der Meinung, dass auch bei genügend Zeit und ausreichend Ausbildungspersonal die Albaner durch ihre Einbindung in traditionelle Stammesstrukturen nicht fähig bzw. nicht gewillt gewesen wären, in einem größeren militärischen Verband zu kämpfen. ${ }^{405}$

Neuaufstellungen von Divisionen bedeuteten 1944, dass Ausbildungspersonal bei bestehenden Einheiten abgezogen wurde, und entsprechend zwar einen Zuwachs bei der einen, aber den Verlust von erfahrenem Personal bei anderen Einheiten bedeutete, womit sich das Personalproblem letztlich nur verschob. ${ }^{406}$ Auch im Fall der „Skanderbeg“ wurde Personal durch das SS-Hauptamt unter anderem aus der „Handschar“ und der „Prinz Eugen“ zur „Skanderbeg“ versetzt. ${ }^{407}$ Aufgrund des akuten Personalmangels übernahmen auch Deutsche, die vorher für administrative Aufgaben ausgebildet worden waren, kurzerhand Ausbildungsfunktionen. ${ }^{408}$ Der Mangel an Ausbildern war, wie bereits oben beschrieben, kein balkanspezifisches Problem. Vielmehr war er Ausdruck der inneren Strukturkrise, in der sich die Waffen-SS Anfang 1944 seit längerem befand, die durch die horrenden Verluste und das kontinuierliche Aufstellen neuer Verbände noch verschärft wurde. ${ }^{409}$ Die prekären Verhältnisse in Albanien in Bezug auf Ausbildung, Ausbilder, Ausrüstung und Truppenunterkünfte waren somit kein Spezifikum der Lage in Südosteuropa, sondern eher ein Spiegelbild eines gesamteuropäisch zum Vorschein tretenden Mangels innerhalb der Waffen-SS im letzten Kriegsjahr, der sich seit Ende 1942, als die Waffen-SS auf Führerebene bereits mit substanzbedrohenden Verlusten kämpfte, zugespitzt hatte. ${ }^{410}$ Drei bis vier Monate dauerte es durchschnittlich, bis ein Kompanie- oder Bataillonsführer durch Tod, Verwundung oder Abkommandierung zu einer anderen Einheit ausfiel. Gleichzeitg forderte aber der stete Ausbau der Waffen-SS immer mehr Personal, was sich nicht zuletzt auch auf die Altersstruktur auswirkte: Mitte 1943 lag das Alter von Regimentskommandeuren oft bei 31 oder 32 Jahren, Bataillons- und Abteilungskommandeure waren vielfach 30 Jahre alt oder jünger. ${ }^{411}$ Unter der massenhaften Beförderung von Unterführern zu Führern und der Versetzung

405 Vgl. „Zusammenfassender Bericht“ Schmidhuber, 2.10.1944, BArchF, RS 3-21/1, S. 2.

$406 \mathrm{Vgl}$. Wegner, Hitlers politische Soldaten, S. 287.

407 Vgl. „Zusammenfassender Bericht“ Schmidhuber, 2.10.1944, BArchF, RS 3-21/1, S. 4.

408 Vgl. ebd. Vgl. Brief Pistor an Vopersal, undatiert, BArchF, N 756/182b. Siehe hierzu außerdem ausführlich Kapitel „Deutsches Stammpersonal“.

$409 \mathrm{Vgl}$. Wegner, Hitlers politische Soldaten, S. 284f. Zum Mangel an deutschen Ausbildern in der „Skanderbeg“ vgl. Kriegsgefangenenbericht Martin, VA HEM.OK.BOJCKA, 72/1/38.

410 Vgl. Wegner, Hitlers politische Soldaten, S. 284.

411 Vgl. Ebd. 
unerfahrener Unterführer an die Front litt letztlich auch die professionelle Qualität der Führungskader. ${ }^{412}$

Da die Albaner westliche Standards bezüglich militärischer Ausbildung, Uniformierung, Bewaffnung und Kriegführung im Allgemeinen nicht kannten und ihren eigenen Regeln folgten, kam Schmidhuber zum Schluss, dass zuerst das Führer- und Unterführerkorps hätte aufgestellt werden müssen, um es danach mit albanischen Rekruten aufzufüllen. ${ }^{413}$ Aufgrund der schwer zu haltenden Disziplin bei den auszubildenden Albanern schlug er vor, dass auf zwanzig Albaner zwei deutsche Unterführer kommen müssten, und „zwar einer zum Führen und einer hinten zum Aufpassen.“414 Gerne hätte er das gesamte Unterführerkorps mit Albanern besetzt, machte aber ihre mangelnde Disziplin für das Scheitern dieses Vorhabens verantwortlich. Da aber zuerst gar kein und auch später nicht genügend Ausbildungspersonal bei der „Skanderbeg“ eintraf, ${ }^{415}$ - SS-Obersturmbannführer Hauser beispielsweise kam erst im Juni mit sechs Führern und 15 Unterführern bei Berger in Tetovo an ${ }^{416}$ - ging man trotz oben genannter Probleme im Juli 1944 dazu über, auch Albaner in einer Lehrkompanie zu Unterführern auszubilden. ${ }^{417}$

Schwierigkeiten bei der Disziplinierung äußerten sich auch bei der Gewöhnung an Uniformen, wie Schmidhubers Bericht zu entnehmen ist:

Hinsichtlich der Bekleidung standen die Ausbilder oft vor d[en] gleichen Schwierigkeiten wie etwa bei den Negern. Die meisten [Re]kruten vom Lande bekamen zum ersten Mal in ihrem Leben Schuhe an die Füße. Darauf waren sie sehr stolz und zogen sie auch bei Nacht nicht mehr aus. Dagegen ziehen sie diese Schuhe aus, sobald sie länger marschieren müssen und hängen sie über die Schulter. Sobald der Albaner sich jedoch zur Flucht wendet, kündigt er seinen Schuhen die Liebe und wirft sie weg, um barfuss schneller laufen zu können. Das Gewöhnen an einen ordentlichen Anzug ist, wo es gelingt, allein schon eine außerordentliche Leistung in Albanien. ${ }^{418}$

$412 \mathrm{Vgl}$. Ebd. Auf Generalstabsebene verfügte die SS über keine eigene Ausbildung. Ohne mit der Arbeit in höheren Stäben bzw. in Kommandobehörden theoretisch und praktisch vertrautem Ausbildungspersonal war die SS in dieser Beziehung immer vom Heer abhängig; seit 1940 wurden daher die Generalstabslehrgänge der Wehrmacht mit einzelnen SS-Führern aufgefüllt. Vgl. Wegner, Hitlers politische Soldaten, S. 288.

413 Vgl. Schmidhuber, „Zusammenfassender Bericht“, 2.10.1944, BArchF, RS 3-21/1, S. 2.

414 Ebd.

415 Vgl. ebd., S. 4.

416 Vgl. Karl Berger an Vopersal, 18.12.1975, BArchF, N756/182b.

417 Vgl. Bericht Donauzeitung „Im Geiste Skanderbegs“ von Dr. K., 26.7.1944, ASD, RSI, Aff. Pol., Busta, 51.

418 Schmidhuber, „Zusammenfassender Bericht“, 2.10.1944, BArchF, RS 3-21/1, S. 2. 


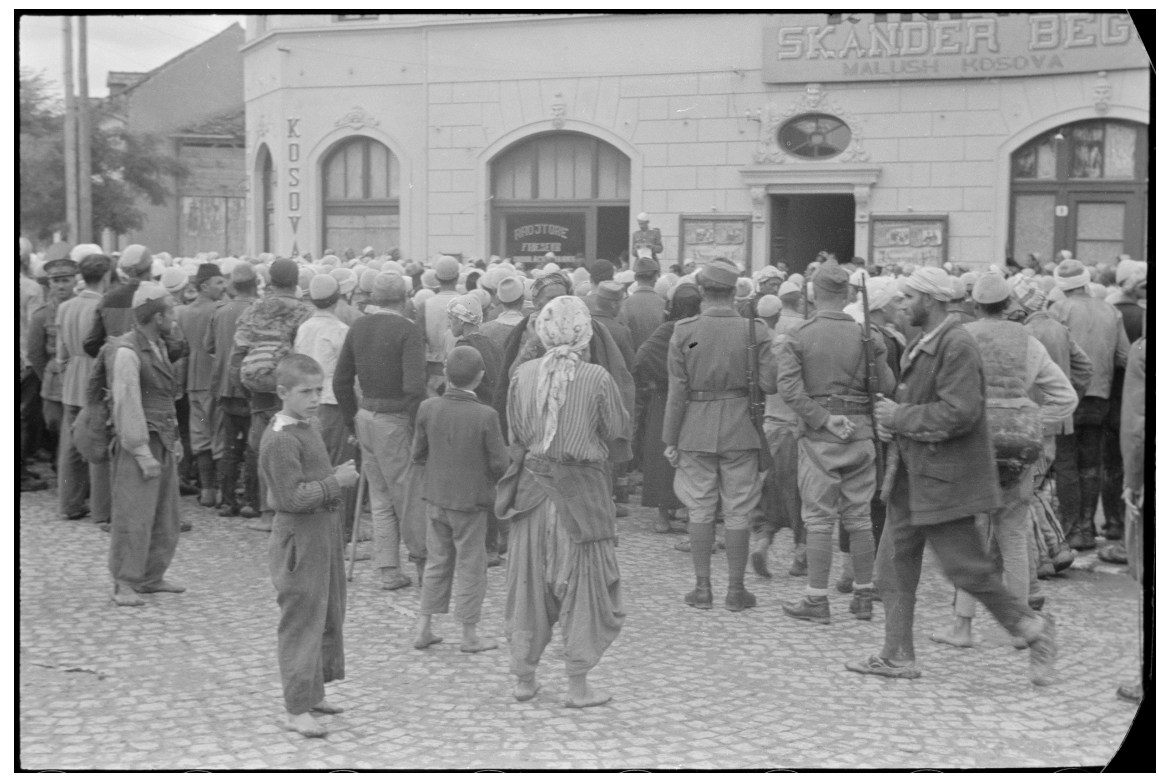

Abb. 36: Gut sichtbar bei dieser Rekrutierungsrede in Mitrovica: Nur die wenigsten tragen Schuhe. Die meisten sind barfuß oder mit Schuhlappen unterwegs. ${ }^{419}$

Auch der ehemalige Divisionsangehörige Fred Martin führte das schleppende Vorangehen der Ausbildung auf die Unlust der Albaner zurück - und er erwähnte einen weiteren wichtigen Aspekt: Ein Teil der Ausbildung konnte aufgrund des akuten Waffenmangels gar nicht durchgeführt werden. Meist wurden die Albaner deshalb nur am Gewehr, und nur selten an M.G. oder an „Spezialwaffen“ ausgebildet. ${ }^{420}$ Da die Division nach sechs Wochen bereits an Gefechten teilnahm, standen die deutschen Ausbilder vor dem Problem, die Ausbildung im Gelände sowie die Schießausbildung zwischen den Einsätzen weiterführen zu müssen: „Die gewonnene Atempause durch den Ausfall zahlreicher kommunistischer Agenten und Kuriere wurde zur intensiven Schnellausbildung benutzt, um auch nach außen schnellstens einsatzbereit zu werden." ${ }^{421}$ Allerdings offenbarte sich in den nachfolgenden Operationen, wie etwa am Čakor-Pass Mitte Juli 1944, dass es den Albanern sowohl an Ausbildung als auch an Ausrüstung mangelte. ${ }^{422}$ Gegen die 1944 bereits gut ausgebildeten und ausgerüsteten Partisaneneinheiten konnten sie kaum

419 ECPAD, LFT SO F2684 L19.

420 Vgl. Kriegsgefangenenbericht Martin, VA HEM.OK.BOJCKA, 72/1/38.

421 „Zusammenfassender Bericht“ Schmidhuber, 2.10.1944, BArchF, RS 3-21/1, S. 5.

422 Vgl. Ebd. 
etwas ausrichten. ${ }^{423}$ Auch Neubacher bestätigte dies in seinen Memoiren: „Diese [Division „Skanderbeg“] erlitt in einem frühen Stadium der Ausbildung bei einem schlecht geführten Vorstoss in ein Partisanengebiet schwerste Verluste.“424

Auch die Vorstellung von Kriegführung unterschied sich zwischen Deutschen und Albanern ganz wesentlich, was sich in der Ausbildung und den Einsätzen widerspiegelte. Ein weiterer lähmender Faktor in der Ausbildung stellte die Verständigung dar. Sowohl die unterschiedlichen Vorstellungen von Kriegführung als auch die sprachlichen Probleme werden im Unterkapitel zu Schwierigkeiten noch näher beleuchtet.

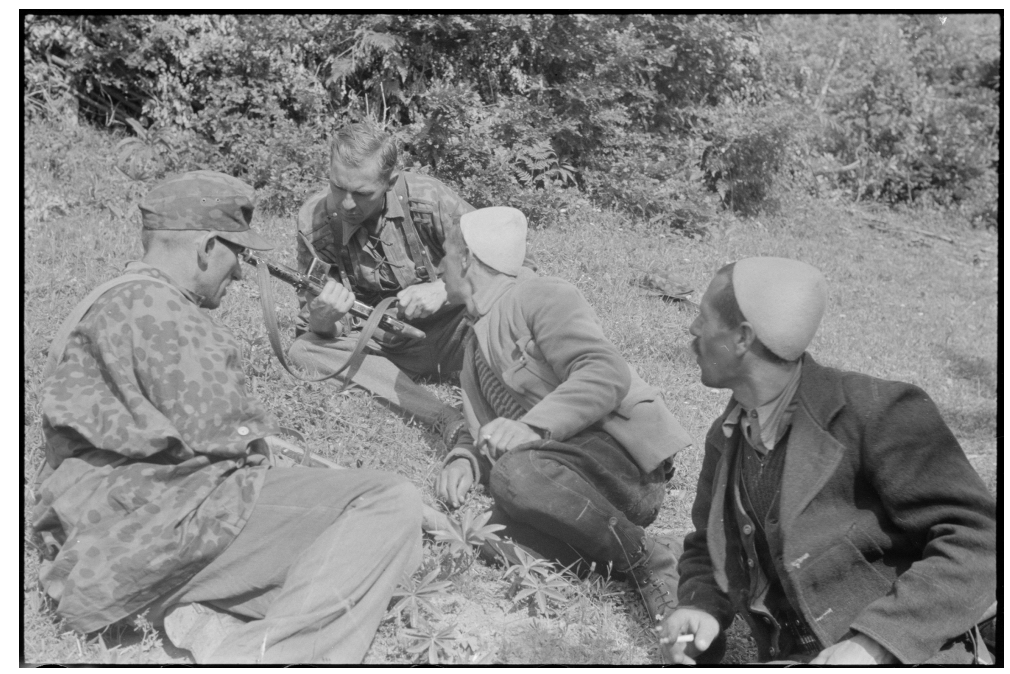

Abb. 37: Training oder Zigarettenpause ${ }^{425}$

\subsection{Aufbau, Struktur und Zusammensetzung}

Im Mai 1944 schrieb Phleps an Himmler, dass Schmidhuber trotz der Unterstützung albanischer Behörden keine Chance hätte, die Division „Skanderbeg“ ohne deutsche Führer, Unterführer und Mannschaften aufzustellen. Er räumte jedoch ein, dass auch die Aufstellung der „Handschar“ und sogar der „Prinz Eugen“ ohne deutsche Führer unmöglich gewesen wäre. Schon bei diesen beiden Divisio-

423 Vgl. ebd.

424 Neubacher, Sonderauftrag Südost, S. 116.

425 ECPAD, LFT SO F2683 L16. 
nen hatte Phleps die personelle Unterstützung durch deutsches Rahmenpersonal benötigt. ${ }^{426}$ Problematisch schien im Frühjahr 1944 aber vor allem der Faktor Zeit. Der gravierende Mangel an Personal durch Verluste, wie auch die Unmöglichkeit, die entstandenen Lücken mit frisch ausgebildeten deutschen SS-Führern, Unterführern und Mannschaften rasch zu füllen, ist in den Akten nachzulesen: Phleps betonte gegenüber Himmler, dass weder Rahmenpersonal der „Prinz Eugen“ noch der „Handschar“ für den Aufbau der „Skanderbeg“ verwendet werden könnte, da sich der akute Mangel auch dort bemerkbar machte: In der „Prinz Eugen“ fehlten zu diesem Zeitpunkt 50\% des vorgesehenen Führungspersonals; Phleps konnte während der anhaltenden Kämpfe zwar die Ausfälle wettmachen, das bereits vorhandene Defizit an Führungskräften aber nicht mehr ausgleichen. ${ }^{427}$ Um die „Handschar“ stand es noch schlimmer: „Die 13. hat gerade genug, um gehütet zu sein.“ ${ }^{428}$ Als Unterstützung der Division „Skanderbeg“ kam daher personeller Nachschub entweder aus dem Reich oder dem Südosten, „Volksdeutsche“ aus Ungarn und Siebenbürgen, in Frage. Phleps war dennoch optimistisch, dass aus der „Alb.[anischen] Div.[ision] eine Gardediv[ision] " würde. ${ }^{429}$

Obwohl sich mehrheitlich muslimische Albaner rekrutieren ließen, traten auch katholische Albaner in die Waffen-SS ein, ${ }^{430}$ und obwohl die meisten Rekruten aus „neualbanischen“ Gebieten stammten, gab es auch Ausnahmen aus „Altalbanien“. ${ }^{431}$ Die Rekrutierungen wurden nicht auf das von Schmidhuber genannte Dreieck Pejë/Peć-Prishtina/Priština-Prizren beschränkt, sondern auf die serbischen und montenegrinischen Gebiete des Sandžaks, auf Nordgriechenland und die unter bulgarischer Herrschaft stehenden Grenzgebiete Mazedoniens ausgedehnt. ${ }^{432}$ Im Kapitel zur Division „Handschar“ wurden bereits diejenigen Albaner genauer betrachtet, die als Bataillon und in weiteren Einheiten in der bosnischen Division kämpften. ${ }^{433}$ Sie kamen im Frühjahr 1944 als Stammpersonal zur Division „Skanderbeg“. Diese albanischen Soldaten hatten seit Frühjahr 1943 einschlägige Gewalterfahrungen sammeln können; insbesondere Kriegverbrechen

426 Vgl. Schreiben Phleps an Himmler, 7.5.1944, BArchB, NS 19/2601, Bl. 95.

427 Ebd.

428 Ebd.

429 Ebd.

430 Vgl. Interview mit Tush Mark Ndou (geführt von Franziska Zaugg), 7.6.2017.

431 Vgl. Brief Kopf an Vopersal, 4.7.1976, BArchF, N 756/182a.

432 Vgl. Schmidhuber, „Zusammenfassender Bericht“, 2.10.1944, BArchF, RS 3-21/1, S. 3 f. Vgl. Herkunftsorte der Rekrutierten in Arkivi Kosoves, F: Dosjete robërve të luftës në Gjermani, V: 1940-1945, K: 1. Vgl. Herkunftsorte der Rekrutierten in Arhiv Jugoslavjie, AJ 110, F 692-730. Vgl. auch Frolov, Pod barjakom Skenderbega, S. 44.

433 Vgl. Teil „Handschar“, Kapitel „Rekrutierungen im Sandžak und Kosovo-Gebiet“, S. 216-218. 
gegenüber der lokalen serbischen Bevölkerung auf ihrem Weg durch Bosnien sind mannigfach belegt. ${ }^{434}$ Weil sie sich diesbezüglich mehrfach über Befehle hinwegsetzten, sollten diese albanischen Soldaten aus der „Handschar“ entfernt und in die „Skanderbeg“ versetzt werden. ${ }^{435}$ Die Idee, sie als Stammpersonal zu verwenden, entsprach somit eher einer Notlösung. Wie sich diese Gewalterfahrungen auf die Dynamik der „Skanderbeg“ auswirkte, kann heute nicht mehr im Detail rekonstruiert werden. Doch dass das Verhalten dieses Stammbataillons, das bereits zu Beginn der Aufstellung innerhalb der Division eine dominierende Rolle spielte und auf verschiedene Einheiten verteilt wurde, die neuen Rekruten in Bezug auf die Ausübung von Gewalt beeinflusste, steht außer Frage. Auch Gewalterfahrungen ihrer deutschen und „volksdeutschen“ Vorgesetzten in Ost- und Südosteuropa dürften bei der Sozialisierung der zumeist sehr jungen albanischen Soldaten eine wesentliche Rolle gespielt haben. ${ }^{436}$

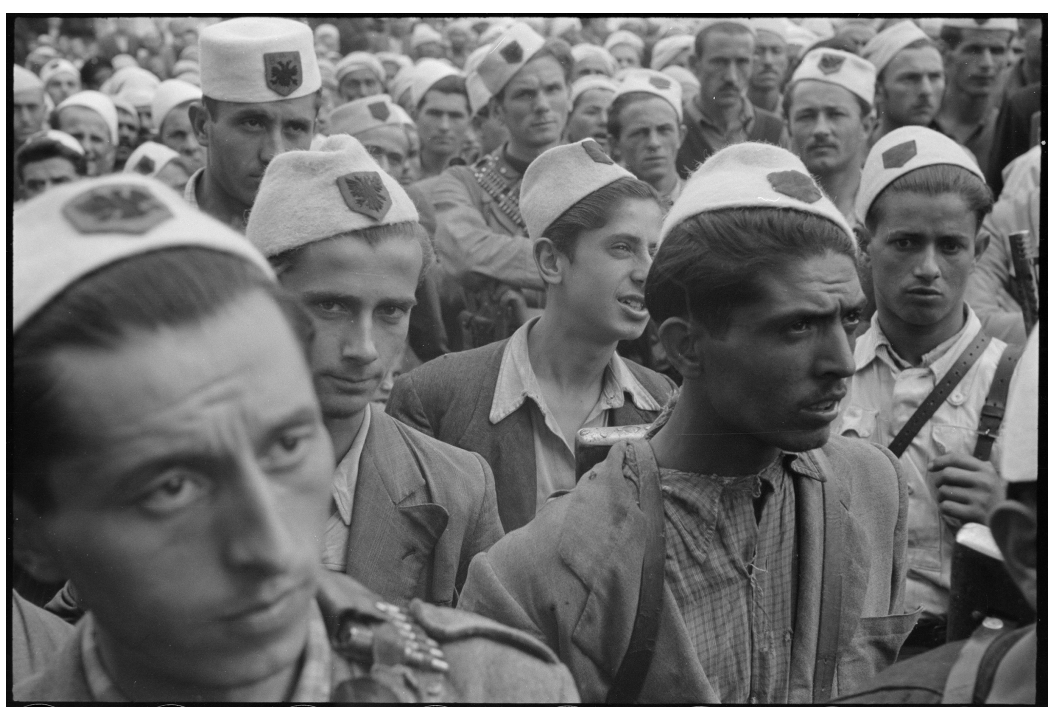

Abb. 38: Rekruten. ${ }^{437}$

434 Vgl. Zaugg, Albanische Muslime, S. $191 \mathrm{f}$.

435 Vgl. Vernehmungsprotokoll Matheis, Franje, Office of Chief of Council for War Crimes Translation of Document No. NO-4951, Landeskommission der Feststellung der Verbrechen der Okkupatoren und ihrer Helfershelfer, Inv. Nr. 35874, Nachlass Vopersal, BArchF, N 756/169a.

436 Vgl. hierzu das Kapitel „Kriegsverbrechen: Ausdruck interethnischer lokaler Konflikte oder Weiterführung der KZ- und Ost-Erfahrungen?“, S. 435-437.

437 Albanische Rekruten, ECPAD, LFT SO F2684 L11. 


\subsubsection{Rahmenpersonal}

Um als Deutscher bzw. als „Volksdeutscher“ zur „Skanderbeg“ versetzt zu werden, waren zwei Faktoren ausschlaggebend: Einerseits wurde bei der Versetzung darauf geachtet, wie gut die Kenntnisse des Betreffenden über die Region bereits waren, in welcher die neue Division aufgestellt werden sollte. Divisionskommandeur Schmidhuber ist ein typisches Beispiel einer solchen Versetzung, hatte er doch in seiner Zeit als Regimentskommandeur bei der „Prinz Eugen“ bereits einschlägige Erfahrungen im südosteuropäischen „Bandenkampf“ sammeln können. ${ }^{438}$ Ein propagandistischer Zeitungsbericht von einem gewissen Dr. K. in der „Donauzeitung“ lobte, dass er bei seinem Stab „berühmt, und in mancher Hinsicht auch ,berüchtigt““ war: ${ }^{439}$ „Denn Standartenführer Sch[midhuber] ist berühmt für die harte Ausbildung, die er seinen Verbänden gibt, für den Kampfwert, den er ihnen in der sorgfältigen Schulung zu verleihen weiß.“440

Der zweite Faktor lässt sich als eine Voraussetzung mit negativen Vorzeichen klassifizieren: Wenn man die Biografien von HSSPF Fitzthum oder Schmidhuber näher untersucht, so lässt sich feststellen, dass ihre SS-Existenzen nicht ganz blütenrein waren. Beide standen wegen verschiedener Delikte unter Anklage bzw. vor Gericht. ${ }^{441}$ Wichtiger noch: Sie stellen damit keine Ausnahme dar. Nach Albanien versetzt zu werden, einem Nebenkriegsschauplatz mit einem unübersichtlichen Gegeneinander verschiedenster Konfliktparteien, war keine Ehre, sondern eher eine Strafe. Ob das auch für die niedrigen Dienstgrade Geltung hatte, lässt

438 Vgl. zur Stationierung der „Prinz Eugen“ im Kosovogebiet, Gesandtschaft Belgrad Mameli an Italienisches Außenministerium, 6.1.1943, ASD, AG, 1923-1943, Busta 1492, Serbia 4. Schmidhuber berichtet von Einsätzen in Südserbien zwischen September 1942 bis Dezember 1942. Es werden keine Ortsnamen genannt. Bei Einsätzen im Zeitraum Februar 1944 bis Januar 1945 nennt er u. a. auch die Sandžak-Region. Vgl. Kriegsgefangenenbericht Divisionskommandeur „Skanderbeg“ August Schmidhuber, 6.1946, VA HEM.OK.BOJCKA, 72/2/33.

439 Bericht Donauzeitung „Im Geiste Skanderbegs. Albanische SS-Freiwillige kämpfen für ihre Heimat - ein Bollwerk gegen den Bolschewismus, der alle Völker in ihrer Kultur und Existenz bedroht“ von Dr. K., 26.7.1944, ASD, RSI, Aff. Pol., Busta 51.

440 Ebd. Schmidhuber war allerdings zum Zeitpunkt des Erscheinens des Artikels bereits zum SS-Oberführer befördert worden.

441 Vgl. betr.: August Schmidhuber, Führer bei der SS-Verfügungstruppe, Stellungsnahme des Rechtsberaters des SS-Oberabschnitts Süd, SS-Sturmbannführer Lorenz Hollfelder, 1.7.1935, BArchB, SSO 84B, Schmidhuber, August, 8.5.1901. Vgl. Vernehmungsniederschrift unterzeichnet von SS-Standartenführer Georg Bilgeri und SS-Standartenführer Tondock, 27.12.1939, BArchB, SSO 210, Fitzthum, Josef, 14.9.1896, Bl. 301. Vgl. Zweite Übertragung aus dem Stenogramm, 14.12.1939, BArchB, SSO 210, Fitzthum, Josef, 14.9.1896, Bl. 304. Vgl. auch, Klee, Personenlexikon zum Dritten Reich, S. 154. 
sich heute nicht mehr im Detail beweisen. Kumms diesbezügliche Aussagen zu den Versetzungen zur „Prinz Eugen“ deuten aber darauf hin, dass wohl auch eine Versetzung zur „Skanderbeg“ als Bestrafung angesehen wurde. ${ }^{442}$

Das Rahmenpersonal der „Skanderbeg“ sollte zunächst nur aus Deutschen bzw. „Volksdeutschen“ bestehen. ${ }^{443}$ Diese Neuzugänge sollten aus dem Reich selbst und aus Rumänien und Ungarn stammen. ${ }^{444}$ Italienische Quellen berichten, dass vor allem Österreicher in Albanien stationiert waren, es ist aber auch von deutschen Offizieren und sogar von Polen die Rede. ${ }^{445}$ Laut Quellen sollen vor allem erstere einen Hang zur Korruption gezeigt haben. ${ }^{446}$

Schmidhuber schreibt rückblickend, insbesondere der Mangel an „deutschen Führern, Unterführen und Mannschaften“ hätte ein Problem dargestellt. Für die Division vorgesehen waren 491 Führer und 2.737 Unterführer, eine Summe von 3.228. Das Ist sah allerdings ernüchternd aus: im September waren insgesamt 500 Führer und Unterführer in der Division eingesetzt. ${ }^{447}$ Aufgrund des anhaltenden Mangels an Rahmenpersonal waren in der „Skanderbeg“ Anfang Oktober 1944 bei den insgesamt 467 Unterführern auch 38 Albaner zu finden. ${ }^{448}$ Graf bestätigt ebenfalls, dass ehemalige albanische Unteroffiziere der jugoslawischen Armee, die aus der Kriegsgefangenschaft entlassen wurden, um bei der „Skanderbeg“ zu kämpfen, zu einem Unterführerlehrgang zusammengezogen wurden. ${ }^{449}$

Das XXI. Gebirgskorps stellte der „Skanderbeg“ von seiner Seite nur einen Offizier und zwei Unteroffiziere zu Verfügung. ${ }^{450}$ Da kein weiteres Ausbildungspersonal eintraf, wurde das gesamte Verwaltungspersonal der Division kurzfristig als Ausbildungspersonal eingesetzt.

442 Kumm, Vorwärts Prinz Eugen, S. 39.

443 Bericht Donauzeitung „Im Geiste Skanderbegs. Albanische SS-Freiwillige kämpfen für ihre Heimat - ein Bollwerk gegen den Bolschewismus, der alle Völker in ihrer Kultur und Existenz bedroht“ von Dr. K., 26.7.1944, ASD, RSI, Aff. Pol., Busta, 51.

444 Vgl. Schreiben Phleps an Himmler, 7.5.1944, BArchB, NS 19/2601, Bl. 95.

445 Vgl. Befragung Domenico Sivera, 15.5.1944, I3/b13/f1, S. 2. Vgl. „Situazione politica-militare dell'Albania a tutto, il 19 ottobre 1943“, AUSSME I3/b13/f1, S. 1 f.

446 Vgl. Befragung Cpt. Renato Predome und Ten. Giorgio Cortese, 10.10.1943, AUSSME I3/ b13/f1, S. 2.

447 Stärkemeldung „Skanderbeg“, 10.9.1944, BArchB, NS19/1475, Bl. 19.

448 Vgl. Schmidhuber, „Zusammenfassender Bericht“, 2.10.1944, BArchF, RS 3-21/1, Bl. 6.

449 Vgl. Graf an Vopersal, 1973, BArchF, N 756/182b, Bl. 3.

450 Vgl. „Zusammenfassender Bericht“ Schmidhuber, 2.10.1944, BArchF, RS 3-21/1, S. 4. 
Es wurden von dem Verwaltungspersonal zum Beispiel Untersturmführer Abteilungs-Führer, Kassenleiter Kompanie-Führer, Rechnungsführer Zugführer. Ein Rechnungsführer hatte durchschnittlich fünfzig Albaner auszubilden. Dabei wurde ausbildungsmäßig das Beste geleistet. Das SS-Verwaltungshauptamt hat somit in der Aufstellung der Division von allen Dienststellen in jeder Hinsicht den wertvollsten Beitrag geleistet. ${ }^{451}$

Auch das nötige Sanitätspersonal traf nicht bei der Division ein. ${ }^{452}$ Dies war nicht etwa eine Ausnahme, sondern vielmehr ein Ausdruck der sich zuspitzenden Krise zwischen Wehrmacht und Waffen-SS um die Versorgung mit spärlichen Menschenressourcen. ${ }^{453}$ Aus diesem Grund hätte das optimale Vorgehen darin bestanden, das Unterführerkorps mit Einheimischen zu besetzen, wie Schmidhuber rückblickend meinte. Gleichzeitig war er aber der Meinung, dass aufgrund mangelnder albanischer Disziplin auf zwanzig Albaner zwei deutsche Unterführer hätten kommen müssen. ${ }^{454} \mathrm{Er}$ hielt daher deutsches Rahmenpersonal für das Gelingen der Operationen im albanischen Raum für unentbehrlich und forderte, dass Deutsche bis hinunter zur Funktion des Gruppenführers eingesetzt werden müssten. Damit meinte er die dem Zugführer unterstellten Gruppenführer, die kleinste Teileinheiten führten. ${ }^{455}$

Die nachträglichen Angaben Grafs und Kopfs zur Anzahl der in der „Skanderbeg“ eingesetzten Deutschen unterscheiden sich stark: Graf geht von etwa 900 Deutschen aus, Kopf hingegen von rund 1.200. ${ }^{456}$ Leider lässt sich anhand dieser Zahlen nicht nachvollziehen, wer davon zum Führer-/Unterführerkorps und wer zu den Mannschaften gehörte. Aufgrund der DRK-Vermisstenlisten lässt sich aber feststellen, dass Deutsche auch als Mannschafts-Dienstgrade eingesetzt waren. Zudem offenbart dieser Ausschnitt, dass von Griechenland kommende Marineeinheiten in der „Skanderbeg“ aufgingen:

451 Ebd.

452 Vgl. ebd., S. 3-5. Vgl. auch Phleps an Himmler, 7.5.1944, BArchB, NS 19/2601, Bl. 95.

453 Vgl. Kroener, „Menschenwirtschaftung“, S. 998.

454 Vgl. „Zusammenfassender Bericht“ Schmidhuber, 2.10.1944, BArchF, RS 3-21/1, S. 2.

455 Vgl. Abschließender Gefechtsbericht Unternehmen „Draufgänger“ Schmidhuber, 18.-28.7.1944, NARA, T314/664, F. $293 \mathrm{f}$.

456 Vgl. Kriegsgefangenenbericht Graf, VA, HEM.OK.BOJCKA, 72/2-1/32. Vgl. Briefwechsel Kurt Kopf und Leopold Stütz, 28.5.1964, BArchF, N 756/182a. 


\begin{tabular}{|c|c|c|c|c|c|}
\hline Name & Vorname & Dienstgrad & Feldpostnummer & Einheit & $\begin{array}{l}\text { Letzte } \\
\text { Nachricht }\end{array}$ \\
\hline Scholl & Matthias & Jäger & $955720^{457}$ & - & Januar 1945 \\
\hline Fischer & Lothar & Rottenführer & 12939 & Stab & Dezember \\
\hline Gross & Fritz & Sturmmann & " & " & $\begin{array}{l}1944 \\
\text { Januar } 1945\end{array}$ \\
\hline Gubesch & Josef & $?$ & 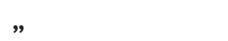 & ” & $?$ \\
\hline Henneberg & Waldemar & Obersturmführer & $”$ & " & Februar 1945 \\
\hline Perndl & Franz & Sturmmann & “ & “ & Januar 1945 \\
\hline Possin & Willi & Unterscharführer & $”$ & $"$ & Januar 1945 \\
\hline Behrmann & Wilhelm & Rottenführer & $”$ & $"$ & $\begin{array}{l}\text { Dezember } \\
1944\end{array}$ \\
\hline Glöckler & Helmuth & Jäger & “ & “ & $\begin{array}{l}\text { Dezember } \\
1944\end{array}$ \\
\hline Hennemann & Ludwig & Rottenführer & \#A & $"$ & $\begin{array}{l}\text { Dezember } \\
1944\end{array}$ \\
\hline Kugler & Paul & Jäger & „A & $"$ & Januar 1945 \\
\hline Matheis & Paul & Unterscharführer & \#A & ” & Februar 1945 \\
\hline Naetzel & Heinz & Sturmführer & \#A & $"$ & $\begin{array}{l}\text { Dezember } \\
1944\end{array}$ \\
\hline Braun & Johann & Jäger & \#A & $"$ & $\begin{array}{l}\text { Dezember } \\
1944\end{array}$ \\
\hline Ertel & Erhard & Jäger & $21739 \mathrm{~A}$ & $\mathrm{I} / 1$ & März 1945 \\
\hline Wedermann & $\begin{array}{l}\text { Karl- } \\
\text { Heinrich }\end{array}$ & Jäger & $25306 \mathrm{~B}$ & $1 / 1$ & August 1944 \\
\hline Heitzmann & Eugen & Unterscharführer & $27508 \mathrm{~A}$ & $1 / 2$ & Oktober 1944 \\
\hline Richter & Fritz & Rottenführer & $”$ & ” & März 1945 \\
\hline Wiezorke & Wilhelm & Oberscharführer & $”$ & 川 & Juli 1944 \\
\hline Wunglück & Willi & Oberscharführer & $”$ & 川 & Februar 1945 \\
\hline Glogner & Paul & Matrose Obergefreiter & ,C & 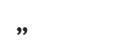 & Januar 1945 \\
\hline Sokoloweki & Helmut & Matrose Obergefreiter & $”$ & $"$ & $\begin{array}{l}\text { November } \\
1944\end{array}$ \\
\hline Vieth & Franz & Jäger & ” & $"$ & $\begin{array}{l}\text { Dezember } \\
1944\end{array}$ \\
\hline Meine & Gerhard & Unterscharführer & „D & $"$ & Februar 1945 \\
\hline Bohn & Jakob & Unterscharführer & „E & ” & Juli 1944 \\
\hline Wister & Karl & Rottenführer & 24736 & $\mathrm{II} / 2$ & Februar 1945 \\
\hline Lehmbach & Arthur & Rottenführer & \# B & $"$ & Januar 1945 \\
\hline Schmidt & Wilhelm & Rottenführer & $"$ & $"$ & $\begin{array}{l}\text { Dezember } \\
1944\end{array}$ \\
\hline
\end{tabular}

457 Diese Feldpostnummer lässt sich nicht ermitteln und muss entsprechend falsch übertragen worden sein. 
(fortgesetzt)

\begin{tabular}{|c|c|c|c|c|c|}
\hline Name & Vorname & Dienstgrad & Feldpostnummer & Einheit & $\begin{array}{l}\text { Letzte } \\
\text { Nachricht }\end{array}$ \\
\hline Rieder & Fritz & Rottenführer & \#C & ” & $\begin{array}{l}\text { Dezember } \\
1944\end{array}$ \\
\hline Schwarz & August & Oberscharführer & $"$ & ” & $\begin{array}{l}\text { Dezember } \\
1944\end{array}$ \\
\hline Hammerich & Alfred & $?$ & $22466 \mathrm{~A}$ & $\mathrm{III} / 2$ & Oktober 1944 \\
\hline Hamdorf & Willi & Unterscharführer & ” & " & Juli 1944 \\
\hline Ateke & Walter & Untersturmführer & $"$ & ” & Juli 1944 \\
\hline Büsing & August & Rottenführer & \# B & ” & $\begin{array}{l}\text { Dezember } \\
1944\end{array}$ \\
\hline Kraus & Johann & Sturmann & ” & " & Juli 1944 \\
\hline Lieshof & Kurt & Marine Obermaat & ” & ” & Januar 1945 \\
\hline Potschek & Sepp & Unterscharführer & $"$ & ” & Juni 1944 \\
\hline Putzer & Johann & Sturmmann & ” & ” & Januar 1945 \\
\hline Purann & Otto & Matrose Obergefreiter & $"$ & " & Februar 1945 \\
\hline Hoffmann & Erhard & $\begin{array}{l}\text { Hauptmann der } \\
\text { Gendarmerie }\end{array}$ & $\# \mathrm{C}$ & ” & $\begin{array}{l}\text { Dezember } \\
1944\end{array}$ \\
\hline Staab & Anton & Unterscharführer & $"$ & " & $\begin{array}{l}\text { November } \\
1944\end{array}$ \\
\hline Wöhlk & Friedrich & Sturmmann & ” & ” & $\begin{array}{l}\text { November } \\
1944\end{array}$ \\
\hline Clebusch & Helmut & Rottenführer & \# & " & $\begin{array}{l}\text { November } \\
1944\end{array}$ \\
\hline Hummel & Otto & Sturmmann & $"$ & ” & $\begin{array}{l}\text { November } \\
1944\end{array}$ \\
\hline Saassenrath & Erwin & Rottenführer & $"$ & $”$ & $\begin{array}{l}\text { November } \\
1944\end{array}$ \\
\hline Stein & Herbert & Rottenführer & " & ” & August 1944 \\
\hline Visser & Michel & Rottenführer & $"$ & ” & $\begin{array}{l}\text { November } \\
1944^{458}\end{array}$ \\
\hline
\end{tabular}

458 DRK Vermisstenliste „Skanderbeg“, ohne Datum, Nachlass Vopersal, BArchF, N756/182b. 
Da bis Juli 1944 nicht genügend Ausbildungspersonal bei der „Skanderbeg“ eingetroffen war, ${ }^{459}$ ging Schmidhuber dazu über, auch Albaner in einer Lehrkompanie zu Unterführern auszubilden. ${ }^{460}$ Per 31. August 1944 waren noch 106 Führer und 394 Unterführer in der Division eingesetzt. ${ }^{461}$

Von den wenigen Deutschen, die in Kosovo und angrenzenden Gebieten eingesetzt waren, nutzten einige die schwer kontrollierbaren, zuweilen chaotischen Zustände, um persönlichen Interessen nachzugehen. So gab der ehemalige Divisionsangehörige Karl Berger später an, SS-Untersturmführer Walter, der in Gostivar die Aufgabe hatte, mit zwei Unterführern das dort stationierte Bataillon ,in Schwung zu bringen“, hätte ein „lockeres Leben“ geführt und zusammen mit Offizieren der 297. Infanterie-Division „,höchste Freudenfeste“ gefeiert. ${ }^{462}$

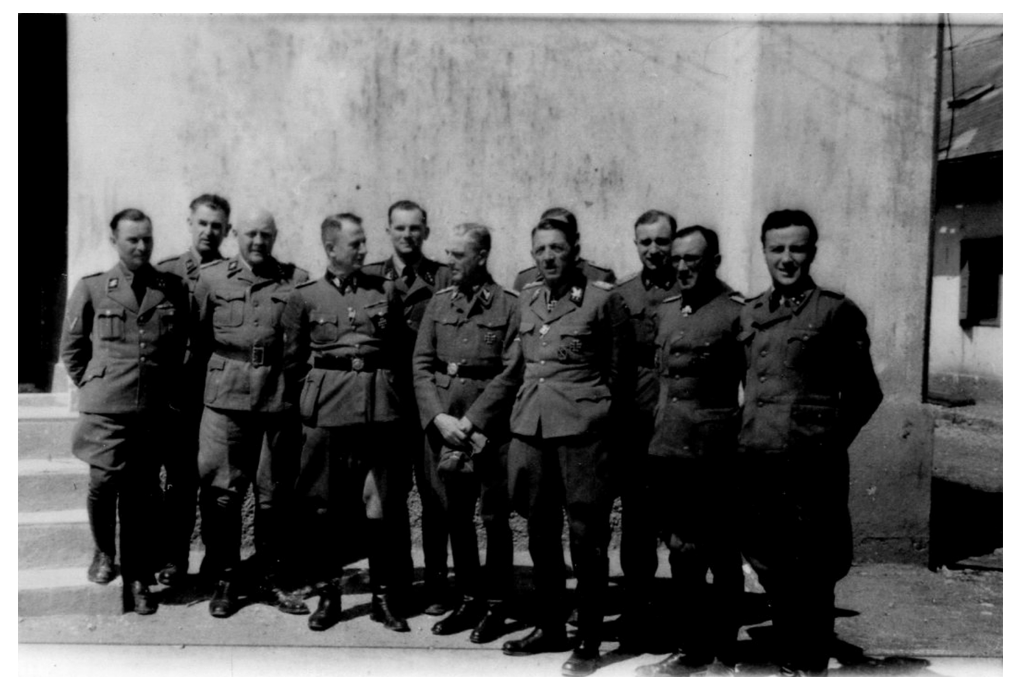

Abb. 39: Schmidhuber mit Divisionsstab in Prizren. Zweiter von rechts Divisionskommandeur Schmidhuber, rechts neben ihm Phleps, Frühjahr $1944 .{ }^{463}$

459 Vgl. Schmidhuber, „Zusammenfassender Bericht“, 2.10.1944, BArchF, RS 3-21/1, S. 4. 460 Bericht Donauzeitung „Im Geiste Skanderbegs. Albanische SS-Freiwillige kämpfen für ihre Heimat - ein Bollwerk gegen den Bolschewismus, der alle Völker in ihrer Kultur und Existenz bedroht“ von Dr. K., 26.7.1944, ASD, RSI, Aff. Pol., Busta, 51. So traf etwa SS-Obersturmbannführer Hauser erst im Juni mit sechs Führern und 15 Unterführern bei Berger in Tetovo ein. Vgl. Brief Karl Berger an Vopersal, 18.12.1975, BArchF, N 756/182b.

461 Stärkemeldung „Skanderbeg“, 5.9.1944, BArchB, NS19/1475, Bl. 13.

462 Vgl. Brief Karl Berger an Vopersal, 18.12.1975, BArchF, N 756/182b.

463 Kriegsberichter Westermann, NARA, Nr. 9. 


\subsubsection{Zu den Divisionskommandeuren}

\section{Divisionskommandeur August Schmidhuber}

August Schmidhuber wurde am 8. Mai 1901 in Augsburg geboren. Von 1913 bis 1916 besuchte er das humanistische Gymnasium und begann anschließend eine Bierbrauerlehre. Im Mai 1919 trat er als „Zwölfjährig-Freiwilliger“ zuerst in das Ausbildungsbataillon Ulm und einen Monat später in das Freikorps Epp ein. Im Oktober wurde Schmidhuber als 18-Jähriger in die Reichswehr übernommen. 1933 wurde er Mitglied der SA. Ein Jahr später verließ er diese bereits wieder und trat am 17. Mai 1935 der SS als hauptamtlicher Führer bei. Von diesem Tag bis zum 1. Februar 1936 war er als Führer des 7. Sturms der SS-Standarte 1 der Verfügunsgtruppe in Dachau tätig. ${ }^{464}$ Nach einer Denunziation durch SS-Untersturmführer Adolf Ott förderten Dokumente aus der frühen NS-Zeit zutage, dass Schmidhuber „hetzerisch gegen die NSDAP gearbeitet“ habe, wie Rechtsberater Lorenz Hollfelder bestätigte. Gleichzeitig betonte dieser aber auch, dass ihm Schmidhuber „durchaus für die SS Verfügungstruppe geeignet und auch heute [...] politisch absolut zuverlässig“ schien. Er hielt ihn „für einen ausgesprochen tüchtigen Soldaten, der lediglich Soldat sein will [...].“465

Vom 1. Mai bis am 1. November 1939 oblag Schmidhuber die Führung des 1. Sturmbanns der SS-Standarte „Germania“. Er behielt dieses Kommando bis Ende 1940. Der Regimentkommandeur der SS-Standarte „Germania“, SS-Oberführer Demelhuber, schätzte Schmidhuber als „weltanschaulich gefestigt und überzeugten Nationalsozialisten“ ein. Schließlich wurde Schmidhuber am 1. Dezember 1940 mit der Führung des II. Sturmbanns der SS-Totenkopfstandarte 11 beauftragt. Nach deren Umbenennung in SS-Infanterie-Regiment 11 (Division „Reich“) am 25. Februar 1941 war er zunächst als Kommandeur des II. Bataillons und danach als Regimentskommandeur derselben Einheit tätig. ${ }^{466}$

Am 25. April 1942 wurde Schmidhuber als Regimentskommandeur zur „Prinz Eugen“ versetzt, wo er das SS-Gebirgs-Jäger-Regiment 2 kommandierte. Diese Einheit eroberte am 12. September Dubrovnik/Ragusa, wobei Schmidhuber den dortigen italienischen Befehlshaber, General Giuseppe Amico, ohne Gerichtsbeschluss erschießen ließ. Er fungierte anschließend als Gouverneur der Stadt, kommandierte aber weiterhin das nun als SS-Gebirgs-Jäger-Regiment 14 bezeichnete Regiment 2. Am 17. April 1944 kam er zum Aufstellungsstab der Division „Skanderbeg“

464 Vgl. Schulz, Zinke, Die Generale der Waffen-SS und der Polizei, Bd. 5, S. 45 f.

465 Stellungnahme des Rechtsberaters des SS-Oberabschnitts Süd, SS-Sturmbannführer Lorenz Hollfelder, Betr.: August Schmidhuber, Führer bei der SS-Verfügungstruppe, 1.7.1935, BArchB, SSO 84B, Schmidhuber, August, 8.5.1901.

466 Vgl. Schulz, Zinke, Die Generale der Waffen-SS und der Polizei, Bd. 5, S. 47 f. 
nach Prizren, dessen Kommando er aber im Oktober 1944 an Alfred Graf übergab, und stattdessen von Januar bis Mai 1945 die Reste der Division „Prinz Eugen“ kommandierte. ${ }^{467}$ Schmidhuber geriet schließlich am 12. Mai 1945 in der Nähe von Celje/Cilli in sowjetische Kriegsgefangenschaft und wurde kurz darauf an den jugoslawischen Staat ausgeliefert. Er wurde nach knapp zwei Jahren Gefangenschaft und mehreren von ihm auf Befehl geschriebenen ausführlichen Berichten zu seinem Dienst in der „Prinz Eugen“ und der „Skanderbeg“ durch das Militärgericht der 3. Jugoslawischen Armee zum Tode verurteilt und am 16. Februar 1947 hingerichtet. ${ }^{468}$

\subsubsection{Truppe}

Für die multikulturelle Zusammensetzung deutscher Truppen in Albanien, auch der Waffen-SS, liefern die Befragungen heimgekehrter italienischer Soldatn interessante Informationen, da deutsche Quellen aus der Region, die Aufschluss darüber geben könnten, oft nicht mehr erhalten sind. Domenico Sivera gab nach seiner Rückkehr nach Italien zu Protokoll, dass die ab März neu aufgestellte deutsche Truppe, die Division „Skanderbeg“, aus sehr verschiedenen Ethnien zusammengesetzt gewesen sei. Nicht nur Österreicher, Deutsche und Kosovaren waren hier anzutreffen, sondern auch Armenier, Bessarabier, Elsässer, Polen und Bulgaren. ${ }^{469}$ Auch Danilo Marchione gab zu Protokoll, dass es sich bei den in Albanien stationierten deutschen Verbänden um multikulturelle Formationen, bestehend aus jungen Soldaten gehandelt habe: „innerhalb der Truppen fanden sich zahlreiche polnische, kroatische, elsässische und österreichische Elemente, die sehr jung waren. “470 Anfang Oktober 1944 gab Schmidhuber an, dass von den verbliebenen 887 Männern der Division nur 499 Albaner waren. ${ }^{471}$ Den Kern der Mannschaften bildeten die bereits erwähnten, aus der „Handschar“ versetzten Albaner. ${ }^{472}$

467 Vgl. ebd., S. 48-50.

468 Vgl. ebd., S. 51. Vgl. Sammlung von Erkenntnissen über die Beteiligung deutscher Dienststellen und Angehöriger der SS- Division Skanderbeg an Tötungsdelikten in Albanien im Jahr 1944, Aktenkarte zu Schmidhuber, USHMM/BArchL, B162/21.009, Bl. 129.

469 Vgl. Befragung Domenico Sivera, 15.5.1944, I3/b13/f1, S. 2. Vgl. Bericht Danilo Marchione, „Situazione militare delle truppe tedesche“, 5.11.1943, AUSSME I3/b13/f1, S. 4.

470 Bericht Danilo Marchione, „Situazione militare delle truppe tedesche“, 5.11.1943, AUSSME I3/b13/f1, S. 4.

471 Vgl. Schmidhuber, „Zusammenfassender Bericht“, 2.10.1944, BArchF, RS 3-21/1, Bl. 6.

472 Vgl. Vernehmungsprotokoll Matheis, Franje, Office of Chief of Council for War Crimes Translation of Document No. NO-4951, Landeskommission der Feststellung der Verbrechen der Okkupatoren und ihrer Helfershelfer, Inv. Nr. 35874, Nachlass Vopersal, BArchF, N 756/169a. 
Daneben stammten viele der in der „Skanderbeg“ dienenden Soldaten aus dem Kerngebiet der Rekrutierungen, der Kosovo-Region. Darüber hinaus lassen sich Rekrutierungen aus den angrenzenden Regionen, etwa der Sandžak-Region, Südserbien, Nordgriechenland und Montenegro für deutsche Verbände, darunter auch für die „Skanderbeg“ feststellen. ${ }^{473}$ Zudem waren längst nicht alle Soldaten Muslime. In den Mannschaften waren auch, wie bereits erwähnt, Katholiken zu finden. ${ }^{474}$

\subsubsection{Zusammenarbeit mit Hilftruppen}

Neben den für die „Skanderbeg“ rekrutierten Soldaten kämpften tausende in „nationalen Banden“ für den Sieg der Deutschen. Diese Hilfstruppen rekrutierten sich oft aus den Gefolgsleuten bzw. den Privatarmeen von Mitgliedern der „Zweiten Liga von Prizren“ wie auch des „Balli Kombëtar“, der so genannten Ballisten. ${ }^{475}$ Das darf aber nicht daürber hinwegtäuschen, dass die Organisation „Balli Kombëtar“ sehr unterschiedliche Mitglieder vereinte, darunter auch Gegner der deutschen Besatzer - die national, nationalistisch, bisweilen auch demokratisch eingestellt waren; aber nicht kommunistisch. ${ }^{476}$ Bis 1943 lassen sich aber Versuche der Zusammenarbeit zwischen Kommunisten und dem „Balli Kombëtar“ nachweisen ${ }^{477}$, nach dem Bruch zwischen den beiden Fraktionen, suchten Teile des „Balli Kombëtar“ Unterstützung bei den Deutschen, die in eine militärische Zusammenarbeit mündete. ${ }^{478}$ Weitere zugewandte Gruppen stellten auch bei dieser Division die Četniks dar, was jedoch bei den rekrutierten Albanern Empörung hervorrief. 479

473 Aufschlussreich sind hierzu die beiden Bestände, einersiets aus dem Arhiv Jugoslavije, AJ 110, andererseits aus dem Staatsarchiv Kosovo, F: dosjete robërve të luftës në Gjermani, V: 1940-1945.

474 Vgl. Tom Tushi, E-mail an die Verfasserin, 19.3.2017.

475 Die Mitglieder der „Zeiten Liga“ waren oft gleichzeitig auch Mitglieder des „Balli Kombëtar“.

476 Vgl. Zaugg, Albanische Muslime, S. 68, 72, 96.

477 Vgl. ebd., S. 73.

478 Vgl. ebd., S. 73, 210, 233.

479 Vgl., ebd., $233 \mathrm{f}$. 


\subsubsection{Gliederung und Unterstellung}

21. Waffen-Gebirgs-Division der SS „Skanderbeg“ (albanische Nr. 1), Stab [FPNr. 12939]

Divisionskommandeur

la (Führung)

Bei la, Offiziere mit unbekannter Dienststelle

01 (1. Ordonnanzoffizier)

Dolmetscher beim Divisionskommandeur

Ib (Versorgung)

02 (2. Ordonnanzoffizier)

Ic (Feindlage/Abwehr)

Ila (Div. Adjudant)

IVa (Div. Intendant)
Schmidhuber, August, SS-Staf., SS-Oberf.

Krone Major (Heer)

Berger, Georg, SS-Hstuf.

Backhausen, (Heer oder Polizei)

Krah, Josef, SS-Ostuf.

Decg, Thela, SS-Hstuf.

Graf, Alfred, SS-Ostubaf.

Balke, Herbert, SS-Ostuf.

Schweissgut, SS-Hscha.

Schesto, Georg, SS-Ostuf.

Er(r)elis, Heinz, SS-Hstuf.

Seltmann, Richard, SS-Stubaf.

Weichseldorfer, Karl-Theodor, SS-Stubaf.

von Pistor, Talbot, SS-Hstuf. ${ }^{480}$

Waffen-Gebirgs-Jäger-Regiment-der-SS 50 (albanisches Nr. 1) [FPNr. 16034]

\begin{tabular}{ll}
\hline Rgt.Kommandeur & $\begin{array}{l}\text { Ludwig, Ernst, SS-Staf. (?) } \\
\text { Hauser, Jakob, SS-Ostubaf. (seit 6.1944) }\end{array}$ \\
\hline IIa (Rgt. Adjudant) & Krah, Josef, SS-Ostuf. \\
\hline IVa (Rgt. Intendant) & Klingenberg, Rudolf, SS-Hstuf. \\
\hline I. Bataillon [FPNr. 25306] & Zeitler, Alfons, SS-Hstuf., Stubaf. \\
\hline II. Bataillon [FPNr. 21739] & Wolf, Richard, SS-Stubaf. ${ }^{481}$ \\
\hline
\end{tabular}

480 Vgl. Zaugg, Albanische Muslime, S. 212f. Vgl. Frans Noij, Zusammenstellung der höheren Dienstgrade innerhalb der Division, unveröffentlicht.

481 Vgl. ebd. 
Waffen-Gebirgs-Jäger-Regiment-der-SS 51 (albanisches Nr. 2) [FPNr. 22892]

\begin{tabular}{ll}
\hline Rgt.Kommandeur & Keidel, Friedrich, SS-Stubaf. \\
\hline Ila (Rgt. Adjutant) & Schrader, Alfred, SS-Ostuf. \\
\hline I. Bataillon [FPNr. 27508] & Hauser, Jakob, SS-Ostubaf. ? \\
\hline III. Bataillon [FPNr. 22466] & Bormann, Walter, SS-Hstuf., Stubaf. ${ }^{482}$ \\
\hline
\end{tabular}

Waffen-Gebirgs-Artillerie-Regiment-der-SS 21 (albanisches Nr. 1) [FPNr. 17493]

Rgt.Kommandeur Wunder, Adolf, SS-Staf.

SS-Gebirgs-Aufklärungs-Abteilung 21 [FPNr. 25618]

\begin{tabular}{ll}
\hline Abt.Kommandeur & Köhler, Heinz, SS-Hstuf. \\
\hline Ila (Abt. Adjudant) & Wagner, Willi, SS-Ostuf. \\
\hline
\end{tabular}

SS-Panzerjäger-Abteilung 21 [FPNr. 23943]

Abt.Kommandeur

Bauer, Fritz, SS-Stubaf.

Hoppe, Herbert (oder Wilhelm), SS-Hstuf. (?)

SS-Gebirgs-Nachrichten-Abteilung 21 [FPNr. 30055]

\begin{tabular}{ll}
\hline Abt.Kommandeur & Feige, Wolf, SS-Hstuf. ? \\
& Wirsch oder Wiersch, Wilhelm
\end{tabular}

SS-Wirtschafts-Bataillon 21 [FPNr.?] / SS-Verwaltungs(truppe)-Abteilung 21 [FPNr. 31182]

Abt.Kommandeur

Weichseldorfer, Karl-Theodor, SS-Stubaf. von Pistor, Talbot, SS-Hstuf.

SS-Divsions-Nachschubführer 21 [FPNr. 21111]

Schröder, Karl, SS-Hstuf. ${ }^{483}$

482 Vgl. ebd.

483 Vgl. ebd. 
In der seit Oktober 1944 zum Rgiment bzw. zur Kampfgruppe restrukturierten „Skanderbeg“ können folgende Führer namentlich zugeordnet werden: SS-Regiments-Kampfgruppe „Skanderbeg“ [FPNr. 16034 ?]

\begin{tabular}{ll}
\hline Regimentskommandeur & Graf, Alfred, SS- Ostubaf. \\
\hline Ia (Führung) & Krah, Josef, SS- Ostuf. \\
\hline O1 (1. Ordonnanzoffizier) & Sommerfeld, Olt. zur See (Kriegsmarine) \\
\hline Ib (Versorgung) & Balke, Herbert, SS- Ostuf. \\
\hline O2 (2. Ordonnanzoffizier) & Hornung, Alfred, SS-Hscha. \\
\hline Ic (Feindlage/Abwehr) & Er(r)elis, Heinz, SS-Hstuf. ${ }^{484}$ \\
\hline
\end{tabular}

\subsubsection{Stärke}

Am 5. September 1944 verzeichnete die „Skanderbeg“ folgende Stärke: ${ }^{485}$

\begin{tabular}{lrrrrr}
\hline & Führer & Unterführer & Mannschaften & Davon Hilfswillige & Gesamt \\
\hline Soll & 491 & 2.737 & 15.811 & 2.782 & 19.039 \\
\hline Ist (per 31.8.1944) & 106 & 394 & 7.951 & 12 & 8.451 \\
\hline
\end{tabular}

Die Zahlen vom 10. September 1944 zeigen innerhalb der fünf Tage keine Veränderung beim Personal: ${ }^{486}$

\begin{tabular}{rrrrrr}
\hline & Führer & Unterführer & Mannschaften & Davon Hilfswillige & Gesamt \\
\hline Soll & 491 & 2.737 & 15.811 & 2.782 & 19.039 \\
\hline Ist & 106 & 394 & 7.951 & 12 & 8.451 \\
\hline
\end{tabular}

484 Vgl. ebd.

485 Stärkemeldung „Skanderbeg“, 5.9.1944, BArchB, NS19/1475, Bl. 13.

486 Stärkemeldung „Skanderbeg“, 10.9.1944, BArchB, NS19/1475, Bl. 19. 
Für die Iststärkemeldung per 20. September 1944 sind keine Angaben mehr vorhanden: ${ }^{487}$

\begin{tabular}{|c|c|c|c|c|c|}
\hline & Führer & Unterführer & Mannschaften & Davon Hilfswillige & Gesamt \\
\hline Soll & 491 & 2.737 & 15.811 & 2.782 & 19.039 \\
\hline Ist & - & - & - & - & - \\
\hline
\end{tabular}

Eine letzte Iststärke per Stichtag 1. Oktober 1944 wurde von Divisionskommandeur Schmidhuber in seinem zusammenfassenden Bericht festgehalten: ${ }^{488}$

\begin{tabular}{lrrrrr}
\hline & Führer & Unterführer & Mannschaften & Rekruten & Gesamt \\
\hline Soll & 491 & 2.737 & 15.811 & & 19.039 \\
\hline Ist & 86 & 467 & 887 & 3.504 & 4.944 \\
\hline
\end{tabular}

$\mathrm{Zu}$ diesem Zeitpunkt waren 3.425 Mann als fahnenflüchtig gemeldet, 373 waren regulär entlassen worden. Am höchsten war die Zahl der Deserteure bei der Gruppe Hauser, die als Verbindungsstab zu den nationalen Banden fungierten (1.055 Mann), sowie beim Feldersatz-Bataillon 21 (854 Mann). ${ }^{489}$

\subsection{Ausrüstung und Besoldung}

Bereits Ende Oktober 1943, nach der Rückkehr in ihr Heimatland, berichteten die beiden italienischen Soldaten Lamberto Francesconi und Roberto Ponsard bei ihrer Vernehmung, dass die deutschen Truppen in Albanien schlecht ausgerüstet und unterernährt waren: „Viele von ihnen sagen, dass sie kriegsmüde seien und dass sie sicher sind, dass Deutschland den Krieg jetzt nur noch verlieren kann." 490 Außerdem würden die deutschen Soldaten aufgrund ihrer prekären Situation alles Mögliche verkaufen. ${ }^{491}$

487 Stärkemeldung „Skanderbeg“, 20.9.1944, BArchB, NS19/1475, Bl. 24.

488 Vgl. Schmidhuber, „Zusammenfassender Bericht“, 2.10.1944, BArchF, RS 3-21/1, Bl. 6.

489 Vgl. ebd., Bl. 6.

490 Vernehmung Lamberto Francesconi und Roberto Ponsard, 31.10.1943, AUSSME I3/b13/f1, S. 7.

491 Ebd. 
Die Ausrüstungssituation verschärfte sich im folgenden Halbjahr noch. Überblickt man die kurze Zeit des Bestehens der Division „Skanderbeg“, wird ein Mangel an fast allem offensichtlich. Die Ausrüstung setzte sich hauptsächlich aus Beutebeständen italienischer Provenienz zusammen. Die spät aufgestellten Divisionen sind deshalb nicht vergleichbar mit frühen Divisionen der Waffen-SS, wie etwa der „Leibstandarte Adolf Hitler“, „Das Reich“ oder der „Totenkopf“. ${ }^{492}$ In einem Schreiben an Berger meinte der Leiter des Referats VIa, Walter Letsch, bereits Ende 1943, dass es bereits als Vorteil gewertet werden müsste, dass zur Ausrüstung der neu aufgestellten Verbände in Südosteuropa überhaupt Waffen zur Verfügung stünden und die Verpflegung zu großen Teilen aus dem Land selbst bezogen werden könnte. ${ }^{493}$ Um trotz zusammengewürfelter Ausrüstung und Uniformen ein Zusammengehörigkeitsgefühl zu erzeugen, setzten Himmler und Berger auf nationale Symbole. Die Kopfbedeckung sollte dabei der lokalen traditionellen Mode entsprechen, wobei nicht der für die „Handschar“ übliche osmanische Fez, sondern eine landeseigene Filzkappe, die Qeleshe oder der Plis, gewählt wurde. ${ }^{494}$

Schmidhuber schrieb Anfang Oktober 1944, dass er insgeheim sogar froh darüber war, dass die durch Pejani und die „Zweite Liga“ zugesicherten 10.000 Mann nicht allesamt per 1. Mai 1944 gemeldet hatten, da die Unterkünfte zuerst instandgesetzt werden mussten. Die Bewaffnung war von Anfang an unzureichend. Laut Schmidhuber waren „Waffen, Gerät und Bekleidung“ gar nie bei der Division eingetroffen. Die Besoldung konnte den rund 6.000 Mann nur im Mai und Juni vollumfänglich ausgezahlt werden. Bei einem Massenandrang zur Division hätte sie von Beginn an nicht ausgereicht, notierte Schmidhuber Anfang Oktober 1944. ${ }^{495}$

\subsection{Stationierung und Einsatzbereiche}

Der Historiker Schmider ist der Meinung, dass die ethnische Zusammensetzung und die Motivation der Mannschaft, ihr Gebiet vor „ethnischen Säuberungen“ durch andere Kriegsparteien, wie Četniks, Tito-Partisanen oder der albanischen „Nationalen Befreiungsfront“, zu schützen, den Einsatz im ursprünglichen Rekrutierungsraum zwingend vorausgesetzt habe, ${ }^{496}$ gerade weil man aus Erfah-

492 Vgl. Schreiben Berger an das AA, z.Hd. Reichel, 11.10.1943, BArchB, NS 19/1660, Bl 4.

493 Vgl. Schreiben Letsch an Berger, 8.10.1943, BArchB, NS 19/1660, Bl. 2.

494 Vgl. Zaugg, Albanische Muslime, S. 185.

495 Vgl. Schmidhuber, „Zusammenfassender Bericht“, 2.10.1944, BArchF, RS 3-21/1, S. 4.

496 Vgl. Schmider, Partisanenkrieg, S. 538. 
rung bei der „Handschar“ wusste, dass sich die Angriffe auf die heimatlichen Gebiete mehren würden, wenn diese ungeschützt blieben. ${ }^{497}$

Somit war diese Division von Anfang an „für den lokalen Partisanenkrieg innerhalb der Grenzen des Landes“ vorgesehen, wie Neubacher nachträglich schreibt, denn seit der Kapitulation Italiens gestaltete sich die interne Situation in Albanien chaotisch und wies bürgerkriegsähnliche Züge auf. Die „Skanderbeg“ hatte dementsprechend verschiedene Funktionen $\mathrm{zu}$ erfüllen. ${ }^{498}$ Erstens war die Division zuständig für die Sicherung der zwei wichtigsten Rückzugsstraßen. Die eine führte von Skopje über Mitrovica nach Belgrad, die andere von Peć/Pejë in Richtung montenegrinisch-kroatische Küste. Auch die Sicherung regionaler Verkehrsverbindungen in „Neualbanien“, beispielsweise die Passstraße bei Đjakovica/Gjakova, gehörte zu ihren Aufgabenbereichen. ${ }^{499}$ Zweitens galt die Aufmerksamkeit verschiedenen wehrwirtschaftlich relevanten Objekten, etwa den Chromerzgruben Đjakovica/Gjakova und Kukës, den Bleiminen bei Trepča/ Trepça und weiteren ähnlichen Einrichtungen. Drittens sollte die Division durch ihre Präsenz und durch Personenkontrollen dafür sorgen, dass in den „neualbanischen“ Gebieten „Ruhe und Ordnung“ aufrechterhalten werden konnten, und ihre Grenzen gegen außen sichern. ${ }^{500}$

Viertens rekrutierte sich aus der „Skanderbeg“, insbesondere aus ehemaligen albanischen Divisionsangehörigen der „Handschar“, die Wachmannschaft für das ebenfalls durch die „Skanderbeg“ aufgebaute Konzentrationslager in Priština/Prishtina. ${ }^{501}$ Potentielle Feinde wurden nicht nur bei den wachsenden Partisanenarmeen von außen, in Serbien und Montenegro bzw. Mittel- und Südalbanien verortet, sondern auch innerhalb der kosovarischen Bevölkerung, denn auch im Kosovo gab es kommunistische Partisanengruppen, so etwa diejenigen unter dem Kommando Fadil Hoxhas. ${ }^{502}$ Wie Schmidhuber Ende Mai 1944 an die Präfekten von Prishtina/Prišina, Pejë/Peć, Prizren schrieb, waren somit die

497 Vgl. Brief Nr. 9 Divisionskommandeur Sauberzweig an Mannschaft der 13. SS-Division, 27.3.1944, BArchB, NS 19/2601, Bl. 214.

498 Vgl. Neubacher, Sonderauftrag Südost, S. 116, Birn, Höhere SS- und Polizeiführer, S. 285 sowie „Zusammenfassender Bericht“ Schmidhuber, 2.10.1944, BArchF, RS 3-21/1, S. 7.

499 Vgl. Brief Kopf an Leopold Stütz, 28.5.1964, BArchF, N 756/182a. Vgl. Kriegsgefangenenbericht Schrader, VA HEM.OK.BOJCKA, 72A/1a/34, S. 2.

500 Vgl. Schreiben Schmidhuber, 31.5.1944, BArchF, RH 19 XI/9.

501 Vgl. Schmidhuber an die Präfekten von Pršitina, Prizren und Peć, 31.5.1944, BArchF, RH 19-XI/9, Bl. 27.

502 Fadil Hoxha war ab 1945 Vorsitzender der Volksversammlung und gleichzeitig auch Vorsitzender des Exekutivrats für Kosovo. Über die verschiedenen im Raum Kosovo agierenden Partisaneneinheiten unter Fadil Hoxha siehe Archiv Prishtina. Vgl. AK, F: Dosjete robërve të luftës në Gjermani, K 1. 
„Erhaltung der Ruhe und Ordnung im inneren Kosovo sowie [die] Sicherung der Grenzen Kosovos gegen ein Eindringen des Kommunismus“ zentrale Aufgabenfelder der „Skanderbeg“. 503

Das Gebiet, in welchem die Division „Skanderbeg“ agierte, reichte von den heute mazedonischen Regionen bei Kičevo und Tetovo, über Kukës in „Altalbanien“, den heutigen Kosovo, bis hinein nach Montenegro bis Rožaje/Rozhaj, Plav und Berane. Dieses Territorium entspricht in etwa demjenigen der Straßensicherung, wenngleich einzelne Einsätze über diese Grenzen hinausgingen. Da die Division nie die Sollstärke erreichte, sie weder über eine adäquate militärische Ausbildung noch über die nötige Ausrüstung verfügte, wurde sie schließlich, anders als ursprünglich vorgesehen, kaum mehr zur Sicherung des Rückzuges der Wehrmacht, sondern nur noch für den lokalen „Bandenkampf“ eingesetzt. ${ }^{504}$

Die Einheiten der Division „Skanderbeg“ waren in folgenden Orten stationiert:

\begin{tabular}{lll}
\hline Einheit & Ort & Kommandeur \\
\hline Div.Stab. & Prizren & Schmidhuber \\
\hline Stab 1. Rgt. & Pejë/Peć & SS-Staf Ludwig, nur für einige Wochen \\
\hline I./1 & Pejë/Peć & SS-Stubaf Zeitler \\
\hline II./1 & Im Kloster Deçan/ & SS-Stubaf Wolf \\
& Dečani & \\
\hline III./1 & Đakovica/Gjakova & $?$ \\
\hline Stab 2. Rgt. & $?$ & Nicht besetzt \\
\hline I./2 & Tetovo & SS-Ostubaf Hauser \\
\hline II./2 & Gostivar & Nicht besetzt \\
\hline III./2 & Kičevo & Nicht besetzt \\
\hline AA & Đakovica/Gjakova & SS-Stubaf Meyer (magen- und leberleidend), Nachfolger: SS- \\
\hline Art.Rgt. & Prishtina/Priština & SS-Hstuf Gerstenberger, Rudolf \\
\hline
\end{tabular}

503 Schreiben August Schmidhuber an die Präfekten von Priština, Prizren und Peć, 31.5.1944, BArchF, RH 19-XI/9, Bl. 27.

504 Vgl. Brief Kopf an Vopersal, 19.4.1976, BArchF, N 756/185a. 
(fortgesetzt)

\begin{tabular}{lll}
\hline Pz.Jg.Abt. & Prishtina/Priština & SS-Stubaf Bauer \\
\hline Nachr.Abt. & Prizren & SS-Ostuf Strantz, Alfred und SS-Ostuf Neumann, Herbert \\
\hline Nachschub- & Gračanica & SS-Hstuf Schröder ${ }^{505}$ \\
Abt. & & \\
\hline
\end{tabular}

Die Einheiten waren zum Teil in ehemaligen Kasernen und in Schulen, eine Einheit auch im Kloster Deçan/Dečani und eine in einer Klosterschule untergebracht. Innenminister Deva hatte den Vertretern der SS versprochen, fehlende Truppenunterkünfte neu aufzubauen. ${ }^{506}$ Schmidhuber hingegen gab an, dass für die Mannschaften vor allem ehemalige italienische Truppenunterkünfte vorgesehen waren, die allerdings, da sie „restlos verwahrlost“ waren, zuerst instand gesetzt oder ganz neu aufgebaut werden mussten. ${ }^{507}$ Graf erinnerte sich, dass für dieses Vorhaben bereits eine SS-Bauleitung sowie ein Trupp SS-Geologen in Prizren stationiert waren. Die oben aufgeführten Einheiten waren die einzigen, die in Wirklichkeit bestanden, alle anderen hätten nur auf dem Papier existiert, so Graf. ${ }^{508}$

505 Vgl. Aufzeichnungen Alfred Graf an Vopersal, 1973, Nachlass Vopersal, BArchF, N 756/182b. 506 Vgl. ebd.

507 Vgl. „Zusammenfassender Bericht“ Schmidhuber, 2.10.1944, BA-MA, RS 3-21/1, S. 4. 508 Vgl. Aufzeichnungen Alfred Graf an Vopersal, 1973, Nachlass Vopersal, BArchF, N 756/182b. 


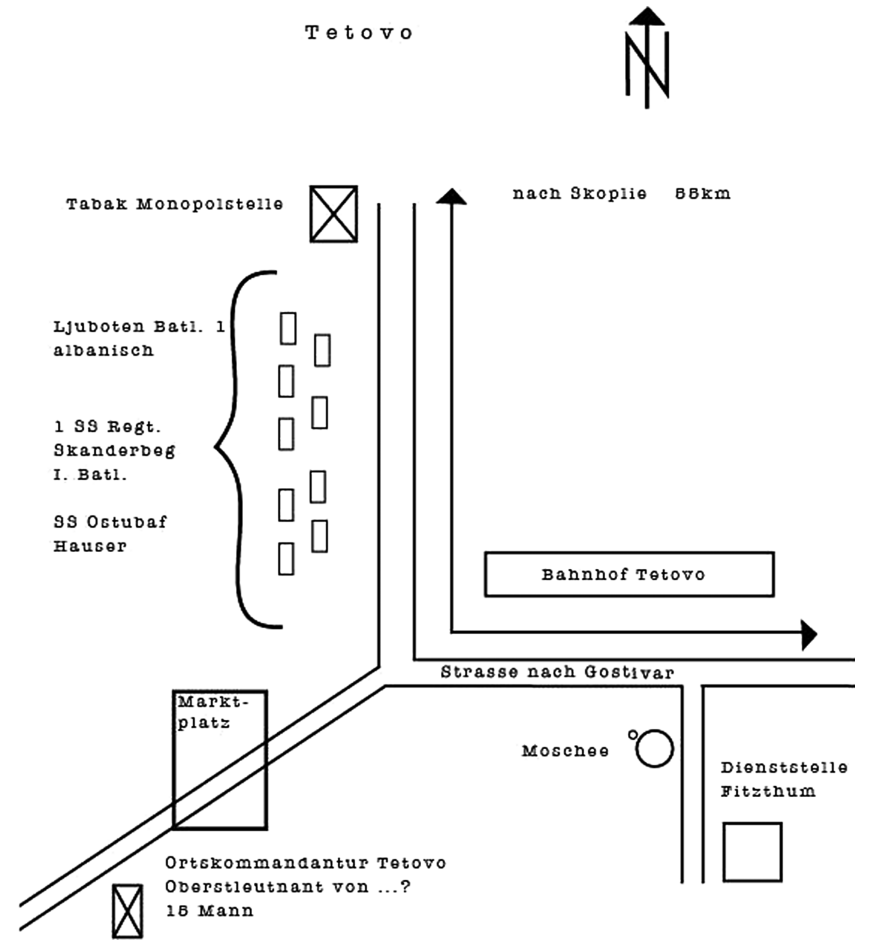

Abb. 40: Karte Tetovo. ${ }^{509}$

509 Karte Tetovo (I./1 Hauser) gezeichnet von Belina Zaugg anhand einer Skizze in BArchF, Nachlass Vopersal, N 756/182b. 


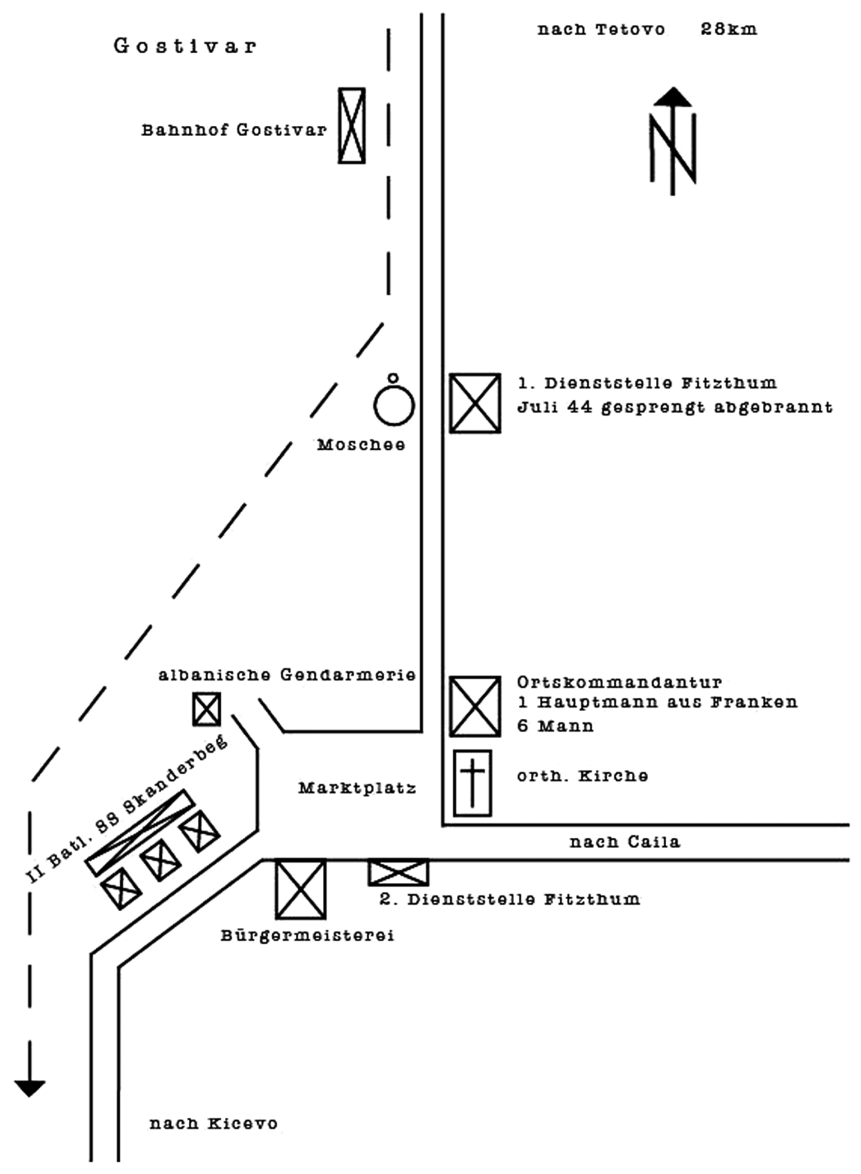

Abb. 41: Karte Gostivar. ${ }^{510}$

510 Karte Gostivar (II Btl. Skanderbeg) gezeichnet von Belina Zaugg anhand einer Skizze in BArchF, Nachlass Vopersal, N 756/182b. 


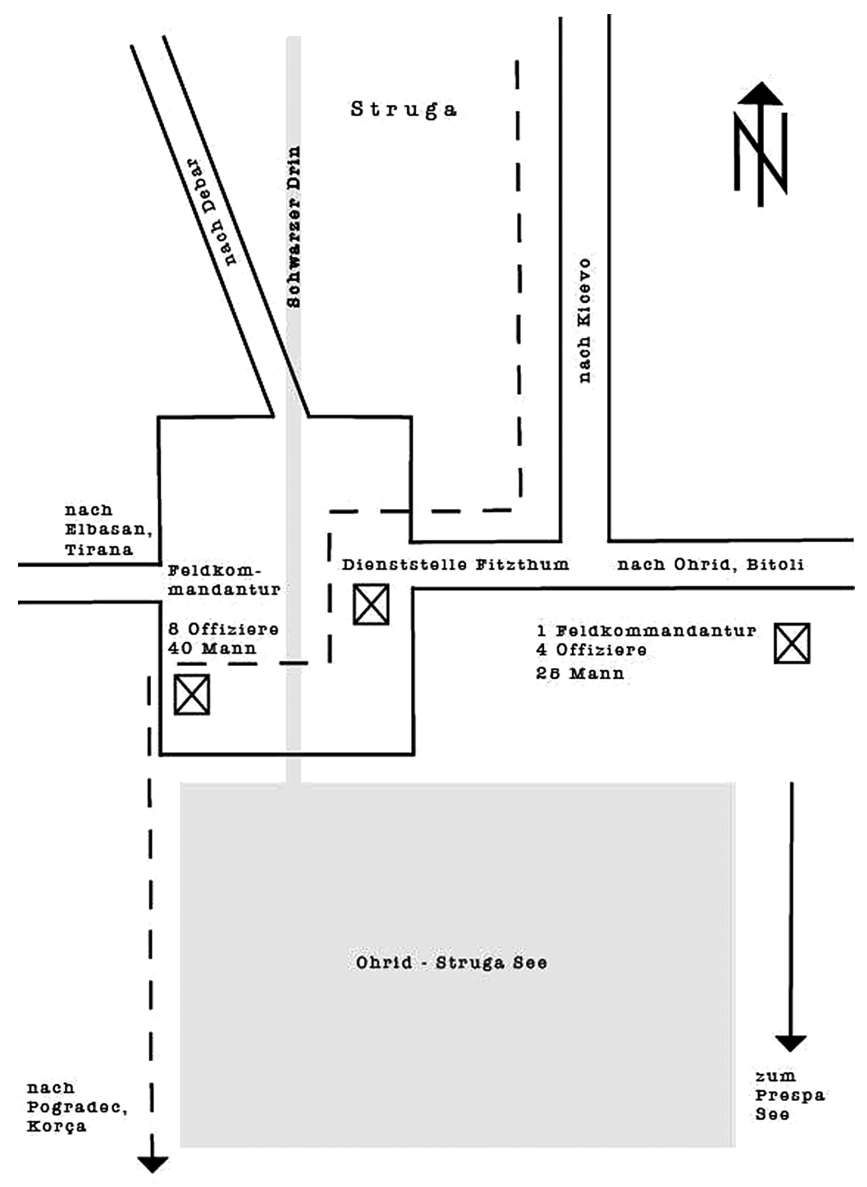

Abb. 42: Karte Struga..$^{511}$

511 Karte Struga gezeichnet von Belina Zaugg anhand einer Skizze in BArchF, Nachlass Vopersal, N 756/182b. 


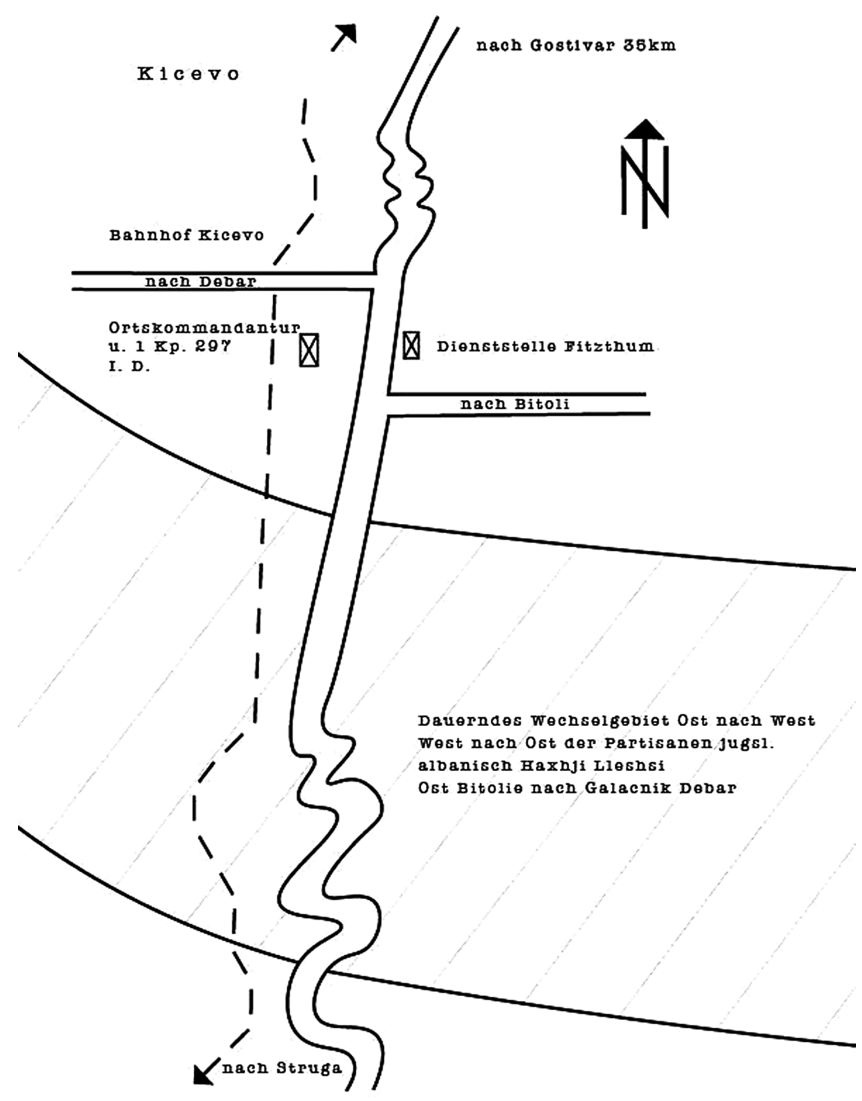

Abb. 43: Karte Kičevo. ${ }^{512}$

\subsubsection{Sicherung der Verkehrswege im Raum Kosovo}

Der Raum Kosovo ist Grenzgebiet zwischen verschiedenen Ländern und gilt bis heute als eine Schnittstelle zwischen verschiedenen Kulturen. Die Topographie dieser Region eignete sich für einen Guerillakrieg besonders: In den 1940er Jahren gab es kaum befahrbare Straßen, große Teile waren bewaldetes Gebiet oder hügelige bis bergige Karstlandschaften. Den deutschen Besatzern war seit ihrer

512 Karte Kičevo gezeichnet von Belina Zaugg anhand einer Skizze in BArchF, Nachlass Vopersal, N 756/182b. 
Ankunft 1941 nicht entgangen, dass Kosovo ein stark frequentiertes Durchzugsgebiet einerseits von „deutschfeindlichen“ Gruppierungen, andererseits von Flüchtlingen war, die versuchten, über Serbien nach „Altalbanien“ zu gelangen. ${ }^{513}$ Schmidhuber und Fitzthum gingen aber davon aus, dass auch aus „Altalbanien“ Kommunisten und antideutsche Gruppierungen in die „neualbanischen“ Gebiete, vor allem Kosovo, eindringen würden. Schmidhuber versuchte diesen Bewegungen Einhalt zu gebieten, indem er Straßenkontrollen anordnete. Die Angehörigen der „Skanderbeg“ sollten am 15. Juni 1944 sowohl Reisende im Straßen- als auch im Eisenbahnverkehr auf ihre Identität, als auch Ausgangsort, Reiseziel und Zweck der Reise kontrollieren. Bei jeder vermeintlich verdächtig aussehenden Person durften die Angehörigen der „Skanderbeg“ Gepäckkontrollen durchführen. Konnte ein Reisender sich nicht befriedigend erklären, wurde er in das „Anhaltelager der Division“ nach Prishtina/Priština überstellt. In den folgenden Monaten sollten diese Kontrollen jeweils wöchentlich für 24 Stunden wiederholt werden. Kontrollen fanden an der Verbindungsstraße Shkodër-Kukës, Gostivar-Kicevo, Skopje-Tetovo und Skopje-Uroševac durch die jeweiligen Ortskommandanturen der „Skanderbeg“ statt. Diese hatten jeweils am ersten Tag des Folgemonats über die durchgeführten Streifen und Erfolge dem Ic der „Skanderbeg“, SSHauptscharführer Schweissgut, Bericht zu erstatten. ${ }^{514}$

Die wenigen Straßen und mehr noch die Eisenbahnverbindung durch Kosovo galten als „Lebensnerv aller auf dem Balkan kämpfenden deutschen Soldaten“. Weil diese Eisenbahnstrecke die einzige in ganz „Großalbanien“ war, gab das Generalkommando des XXI. Gebirgskorps die Weisung aus, dass die Aufrechterhaltung dieser Eisenbahnverbindung oberste Priorität hatte. ${ }^{515}$ Hinzu kamen im Gebiet Kosovos bzw. „Neualbaniens“ einige Flugplätze, die im Verantwortlichkeitsbereich der „Skanderbeg“ lagen: ${ }^{516}$

513 Vgl. Ramaj, Albert, Rettung von Juden in Albanien, in: Ökumenisches Forum für Religion und Gesellschaft in Ost und West, G2W, 2/2007, S. 18.

514 Vgl. Abschrift „Kontrolle des Ein- und Durchreiseverkehrs im Kosovogebiet“, Div. Kdr. Schmidhuber, 15.6.1944 (Anlage 10 zu DGA Nr. 3046/44 g.v. 23.6.1944), BArchF, RH 19-XI/9, Bl. 24. 515 Vgl. Gen.Komm. XXI. Geb.A.K. an 21. Waffen-Geb.Div, undatiert, NARA, T314/664, Bl. 772. 516 „Verantwortliche für Flugplätze“, NARA, T314/664, Bl. 180. 


\begin{tabular}{|c|c|c|c|}
\hline Flugplatz & $\begin{array}{l}\text { Verantwortl. } \\
\text { Offizier }\end{array}$ & Truppenteil-Einsatzort & Bedarf an Ausrüstungsgegenständen \\
\hline Priština & $\begin{array}{l}\text { SS-Ostuf. } \\
\text { Schaumüller }\end{array}$ & $\begin{array}{l}\text { Pz.Jg.Abt.SS } 21 \\
\text { Priština }\end{array}$ & $\begin{array}{l}\text { Je } 1 \text { Finnenzelt, Landekreuz, } \\
\text { Leuchtpistole }\end{array}$ \\
\hline Peć & SS-Stubaf. Köhler & $\begin{array}{l}\text { I./Geb.Jg.Rgt.SS } 51 \\
\text { Peć }\end{array}$ & $\begin{array}{l}\text { Je } 1 \text { Finnenzelt, Landekreuz, } \\
\text { Leuchtpistole }\end{array}$ \\
\hline Đjakovica & SS-Ustuf. Markovic & $\begin{array}{l}\text { Aufkl.Abt.SS } 21 \\
\text { Djakovica }\end{array}$ & $\begin{array}{l}\text { Je } 1 \text { Finnenzelt, Landekreuz, } \\
\text { Leuchtpistole }\end{array}$ \\
\hline Prizren & SS-Ustuf. Krah & $\begin{array}{l}\text { III./Geb.Jäg.Rgt.SS } 51 \\
\text { Prizren }\end{array}$ & $\begin{array}{l}\text { Je } 1 \text { Finnenzelt, Landekreuz, } \\
\text { Leuchtpistole }\end{array}$ \\
\hline Tetovo & SS-Hstuf. Peters & $\begin{array}{l}\text { I./Geb.Jäg.Rgt.SS } 50 \\
\text { Tetovo }\end{array}$ & $\begin{array}{l}\text { Je } 1 \text { Finnenzelt, Landekreuz, } \\
\text { Leuchtpistole }\end{array}$ \\
\hline Struga & $\begin{array}{l}\text { SS-Hstuf. und } \\
\text { Hptm. der } \\
\text { Gendarmerie Graf }\end{array}$ & $\begin{array}{l}\text { Gend. Insp. II } \\
\text { Struga }\end{array}$ & $\begin{array}{l}\text { Je } 2 \text { weiße und gelbe Fliegertücher, } \\
\text { Leuchtpistole, weiße, rote, grüne } \\
\text { Leuchtpistolen, Rauchkörper }\end{array}$ \\
\hline
\end{tabular}

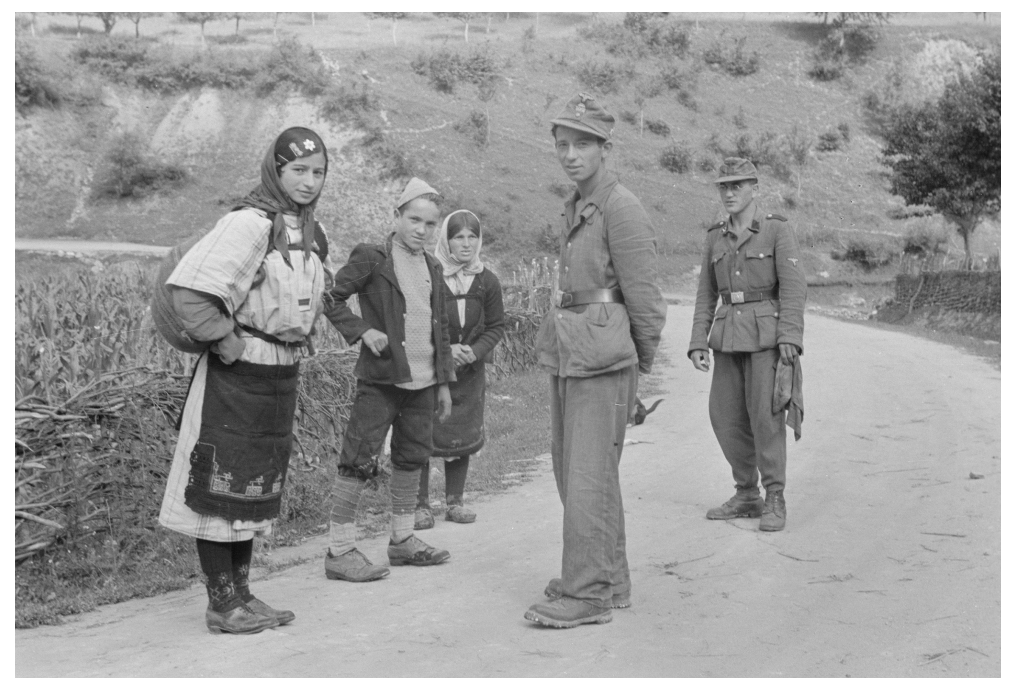

Abb. 44: Junger „Skanderbeg“-Angehöriger im Austausch mit anderen Jugendlichen. Gut sichtbar: Die Strassen im Kosovo waren nicht ausgebaut. ${ }^{517}$ 


\subsubsection{Sicherung kriegswirtschaftlich relevanter Einrichtungen ${ }^{518}$}

Aufgrund der allgemeinen Kriegssituation zählte Albanien $1944 \mathrm{zu}$ den wichtigen Lieferanten für die deutsche Kriegswirtschaft - nicht nur im Bereich der Chromerzförderung, ${ }^{519}$ sondern auch als Erdöllieferant. Bergwerke waren aber nicht nur strategische Anschlagsziele lokaler Partisanengruppen, sie waren auch verhältnismäßig einfache Ziele. Deshalb war, wie bereits erwähnt, einer der wichtigsten Einsatzbereiche der „Skanderbeg“ der Schutz „wehrwirtschaftlich wichtiger Objekte“. Dazu gehörten etwa die Chromerzgruben von Đjakovica/Gjakova und Kukës. Auch die Sicherung der Grube von Pogradec wäre in den Aufgabenbereich der „Skanderbeg“ gefallen; diese Anlage wurde aber nie in Betrieb genommen. ${ }^{520}$

Am 4. Juli 1944 erließ Generalmajor Helmuth von Grolman, Chef des Generalstabs der 2. Panzerarmee, der die „Skanderbeg“ unterstellt war, die Richtlinie, dass die Sicherung aller Gruben, kriegswichtigen Betriebe und Industrieanlagen „auf Grund ihrer kriegsentscheidenden Bedeutung - zu einer taktischen Angelegenheit geworden und verantwortlich durch die Führungsabteilungen der einzelnen Kommandobehörden zu bearbeiten" war. 521

[Die] Durchführung dieser Aufgabe stellt eine neue Belastung der ohnehin schon stark angespannten Kräfte dar. Sie muss - im Hinblick auf ihre entscheidende Bedeutung - in Kauf genommen und durchgeführt werden. Alle für die Kriegsrüstung und Kriegswirtschaft wichtigen Gruben, Industrie- usw. Anlagen müssen kräfte- und ausbaumäßig gegebenenfalls unter Zurückstellung anderer taktischer Erfordernisse - so gesichert werden, dass ihre Ausschaltung oder eine Minderung ihrer Leistungsfähigkeit durch Bandenangriffe oder Sabotage ausgeschlossen ist. ${ }^{522}$

Aufgrund personeller Engpässe und weil die Chromerzgruben für die Partisanen ein einfaches Ziel boten, konnte ihre Sicherung im Spätsommer 1944 nur

518 Vgl. zu diesem Unterkapitel ausführlich Zaugg, Albanische Muslime, S. 252-254.

519 Vor 1939 waren es vor allem die Türkei, Griechenland und Südafrika, welche Deutschland mit Chromerz versorgten. Vgl. hierzu ausfürhlich Zaugg, Albanische Muslime, S. 113-123.

520 Vgl. OB Südost, Bericht „Entwicklung der militärischen Lage in Albanien im Herbst 1944“, undatiert, BArchF, RW 40/116a, Bl. 52. Welche Bedeutung der Sicherung der Chromerzgruben zukam, zeigt der Befehl, dass die „Skanderbeg“ sogar während eines Vorstoßes zur Zurückdrängung des „roten Gegners“ melden musste, „,welche Kräfte hierfür unter Berücksichtigung der absoluten Sicherung des Chromerzabbaues Djakovica [sic] und südl. Kukes [sic]“ sie überhaupt entbehren konnte. Gen. Kdo. XXI Geb.A.K. Ia Nr 4751/44 an SS-Div. ,Skanderbeg‘, nachrichtl. an 181. Inf. Div., 297. Inf. Div., 9.7.1944, NARA, T314/664, F. 160.

521 „Richtlinien über die Sicherung wehrwirtschaftlicher Objekte im Bereich Pz.AOK.2“, Chef des Generalstabes, Generalmajor Helmuth von Grolman, an Ia/Ic 4.7.1944, NARA, T314/664, F. 173f. Hervorhebung im Original.

522 Ebd. 
noch mit Mühe aufrechterhalten werden. Während des Unternehmens „Fuchsjagd“ in der zweiten Augusthälfte 1944, das zahlreiche Kräfte der „Skanderbeg“ band, sind mehrere Angriffe auf die Chromerzgruben von Gjakova/Đjakovica dokumentiert. ${ }^{523}$ Trotz der zunehmend schwierigen, geradezu aussichtslosen Situation, erteilte Hitler der „Skanderbeg“ den Auftrag, die Chromerzgruben noch mindestens bis zum 7. Oktober 1944 zu halten. ${ }^{524}$

\subsubsection{Verfolgung von Juden und Kommunisten}

Der Befehl Schmidhubers vom 25. Mai 1944, alle ortsansässigen Einwohner in den Präfekturen Prizren, Prishtina/Priština und Pejë/Peć bis zum 1. Juni 1944 zu erfassen und an jedem Haus ein Verzeichnis der darin wohnenden Personen anzubringen, war ein Versuch, die wenigen jüdischen Familien sowie verdächtige Zivilpersonen sofort verorten zu können, sobald ihre Namen gefallen waren. Flüchtlingen wurde die Reise durch Neualbanien außerdem durch die Personenkontrollen erschwert, die bei nicht befriedigender Auskunft eine Deportation ins Lager Prishtina/Priština zur Folge hatten. ${ }^{525}$

Zwar ging der OB Südost davon aus, dass „Juden [...] so gut wie gar nicht in Albanien vorhanden [waren].“ Es schien ihm außerdem auch nicht möglich, „in dem selbständigen Staat [...] hier irgendwie einzugreifen“, ${ }^{526}$ da die Behörden in „Altalbanien“ an der Auslieferung von albanischen und ausländischen Juden nicht sonderlich interessiert waren. ${ }^{527}$ „Neualbanien“ hingegen war ein von Flüchtlingen stark frequentiertes Gebiet und musste auch von fliehenden Juden, die nach „Altalbanien“ gelangen wollten, durchquert werden. Schmidhuber for-

523 Neben den in den Aufgabenbereich der „Skanderbeg“ fallenden Abbaustätten Đjakovica und Kukës, wurden in „Großalbanien“ die Erdölfelder in Devolli und die Zementfabrik Shkodër als besonders relevant für die deutsche Kriegswirtschaft und daher als schützenswert eingestuft. In Devolli übernahm die 297. Infanterie-Division die Bewachung, in Shkodër die 181. Infanterie-Division. Vgl. Fernschreiben Gen.Kdo. XXI. Geb.A.K an Pz.AOK.2, 22.8.1944, NARA, T314/664, Bl. 574. Vgl. Tagesmeldung Gen.Kdo. XXI. Geb.A.K. an Pz.AOK.2, 21.8.1944, NARA, T314/664, F. 562, 571, 574 u. 637.

524 Vgl. Fernschreiben OB Südost, Winter, an Oberkommando Heeresgruppe E, Pz.AOK 2, Armeeabteilung Serbien (Mil. Befehlsh. Südost), 7.10.1944, BArchF, RH 19/XI/22, Bl. 171.

525 Vgl. Abschrift „Kontrolle des Ein- und Durchreiseverkehrs im Kosovogebiet“, Div. Kdr. Schmidhuber, 15.6.1944 (Anlage 10 zu DGA Nr. 3046/44 g.v. 23.6.1944), BArchF, RH 19-XI/9, Bl. 24.

526 OB Südost, Bericht „Entwicklung der militärischen Lage in Albanien im Herbst 1944“, undatiert, BArchF, RW 40/116a, Bl. 61.

527 Vgl. Albert Ramaj, Rettung von Juden in Albanien, S. 18. 
derte daher die Bevölkerung im Kosovo auf, ,alle ortsfremden Personen von sich aus festzuhalten und der nächsten deutschen SS- oder Militärbehörde zuzuführen“. ${ }^{528}$ Im Kosovo wurden insgesamt, je nach Quelle, zwischen 281 und 400 Juden verhaftet; ${ }^{529}$ teilweise nachdem sie von lokalen Personen verraten worden waren, wie im Falle der Familie von Raul Teitelbaum in Prizren. ${ }^{530}$

Kosovo war aufgrund der noch offenen Frage, zu welchem Staat es nach dem Krieg zählen würde, somit einerseits das Gebiet mit der höchsten Rate an Kollaborationswilligen, andererseits aber sowohl durch seine geographische Lage zwischen Montenegro, Serbien, Bulgarien und Mazedonien als auch aufgrund seiner Geschichte ein Knotenpunkt anti-deutscher Strömungen und Fluchtbewegungen; im Personen-, Waren- und Nachrichtenverkehr spielte die Region daher eine zentrale Rolle. Schmidhuber sah die Aufgabe seiner Division darin, Kosovo als Durchzugsgebiet für Partisanen und Flüchtlinge möglichst unattraktiv zu machen, indem die oben genannten Maßnahmen so rasch wie möglich umgesetzt wurden. ${ }^{531}$ Obwohl DGA Gullmann einwandte, dass Schmidhuber keine direkten Weisungen an Präfekturen und andere albanische Regierungs- und Verwaltungsstellen erlassen könne, sondern der Dienstweg über ihn zu führen habe, durfte Schmidhuber weiterhin erforderliche „Sofortmaßnahmen“ ohne Rücksprache mit den territorialen Dienststellen durchführen. Die oben genannten am 25. Mai 1944 an die Präfekturen erfolgten Weisungen blieben entsprechend bestehen. Allerdings wehrte sich Gullmann in Bezug auf Waffenscheine. Aus Rücksicht auf die

528 Schreiben „Betr.: Personenerfassung und Waffenscheine im Kosovo-Gebiet“ Schmidhuber an die Präfekten von Prizren, Priština und Peja, 25.5.1944, (Abschrift, Anlage 10 zu DGA Nr. 3046/44/geh.v.23.6.1944), BArchF, RH 19-XI/9, Bl. 26. Volkstumsreferent Feninger gab 1941 nach seiner Reise durch das Kosovogebiet unter deutscher Militärherrschaft den Anteil der ansässigen jüdischen Bevölkerung als „ziemlich gering“ an. Am höchsten sei der Anteil von Juden in Novi Pazar gewesen (240 Juden), während in Mitrovica nur 60 bis 70 Juden gelebt hätten. Vgl. Bericht „über die Reise in das Arnautengebiet von Kosovska Mitrovica und Novi Pazar“ des Volkstumsreferenten Dr. Feninger beim Bevollmächtigten des AA in Belgrad, 15.-26.10.1941, PAAA, R261153, Bl. 39.

529 Vgl. Albert Ramaj, Bedrängte Juden im Kosovo, in: Ökumenisches Forum für Religion und Gesellschaft in Ost und West, G2W, 2/2007, S. 20. Vgl. auch Sara Berger, Erwin Lewin, Sanela Schmid, Maria Vassilikou, Verfolgung und Ermordung der Juden 1933-1945, in: Besetztes Südosteuropa und Italien, Bd. 14, Berlin/Boston: De Gruyter/Oldenbourg 2017, S. $83 \mathrm{f}$.

530 Raul Teitelbaum, https://collections.ushmm.org/search/catalog/pa1178094, USHMM (Stand: 28.2.2018).

531 Vgl. Schreiben „Betr.: Personenerfassung und Waffenscheine im Kosovo-Gebiet“ Schmidhuber an die Präfekten von Prizren, Priština und Peja, 25.5.1944, (Abschrift, Anlage 10 zu DGA Nr. 3046/44/geh.v.23.6.1944), BArchF, RH 19-XI/9, Bl. 26. 
Sitten der Bevölkerung „habe ich man davon Abstand genommen, Waffenscheine ausstellen $\mathrm{zu}$ lassen. “532

Schmidhuber bestätigt die oben genannte Aktion in seinem Bericht vom Oktober 1944: Die Division habe aufgrund der Auswirkungen „einer verstärkten kommunistischen Propaganda“ im „Innern Kosovos“ in zwei Überraschungsaktionen die Verhaftung aller 281 Juden durchgeführt. Außerdem rapportierte er „die Aushebung einer umfangreichen kommunistischen Organisation, die insgesamt 210 kommunistische Funktionäre“ umfasst haben soll. ${ }^{533}$ Verschiedene Meldungen aus dem Divisionstagebuch bestätigen, dass tatsächliche oder vermeintliche Gegner der Deutschen auch in den Grenzgebieten, beispielsweise in jenem zu Montenegro, verfolgt wurden. ${ }^{534}$

Dass in „Großalbanien“, auch im Kosovo, noch im Sommer 1944 ein gewisser Spielraum hinsichtlich der Behandlung von Juden herrschte, zeigt etwa folgendes Beispiel: Am 20. Juni 1944 wurde der Jude Gahr in Rožaje verhaftet und anschließend nach Prishtina/Priština gebracht. SS-Untersturmführer Hummer erkundigte sich daraufhin, ob er der Bitte von Frau Gahr stattgeben dürfe, ihrer erwachsenen Tochter und ihrem Sohn zu erlauben, Rozhaj/Rožaje in Richtung Tirana zu verlassen. ${ }^{535}$

Problematisch gestaltete sich auch der Abtransport von Gefangenen in das KZ Prishtina/Priština. Der Mangel an Personal und an Fahrzeugen behinderte den Gefangenentransport. Die Kampfgruppe Bormann konnte zwei Gefangene nicht nach Prishtina/Priština ins Konzentrationslager überführen, weil auf den wenigen Fahrzeugen akuter Platzmangel herrschte. Auch das Wachkommando konnte den Transport nicht übernehmen, da es nur zwei Personen stark war. Blatz vom Meldekopf Rozhaj/Rožaje fragte deshalb bei Ic Hauptscharführer Schweissgut an, was mit den Gefangenen geschehen solle. ${ }^{536}$

532 Schreiben Gullmann an Fitzthum, 5.6.1944, BArchF, RH 19-XI/9, S. 4. Durchgestrichen im Original.

533 „Zusammenfassender Bericht“ Schmidhuber, 2.10.1944, BArchF, RS 3-21/1, S. 4.

534 Vgl. Ia an Hstf. Bormann, Rožaje, 14.6.1944, BArchF, RS 3/21/2, S. 11. Vgl. Meldekopf Rožaje an Hptm. Bendl, 21.7.1944, BArchF, RS 3-21/2, S. 22. Meldekopf Rožaje an Hptm. Bendl, 27.7.1944, BArchF, RS 3-21/2, S. 35.

535 SS-Untersturmführer Hummer an Ic, Schweissgut, BArchF, RS 3-21/2, 20.6.1944, Bl. 111. 536 Vgl. Blatz an Div. Ic, provisorisch Hptscharf. Schweissgut, 23.6.1944, BArchF, RS 3-21/2, Bl. 117. 


\subsubsection{Aufbau des Konzentrations- und Anhaltelagers Prishtina/Priština}

Seit Frühjahr 1944 war die Division zuständig für den Aufbau und Unterhalt des Konzentrationslagers Prishtina/Priština. In einigen Dokumenten wird dieses auch als Anhaltelager bezeichnet. Unerwünschter Durchgangsverkehr von Flüchtlingen und Partisanen im Kosovo und angrenzenden Regionen machten nach Ansicht Schmidhubers in einem Schreiben an die Präfekten in Prishtina/Priština, Prizren und Pejë/Peć Ende Mai 1944 „die Einrichtung eines Erziehungslagers für politisch, insbesondere kommunistisch Verdächtige und Schuldige notwendig “. 537

Im Bericht des Generalkommandos des XXI. Gebirgskorps vom 13. Juli 1944 ist zu lesen, dass die „Skanderbeg“ zwischen dem 28. Mai und dem 5. Juli „510 Juden, Kommunisten, Bandenhelfer und politisch Verdächtige“ verhaftet habe, die in das sich im Aufbau befindende KZ Prishina/Priština überführt wurden. Laut diesem Bericht wurden 249 dieser Häftlinge „zur Arbeitsleistung ins Reich“ deportiert. ${ }^{538}$ Robert Elsie hat die Namen von insgesamt über 700 Häftlingen serbischen, albanischen, kosovarischen, bosniakischen und jüdischen Männern und Frauen - zusammengestellt, über die für den Abtransport vom KZ Prishina/ Priština nach Deutschland Listen geführt wurden. ${ }^{539}$ In lokalen Berichten der Waffen-SS tauchen Festnahmen und Überführungen von Partisanen in das KZ Prishina/Priština nur sporadisch auf. So wurden etwa am 18. August 1944 drei Partisanen verhaftet und in das KZ überstellt. Dass auch gegen albanische Militärs vorgegangen wurde, zeigt etwa die Festnahme des Majors Suleiman Malai am 19. August, der in das KZ Prishina/Priština gebracht wurde. ${ }^{540}$ Anfang Juli 1944 berichtete Schmidhuber ganz optimistisch, dass nebst der Verhaftung, Enteignung und Deporation der wenigen lokalen jüdischen Familien und solchen auf der Durchreise von Jugoslawien nach „Altalbanien“ auch die „Aufdeckung der gut organisierten kommunistischen Organisation sowie die Sicherungsverwahrung der Kommunisten und der Bandenhelfer in einem KZ in Priština“ beim „alteingesessenen Volk Kosovos Genugtuung erzeugt“ hätte. ${ }^{541}$ Problematisch ge-

537 Schreiben August Schmidhuber an die Präfekten von Priština, Prizren und Peć, 31.5.1944, BArchF, RH 19-XI/9, Bl. 27. Das KZ Priština erwähnen auch Broszat und Neuwirth. Vgl. Broszat, Albanische Milizen, S. 346. Vgl. Neuwirth, Widerstand und Kollaboration, S. 135.

538 Vgl. „Lagebericht“ Gen.Kdo. XXI. Geb.AK, 13.7.1944, NARA, T314/664, Bl. 227.

539 http://www.albanianhistory.net/1944_Prisoners-of-the-Nazis-in-Kosovo/index.html (Stand: 5.3.2019).

540 Vgl. Meldekopf Rožaje, Hstuf. Hummer an Div. Ia, 18.6.1944, BArchF, RS 3-21/2, Bl. 110. Vgl. Meldekopf Rožaje, Hstuf. Hummer an Div. Ic, provisorisch Hptscharf. Schweissgut, 19.6.1944, BArchF, RS 3-21/2, Bl. 110.

541 Vgl. Lagebericht Schmidhuber, 7.7.1944, BAB, NS 19/2071, Bl. 22. 
staltete sich für ihn aber die Tatsache, dass das Lager zunehmend zur Umsetzung serbenfeindlicher Aktionen genutzt wurde, die nicht von deutscher Seite angeordnet worden waren. Nachdem in Prizren und Prishtina/Priština nationale Serben als Kommunisten verhaftet und nach einem Aufenthalt im KZ Prishtina/Priština ins Reich zum Zwangsarbeitseinsatz abgeschoben wurden, und sich im Sommer 1944 erneut 600 serbische Häftlinge im KZ Prishtina/Priština befanden, sollte Konsul Schliep im August 1944 der Regierung in Tirana mitteilen, „die bekannten Maßnahmen gegen das Serbentum einzustellen“. 542 Dies war nicht die erste Intervention von deutscher Seite; bereits im April hatte Neubacher auf die Serbenvertreibungen im Kosovo und damit einhergehende Gewaltakte hingewiesen. ${ }^{543}$

Die Quellen zum Aufbau und Unterhalt des KZ Prishtina/Priština sind sehr lückenhaft, weshalb es heute schwierig ist, zu beurteilen, inwiefern das Lager der nach 1934 einsetzenden Vereinheitlichung der durch die SS geführten Konzentrationslager entsprach. ${ }^{544}$ Vieles dürfte in diesem letzten Kriegsjahr und aufgrund der Situation vor Ort improvisiert gewesen sein. Immerhin hatte Schmidhuber große Pläne, sollte doch nach ihm „der Aufbau und die Organisation des Erziehungslagers [...] nach dem Muster deutscher Konzentrationslager“ ${ }^{\circ 45}$ erfolgen. Mit der Organisation des KZ beauftragte er SS-Oberscharführer Otter aus der II./Waffen-Gebirgs-Jäger-Regiment der SS 51, und als dessen „Hilfskraft“ SS-Sturmmann Hinner der Stabskompanie des III./Waffen-Gebirgs-Jäger-Regiments der SS 51. Die Wachmannschaft setzte sich aus von ihm als besonders verlässlich bezeichneten Soldaten zusammen, die vorher bereits in der Division „Handschar“ gedient hatten. Schmidhuber betonte, dass „bei der Auswahl der Mannschaften [...] unbedingt moralische Sauberkeit und Zuverlässigkeit“ vorauszusetzen seien. ${ }^{546}$ Der SSStandort-Kommandant Prishtina/Priština sollte SS-Oberscharführer Otter beim

542 Vgl. Schreiben Junker an Schliep, Konsugerma Tirana, 5.8.1944, PAAA, R27305. Vgl. Blatz an Div. Ic, provisorisch Hptscharf. Schweissgut, 23.6.1944, BArchF, RS 3-21/2, Bl. 117.

543 Vgl. auch Neubacher an deutsches Konsulat Tirana, Serbenvertreibungen im Kosovo, 9.4.1944, PAAA, R27305.

544 Zur angestrebten und umgesetzten Monopolisierung und Vereinheitlichung und zur Entwicklung eines Modells der inneren Lagerordnung und allgemeiner Regeln hinsichtlich Kompetenzen und Bewachungsmannschaften vgl. Martin Broszat in: Hans Buchheim et al., Anatomie des SSStaates, Bd. 2: Konzentrationslager, Kommissarbefehl, Judenverfolgung, Olten/Freiburg i. Br. 1965, S. 53.

545 Schreiben August Schmidhuber an die Präfekten von Priština, Prizren und Peć, 31.5.1944, BArchF, RH 19-XI/9, Bl. 27.

546 Ebd. 
Aufbau und der Organsation des KZ unterstützen. ${ }^{547}$ Die Dienstaufsicht über das Lager lag beim jeweiligen SS-Standortältesten in Prishtina/Priština - im Mai 1944 war dies SS-Sturmbannführer Bauer. Die ärztliche Überwachung oblag dem SSStandortarzt Prishtina/Priština. ${ }^{548}$ Neben den wenigen deutschsprachigen Vorgesetzen waren es vor allem die albanischen Wachmannschaften, die den Lageralltag mitbestimmten und die oft ein großes Maß an Gewalterfahrung mitbrachten, wie folgende zwei Aussagen zeigen: Erstens wurden die albanischen Mannschaften aus den Albanern rekrutiert, die vorher in der „Handschar“ gekämpft hatten, und auf ihrem Marsch durch Bosnien besonders grausam gegen die serbische Zivilbevölkerung vorgegangen waren, was unter anderem zu ihrer Entfernung aus der „Handschar“ und ihrer Versetzung zur „Skanderbeg“ geführt hatte. ${ }^{549}$ Zweitens gab der mit dem Aufbau des Auffanglagers Zemun/Semlin betraute Walter Eipel von der Division „Handschar“ in einem Verhör 1947 an, dass bereits in Semlin überwiegend albanische Freiwillige Dienst taten. ${ }^{550}$ Die Verhafteteten selbst mussten das Lager aufbauen, darunter auch die Planierung des gesamten Kasernengeländes in Prishtina/Priština. Die weiblichen Insassen mussten eine Waschanstalt sowie eine Divisions-Näh- und Flickwerkstätte einrichten und waren im Küchendienst eingesetzt. ${ }^{551}$

\subsubsection{Im Partisanen- oder im Bürgerkrieg?}

Bis zum August 1943 wurde sowohl von außen als auch im Innern Albaniens versucht, die antifaschistischen Kräfte zu bündeln und vereint gegen die italienischen und deutschen Besatzer einzusetzen, wie etwa Amery dokumentiert. ${ }^{552}$ Doch obwohl am Treffen von Mukje vom 1. und 2. August 1943 das „Komiteti për shpëtimin e Shqipërisë“ („Komitee zur Rettung Albaniens“) gegründet wurde, das aus je sechs Vertretern des Balli Kombëtar und der kommunistischen „Nationalen Befreiungsfront“ bestand, sollte diese Konferenz das Ende eines Zusammengehens kommunistischer und nationalistischer Kräfte einläuten. In den verabschiedeten Punkten sticht aus heutiger Perspektive besonders der zweite Punkt heraus, der

547 Vgl. Schreiben Schmidhuber an die Präfekten von Priština, Prizren und Peć, 31.5.1944, BArchF, RH 19-XI/9, Bl. 27.

548 Vgl. ebd.

549 Vgl. Zaugg, Albanische Muslime, S. 191f. Vgl. im Teil „Handschar“ das Kapitel zu „Kriegsverbrechen“.

550 Vgl. Kriegsgefangenenbericht Eipel, 14.11.1947, VA, HEM.OK.BOJCKA, 72-A/1-a/32.

551 Ebd.

552 Vgl. Amery, Sons of the Eagle, S. 37. 
ein Festhalten an einem „ethnischen“ Albanien, welches alle albanischen Bevölkerungsteile einschließen sollte, festhält. ${ }^{553}$

1. Kampf gegen die feindliche Besatzung und andere mögliche Besatzer

2. Kampf für ein unabhängiges Albanien, nach Grundsätzen der Atlantik Charta. Für ein ethnisches Albanien.

3. Für ein freies, unabhängiges und volksdemokratisches Albanien.

4. Ein Komitee wird mit der Aufstellung einer provisorischen Regierung beauftragt.

5. Regierungsform wird durch das Volk entschieden, eine konstituierende Versammlung wird allgemeine direkte Wahlen ausschreiben. ${ }^{554}$

Nur wenige Wochen später kündigten die Kommunisten das Abkommen, indem sie den Balli Kombëtar der Kollaboration bezichtigten. Der eigentliche Grund für den Rückzieher dürfte aber die Kosovo-Frage, also Punkt 2, gewesen sein, denn die albanischen Kommunisten mussten der Forderung ihrer jugoslawischen Genossen, Kosovo nach dem Krieg abzutreten, nachkommen, wollten sie diesen starken Bündnispartner nicht verlieren. Der Balli Kombëtar hingegen setzte weiterhin auf ein ethnisches „Großalbanien“. 555

Am Vorabend und während der italienischen Kapitulation fand in Labinot vom 4. bis 9. September 1943 eine weitere Konferenz statt, diesmal nur noch von der „Nationalen Befreiungsfront“. Die Zogisten als dritte große Gruppierung entfernten sich in jenem Herbst ebenfalls von der „Nationalen Befreiungsfront" und dem Balli Kombëtar, und gründeten ihre eigene Dachorganisation „Legaliteti“. 556

Von einem Zusammengehen der verschiedenen Widerstandgruppen konnte also nicht mehr die Rede sein. Sie waren zu unverhohlenen Feinden geworden, die sich bald offen bekämpfen sollten. ${ }^{557}$ Vor diesem Hintergrund ist auch die Kollaboration von Teilen des Balli Kombëtar mit den deutschen Besatzern zu

553 Vgl. Neuwirth, Widerstand und Kollaboration, S. 94. Noch wurde eine ausgeglichene Regierung angestrebt, in der sich keine dominierende Rolle der Kommunisten abzeichnete. In der vorgesehenen Regierung sollten drei bzw. später zwei Ballisten und fünf Mitglieder der „Nationalen Befreiungsfront“ vertreten sein. Davon können aber zwei als Zogisten bezeichnet werden, womit nur drei Kommunisten in der Regierung vertreten gewesen wären. Vgl. ebd.

554 Vgl. Tönnes, Sonderfall Albanien, S. 455. Vgl. Neuwirth, Widerstand und Kollaboration, S. $93 \mathrm{f}$.

555 Vgl. Tönnes, Sonderfall Albanien, S. 455. Vgl. Neuwirth, Widerstand und Kollaboration, S. $114 \mathrm{f}$.

556 Vgl. ebd., S. 96.

557 Vgl. Tönnes, Sonderfall Albanien, S. 455f. Vgl. Fernschreiben der 118. Jäg.Div.Abt. Ia vom 5.10.1943, 12.15 Uhr an 297. Inf.Div. Abt. Ia, BArchF, RH 26-181/38. 
sehen, die seine Mitglieder im sich anbahnenden Bürgerkrieg mit Waffen versorgen und bei der Realisierung eines ethnischen „Großalbaniens“ helfen sollten. ${ }^{558}$

Noch während dieser beiden letzten Konferenzen, die den Auftakt zu den nun folgenden bürgerkriegsähnlichen Konflikten in Albanian darstellten, kapitulierte Italien, ohne die in Albanien stationierten Generale der 6. und 9. Armee, General Ezio Rosi und General Lorenzo Dalmazzo, oder die Soldaten informiert zu haben. ${ }^{559}$ Von dieser für sie komplett neuen Situation erfuhren die italienischen Soldaten über das Radio aus London. ${ }^{560}$ Chaos brach aus, und die je nach Schätzungen 100.000 bis $130.00 \mathrm{zu}$ diesem Zeitpunkt in Albanien stationierten Soldaten irrten auf Plätzen und in den Hafenvierteln umher, mit dem Ziel, eine Fahrt nach Italien zu organisieren. ${ }^{561}$

Kurz nach der italienischen Kapitulation retteten sich tausende ehemaliger italienischer Soldaten zu den Partisanen, um nicht von ihren ehemaligen Verbündeten erschossen oder von Albanern misshandelt oder gelyncht $\mathrm{zu}$ werden; ${ }^{562}$ dennoch gerieten von sechs Divisionen vier fast vollständig in deutsche Gefangenschaft. Von der 151. und der 41. Infanterie-Division liefen große Teile zu den Partisanen über - dies nach einigen Tagen sogar mit Erlaubnis des neu eingesetzten Commando Supremo in Rom. Über die nach der Kapitulation durch Truppen der Wehrmacht und Waffen-SS begangenen Kriegsrechtsverstöße gegen ehemalige italienische Soldaten in Albanien ist bislang wenig bekannt. Vernehmungsprotokolle der nach Italien zurückgekehrten italienischer Soldaten, wie Emilio Moncalvo, Lamberto Franscesconi oder Roberto Ponsard, geben Auskunft über die radikale Verwandlung der ehemaligen Verbündeten. ${ }^{563}$ Viele Albaner gewährten italienischen Soldaten Schutz und hielten sie im Gegenzug als äußerst billige Arbeitskräfte, wie unter anderem ein Fernschreiben des Ersten Generalstabsoffiziers der 118. Jäger-Division an die 297. Infanterie-Division belegt. ${ }^{564}$

558 Vgl. Neuwirth, Widerstand und Kollaboration, S. 118.

559 Vgl. Aga Rossi, Giusti, Guerra a parte, S. 310. Vgl. Auch im Bericht „Albania - situazione politica-militare, dall 1943 al 25 gennaio 1944“ ist von einem „Bürgerkrieg“ die Rede, AUSSME, I3/b13/f1, S. 8.

560 Sottotenente Nazzareno Garat Crema, 10/27/1943, AUSSME, I3/b13/f1.

561 Vgl. Aga Rossi, Giusti, Guerra a parte, S. 309. Vgl. Lia Tosi, Caro nemico, S. 127.

562 Sottotenente Nazzareno Garat Crema, 10/27/1943, Uff.Stor. I3/b13/f1. Neubacher, Sonderauftrag Suedost, S. $106 \mathrm{f}$.

563 Bericht von sottotenente Emilio Moncalvo, 9/21/1943, AUSSME, I3/b13/f1, S. 2. Vgl. auch Bericht von Lamberto Francesconi und Roberto Ponsard, 10/31/1943, AUSSME, I3/b13/f1, S. 1 f. Vgl. Nevila Nika, Storie di italiani dopo l'8 settembre in Albania, S. 148.

564 Fernschreiben der 118. Jäg.Div.Abt. Ia vom 5.10.1943, 12.15 Uhr an 297. Inf.Div. Abt. Ia, BArchF, RH 26-181/38. Viele Italiener hatten aufgrund dieses teilweise 2-jährigen Ausharrens 
Zur selben Zeit gestaltete sich die Situation für die deutschen Besatzer aufgrund der durch die Italiener verstärkten Partisaneneinheiten und ihrer Kriegserklärung an den ehemaligen Verbündeten immer unübersichtlicher: Glückliche Zufälle, wie das Auffinden einer Liste von Namen verschiedener kommunistischer Partisanenführer im Tagebuch eines Partisanen in Debar, blieben für die 118. Jägerdivision und die 297. Infanterie-Division die Ausnahme. ${ }^{565}$ Die deutsche Wehrmacht und die Waffen-SS versuchten, mit „Säuberungsaktionen“ den verschiedenen Partisanengruppen der „Legaliteti“, Teilen des „Balli Kombëtar“ und vor allem der kommunistischen „Nationalen Befreiungsfront“ Herr zu werden. $\mathrm{Zu}$ jenen sehr unterschiedlichen Gegnern, die zu diesem Zeitpunkt überdies alle von der englischen SOE Mission zum aktiven Aufstand gegen die deutschen Besatzer angehalten wurden, kamen in den kosovarischen, serbischen und montenegrinischen Grenzgebieten zusätzlich Tito-Partisanen und verschiedene Četnik-Formationen.

In dieser verworrenen innenpolitischen Situation hofften die deutschen Kräfte auf Unterstützung durch lokale Soldaten und nationalistische Gruppierungen (Teile des Balli Kombëtar), die gegen die Partisanen im Süden und Nordosten kämpfen sollten. Die Winteroffensive 1943/44 führte zu einigen Teilerfolgen, und dadurch schließlich zur Beruhigung der innenpolitischen Situation bis ungefähr Februar 1944. ${ }^{566}$ Im Sommer 1944 misslangen allerdings nicht nur die geplanten Operationen, Waffen-SS und Wehmacht hatten in Albanien zusätzlich mit zahlreichen Anschlägen durch Partisanen zu kämpfen. Die Schwäche der Deutschen offenbart sich etwa in Berichten wie demjenigen des ehemaligen Divisionsangehörigen Berger, dass SS-Sturmscharführer Ohmen bei einem Überfall in Debar nur mit dem Hemd bekleidet aus seinem Haus fliehen musste. Auch auf Bergers eigene Dienststelle in Tetovo wurde ein Anschlag verübt. Sie wurde von den Partisanen mit italienischer Munition gesprengt. Berger entging dem Anschlag, weil er an diesem Tag aufgrund der Hitze die zweite Dienstschicht erst um 19 Uhr antreten sollte. Sein Dolmetscher Faris Bajazid hingegen wurde bei dem Attentat erschossen. ${ }^{567}$

in Verstecken später psychische Probleme. Vgl. Report of Luigi Pastore, 1/11/1943, Uff.Stor. I3/ b13/f1, S. 7.

565 Es werden folgende Namen genannt: Qamil Ramis, Haxi Leshi, Cen Elesi, Aqif Lleshi, Dan Kaloshi, Qasim Strazimiri, Fiqri Dine, Selim Kaloshi, Ali Alia, Ali Maligi, Hisni Dema, Aqif und Tusha Jashari, Djemail Agoli, Jasin Gjeloshi, Ferid Muha, Faik Shevo, Dopall Dia, Cen Elisix, Risa Navaku. Vgl. Fernschreiben der 118. Jäg.Div.Abt. Ia vom 5.10.1943, 12.15 Uhr an 297. Inf. Div. Abt. Ia, BArchF, RH 26-181/38.

566 Vgl. Neuwirth, Widerstand und Kollaboration, S. 199.

567 Vgl. Brief Karl Berger an Vopersal, 18.12.1975, BArchF, N 756/182b. 
Die in Zusammenarbeit mit verschiedenen Wehrmachtsverbänden und teilweise auch der „Prinz Eugen“ durchgeführten militärischen Operationen der Division „Skanderbeg“ misslangen, wobei sich die wohl schlimmste Niederlage in der Operation „Draufgänger“ ergab. Der Historiker Klaus Schmider schreibt, dass diese Erfolge der Partisanen bzw. Misserfolge der deutschen Streitkräfte umso bemerkenswerter waren, weil die Partisanen in der jugoslawischen Volksbefreiungsarmee oft gar nicht in ihren Heimatgebieten kämpften. ${ }^{568}$ Die Formationen der albanischen Partisanen hingegen kämpften oft in ihren Heimatgebieten und drangen 1944 von ihren Zentren in den Bergen um Dibra, Elbasan, Tirana und vom Raum Korçë und südöstlich von Vlorë gegen Norden vor. ${ }^{569}$

Die Division „Skanderbeg“ geriet in ihrem Operationsgebiet von verschiedenen Seiten in Bedrängnis: Einerseits agierten Tito-Einheiten auf montenegrinischer Seite um Rožaje. Verschiedene Vorstöße aus dem „Bandenzentrum“ Berane-Andrijevica gegen Murina-Kacuber an der albanisch-montenegrinischen Grenze wurden durch Teile des Waffen-Geb.Jäg.Rgt. der SS 50 sowie durch albanische Milizen abgewehrt. Auch aus den Grenzgebieten Mazedoniens führten kommunistischen Partisaneneinheiten Offensiven durch. Örtlich begrenzte Vorstöße östlich von Prishtina/Priština von als bulgarisch-mazedonisch bezeichneten Partisanengruppen konnten durch Teile des Waffen-Geb.Jäg.Rgt. der SS 51 abgewehrt werden. Von Süden her schloss die von den albanischen Kommunisten dominierte „Nationale Befreiungsfront“ im Sommer gegen Mittel- und Nordalbanien auf. Im Kosovo selbst fielen bereits im Mai 1944 zwei Partisanengruppen auf: Die eine stand unter dem Kommando von Enver Dajçi, war ungefähr 30 Mann stark und außergewöhnlich gut ausgerüstet. Auch die andere Gruppe unter dem Kommando von Qamil Brovina aus Gjakova/Đakovica war gut ausgerüstet und verfügte sogar über automatische Waffen. Brovina und seine Gruppe sowie Mustafa Bakiu, Vehap Shita, Zeqirja Zeka waren nach deutschen Angaben veranwortlich für einen Anschlag auf die Telegraphenlinie entlang der Straßen von Gjakova/Đakovica-Pejë und Gjakova/Đakovica-Prizren. In Zusammenhang mit diesen Sabotageakten exekutierten die Deutschen den Partisan Bakiu. ${ }^{570}$

Obwohl die Division selbst bei kleineren Gefechten auch Erfolge verzeichnen konnte, galt die Kampfkraft verbündeter albanischer Verbände insgesamt „als völlig unzulänglich“. Bereits im Sommer 1944 war Schmidhubers Urteil über die „Skanderbeg“ und die ihr angegliederten albanischen Hilfstruppen vernichtend: „Feindlichen Angriffen sind diese Kräfte ohne starke Unterstüt-

568 Vgl. Schmider, Partisanenkrieg, S. 547.

569 Vgl. Neuwirth, Widerstand und Kollaboration, S. 198.

570 Vgl. Bericht des Polizeikommando Prizren, Mai 1944, A.Q.SH. F.153, 1944, D 141, S. 10 f. 
zung durch deutsche Einheiten auf keinen Fall gewachsen. “571 In diesem Zeitraum wurden Teile der „Skanderbeg“ bei Kämpfen am Čakor-Pass in der Nähe von Andrijevica eingekesselt und zu großen Teilen aufgerieben. Kurt Kopf, ehemaliger Fahrer von Divisionskommandeur Schmidhuber, fiel auf, dass die Partisanen den deutschen Verbänden in geographischen Kenntnissen und der Anwendung von Guerillataktiken überlegen waren. Nachdem der Hauptverbandsplatz der „Skanderbeg“-Einheiten überfallen und die Brücke gesprengt worden war, konnten die Verletzten wegen mangelnder Landemöglichkeiten nicht wie geplant mit einem Fieseler Storch abtransportiert werden. Die Soldaten der „Skanderbeg“ saßen in der Falle; viele erlagen ihren Verwundungen und wurden auf einer nahegelegenen Passhöhe begraben. ${ }^{572}$

In den letzten Kriegsmonaten rückten die aufgrund der zahlreichen Desertionen mittlerweile zur Kampfgruppe geschrumpfte „Skanderbeg“ und die verbliebenen Teile der Wehrmacht immer enger zusammen: Operationen wurden gemeinsam geplant und umgesetzt. ${ }^{573}$ Obwohl die „Skanderbeg“ von den Verantwortlichen wie Schmidhuber oder Fitzthum als schwach eingestuft wurde, galt sie neben der 297. Infanterie-Division und der 181. Infanterie-Division dennoch als wichtigster Rückhalt des XXI. Gebirgskorps in diesen letzten Kriegsmonaten. ${ }^{574}$

Die Deutschen kämpften nicht nur mit der Schwäche der eigenen Truppen, sondern parallel dazu auch mit einer zunehmender Ablehnung innerhalb der Bevölkerung im Kosovo, die „wie die Aasgeier“ bereit saßen, um sich auf die sich auflösenden deutschen Einheiten zu stürzen und so ihre Waffen- und Munitionsbestände aufzubessern, wie sie es ein Jahr zuvor bei der italienischen Kapitulation getan hatten. ${ }^{575}$ Es kam vor, dass sich plötzlich ganze Dörfer an anti-deutschen Aktionen beteiligten: So plünderten am 11. September 1944 1.500 Bewohner zahlreicher Dörfer der Umgebung nach einen Partisanenangriff ein deutsches Munitionslager am Ortsrand von Gjakova/Đjakovica. Erst zwei Tage später wurde die

571 Vgl. „Lagebericht“, Gen.kdo. XXI. Geb.A.K., 13.7.1944, NARA, T314/664, F. 221.

572 Brief Kopf an Leopold Stütz, 28.5.1964, BArchF, N 756/182a. Brief Stütz an Kopf, 16.5.1964, BArchF, N 756/182a.

573 Vgl. Gen. Kdo. XI. Geb. A.K., von Klocke an 297. Inf. Div., 181 Inf. Div., SS-Div. ,Skanderbeg‘, 10.7.1944, NARA, T314/664, F. 164. „Zusammenfassender Bericht“ Schmidhuber, 2.10.1944, BArchF, RS 3-21/1, Bl. 5.

574 Vgl. BArchF, XXI. Geb.A.K. 59824/5, f.3, nach Kühmel, Deutschland und Albanien, S. 311. In Nordalbanien und Montenegro wurden in jener Phase neben deutschen Verbänden auch das 72., 81., 82., 86., 111. und 144. Schwarzhemdenbataillon eingesetzt. Zahlenmäßig war der Anteil der Camicie Nere aber mit 2.600 Mann gering. Es bleibt unklar, ob es sich um ursprünglich italienische Einheiten der MVSN oder aber um solche der MFA handelte. Vgl. ebd.

575 „Zusammenfassender Bericht“ Schmidhuber, 2.10.1944, BArchF, RS 3-21/1, S. 6. 
„Skanderbeg“ wieder Herr der Situation; 104 Partisanen und 10 Divisionsangehörige wurden dabei getötet. ${ }^{576}$

Vor diesem Hintegrund waren auch die mit 25.000 als einflussreicher Faktor zu bewertenden Hilfstruppen, so genannte „nationalen Banden“, schwer zu kontrollieren, ${ }^{577}$ denn die ausgegebene Parole „Kein Kampf von Albanern gegen Albaner!“ hätte dazu geführt, dass sich die „nationalen Banden“ nun neutral verhielten und somit das Vorgehen gegen die kommunistischen Partisanen lähmten. ${ }^{578}$ Einen letzten Hoffnungsschimmer sah Schmidhuber darin, dass die kommunistischen Partisanen auch Banden und deren Dörfer angegriffen hatten, die weder mit den Partisanen noch mit den Deutschen zusammenarbeiteten. Nach seiner Auffassung bestand aufgrund dessen die Möglichkeit, dass sich einige „nationale Banden“ doch noch zur bedingungslosen Unterstützung der Deutschen überwinden würden. ${ }^{579}$

Sowohl im Bürgerkrieg als auch im Kampf gegen die deutschen Besatzer zeichnete sich im Sommer 1944 klar die Überlegenheit der kommunistischen Partisanenverbände $\mathrm{ab}$, die durch die britische SOE mit Ausrüstung versorgt wurden. Schmidhuber nahm zudem an, dass die Briten ihre Unterstützung seit der Aufstellung der „Skanderbeg“ noch intensiviert hatten:

Diese Vermutung [westalliierter Unterstützung] gründet sich auf die Erfahrungen des ersten Einsatzes, wo es sich beim Gegner nicht mehr um Banditen im üblichen Sinne, sondern um eine reguläre, disziplinierte, einheitlich englisch uniformierte und ausgezeichnet bewaffnete Truppe unter sehr guter und wendiger Führung von überlegener Stärke handelte. Auf ein deutsches Maschinengewehr kamen rund 30 englische Maschinengewehre, während auf der feindlichen Seite soviel Maschinenpistolen schossen wie auf der eigenen Gewehre. $^{580}$

Im Herbst/Winter 1944/1945 verfügte die kommunistische „Nationale Befreiungsfront“ nach Angaben offizieller albanischer Quellen über knapp 70.000 Mann. ${ }^{581}$

576 Vgl. ebd.

577 Vgl. Gen. Kdo. XXI. Geb.A.K., von Klocke an 297. Inf. Div., 181 Inf. Div., SS-Div. ,Skanderbeg‘, 10.7.1944, NARA, T314/664, F. 164. „Zusammenfassender Bericht“ Schmidhuber, 2.10.1944, BArchF, RS 3-21/1, Bl. 5.

578 Ebd., S. 6.

579 Vgl. ebd. Vgl. hierzu auch „Betr.: Unternehmen „Fuchsjagd““, Gen.Kdo. XXI. Geb.A.K., 16.8.1944, NARA, T314/664, F. 545.

580 „Zusammenfassender Bericht“ Schmidhuber, 2.10.1944, BA-MA, RS 3-21/1, S. 5. Hier wird nun bereits das Negativbild, das in den letzten Monaten deutscher Besatzung entstand, deutlich hervorgehoben. Siehe dazu ausführlich Kapitel „Entstehung und Wandel eines deutschen Albanerbildes“.

581 Vgl. Neuwirth, Widerstand und Kollaboration, S. 203. Hier noch nicht mitgerechnet sind die Tito-Partisanen, die aus dem serbischen, montenegrinischen und makedonischen Grenz- 
Der Rückzug deutscher Verbände von Griechenland durch die Gebiete der albanischen Partisanen bis Mitrovica und danach durch diejenigen der jugoslawischen Partisanen über Višegrad nach Sarajevo, geriet zum Desaster und führte daher auf deutscher Seite zu großen Verlusten an Menschen und Material. ${ }^{582}$

\subsection{Kriegsverbrechen}

Das folgende Kapitel ist den mit den Einsätzen einhergehenden Kriegsverbrechen gewidmet. ${ }^{583}$ Wie bei den anderen Divisionen können militärische Einsätze und Kriegsrechtsverstöße meist nicht getrennt voneinander betrachtet werden, denn oft kam es gerade im Zuge geplanter Unternehmen zu Übergriffen und Massakern gegen die Zivilbevölkerung. Die „Skanderbeg“ nahm im Vergleich $\mathrm{zu}$ anderen Waffen-SS-Divisionen an wenigen Unternehmen teil - nicht zuletzt wegen ihres kurzen Bestehens von nur wenigen Monaten. Bei den Einsätzen von Mai bis November 1944 handelte es sich um einige größere Operationen im Rahmen der „Bandenbekämpfung“, als die Partisanenarmeen Titos und Hoxhas bereits wesentlich besser ausgebildet und ausgerüstet waren. ${ }^{584}$ Kriegsverbrechen sind, wie in allen Kriegsgebieten, nur teilweise oder gar nicht dokumentiert. Am besten überliefert und in der Erinnerung der serbischen und montenegrinischen Bevölkerung verankert ist das Massaker von Velika, welches am 28. Juli 1944 im Laufe des Unternehmens „Draufgänger“ begangen wurde. 585

Allerdings können Drittpersonen, in diesem Falle die Italiener, die nach der Kapitulation in Albanien festsaßen, weitere Informationen über Kriegsverbrechen liefern. So schrieb etwa General Arnaldo Azzi in einem Bericht vom Sommer 1944 von „Vergewaltigungen und Exzessen“, die durch die „kosovarische Miliz“ bzw. Angehörige der „Skanderbeg“, begangen worden wären. ${ }^{586}$ Wie be-

raum heraus operierten. Im Vergleich dazu: dem XXI. Gebirgskorps unterstanden zu jenem Zeitpunkt insgesamt noch rund 65.000 Mann. Vgl. OB Südost, Bericht „Entwicklung der militärischen Lage in Albanien im Herbst 1944“, undatiert, BArchF, RW 40/116a, Bl. 2.

582 Vgl. Schmider, Partisanenkrieg, S. 551. Ausfälle waren nicht nur durch Partisanen- und Fliegerangriffe, sondern auch durch das Fehlen von Unterkünften, Erfrierungen, Erkältungen, „Fußkranke“ und Mangel an warmer Kleidung zu beklagen. Vgl. Kriegsgefangenenbericht Heinrich Maus, ohne Datum, VA HEM.OK.BOJCKA, 71/1/19.

583 Vgl. hierzu auch Zaugg, Albanische Muslime, S. 250-272.

584 Vgl. Gen.Kdo. XXI. Geb.A.K., „Lagebericht“, 13.7.1944, NARA, T314/664, F. 221. Vgl. Schmidhuber, „Zusammenfassender Bericht“, 2.10.1944, BArchF, RS 3-21/1, S. 5.

585 Vgl. http://www.velika.me/index.php?page_id=874\&lang=engleski (1.12.2019).

586 Bericht General Arnaldo Azzi, 24.6.1944 bzw. 30.8.1944, AUSSME I3/b13/f1, S. 1. 
reits erwähnt nahmen die albanischen Soldaten nach nur sechswöchiger Ausbildung und schlecht ausgerüstet an ihren ersten Einsätzen teil. ${ }^{587}$ Einzig das Rahmenpersonal und die als Stammpersonal von der „Handschar“ zur „Skanderbeg“ versetzten albanischen Soldaten verfügten über eine intensivere Ausbildung von mehreren Monaten. ${ }^{588}$ Dieses von der „Handschar“ zur „Skanderbeg“ versetzte „Albanerbataillon“ brachte nicht nur Kampferfahung mit, sondern war in Südosteuropa bereits einschlägig bekannt für die an serbischen Zivilisten in Bosnien und im serbischen Grenzgebiet begangenen Kriegsverbrechen, wie bereits im Teil zur „Handschar“ erläutert wurde. ${ }^{589}$ Nun wurde ihr Einsatzwille noch durch das Einsatzgebiet gesteigert, welches in etwa dem Rekrutierungs- und Ausbildungsraum der Division und somit ihrem Heimatgebiet entsprach - im Gegensatz zur „Handschar“ wurde die „Skanderbeg“ von Anfang bis Ende ihres Bestehens im Raum Kosovo/Sandžak eingesetzt; auch in dieser Sicht hatte man aus den bei der „Handschar“ begangenen Fehlern gelernt. ${ }^{590}$

Dass das Vorgehen der in Albanien stationierten deutschen Kräfte bereits vor der Kapitulation Italiens von brutalen Übergriffen geprägt war, zeigen etwa die Massaker in Borova und Barmash im Juli 1943 in Südalbanien. Die 1. Gebirgs-Division der Wehrmacht ermordete dabei zwischen 450 und 500 Personen, weil Teile der Division kurz zuvor von albanischen Partisanen angegriffen worden waren. ${ }^{591}$

In seinem Aufsatz „KZ-System und Waffen-SS“ untersucht Stefan Hördler Personalverschiebungen von KZ-Personal zu Waffen-SS-Einheiten. In einem hohen Maß kann er solche Versetzungen für die „Prinz Eugen“ nachweisen, von wo aus auch Rahmenpersonal zur „Skanderbeg“ kam. Die zahlreichen in Südosteuropa begangenen Kriegsverbrechen müssen einerseits vor diesem Hintergrund, aber auch in Zusammenhang mit bereits schwelenden interethnischen Spannungen gesehen werden. ${ }^{592}$

Sowohl Divisionskommandeur Schmidhuber als auch der spätere Kommandeur des Regiments „Skanderbeg“, Alfred Graf, wurden in jugoslawischer Kriegsgefangenschaft der Verbrechen gegen die Menschlichkeit angeklagt. Die

587 „Zusammenfassender Bericht“ Schmidhuber, 2.10.1944, BArchF, RS 3-21/1, S. 5.

588 Vgl. Lepre, Himmler's Bosnian Division, S. 44-64.

589 Vgl. Vernehmungsprotokoll Matheis, Franje, Office of Chief of Council for War Crimes Translation of Document No. NO-4951, Landeskommission der Feststellung der Verbrechen der Okkupatoren und ihrer Helfershelfer, Inv. Nr. 35874, Nachlass Vopersal, BArchF, N 756/169a.

590 Vgl. Bernwald, Muslime, S. 120.

591 Herman Frank Meyer, Blutiges Edelweiß, S. 161-163.

592 Vgl. Hördler, KZ-System und Waffen-SS, S. 94-96. Vgl. Zaugg, Albanische Muslime, S. 148177. 
Militäranwaltschaft Belgrad, vertreten durch den Militäranwalt Hauptmann Ilija Djekić, klagte Graf am 1. September 1948 an, er habe Kriegsverbrechen zu verantworten, die „nicht nur von operativen Einheiten begangen wurden, die auf irgendein Gebiet einfielen, sondern auch von jenen Teilen, die später eintrafen oder im Hinterland waren. Ebenso wurde festgestellt, dass die deutschen Einheiten während des Kampfes im Oktober und November 1944 in der Umgebung von Kraljevo und Čačak Massentötungen auf dem Operationsgebiet sowie im Hinterland, das sie hielten, begingen. “593

Die Zentrale Stelle der Landesjustizverwaltungen zur Aufklärung nationalsozialistischer Verbrechen Ludwigsburg sammelte auch zur Division „Skanderbeg“ für die Aufklärung nationalsozialistischer Verbrechen Beweise, um Verantwortliche vor Gericht bringen zu können. Ein Fall aus „Großalbanien“, der durch seine Grausamkeit besonders hervorsticht, ist derjenige von SS-Sturmbannführer Günther Hausding. Am 20. Oktober 1960 wurde der Erste Staatsanwalt der Staatsanwaltschaft München, Dr. Lehmann, umfassend von den „Verbrechen gegen die Menschlichkeit“, die von Günther Hausding begangen worden waren, unterrichtet. Hausding wurde angeklagt, in seiner Funktion als Kriminalrat und später als SS-Sturmbannführer zahlreiche Morde an verschiedenen Schauplätzen in Südosteuropa befohlen zu haben. Sein Einsatzgebiet reichte 1941 von Belgrad bis Süd-Südwestserbien. Nach dem Balkanfeldzug war er als Befehlshaber der Sicherheitspolizei und des SD in Belgrad eingesetzt. In dieser Funktion rühmte er sich gemäß eigenen Angaben, in Dalmatien und Kragujevac „große Taten“ vollbracht zu haben. Dabei soll er auch an den Massakern in Kragujevac bzw. Kraljevo im Oktober 1941 beteiligt gewesen sein, bei welchen rund 4.000 Zivilpersonen ermordet wurden. ${ }^{594}$ In der Zeit zwischen 1941 und Herbst 1943 war Hausding als Außendienststellenleiter in Mitrovica im serbischen und somit unter deutscher Herrschaft stehenden Teil des Kosovogebiets eingesetzt, und konnte dort nach Angaben des Anklägers „frei schalten und walten, was er wollte“. ${ }^{595}$ Kurz nach der Kapitulation Italiens, im Oktober 1943, führt seine Spur weiter nach Shkodër/ Skutari. Mit seinem „Nebeltrupp Hausding“, 6 bis 8 Mann in zwei PKW, rückte er

593 Anklageschrift des Militäranwalts Hauptmann Ilija Djekic gegen Alfred Graf, 1.9.1948, BArchF, N 756/182b, S. 1. Vgl. hierzu auch die Aussagen Gullmanns über Befehle Schmidhubers zur Erhängung von Menschen im Kosovo, Schreiben Gullmann an Winter, 23.6.1944, BArchF, RH 1-XI/9, S. 8.

594 Vgl. Erste Staatsanwalt der Staatsanwaltschaft München, Dr. Lehmann, „Verbrechen gegen die Menschlichkeit ausgeführt von Günther Hausding“, 20.10.1960, USHMM/BArchL, B162/2.393, Bl. 2f. In der Anklageschrift geht der Ankläger von 40.000 Menschen aus, es waren aber rund 4.000 Menschen, die in Kraljevo und Kragujevac erschossen wurden.

595 Abschrift „Verbrechen gegen die Menschlichkeit ausgeführt von Günther Hausding“, 20.10.1960, USHMM/BArchL, B162/2.393. 
vor den übrigen deutschen Truppen in dieses Gebiet vor. In Shkodër ließ er sich in einem ehemaligen italienischen Konsulatsgebäude nieder. Nach seiner Einsetzung als HSSPF Albanien, zu Beginn des Winters 1943/44, kam Hausding in Fitzthums Stab bzw. unterstand von nun an dessen Dienststelle mit Hauptsitz in Tirana. ${ }^{596}$ In dieser Funktion soll er sowohl am Aufbau des KZ Prishtina/Priština als auch an der Ermordung der jüdischen Bevölkerung der Region beteiligt gewesen sein, und stand somit in intensivem Austausch mit der Division „Skanderbeg“. 597

Auch gegen Walter Borchert wurden Ermittlungen eingeleitet, weil er verdächtigt wurde, unter anderem als Leiter der Abteilung IV A 1 BdS Belgrad die Erschießung von Häftlingen als Sühnemaßnahmen sowie von Juli 1943 bis September 1944 Deportationen in Konzentrationslager in Belgrad und KosovskaMitrovica befohlen zu haben. ${ }^{598}$

Hausding führte nach Angaben der Staatsanwaltschaft viele der Verbrechen auf Anordnung des Befehlshabers der Sicherheitspolizei in Belgrad durch. Andere vor allem solche im albanischen Raum - beging er eigenmächtig. Dazu gehörte auch, dass er kurz vor dem Rückzug der Deutschen im Oktober 1944 zwanzig wohl einflussreiche - Albaner festnehmen ließ, die nach seiner Einschätzung Kommunisten waren. Diese waren aber laut offiziellen Angaben zwar den Italienern und Deutschen gegenüber feindlich eingestellt, gehörten aber nicht zur kommunistischen Organisation von Enver Hoxha, Mehmet Shehu und Haxhi Lleshi. Nachdem die Festgenommenen auch nach Verhör und Folter nicht zugaben, Kommunisten zu sein, beschloß Hausding kurzerhand, sie erschießen und verscharren zu lassen. Brisant daran ist insbesondere, dass einer der Erschossenen von den Westalliierten als späterer Minister vorgesehen war und sich gegen die Übermacht der Kommunisten hätte durchsetzen sollen. ${ }^{599}$

Alle Außendienststellen des HSSPF sammelten sich am 2. November 1944 in Shkodër im Trupp I des XXI. Gebirgskorps, um sich über Montenegro nach Norden durchzukämpfen, sowie im Trupp II unter Fitzthums Kommando, um den Weg über Kosovo nach Wien anzutreten. Wahrscheinlich traf dieser Trupp unterwegs auf Teile der Division „Skanderbeg“. Der dritte und letzte Trupp unterstand Hausdings Kommando. Mitte Dezember erreichte er Wien ohne Ver-

596 Vgl. ebd.

597 Vgl. Anklageschrift gegen Günther Hausding, USHMM/BArchL, B162/28.276. Vgl. Anklageschrift gegen Günther Hausding, USHMM/BArchL, B162/2.393.

598 Vgl. Fall Borchert, Walter, USHMM/BArchL, B162/15662.

599 Vgl. Abschrift „Verbrechen gegen die Menschlichkeit ausgeführt von Günther Hausding“, 20.10.1960, USHMM/BArchL, B162/2.393, Bl. 2-3. 
luste. Seine Spur führt allerdings noch weiter bis nach Berlin, wo er bis April 1945 für Exekutionen verantwortlich war. ${ }^{600}$

Ende 1943 leitete der stellvertretende Oberbefehlshaber Südost Alexander Löhr Hitlers Befehl weiter, die bisher angeordneten Sühne- und Vergeltungsmaßnahmen für den südosteuropäischen Raum zu lockern, da sich nicht die gewünschten Erfolge eingestellt hatten und auch Neubacher dagegen interveniert hatte:

Der Führer hat eine einheitliche Gegenaktion gegen die kommunistische Gefahr im Südosten befohlen, mit deren politischen Leitung der Gesandte Neubacher beauftragt ist. Die bisher üblichen Sühne-, Straf-, und Vergeltungsmassnahmen müssen in Zukunft der neuen politischen Zielsetzung Rechnung tragen. Erster Grundsatz muss sein, bei Anschlägen, Sabotageakten usw. die Täter selbst zu fassen und Sühnemaßnahmen erst in zweiter Linie zu ergreifen, wenn durch Sühnemaßnahmen die Verhütung künftiger Anschläge zu erwarten ist.[...] Das Verfahren, nach dem Überfall oder Sabotageakt aus der näheren Umgebung des Tatortes wahllos an Personen und Wohnstätten Sühnemaßnahmen zu vollziehen, erschüttert das Vertrauen in die Gerechtigkeit der Besatzungsmacht und treibt auch den loyalen Teil der Bevölkerung in die Wälder. ${ }^{601}$

Bezüglich dieser neuen Zielsetzungen befahl Löhr weiter, dass Sühnemaßnahmen ab sofort mit der zuständigen Feldkommandantur oder, soweit hier kein gegenseitiges Einvernehmen zustande kam, mit dem zuständigen Territorialbefehlshaber abgesprochen werden mussten. ${ }^{602}$ Außerdem sollte vor der Anordnung einer Sühnemaßnahme fernschriftlich die Genehmigung des Militärbefehlshabers Südost geholt werden. ${ }^{603}$ Divisionskommandeur Schmidhuber hielt sich indes nicht an diese Vorgaben. Die weder mit den zuständigen Feldkommandanturen noch mit dem territorialen Befehlshaber, dem DGA, abgesprochenen und zuweilen spontanen Übergriffe und Vergeltungsmaßnahmen im Operationsgebiet der Division „Skanderbeg“ sind auch durch DGA Gullmann belegt:

Im Kosovogebiet ereigneten sich in letzter Zeit mehrere unmittelbare Eingriffe des dortigen Div[isions]-K[omman]deurs [Schmidhuber] in rein territorialen Angelegenheiten und gegen den Grundsatz der Souveränität des alban[ischen] Staates [...]; es wurden sogar Befehle unmittelbar von ihm an meine Dienststellen erteilt, es erfolgten unmittelbare Be-

600 Vgl. ebd.

601 OB Südost, Generaloberst Alexander Löhr, Abschrift „Sühnemaßnahmen“, 22.12.1943, BArchF, RW 40/89, S. 1, 3. Vgl. hierzu auch Weisung „Sühnemaßnahmen“ OB Südost i.V. Generaloberst Alexander Löhr, 22.12.1943, BArchF, RW 40/89. Vorher galt (seit 28.9.1941) bei „Sühnemaßnahmen“ die Weisung, 50 Geiseln für einen verwundeten, 100 Geiseln für einen getöteten deutschen Soldaten zu erschießen. Vgl. bspw. Calic, Geschichte Jugoslawiens, S. $142 \mathrm{f}$.

602 Vgl. Betr.: „Sühnemaßnahmen“ Militärbefehlshaber Südost, General Hans-Gustav Felber, 1.1.1944, BArchF, RW 40/89, S. 2.

603 Vgl. ebd. 
fehle an die Präfekten, es wurden Menschen erhängt u.a.m. ohne Einhaltung der hierfür von höchster Stelle getroffenen Bestimmung. ${ }^{604}$

Es wäre weit gefehlt anzunehmen, dass es Gullmann dabei um das Wohlergehen der Zivilbevölkerung in diesem Gebiet ging. Er war vielmehr lediglich bemüht, seine eigene Stellung gegenüber Schmidhuber zu behaupten, wie er deutlich machte:

Es ist klar, dass die Übergriffe in Zukunft unterbleiben müssen, wenn ich sie auch nicht tragisch nehme. Es wird ersucht, diese Fehler durch entsprechende Einwirkung auf den Div [isions]-K[omman]deur [Schmidhuber] auch durch das Korps in Ordnung zu bringen. ${ }^{605}$

Als die Četniks unter dem Kommando Jakša Račić Ende Juni 1944 annahmen, dass „Sühnemaßnahmen“ aufgrund der Schwäche der Deutschen nicht mehr zu erwarten wären, sollten sie sich täuschen. ${ }^{606}$ Denn obwohl Junker, Vortragender Legationsrat bei der Dienststelle des Sonderbevollmächtigten Südost in Belgrad, Neubacher und Schliep vier Tage zuvor gemeldet hatte, dass ,in Gegenden, in denen Überfälle und Sabotagen von Kommunisten sichtbar eingestellt werden“ keine Geiselerschießungen mehr erfolgen würden, sollte die Gewalt in und um Kosovo noch lange kein Ende finden. ${ }^{607}$ Als etwa Angehörige der Division „Skanderbeg“ auf Befehl Schmidhubers im August 1944 in Kosovo Partisaninnen erhängten, sollten diese öffentlichen Hinrichtungen von Frauen in der sehr traditionellen Gesellschaft „Neualbaniens“ „ungeheure Erbitterung“ auslösen, wie aus der Gesandtschaft Tirana zu vernehmen war. ${ }^{608}$ Auch Neubacher berichtete Ribbentrop, dass diese an Frauen verübte „Sühnemaßnahme“ im Kosovo „bei muselmanischer Bevölkerung [eine] besondere Reaktion auslöste.“609 Die Rache der Partisanen wie auch der lokalen Bevölkerung ließ nicht lange auf sich warten: Am 6. September 1944 um 3.30 Uhr überfielen Partisanen unter dem Kommando Fadil Hoxhas 20 Kilometer vor Prizren einen Konvoi Richtung Belgrad mit 40 deutschen Frauen. 22 von ihnen wurden getötet, drei verschleppt. Das eigentliche Ziel der Partisanen war es, Frau Schliep, die Frau des deutschen Konsuls in Tirana, als Geisel zu nehmen. Diese konnte aber verletzt entkommen,

604 Schreiben Gullmann an Winter, 23.6.1944, BArchF, RH 1-XI/9, S. 8.

605 Ebd.

606 Vgl. Schreiben Junker an Generalkonsulat Tirana, 20.6.1944, PAAA, R27305.

607 Junker an Neubacher und Generalkonsulat Tirana, 16.6.1944, PAAA, R27305.

608 Aufzeichnung Gesandtschaftsrat Karl Werkmeister (Botschaft Budapest), 26.10.1944 von Mitteilung Schliep (in Kitzbühel) über AA an Neubacher vom 22.10.1944, PAAA, Handakten Botschafter Ritter, R27772.

609 Vgl. Neubacher an AA/Ribbentrop, 22.10.1944, PAAA, Handakten Botschafter Ritter, R27772, S. 3. 
indem sie einen Hang hinunterrollte. ${ }^{610}$ Die Geiselnahme und die ausbleibende Unterstützung der sonst eher pro-deutschen kosovarischen Bevölkerung sahen Schliep wie auch Neubacher in direktem Zusammenhang zu den im August verübten „Sühnemaßnahmen“ an Frauen im Kosovo. ${ }^{611}$

Der OB Südost von Weichs erteilte Anfang Oktober 1944 den Befehl, bei Maßnahmen, die im Zuge der Räumung ergriffen werden mussten, nur dort die „freundschaftlichen Beziehungen zu Staat und Volk“ zu berücksichtigen, wo den Deutschen eine „freundschaftliche oder korrekte Haltung“ entgegengebracht worden war. ${ }^{612}$ So wurden Divisionskommandeur Schmidhuber und der spätere Kommandeur des Regiments „Skanderbeg“ Graf später auch für die auf dem Rückzug begangenen Verbrechen angeklagt. ${ }^{613}$

Während des Rückzugs war Graf in seiner Funktion als Regimentskommandeur der „Skanderbeg“ auch Mitglied des Standgerichts und verantwortlich für weitere Kriegsverbrechen, die Djekić nicht einzeln aufführt. ${ }^{614}$ Noch im September 1944 sollen auf Befehl Hausdings vom Außenkommando Mitrovica wegen eines Partisanenüberfalls im Raum Kukës-Pirzren-Prishtina/Priština 350 Personen in das KZ Prishtina/Priština gebracht worden sein. Die wohlhabenden Albaner wurden gegen Bezahlung entlassen, der Rest erschossen. ${ }^{615}$ Doch auch der ganz alltägliche Terror der deutschen Besatzung in Albanien ist durch Tagesmel-

610 Der bereits bekannte „Volksgruppenführer“ der Banater „Volksdeutschen“ Sepp Janko sollte über die Auslösung der drei weiblichen Geiseln, Elsa Koch, Irmgrand Tennius und Erna Schubert, verhandeln. Die Partisanen stellten drei Forderungen: 1) 100 Goldstücke pro Person, 2) Freilassung kommunistischer Geiseln, 3) Freilassung des britischen Generals Davies. Vgl. Gesandtschaftsrat Karl Werkmeister (Botschaft Budapest) an Schliep (in Kitzbühel) über AA an Neubacher, 26.10.1944/22.10.1944, PAAA, Handakten Botschafter Ritter, R27772. Vgl. zu den drei Frauen, die 12 Jahre nicht aus der Geiselhaft befreit werden konnten: https://memorie.al/ historia-e-panjohur-e-tre-vajzave-elsa-koch-irmgrand-tennius-dhe-erna-schubert-pengje-te-en verit-qe-coi-ne-pushkatimin-e-104-te-burgosurve-te-prishtines/ (Stand: 3.3.2020).

611 Vgl. ebd. Der Transport mit den Überlebenden traf schließlich am 12.9.1944 in Belgrad ein. Vgl. Telegramm Junker an Schliep und DGA, 12.9.1944, PAAA, R27305.

612 Vgl. Telegramm Neubacher an Auswärtiges Amt, 3.10.1944, Walter Bußmann et al. (Hg.), Akten zur deutschen Auswärtigen Politik, Bd. VIII, S. 488. Hierzu vgl. auch Fischer, Albania at War, S. 226-227.

613 Vgl. Anklageschrift des Militäranwalts Hauptmann Ilija Djekic gegen Alfred Graf, 1.9.1948, BArchF, N 756/182b, S. 1. Vgl. hierzu auch die Aussagen Gullmanns über Befehle Schmidhubers zur Erhängung von Menschen im Kosovo, Schreiben Gullmann an Winter, 23.6.1944, BArchF, RH $1-\mathrm{XI} / 9, \mathrm{~S} .8$.

614 Vgl. ebd.

615 Vgl. Vernehmung Heinz Errelis in der Sache Hausding, 29.1.1968, USHMM/BArchL, B162/ 21.009, S. 2. 
dungen der „Skanderbeg“ belegt, die Sühnemaßnahmen für einzelne Anschläge dokumentieren. ${ }^{616}$

\subsubsection{Massaker von Velika}

Velika liegt im kosovarisch-montenegrinischen Grenzgebiet nahe der Ortschaft Plav. Das Massaker, welches während des Unternehmens „Draufgänger“ am 28. Juli 1944 unter anderem Einheiten der „Skanderbeg“, so etwa Teile des Waffen-Geb.Jäg.Rgt. der SS 51 an der montenegrinischen Bevölkerung jenes Dorfes verübten, kostete 428 Zivilpersonen das Leben. ${ }^{617}$ Nach Gordana Kostic und Laurent Latruwe befanden sich in diesem Regiment besonders viele Albaner, die aus der nächsten Umgebung, aus Plav, Gusinje sowie aus Peć/Peja, stammten. ${ }^{618}$ Schmidhuber rechtfertigte die Ermordung der Dorfbewohner damit, dass diese die Partisanen unterstützt hätten: ${ }^{619}$ „Offensichtlich wurde der Gegner des von Montenegrinern bewohnten Dorfes VELIKA entsprechend unterstützt. Nach Aussagen eines aus VELIKA stammenden Gefangenen waren dort wiederholt Propagandatrupps der Banditen gewesen und hatten 20 junge Montenegriner angeworben. Das Auftreten dieser roten Propagandatrupps war von den Einwohnern nie gemeldet worden. Ebenfalls nicht das Einrücken der jungen Männer zu den Banditen nach Montenegro.“620

Doch nicht nur die Waffen-SS, sondern auch Wehrmachtsangehörige, die sich im Herbst im gleichen Gebiet und teilweise zusammen mit der Division „Skanderbeg“ auf dem Rückzug befanden, waren in Kriegsverbrechen verwickelt: So soll etwa Leutnant Kurt Waldheim, Angehöriger des Stabes der Heeresgruppe E und späterer österreichischer Außenminister und Generalsekretär der Vereinten Nationen, auf dem Rückzug von Thessaloniki Richtung Nordosten, im Oktober

616 Hier seien nur zwei von zahlreichen Einzelbeispielen genannt: „[...] SS-Div. „Skanderbeg“: Alban. Jäg. Rgt. 1 bei Vorgehen Richtung Berane 3 W Kacuber auf starken Feind gestoßen. 2 Kommun[isten] als Vergeltung für Brückensprengung und Fernsprechleitungssabotage bei Skivjani erhängt.“ NARA, T314/664, F. 101. „1.) Gesamtlage unverändert [...] SS-Div. „Skanderbeg“: Bei Überfällen O[stwärts] Kukes geringe eig.[ene] und Zivilverluste, 2 Lkw ausgebrannt. 6 Geiseln am Überfallort erhängt.“ 2. Panzer-AOK, 11.8.44, NARA, T314/664, Bl. 482.

617 Nach Erkenntnissen von Frolov soll SS-Stubaf. Heinz Koeler das Massaker befohlen haben. Vgl. Frolov, Pod barjakom Skenderbega, S. 165-169.

618 Vgl. Kostic, Latruwe, Division Skanderbeg, S. 175. Vgl. auch Dželetović, 21. SS Divizija Skenderbeg, S. 158.

619 Vgl. Gefechtsbericht für das Unternehmen „Draufgänger“ vom 18.7.-28.7.1944, Schmidhuber, Lagebeurteilung 22.7.44, NARA, T314/664, F. 283.

620 Vgl. ebd., F293. 
1944 die Hinrichung von 114 Geiseln im benachbarten Nordmazedonien veranlasst haben, bevor er in Löhrs Maschine nach Mitrovica/Kosovska Mitrovica flog. ${ }^{621}$ Einen anderen Hinweis auf solche Vorfälle liefert die in den 1960er Jahren eingereichte Anzeige des Ehepaar Taschs gegen den Wehrmachtsangehörigen Getrost; dieser soll einem Erschießungskommando in Albanien angehört haben. Mit Verweis auf die Möglichkeit, dass es sich um einen Streit unter Nachbarn handeln könnte, bewertete die Polizei die Anzeige aber als unglaubwürdig. Ein Beamter ließ sich sogar dazu hinreissen, die beiden Anzeigeerstattenden als „Psychopathen“ ${ }^{\text {zu bezeichnen. }}{ }^{622}$

\subsection{Schwierigkeiten}

Bei der „Skanderbeg“ tauchten teilweise andere Schwierigkeiten auf als bei der „Prinz Eugen“ oder den beiden bosnischen Divisionen. Die Deutschen versuchten, aus den Fehlern, die sie bei der „Handschar“ gemacht hatten, zu lernen und diese bei der neu aufgestellten albanischen Division $\mathrm{zu}$ vermeiden. Dies zeigt etwa das Beispiel katholischer Albaner, die der „Skanderbeg“ gemäss offiziellen Richtlinien nicht hätten beitreten dürfen; allerdings in der Praxis aufgrund des Personalsmangels dann doch rekrutiert wurden. ${ }^{623}$

Zwischen März 1943 und Oktober 1944 sind primär drei Schwierigkeiten festzustellen: erstens das sehr unterschiedliche Verständnis von Kriegführung, zweitens große sprachliche Schwierigkeiten und drittens die sich verändernde Kriegslage ab Sommer 1944 und die damit einhergehenden Massendesertionen.

Hinzu kamen weitere kriegsbedingte Umstände: Die wechselnden Koalitionen innerhalb Albanien schufen ein hohes Maß an Unsicherheit. Seit der Kapitulation Italiens im September 1943 gestalteten sich die Verhältnisse in Albanien bzw. „Großalbanien“ noch chaotischer und unübersichtlicher als bisher. Dies offenbart beispielsweise der Bericht des Ic der „Skanderbeg“ zum Unternehmen „Berane“. Meist fehlten den deutschen Besatzern genaue Angaben über die Stärke des Gegners, manchmal wussten sie nicht einmal, wer nun genau auf welcher

621 Vgl. Alan Levy, The Nazi Hunter: The Wiesenthal File. How Simon Wiesenthal haunted down the Nazi war criminals, London: Robinson $2002^{2}$, S. 457. Waldheim spielte seine Rolle herunter und beschrieb sich als selbstlosen Offizier, der jegliche Schuld für die Befehle auf sich genommen hätte. Vgl. ebd., S. $458 \mathrm{f}$.

622 Vgl. Sammlung von Erkenntnissen über die Beteiligung deutscher Dienststellen und Angehöriger der SS- Division Skanderbeg an Tötungsdelikten in Albanien im Jahr 1944, USHMM/ BArchL, B 162/21009.

623 Vgl. Interview mit Tush Mark Ndou (geführt von Franziska Zaugg), 7.6.2017. 
Seite kämpfte: Für die im Gebiet um Berane kämpfenden Waffen-SS- und Wehrmachtseinheiten blieb unklar, ob nun die ehemalige italienische Division „Venezia“ mit Kommandeur Oxilia zu Verhandlungen bereit wäre, oder ob sich die Division den Kommunisten anschließen würde. Bis spätestens zum 12. Oktober 1943 wurde von deutscher Seite versucht, solche Verhandlungen mit der „Venezia“ aufzunehmen; im bevorstehenden Unternehmen „Balkanschlucht“ kämpfte die Wehrmacht aber gegen ihre ehemaligen Verbündeten, die jetzt bei den albanischen Kommunisten Unterstützung gefunden hatten. Unklar war für die Deutschen auch, ob Peco Dapcević und seine Gruppe zu den Titoisten gehörten oder nicht. Für das Verständnis der allgemeinen Lage kam erschwerend hinzu, dass auch Gefechte zwischen Četniks und Kommunisten stattfanden. Es war deshalb kaum abzuschätzen, wie sich die Četniks bei einem deutschen Angriff verhalten würden. ${ }^{624}$ Ähnlich verworren gestaltete sich die Lage in „Altalbanien“, wo sich Ballisten und Kommunisten bekämpften.

$\mathrm{Zu}$ weiteren Schwierigkeiten führten die von den Deutschen nicht eingelösten Versprechen: Die Nahrungssituation verschlechterte sich im Sommer 1944 dramatisch, der Sold konnte teilweise nicht mehr bezahlt werden, Unterkünfte waren entweder nicht vorhanden oder verwahrlost, die Bewaffnung war unzureichend. Zum Zeitpunkt der Aufstellung der „Skanderbeg“ waren weder genügend Ausbildungs- und Sanitätspersonal noch genügend Ausrüstung vorhanden. ${ }^{625}$

\subsubsection{Ein unterschiedliches Verständnis von Kriegführung?}

Zahlreiche von deutschen Einheiten begangene Kriegsverbrechen sind während und nach dem Zweiten Weltkrieg dokumentiert und zumindest teilweise vor Gericht gebracht worden. Dass in solchen Fällen das Selbst- und das Fremdbild oftmals weit auseinanderklaffen, ist bereits vielfach beschrieben worden; auch dass Verbrechen der ,anderen“ oft viel intensiver wahrgenommen und dokumentiert wurden als solche der eigenen Truppen. Vier Hauptmerkmale in der Unterscheidung des eigenen und des fremden Verständnisses von Kriegführung treten in den Quellen auf: Nahkampf, Plündern, Massakrieren und Verstümmeln sowie unerlaubtes Entfernen von der Truppe, wobei letzteres oft mit Feigheit gleichgesetzt wurde.

624 Vgl. Bericht Ic, Unternehmen „Berane“, 19.10.1943, BArchF, RH 26-297/106, S. 1. 625 Vgl. Schmidhuber, „Zusammenfassender Bericht“, 2.10.1944, BArchF, RS 3-21/1, S. 3-5. Vgl. auch Phleps an Himmler, 7.5.1944, BArchB, NS 19/2601, Bl. 95. 
Bereits im Herst 1943 beklagte sich die Wehrmacht über das albanische Verständnis von Kriegführung:

Wie sah in Wirklichkeit die albanische Unterstützung aus? Die Nachschubstrasse Pec-Murina wurde von den Albanern gesichert, ebenfalls der $1849 \mathrm{~m}$ hohe Scakor[Čakor]-Pass. Im Übrigen beschränkte sich die ,aktive Unterstützung darauf, dass die nationalen albanischen Freiheitskämpfer sengend, mordend und plündernd der deutschen Truppe nachzogen und dadurch mehr Schaden und Verdruss gestiftet haben, [sic] als Nutzen.

Die albanischen Behörden waren nicht in der Lage, diese niederen Instinkte zusteuern [sic]. Von unserer Seite hätte dies [sic] Vorgehen nur durch Gewalt abgestellt werden können. Dann wäre aber ohne Zweifel der ganze Nachschub für unsere Kampftruppen ernstlich gefährdet gewesen. ${ }^{626}$

Anhand dieses Zitats lässt sich das Dilemma, in welchem sich die Deutschen befanden, gut nachvollziehen: Disziplinierungsmaßnahmen konnten nur marginal umgesetzt werden, da die Deutschen fürchteten, bei Strafmaßnahmen an ihnen wohlgesinnten lokalen Hilfstruppen jegliche Unterstützung der Bevölkerung zu verlieren.

Dieser Umstand veränderte sich auch bei den „neualbanischen“ Rekruten der „Skanderbeg“ nicht. Diese wandten vor allem eine auf Guerrilla-Taktik aufbauende Kriegführung an, die einen raschen Vorstoss mit Überraschungsmoment und einen ebenso raschen Rückzug vorsah. So beschreibt Kaesdorf die Albaner etwa als erfahren im Nahkampf und in den ihnen „vertrauten Bergen“. ${ }^{627}$ Auch von Thadden ist der Meinung, dass die Albaner sich durch ihr Verständnis von Kriegführung gerade im „Bandenkampf in Gebirgsgegenden“ bewährt hätten. ${ }^{628}$ Dass sich die Albaner vor allem in Frontabschnitten auszeichneten, die „den Charakter ausgesprochener Hochgebirgskämpfe“ trugen, bestätigt Kriegsberichter Kollegger. ${ }^{629}$ Kaesdorf schreibt in seinen „Erfahrungen mit albanischen Soldaten“ weiter, dass sie in der Anwendung von „Kriegslisten“ „erfahren und erfinderisch“ waren. ${ }^{630}$ Auch Kollegger wies auf die Anwendung solcher Kriegslisten hin, welche die Albaner im Kosovogebiet bereits während des Balkanfeldzugs 1941 angwandt hätten, indem sie „im Rücken des Feindes“ angriffen, um diesen zu überraschen. ${ }^{631}$

626 Bericht Ic, Unternehmen „Berane“, 19.10.1943, BArchF, RH 26-297/106, S. 3.

627 Vgl. „Erfahrungen mit albanischen Soldaten“, Kaesdorf, undatiert, BArchB, NS 31/444, Bl. 26.

628 Vgl. Schreiben Reichel, Referat Inland IIc, 6.4.1944, PAAA, R100984, Bl. H298869.

629 Vgl. Kollegger, Albaniens Wiedergeburt, S. 62.

630 Vgl. ebd. Bl. 27. Abschließender Gefechtsbericht des Unternehmens „Draufgänger“ vom 18. bis 28. Juli 1944, Schmidhuber, NARA, T314/664, Bl. $293 \mathrm{f}$.

631 Vgl. ebd., S. $65 f$. 
Doch die Ausbildung im Gelände kannten und schätzen die albanischen Rekruten ebenso wenig wie Schießübungen. ${ }^{632}$ Auch Marschdisziplin war nur schwer zu halten. ${ }^{633}$ Beschuss durch schwere Artillerie war den Albanern fremd und verängstigte sie angeblich, da man über diese Distanz den Menschen hinter der Waffe nicht erkennen konnte. Außerdem galt in ihren Augen eine solche Kampfführung als ehrlos. ${ }^{634}$ Schmidhuber war daher überzeugt, dass man die Albaner mit Granatwerfern um den ganzen Globus hätte jagen können. Das Fluchtverhalten bei „schwerer Waffeneinwirkung“ und der archaisch anmutende Kampfstil wurden von den Deutschen als exotisch empfunden und bereitete bei Einsätzen Schwierigkeiten. ${ }^{635}$

Das unterschiedliche Verständnis von Kriegführung betraf aber auch den Umgang mit Zivilisten und deren Besitz. Obwohl Plünderungen durch Wehrmacht und Waffen-SS insbesondere für Osteuropa mannigfach belegt sind, wird im oben erwähntes Zitat deutlich hervorgehoben, dass die albanischen Soldaten mit ihren Plünderungen und den Morden an Zivilisten „niederen Instinkten“ folgen würden. ${ }^{636}$ Dabei wird aber verschwiegen, dass die Deutschen im gleichen Zeitraum gegenüber echten oder vermeintlichen Gegnern innerhalb der Zivilbevölkerung selbst zu drastischen Maßnahmen griffen, wie ein Auszug aus dem Tagebuch eines Kommunisten aus Debar vom Oktober 1943 zeigt: „1.10. Ich komme vom Gefecht bei Kruja zurück. Die Leute sollen nicht mit den Kommunisten gehen, weil sie sonst von den Deutschen an ihre eigenen Haustüren gekreuzigt werden, so wie sie es auch in Kruja gemacht haben. “637

Schmidhuber begründete die sehr unterschiedliche Auffassung von Kriegführung damit, dass die Albaner noch stark in den Clanstrukturen ihrer Großfamilien verhaftet waren. Diese Beobachtung entsprach in gewisser Weise tatsächlich der Wahrheit: Viele der Rekruten folgten den Befehlen ihres angestammten Führers und waren nur dann wirklich bereit, sich den Befehlen der deutschen oder ,volksdeutschen“ Vorgesetzten unterzuordnen, wenn diese in Einklang mit den Absichten des Clanchefs standen. Entsprechend kam Schmidhuber zum Schluss, dass

632 „Zusammenfassender Bericht“ Schmidhuber, 2.10.1944, BA-MA, RS 3-21/1, S. 3.

$633 \mathrm{Vgl}$. „Erfahrungen mit albanischen Soldaten“, Kaesdorf, undatiert, BArchB, NS 31/444, Bl. 26.

634 Ebd.

635 Vgl. „Zusammenfassender Bericht“ Schmidhuber, 2.10.1944, BArchF, RS 3-21/1, S. 2, 5.

636 Vgl. Bericht Ic, Unternehmen „Berane“, 19.10.1943, BArchF, RH 26-297/106, S. 3.

637 Auszug aus dem Tagebuch eines Kommunisten aus Debar in Fernschreiben der 118. Jäg. Div.Abt. Ia vom 5.10.1943, 12.15 Uhr an 297. Inf.Div. Abt. Ia, Übersetzung Tagebuchauszug eines Kommunisten aus Debar, BArchF, RH 26-181/38. 
die albanischen Einheiten nicht in einem militärischen Verband kämpften wollten und konnten. ${ }^{638}$

\subsubsection{Unerlaubtes Entfernen von der Truppe}

Im Sommer 1944 gestaltete sich die Lage in den Grenzgebeiten Albaniens so, dass die deutschen Vorgesetzten nicht mehr in der Lage waren, auf bestimmte Vergehen innerhalb der Truppe entsprechend den eigentlichen Gesetzen zu reagieren. „Unerlaubtes Entfernen von der Truppe“, im Kriegsfall mit dem Tode bestraft, konnte unter Umständen in eine Gefängnisstrafe umgewandelt werden - im Falle der „Skanderbeg“ wurde jedoch meist gar nichts unternommen, denn jeder Mann zählte im Kampf gegen die Partisanen - wie auch aus obenstehendem Zitat aus dem Unternehmen „Berane“ offensichtlich wird. ${ }^{639}$

Während des Unternehmens „Junikäfer“ im Frühsommer 1944 berichtete Bormann: „Werde von allen im Stich gelassen. Milizen haben trotz meines Befehls, ihre Stellung zu halten, diese ohne Grund verlassen und sind fortgegangen. Durch dieses veige [sic] Verhalten ist auch die K[ompanie] des H[auptsturmführers] Galaku unsicher geworden und hat ihre Stellungen verlassen. Bin heute persönlich zurückgegangen und habe die Miliz wieder zusammen geholt und sie in ihre Stellungen geschickt. Halte aber nichts dafon [sic] da die Milizen $\mathrm{zu}$ feige sind. "640 Kaesdorf, der bereits Erfahrungen mit dem Albaner-Bataillon innerhalb der Division „Handschar“ gesammelt hatte, berichtete, dass es nicht selten vorkam, „dass die Männer unterwegs in Häuser verschwinden, um Wasser und Proviant zu besorgen, sich dabei verplauschen und ohne bösen Willen von der Truppe entfernen.“641

\subsubsection{Sprachliche Schwierigkeiten und Analphabetismus}

Selbst die Ausbildungs- bzw. Kommandosprache bereitete den deutschen Vorgesetzten Schwierigkeiten. Phleps führte gegenüber Himmler aus, dass die Albaner nur in verschwindend geringem Maße Schulbildung und keine Deutschkennt-

638 Vgl. Schmidhuber, „Zusammenfassender Bericht“, 2.10.1944, BArchF, RS 3-21/1, S. 2.

639 Bericht Ic, Unternehmen „Berane“, 19.10.1943, BArchF, RH 26-297/106, S. 3.

640 Kampfgruppe Bormann an Schmidhuber, 12.6.1944, BArchF, RS3 21/2, S. 89.

641 Kaesdorf, „Erfahrungen mit albanischen Soldaten“, undatiert, BArchB, NS 31/444, S. 26. 
nisse besäßen. ${ }^{642}$ Auch Hausding vom Außenkommando Mitrovica hatte bereits 1942 eine sehr hohe Analphabetismusquote unter den Albanern festgestellt. ${ }^{643}$ Kaesdorf bestätigte die mangelnde Schulbildung in seinen „Erfahrungen mit albanischen Soldaten“ ebenfalls. ${ }^{644}$

Der in Tirana stationierte Rudolf Vogel bemerkte aber auch, dass bis zum Ende der Besatzung kaum ein Deutscher ein paar Worte Albanisch gesprochen hätte. ${ }^{645}$ Er selbst hatte dafür gesorgt, dass kleine deutsch-albanische Wörterbücher zusammengestellt und gedruckt wurden, wobei die Auflage von 1.000 Stück „natürlich viel zu klein war und uns sofort von den Albanern und der deutschen Truppe aus den Händen gerissen wurde. “646 Das allgemeine Vorgehen bestand darin, dass „das deutsche Rahmenpersonal [...] alle Komman[d]os und Befehle zunächst ins Kroatische und dann ins Albanische übersetzen lassen" musste. ${ }^{647}$ Auch Berger und von Pistor geben an, dass in der Ausbildung der albanischen Einheiten in Albanisch und Serbisch exerziert wurde, ${ }^{648}$ wobei letzteres der Tatsache geschuldet war, dass sich die Kosovaren im serbischen Teil Kosovos und dem Sandžak eher auf Türkisch bzw. Serbisch verständigten, da „den Albanern ihre Sprache zur Zeit der türkischen und serbischen Fremdherrschaft zum Teil verlorengegangen ist“, weil es ihnen verboten war, sich in ihrer Muttersprache zu unterhalten. ${ }^{649}$ Exponenten wie von Krempler spielten

642 Vgl. Schreiben Phleps an Himmler, 7.5.1944, BAB, NS 19/2601, Bl. 95. Vgl. zum „Mangel an Schulbildung“ auch „Erfahrungen mit albanischen Soldaten“, Kaesdorf, undatiert, BAB, NS 31/444, Bl. 27. Während die Albaner aus dem Kosovogebiet zumeist Serbisch bzw. Türkisch verstanden, mussten die Anweisungen für die übrigen Albaner zuerst von Deutsch auf Serbisch und dann von Serbisch auf Albanisch übersetzt werden. Vgl. Brief von Pistor an Vopersal, ohne Datum, BArchF, N 756/182b. Auch Feninger schreibt, dass sich die Albaner unter serbischer Herrschaft selbst als Türken bezeichnet hätten und selten Albanisch sprachen, weil „alles Albanische von den Serben schärfstens verfolgt worden sei.“ Vgl. Bericht „über die Reise in das Arnautengebiet von Kosovska Mitrovica und Novi Pazar“ des Volkstumsreferenten Dr. Feninger beim Bevollmächtigten des AA in Belgrad, 15.-26.10.1941, PAAA, R261153, Bl. 37.

643 Vgl. Lagebericht des Außenkommandos Kosovska-Mitrovica für August 1942, Hausding, 27.8.1942, USHMM/BArchL, B162/15.668, Bl. 41.

644 Vgl. Kaesdorf, „Erfahrungen mit albanischen Soldaten“, undatiert, BArchB, NS 31/444, B1. 27.

645 Vgl. Vogel, Erinnerungen, S. 209.

646 Vgl. ebd., S. 189.

647 „Referat Kriegsgeschichte 1969“, Vopersal, BArchF, N 756/182b.

648 Vgl. Brief Karl Berger an Vopersal, 18.12.1975, BArchF, N 756/182b. Vgl. auch Brief von Pistor an Vopersal, undatiert, BArchF, N 756/182b.

649 Bericht „über die Reise in das Arnautengebiet von Kosovska Mitrovica und Novi Pazar“ des Volkstumsreferenten Dr. Feninger bim Bevollmächtigten des AA in Belgrad, 15.-26.10.1941, PAAA, R261153, Bl. 33. Feninger dokumentierte, dass die Albaner in den Gebieten von Mitrovica, Vučitrn und Podujevo Albanisch, Serbisch und Türkisch sprachen. Die Albaner aus dem 
nicht zuletzt aufgrund ihrer Sprachkenntnisse, in seinem Fall Deutsch, Serbisch und Türkisch, eine herausragende Rolle bei den Rekrutierungen, da es wenige gab, die sich direkt mit allen Beteiligten in den Grenzregionen unterhalten konnten. ${ }^{650}$

$\mathrm{Zu}$ den sprachlichen Schwierigkeiten traten Kommunikationsprobleme auf anderen Ebenen, etwa ein unterschiedlicher Sinn für Humor: „Entsprechend ist auch mit Humor nicht viel bei ihm [dem Albaner] anzufangen. Er ist empfindlich und humorlos und steht jeder leichtnehmenden Einstellung, jeder oberflächlichen Heiterkeit ablehnend gegenüber.“651 Wie bereits im Teil zur „Handschar“ erwähnt, verbot Himmler gegenüber muslimischen Soldaten allgemein jedes Witzeln und „auf den Arm nehmen“, da diese darüber verärgert sein könnten. ${ }^{652}$

\subsubsection{Kriegslage ab Sommer 1944 und Massendesertionen}

Bereits im Mai 1944 hatte Fitzthum Himmler berichten müssen, dass der Aufbau einer albanischen Armee und Gendarmerie gescheitert war, da die albanischen Soldaten und Gendarme ihre deutschen Vorgesetzten im Stich gelassen hatten. Fitzthum sah sich daraufhin gezwungen, vier albanische Wehrmachtsbataillone aufzulösen. ${ }^{653}$ In den Sommermonaten 1944 verschlechterte sich die Lage weiter. Am 12. Juni meldete Bormann dem Divisionskommandeur, dass seine Soldaten trotz des Befehls die Stellung zu halten, diese aufgegen hätten und desertiert seien. ${ }^{654}$ Die Lage spitzte sich $\mathrm{zu}$, da jetzt einerseits der anti-deutsche Widerstand jeglicher Couleur rasch zunahm, andererseits diese sogenannten „Banden“ sich in der Zwischenzeit zu gut ausgebildeten Einheiten unter einwandfreier Führung

Gebiet von Novi Pazar sprachen hingegen nur Serbisch und beherrschten die albanische Sprache nicht. Die Umgangssprache war für die Albaner daher kein maßgebendes Zeichen ihrer Volkszugehörigkeit. Diese wurde vielmehr in erster Linie über die Religion definiert. Vgl. ebd., S. $33 \mathrm{f}$.

650 Vgl. Lepre, Himmler's Bosnian Division, S. 24.

651 Kaesdorf, „Erfahrungen mit albanischen Soldaten“, undatiert, BArchB, NS 31/444, S. 28.

652 Vgl. Entwurf Himmler, August 1943, BArchB, NS 19/2601, Bl. 148.

653 Vgl. Schreiben Fitzthum an Himmler, 23.5.1944, BArchB, NS 19/2071, Bl. 14. Nach Kühmel soll es sich bei der albanischen Wehrmacht insgesamt allerdings nur um 1.570 Soldaten gehandelt haben. Vgl. Kühmel, Deutschland und Albanien, S. 311. Vgl. hierzu auch den Artikel über Hermann Kirchner, der gleichzeitig von deutscher als auch albanischer Seite mit dem Aufbau einer albanischen Armee beauftragt war. Vgl. Marenglen Kasmi, Hermann Kirchner, Im Dienste der albanischen Armee, in: http://www.bundesheer.at/truppendienst/ausgaben/artikel.php? id $=1640$ (Stand: 10.2.2020).

654 Bormann an Schmidhuber, 12.6.1944, BArchF, RS 3-21/2, Bl. 89. 
entwickelt hatten, wie Divisionskommandeur Schmidhuber feststellen musste. Seiner Ansicht nach handelte es sich nicht mehr um Partisanen im herkömmlichen Sinne, sondern um eine „vollwertige europäische Kampftruppe“. ${ }^{655}$ Nachschub erhielten vor allem die unter der „albanischen Befreiungsfront“ vereinigten Gruppierungen von den Briten aus der Luft. In Unternehmen, wie etwa demjenigen mit dem Decknamen „Casanova“, waren die Deutschen dazu übergegangen, mit ihren schwindenen Kräften den Feind nicht mehr frontal anzugreifen, aber durch die Störung der „Bandenluftversorgung“ zumindest die Nachschublinien, „das innere Gefüge und die Kampfkraft“ der Partisanenarmee zu stören. Dies sollte „unter Ausschöpfung aller Möglichkeiten und Einsatz aller irgend geeigneten Kräfte aller Wehrmachtsteile [im Bereich des Pz.AOK.2]“ geschehen. ${ }^{656}$

Auch in der Absicht, ein ,albanischen Landesverteidigungskommando“ aufzubauen, widerspiegelt sich die zunehmende Schwäche des Dritten Reichs. Am 18. August 1944 besprach der Kommandierende General mit HSSPF Fitzthum und dem albanischen General Gustav von Myrdacz ${ }^{657}$ während des laufenden Unternehmens „Fuchsjagd“ „die Möglichkeit der Einrichtung eines albanischen Landesverteidigungskommandos, das Befehl über albanische Wehrmacht, Gendarmerie und Freiwilligen führt“, was letztlich nichts anderes bedeutete, als dass sich die Deutschen langfristig aus dem Gebiet zurückziehen wollten. ${ }^{658}$

Aufgrund von Munitionsmangel, einer unzureichenden Ausbildung und im Falle „reichsdeutscher Soldaten“ in den Führer- und Unterführerrängen Unkenntnis der Topografie waren die Verluste insgesamt hoch, wie sich der ehemalige Fahrer von Divisionskommandeur Schmidhuber Kurt Kopf noch zwanzig Jahre nach Kriegsende erinnerte. ${ }^{659}$ Bei den Verlustmeldungen sticht aber vor allem die hohe Zahl an Vermissten ins Auge. In seinem letzten Bericht meldete Divisionskommandeur Schmidhuber Anfang Oktober 1944166 Vermisste, davon 14 Deut-

655 Gefechtsbericht für das Unternehmen „Draufgänger“ vom 18.7.-28.7.1944, Schmidhuber, Lagebeurteilung 22.7.44, NARA, T314/664, Bl. 283. Siehe zur Problematik der Unterscheidung zwischen Partisanen und regulären Streitkräften ausführlich Lieb, Peter, Konventioneller Krieg oder NS- Weltanschauungskrieg? Kriegführung und Partisanenbekämpfung in Frankreich 1943/ 44, München: Oldenbourg 2007.

656 Gen.Kdo. XXI. Geb.AK, Ia Nr. 4633/44 geh., 5.7.1944, BArchF, RH 26-181/38, Bl. 3.

657 Ehemaliger k.u.k. Generalstabsoffizier, während des Ersten Weltkriegs in Albanien eingesetzt, später von Ahmet Zogu in die albanische Armee übernommen, um diese nach westeuropäischem Vorbild aufzubauen. Vgl. Kasmi, Hermann Kirchner, Im Dienste der albanischen Armee, in: http://www.bundesheer.at/truppendienst/ausgaben/artikel.php?id=1640 (Stand: 10.2.2020).

658 Kriegstgb. 12 Gen. Kdo. XXI. (Geb) A.K vom 1.8. -31.8.1944, Hptm. Hausen, 18.8.1944, BArchF 59 824/2 (alte Signatur), nach Vopersal, BArchF, N 756/182a.

659 Vgl. Brief Kopf an Stütz, 28.5.1964, BArchF, N 756/182a. 
sche und 152 Albaner, 92 Verwundete, davon 20 Deutsche und 72 Albaner, 56 Tote, davon 8 Deutsche und 48 Albaner. ${ }^{660}$

Das Phänomen von Desertionen begleitete die „Skanderbeg“ bereits seit ihren Anfängen. Schon vor ihrer Aufstellung hatten die Deutschen Bedenken gegenüber dem Verhalten der Hilfstruppen der Wehrmacht und Waffen-SS, sogenannten „nationalen Banden“. Dort zeigten nicht nur die unteren Ränge eine sehr wechselhafte Einstellung gegenüber den Besatzern, vielmehr war es auch unter albanischen Befehlshabern üblich, je nach Situation die Seiten zu wechseln. ${ }^{661}$

Das von Bormann im Juni 1944 beschriebene Verhalten der Milizen und Kompanien der „Skanderbeg“, sich unerlaubt von der Truppe zu entfernen, deutet bereits auf die Massendesertionen hin, die später einsetzten. Während Bormann einen Teil der Männer im Sommer wieder zurückholen und sie erneut in ihre Stellungen schicken konnte, sollten diejenigen, die drei Monate später desertierten, nicht mehr zurückkehren. ${ }^{662}$

Dass die Krise deutscher Streitkräfte schon während der Aufstellung der „Skanderbeg“ im Frühjahr 1944 akut war, äußerte sich in den während der Sommermonate 1944 einsetzenden „fast täglichen Desertionen“. Die stete Meldung von Niederlagen, feindlicher Beschuss und die Einschränkung oder das Ausbleiben von Sold, Nahrung und Ausrüstung führten zu einer rapiden Verschlechterung der Moral innerhalb der Truppe. Das Ziel, das man verfolgt hatte, nämlich durch einen Beitritt in die Waffen-SS die eigene Region bei „Großalbanien“ zu halten und reich mit Waffen und Munition ausgestattet zu werden, war in weite Ferne gerückt. ${ }^{663}$ Die Partisanen hingegen hatten ihre Macht ausbauen können. SS-Untersturmführer Daca meldete im Juni 1944, dass den Partisaneneinheiten neben sehr guter Ausrüstung und Bewaffnung und einem zweiten MG für jede Gruppe auch Munition „in rauen Mengen“ zur Verfügung stünden. ${ }^{664}$ Infolgedessen verwundert es nicht, dass die Vorgesetzten nach dem Unternehmen „Draufgänger“, welches zwischen dem 18. und 28. Juli 1944 stattfand, 400 Vermisste melden mussten. Wie der Historiker Schmider betont, waren dies aber nur Vorboten von weit intensiveren Desertionswellen in den kommenden Monaten. ${ }^{655}$ Schrader gab in Kriegsgefangenschaft zu Protokoll, dass in den Schwesterdivisionen diesbezüglich „ähnliche Verhältnisse“ geherrscht

\footnotetext{
660 Vgl. „Zusammenfassender Bericht“ Schmidhuber, 2.10.1944, BArchF, RS 3-21/1, S. 5.

661 Vgl. Neuwirth, Widerstand und Kollaboration, S. $122 \mathrm{f}$.

662 Kampfgruppe Bormann an Schmidhuber, 12.6.1944, BArchF, RS3 21/2, S. 89.

663 Vgl. Kriegsgefangenenbericht Schrader, VA HEM.OK.BOJCKA, 72A/1a/34, S. 3.

664 Vgl. Meldung SS-Ustuf. Daca an Ia, 15.6.1944, BArchF, RS3-21/2, Bl. 96.

665 Vgl. Schmider, Partisanenkrieg, S. 506.
} 
hätten. ${ }^{666}$ Bei Operationen verschwanden ganze Truppenteile, aber auch höhere Dienstgrade kehrten nicht zurück. ${ }^{667}$

Drei Faktoren ließen die Zahl der Desertionswilligen in die Höhe schnellen: Erstens ging die Bevölkerung in Südosteuropa nach dem Kriegsaustritt Rumäniens und Bulgariens Ende August 1944 von einem raschen Sieg der Alliierten aus. Zweitens gewährte Tito allen, die bis zum 15. September $1944 \mathrm{zu}$ seinen Partisanen überliefen, Amnestie bzw. Straffreiheit. ${ }^{668}$ Drittens stellte die albanische kommunistische „Nationale Befreiungsfront“ vom 22. September bis zum 7. Oktober 1944 unter Androhung von Sanktionen bei Nichtbefolgung ein ähnliches Ultimatum. Die angedrohten Strafen erinnerten nach Neuwirth in ihrem Ausmaß an traditionelle Blutrache. ${ }^{669}$ Interimskommandeur bzw. Regimentskommandeur der „Skanderbeg“, Alfred Graf, bestätigte in Kriegsgefangenschaft, dass solche Drohungen und die veränderte Kriegslage Wirkung gezeigt hätten. Da die meisten albanischen Soldaten bis Oktober 1944 der Division den Rücken gekehrt hatten, musste diese, bis auf den „Torso geschrumpft“, aufgelöst und als Regiment neu aufgestellt werden. ${ }^{670}$ Auch Divisionskommandeur Schmidhuber bekräftigte in seinem abschließenden Bericht über die Division Grafs Eindruck: „Die unmittelbare Folge der politisch-militärischen Krise auf dem Balkan bestand jedoch in den schlagartig einsetzenden Desertationen [sic] in der Division, insbesondere in dem an Mazedonien grenzenden Teil von TETOVO - GOSTIVAR, wo der Stamm des gesamten Geb. Jg. Rgt. SS 1 [50] in Stärke von rund 1.000 Mann unter Mitnahme der Waffen und Uniform desertierte. “671 Im Anschluss an diese Massendesertion fand in Tetovo eine „nächtliche deutschfeindliche Kundgebung“ statt. ${ }^{672}$

Für Schmidhuber waren sowohl die Massendesertion als auch die Kundgebung nicht nachvollziehbar, da seiner Ansicht nach die albanischen Rekruten gerade in dieser Region besonders rücksichtsvoll behandelt worden wären. ${ }^{673}$

Andernorts entfernte sich eine wachfreie Mannschaft von zehn Mann unerlaubt von den zwei verbleibenden Brückenposten. Ähnliche Fälle ereigneten sich in einem Ausbildungslehrgang von 30 Reitlehrern und eines Kampfspäh-

666 Vgl. Kriegsgefangenenbericht Schrader, VA HEM.OK.BOJCKA, 72A/1a/34, S. 3.

$667 \mathrm{Vgl}$. ebd.

668 Vgl. Schmider, Der jugoslawische Kriegsschauplatz, S. 1035.

669 Neuwirth, Widerstand und Kollaboration, S. $208 \mathrm{f}$.

670 Vgl. Kriegsgefangenenbericht Graf, VA, HEM.OK.BOJCKA, 72/2-1/32.

671 „Zusammenfassender Bericht“ Schmidhuber, 2.10.1944, BArchF, RS 3-21/1, S. 7. Hervorhebung im Original.

672 Vgl. ebd., Bl. 7.

673 Ebd. 
trupps in Stärke eines Zuges, welche geschlossen desertierten. ${ }^{674}$ Schmidhuber konnte die Desertionswelle nicht aufhalten, gelangte aber zur Überzeugung, dass an dieser Situation auch der Mangel an deutschen Führern und Unterführern schuld war. Selbst 697 Mann der Kernmannschaften der bereits in der „Handschar“ eingesetzten Albaner desertierten im Herbst $1944 .{ }^{675}$ Von Mai bis Ende September 1944 waren 3.425 Mann desertiert ${ }^{676}$ - nicht mitgezählt sind dabei all jene Albaner, die aus deutscher Krieggefangenschaft mit dem Auftrag entlassen wurden, in der „Skanderbeg“ Dienst zu leisten, aber gar nicht erst erschienen waren. ${ }^{677}$

Ein Beispiel eines Deserteurs liefert Alija Ukitć, eingesetzt im III./PolizeiFreiwilligen-Regiment 1, der sich im serbischen Tupale in der Sandžak-Region hatte rekrutieren lassen, der Schrift nicht kundig und daher mit drei Kreuzen und einem Daumenabdruck unterschrieben hatte. Der SS- und Polizeiführer Sandžak meldete ihn als seit dem 5. September 1944 fahnenflüchtig. ${ }^{678}$

Ende August erhielt die aus Griechenland kommende und zu diesem Zeitpunkt in Skopje stationierte 11./SS-Pz.Gren.Rgt. 7 den Auftrag, meuternde Einheiten der „Skanderbeg“ zu entwaffnen. Der ehemalige Divisionsangehörige Helmut Arnemann errinnerte sich später an das Gerücht, dass in Tetovo westlich Skopje albanische Einheiten der dort stationierten „Skanderbeg“ meutern und das deutsche Stammpersonal gefangen halten und bedrohen würden. Die 11./SS-Pz.Gren. Rgt. 7 sollte dementsprechend das deutsche Stammpersonal befreien und die albanischen Einheiten der „Skanderbeg“ entwaffnen:

Es war eine sehr eigenartige Situation, da auf Grund der Information ein Gefecht mit eigenen Einheiten zu erwarten war. Wir erreichten die Ortschaft Tetovo jedoch ohne Gefechtsberührung und fanden das deutsche Stammpersonal unversehrt vor. Alles was zur ,Skanderbeg“ gehörte, hatte sich bei unserer Annäherung in die Berge Richtung Albanien abgesetzt. [...] Ergänzend sei erwähnt, dass die Angehörigen der ,Skanderbeg‘ sämtliche vorhandenen Waffen und Munition mitgenommen hatten. Nach diesem Einsatz haben wir von [albanischen] „Skanderbeg“-Angehörigen nichts mehr gehört. Es kann hier also nicht gesagt werden, ob sie sich aufgelöst haben oder evtl. zu den Partisanen übergegangen sind. ${ }^{679}$

674 Ebd.

675 Ebd.

676 Vgl. ebd., Bl. 6.

677 Vgl. Interview mit Tush Mark Ndou (geführt von Franziska Zaugg), 7.6.2017. Vgl. Zaugg, Albanische Muslime, S. 221.

678 Vgl. Fall Alija Ukitć, AJ, 110-730-648, 657. Vgl. ebenfalls Kreuz als Unterschrift: Nuha, Imer, Belo Polje, Arkivi Kosoves, F: dosjete robërve të luftës në Gjermani, V: 1940-1945, K: 1.

679 Brief Helmut Arnemann an Kopf, 19.1.1982, BArchF, N 756/182a. 
Die Aussagen Arnemanns decken sich mit denjenigen Schmidhubers. ${ }^{680}$ Eine Tagesmeldung des Generalkommandos des XXI. Gebirgskorps offenbart die Resignation auf deutscher Seite bezüglich dieser Massendesertion: „[...] SSDiv. ,Skanderbeg': Von 964 Albanern des SS-Batl. Tetovo 908 Albaner (davon etwa die Hälfte mit Handwaffen) fahnenflüchtig. Sonst k[eine] b[esonderen] E [reignisse]. “681

Vopersal wandte später ein, dass durch den Divisionkommandeur nach Ansprache mit den national-albanischen Banden der Befehl ausgegeben worden wäre, dass ,albanische[n] Einheiten der Division mit ihren Waffen zu den ,nationalen Banden' stoßen sollten, um gemeinsam gegen die kommunistischen Banden im Lande zu kämpfen. Teilweise ging sogar das deutsche Rahmenpersonal zu den national-albanischen Banden, um diese militärisch auszubilden. “682 Schmidhuber bestätigt auch diese Aussage in seinem Bericht von Anfang Oktober $1944{ }^{683}$

Nicht nur „nationale Banden“, auch die noch verbliebenen Soldaten der albanischen Armee und Gendarmerie und andere „fremdvölkische“ Einheiten versuchten, sich am Vorabend der unmittelbar bevorstehenden Niederlage abzusetzen. ${ }^{684}$ Neuwirth schreibt zu dieser Entwicklung: „Im September [1944], als die Auflösungserscheinungen der deutschen Besatzung schon so weit fortgeschritten waren, dass sogar die Kommandanten von albanischer Wehrmacht (Prenk Pervizi) und Gendarmerie (Hysni Dema) das Weite suchten, flüchteten viele der mit den Deutschen verbündeten Cetas (etwa von Halil Alia), hörte die albanische Wehrmacht bis auf kleinere Reste praktische auf zu existieren und war die 21. SS-Division „Skanderbeg“ nur noch für Verteidigungsaufgaben bedingt geeignet. Zudem desertierten vor allem fremdländische Verbände seit August massenhaft, sodass einige deutsche Einheiten sogar aufgelöst werden mussten. “685

Die Vermisstenliste der „Skanderbeg“ vom Frühjahr 1945 zeigt, dass auch von den verbliebenen „Reichs-“ und „Volksdeutschen“ zahlreiche Soldaten versuchten, dem Tod oder einer Gefangennahme durch die jugoslawische Armee durch Desertion zu entkommen. Aus dieser Tabelle lassen sich zwei wesentliche Merkmale herauslesen: Erstens verschwanden eher niedere Dienstgrade wie etwa Sturmmann, Rotten- oder Unterscharführer. Zweitens zeigt sich eine wesentliche Zunahme von Vermisstenmeldungen gegen Ende des Jahres, als die Situation für die „Skanderbeg“ auf ihrem Rückzug über Višegrad, Zvornik nach Bijelina und

680 Vgl. „Zusammenfassender Bericht“ Schmidhuber, 2.10.1944, BArchF, RS 3-21/1, S. 7.

681 Tagesmeldung Gen.Kdo. XXI. Geb.A.K. an Pz.AOK.2, 2.9.1944, NARA, T314/664, Bl. 673.

682 Brief Vopersal an Arnemann, 30.1.1982, BArchF, N 756/182a.

683 Vgl. „Zusammenfassender Bericht“ Schmidhuber, 2.10.1944, BArchF, RS 3-21/1, S. 9.

$684 \mathrm{Vgl}$. Umbreit, Die deutsche Herrschaft in den besetzten Gebieten, S. 93.

685 Neuwirth, Widerstand und Kollaboration, S. 128. 
Brčko zusehends aussichtslos wurde. ${ }^{686}$ Kurt Fleischer schreibt rückblickend, dass aufgrund des akuten Personalmangels auf dem Rückzug schließlich „alles [Personal] im Partisanenkampf eingesetzt [war,] ob Sani oder Nachrichten[,] das war gleich. ${ }^{67}$

\subsubsection{Zusammenarbeit mit Četniks birgt Konfliktpotenzial}

Obwohl bereits 1943 verschiedentlich ein Zusammengehen zwischen albanischnationalen Kräften und Četniks nachgewiesen werden konnte, ${ }^{688}$ kam die von deutscher Seite geplante und teilweise auch umgesetzte Zusammenarbeit mit Četnik-Formationen in den Grenzgebieten Kosovos bei den „neualbanischen“ Eliten nicht gut an. Spätestens seit April 1944 versuchte Berger intensiv, den Kontakt zu den Četniks der Region aufzubauen, um mit ihnen ein gemeinsames Vorgehen im „Bandenkampf“ zu diskutieren. ${ }^{689}$ Im Juni 1944 ließen die Briten dann über die Nachrichtenagentur Reuters verlauten, dass sie die Četniks nicht länger unterstützen würden. ${ }^{690}$ Für die Četnik-Bewegung war dies ein Wendepunkt: Auch Četnik-Verbände, die bisher den deutschen Besatzern kritisch bis feindlich gegenüberstanden, suchten nun die Nähe der Deutschen.

Dass nun aber plötzlich die Erzfeinde im Kampf gegen Kommunismus und westliche Alliierte auch zu den Verbündeten gehören sollten, war für viele albanische Muslime und auch Katholiken schwer nachvollziehbar. Konflikte innerhalb dieser Konförderation waren deshalb vorprogrammiert. Innerhalb der Kampfgruppe „Heckner“ beispielsweise, die Teil der „Skanderbeg“ war, kämpfte im September 1944 eine 500 Mann starke Četnik-Formation. Als ihre Angehörigen davon hörten, dass weiterhin Albaner serbische Familien angriffen, waren sie laut dem Bericht Heckners „sehr verbittert“. ${ }^{691}$

$686 \mathrm{Vgl}$. Zaugg, Albanische Muslime, S. 278f.

687 Fleischer an Vopersal, 24.8.1972, BArchF, N 756/182b.

688 „Die augenblickliche Zusammenziehung von [serbischen] Nationalisten im Gebiet von Zajčevci[Zajçec]-Vrapce-Marovac bedeute eine ernste Gefahr für das Kossovo [sic], denn es handle sich um entschlossene und sehr gut bewaffnete Massen, von eifrigen und fähigen Führern angeführt, die das albanesische Gebiet genau kennen und auf die innere Unterstützung der Serben sowohl als der albanesischen Kreise rechnen können. In dieser Hinsicht ist zu bemerken, dass die Albanesen auf der anderen Seite der Demarkationslinie [auf dem von den Deutschen besetzten Gebiet] in ihrer Masse der Bewegung des Generals Draza Mihajlovic anhängen.“ Auswertestelle Süd, „Lage in Albanien im Mai 1943“, 24.8.1944 unterzeichnet vom Chef der Heeresarchive Oberstleutnant Neumeister, 31. 8.1944, BArchF, RH 18/407.

689 Schreiben Berger an Himmler, 13.4.1944, BArchB, NS19/2071, S. 2-3.

690 Junker an Neubacher und Generalkonsulat Tirana, 21.6.1944, PAAA R27305.

691 Vgl. Heckner (Kacuber) an Division „Skanderbeg“, 8.9.1944, BArchF, RS 3-21/2, Bl. 130. 


\subsection{Nach der Entlassung aus der „Skanderbeg“ geht der Krieg weiter}

Noch am 18. August 1944 notierte Hauptmann Hausen in das Kriegstagebuch des Generalkommandos des XXI. Gebirgskorps, dass die Absicht bestünde, nach Abzug der Deutschen eine autonom agierende albanische Landesverteidigung aufzubauen. In dieser Aussage wird einerseits offensichtlich, dass zu diesem Zeitpunkt bereits klar war, die deutschen Truppen würden in naher Zukunft das Land verlassen. Andererseits zeigt der Eintrag auch, wie eng die Zusammenarbeit von Wehrmacht und Waffen-SS in diesen letzten Monaten war: „Kdr. Gen. bespricht mit SS-Gruppenführer Fitzthum und dem albanischen General von Myrdatsch [Myrdacz] die Möglichkeit der Einrichtung eines albanischen Landesverteidigungskommandos, das Befehl über albanische Wehrmacht, Gendarmerie und Freiwillige führt."692

Bereits Anfang September 1944 rechneten sowohl die albanische Regierung als auch die Bevölkerung Albaniens „mit [dem] baldige[n] Abzug der deutschen Truppen und darauffolgender Anarchie in Albanien“. ${ }^{693}$ Einen Monat später, Anfang Oktober 1944, wurde Albanien zur Kampfzone erklärt und Ende Oktober die meisten Albaner, welche noch nicht desertiert waren, aus der Division entlassen. ${ }^{694}$ Allerdings blieben sie nicht ohne Auftrag. Ihren letzten Einsatz hatte SAOberführer Karl Gstöttenbauer, der seit dem 7. Oktober 1944 in Personalunion Chef Militärverwaltung Albanien und Montenegro war, ${ }^{695}$ bereits geplant. Soweit es die eigene Situation zuließ, sollten diese Einheiten von deutscher Seite mit Ausrüstung, Lebensmitteln und Munition versorgt und gegen den anrückenden Feind, d. h. gegen Sowjets und Bulgaren eingesetzt werden. ${ }^{696}$ Neubacher schrieb in seinen Memoiren, Deva habe darauf gehofft, mit Hilfe deutscher Ausrüstung „nach dem Abmarsch der deutschen Truppen im Lande zu bleiben und einen Guerillakrieg zu führen. “697 Anderen deutschen Angaben zufolge wollte Deva im Kosovo sogar eine neue Regierung ins Leben rufen. Diese

692 Kriegstgb. 12 Gen. Kdo. XXI. (Geb) A.K vom 1.8. -31.8.1944, Hptm. Hausen, 18.8.1944, BArchF 59 824/2 (alte Signatur), nach Vopersal, BArchF, N 756/182a.

693 Dr. Kaltenbrunner und Schellenberg an Vortragenden Legationsrat Wagner, 2.9.1944, PAAA, R101024, Bl. 034.

694 Vgl. Kriegsgefangenenbericht Graf, VA, HEM.OK.BOJCKA, 72/2-1/32. Vgl. Zaugg, Albanische Muslime, S. 284.

695 Schreiben Schliep an AA, 8.10.1944, PAAA, R27772.

696 Schreiben Karl Gstöttenbauer, Dienststelle des Sonderbevollmächtigten Südost „Albanien“ an Neubacher, 3.10.1944, PAAA, R101024, Bl.038f. Vgl. Schmider, Der jugoslawische Kriegsschauplatz, S. 1054.

697 Neubacher, Sonderauftrag Südost, S. 119. 
würde aber, das war auch den Deutschen zu diesem Zeitpunkt klar, nur auf die Kosovoregion Einfluss ausüben können. ${ }^{698}$ Albaner, die aus der Division austraten, versuchten Deva und andere Exponenten des „Komitees“ und der „Zweiten Liga“ zu sammeln und neu zu formieren. An der „neualbanisch“serbischen Grenze waren sie bei der Verteidigung von Prepolac gemeinsam mit der deutschen Kampfgruppe „Scholz“ im Einsatz. ${ }^{699}$ Malcolm geht von 5.000 Kämpfern aus, 700 davon stammten aus Devas Privatarmee. Doch nicht nur die Albaner verstärken die Kampfgruppe „Scholz“ bei diesen letzten Kämpfen, auch lokale Četnik-Formationen waren im Einsatz. ${ }^{700}$ Auch Vogel erwähnt eine solche Milizdivision, die vom Nationalistenführer Shashi Vari mit „Waffen der aufgelösten Skanderbeg-Division“ ausgerüstet worden war und sowohl aus Freiwilligen als auch aus Zwangsrekrutierten bestand. ${ }^{701}$ Anfang 1945 griff schließlich Tito ein, indem er in der Kosovoregion den Ausnahmezustand ausrief, um einen Aufstand des „Balli Kombëtar“ niederzuschlagen. ${ }^{702}$ Nach Schmider ließ er aufgrund anhaltender Unruhen sogar zweimal das Kriegsrecht verhängen. ${ }^{703}$ Wer in der „Skanderbeg“ gedient und mit den Deutschen zusammengearbeitet hatte, der bezahlte entweder mit seinem Leben oder musste nun mit eingeschränkten Rechten weiterleben. Portmann und Suppan gehen von einigen Tausend Soldaten, Beamten und Zivilisten aus, die den Säuberungen zum Opfer fielen. ${ }^{704}$ In Interviews mit Nachkommen ehemaliger Angehöriger der „Skanderbeg“ und solchen, die dem zumeist nationalistisch-konservativen „Balli Kombëtar“ nahestanden, wird deutlich, dass diese Menschen, falls sie mit dem Leben davonkamen, in ihrem sozialen und wirtschaftlichen Aktionsradius nach dem Krieg stark eingeschränkt waren. ${ }^{705}$ Deva selbst „schlug [...] sich sehr spät auf kroatischen Boden durch, von wo er im Dezember 1944 nach Wien kam“, nachdem von deutscher Seite die Unterstützung für den Aufbau einer Kosovo-Armee ausgeblieben war. ${ }^{706}$

698 Vgl. OB Südost, „Lagebild Südost vom 9.10.1944“, 10.10.1944, BArchF, RH 19/XI-22, Bl. 224.

$699 \mathrm{Vgl}$. Kriegsgefangenenbericht Graf, VA, HEM.OK.BOJCKA, 72/2-1/32.

700 Vgl. Malcolm, Kosovo, S. 312.

701 Vgl. Vogel, Erinnerungen, Bd. 1, Unter Skipetaren - Albanische Erinnerungen 1943/44, unveröffentlicht 1989, S. 214.

702 Vgl. Calic, Geschichte Jugoslawiens, S. 180. Vgl. auch Bojan Korsika (Hg.), Srbija i Albanci, Pregled politike Sbjie prema Albancima od 1944 do 1989 godine., Bd. 3, Ljubljana: Ćasopis za kritiko znanosti 1989, S. 18.

703 Vgl. Schmider, Kriegsschauplatz, S. 1054.

704 Vgl. Portmann, Suppan, Serbien und Montenegro, S. 292.

705 Vgl. Interviews der Verfasserin mit B. Berisha, 4.7.2019, I. Neziri, 14.8.2018 und Tush Mark Ndou 7.6.2017.

706 Neubacher, Sonderauftrag Südost, S. 119. 